$\because 21928>0$

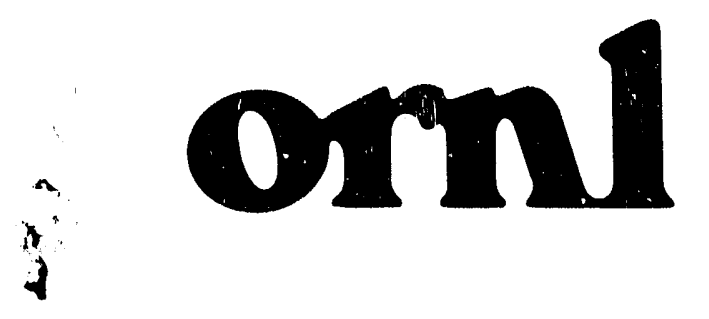

ORNL/TM-12017

OAK RIDGE NATIONAL LABORATORY

MARTIN MALUETRA

Comparative Plant Uptake and Microbial Degradation of Trichloroethylene in the Rhizospheres of Five Plant Species-Implications for Bioremediation of Contaminated Surface Soils

\author{
T. A. Anderson \\ B. T. Walton
}

Environmental Sciences Division

Publication No. 3809

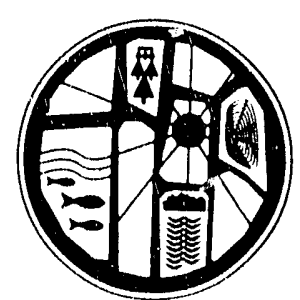


This report has been reproduced directly from the best available copy.

Available to DOE and DOE contractors from the Office of Scientific and Technical Information, P.O. Box 62, Oak Fidge, TN 37831; prices available from (615) 576-8401, FTS 626-8401.

Available to the public trom the National Technical Information Service, U.S. Department of Commerce, 5285 Port Royal Rd., Springfield, VA 22161.

This report was prepared as an account of work sponsored by an agency of the United States Government. Neither the United States Government nor any agency thereoi, nor any of their employees, makes any warranty, express or. implied, or assumes any legal liability or responsibility for the accuracy, completeness, or usefulness of any information, apparatus, product, or process disclosed, or represents that its use would not infringe privately owned rights. Reference herein to any specific commercial product, process, or service by trade name, trademark, manufecturer, or otherwise, does not necessarily constitute or imply its endorsement, recommendation, or favoring by the United States Government or any agency thereof. The views and opinions of authors expressed herein do not necessarily state or reflect those of the United States Government or any agency thereof. 


\title{
COMPARATIVE PLANT UPTAKE AND MICROBIAL DEGRADATION OF TRICHLOROETHYLENE IN THE RHIZOSPHERES OF FIVE PLANT SPECIES--IMPLICATIONS FOR BIOREMEDIATION OF CONTAMINATED SURFACE SOILS 1
}

\author{
T. A. Anderson?2 \\ B. T. Walton
}

\begin{abstract}
1 Submitted as a dissertation by T. A. Anderson to the Graduate Council of the University of Tennessee, Knoxville in partial fulfillment of the requirements for the degree of Doctor of Philisophy.

2 Graduate Program in Environmental Toxicology, The University of Tennessee, Knoxville.
\end{abstract}

\author{
Environmental Sciences Division \\ Publication No. 3809
}

Date Published - January 1992

Prepared for the
Office of Technology Development

(EW 402010 0)

Prepared by the

OAK RIDGE NATIONAL LABORATORY

Oak Ridge, Tennessee 37831-6285

managed by

MARTIN MARIETTA ENERGY SYSTEMS, INC.

for the

U. S. DEPARTMENT OF ENERGY

under contract DE-AC05-84OR21400 
CHAPTER PAGE

I. INTRODUCTION ............................................................................

II. LITERATURE REVIEW ...............................................................

A. Physicochemical Properties of Trichloroethylene ...................... 5

B. Mammalian Toxicity and Effects on Microorganisms................. 7

C. Microbial Degradation of TCE....................................................... 9

D. Rhizosphere Microbiology.......................................................... 30

E. Degradation of Organic Compounds in the Rhizosphere......... 33

F. Manipulation of Root Exudation ................................................... 41

G. Lipid Analysis in Microbial Ecology .............................................. 43

H. Uptake of Organic Chemicals by Plant Roots .............................. 45

III. MATERIALS AND METHODS........................................................ 48

A. Site Description and Sample Collection ....................................... 48

B. Microbial Biomass, Community Structure, and

Metabolic Activity ............................................................... 52

C. Toxicity of TCE and PCE to Soil Microorganisms ...................... 58

D. TCE Degradation in Soil Slurries.............................................. 59

E. ${ }^{14} \mathrm{C}$-TCE Mineralization in Soil Samples ................................... 60

F. PCE Degradation in Soil Slurries ............................................. 61

G. Fate of ${ }^{14} \mathrm{C}$-TCE in Soil-Plant Systems ...................................... 62

$\mathrm{H}$. Influence of Root Exudation on ${ }^{14} \mathrm{C}$-TCE Mineralization............ $\quad 75$

I. Pesticide Root Zone Model (PRZM) ............................................. 76

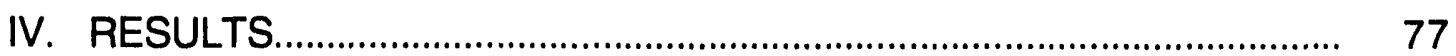

A. Site Despcription and Sample Collection.................................... 77

B. Microbial Biomass, Community Structure, and

C. Toxicity of TCE and PCE to Soil Microorganisms ....................... 107

D. Degradation of TCE in Soil Slurries ........................................... 119

E. Mineralization of ${ }^{14} \mathrm{C}$-TCE in Soil Sampies................................ 127

F. Degradation of PCE in Soil Slurries........................................... 128

G. Fate of ${ }^{14} \mathrm{C}$-TCE in Soil-Plant Systems ..................................... 131

$\mathrm{H}$. Influence of Root Exudation on ${ }^{14} \mathrm{C}$-TCE Mineralization............ 144

I. Root Uptake of ${ }^{14} \mathrm{C}$-TCE-Derived Compounds.......................... 150

J. Pesticide Root Zone Model (PRZM) ........................................... 157

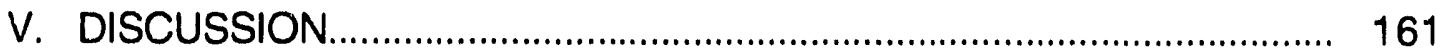

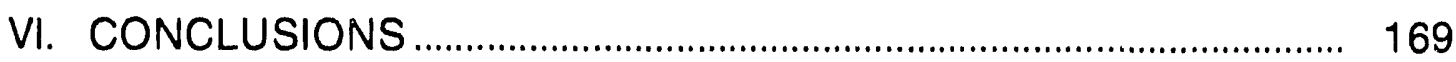




\section{TABLE OF CONTENTS}

CHAPTER

PAGE

LIST OF REFERENCES .

171 


\section{LIST OF TABLES}

\section{TABLE}

PAGE

II - 1. Physicochemical properties of trichloroethylene (TCE) ................... 6

II - 2. Microbial degradation of trichloroethylene (TCE) ............................. 10

II - 3. Studies on the fate of agricultural chemicals in the mizosphere.

IV - 1. Percent organic carbon (\%OC) and $\mathrm{pH}$ of soil samples from the Miscellaneous Chemicals Basin at the Savannah River Site.

IV - 2. Selected physical and chemical properties of the composite, nonvegetated soil from the Miscellaneous Chemicals Basin at the Savannah River Site.

IV - 3. Vegetation survey of the Miscellaneous Chemicals Basin at the Savannah River Site.....

IV - 4. Carbon dioxide efflux on day 3 of incubation from rhizosphere and nonvegetated soils collected at the Miscellaneous Chemicals Basin at the Savannah River Site

IV - 5. Comparisons of microbial biomass determinations of soil collected from the Miscellaneous Chemicals Basin at the Savannah River Site

IV - 6. Phospholipid fatty acid (PLFA) profiles of soil samples collected from the Miscellaneol's Chemicals Basin at the Savannah River Site

IV - 7. Results of polybetahydroxyalkanoate analyses of rhizosphere and nonvegetated soils from the Miscellaneous Chemicals Basin

IV - 8. Tetrachloroethylene (PCE) and trichloroethylene (TCE) concentrations in soil samples used in preliminary studies on reductive dechlorination of PCE in soils collected from the Miscellaneous Chemicals Basin at the Savannah River Site.

IV - 9. Tetrachloroethylene (PCE) and trichloroethylene (TCE) concentrations in soil samples used in studies on reductive dechlorination of PCE in soils from the Miscellaneous 
IV - 10. Total root uptake of ${ }^{14} \mathrm{C}$-trichloroethylene-derived radioactivity in leaves (or needles), stems and roots of plants used in studies on microbial degradation of ${ }^{14} \mathrm{C}$-TCE in the thizosphere.

IV - 11. Distribution of ${ }^{14} \mathrm{C}$-trichloroethylene-derived radioactivity in leaves (or needles), stems, and roots of plants used in studies on microbial degradation of TCE in the rhizosphere.

IV - 1c. Comparison of root uptake of ${ }^{14} \mathrm{C}$-trichloroethylene-derived radioactivity in leaves (or needles), stems, and roots of plants used in studies on the influence of environmental conditions on microbial degradation of TCE in the rhizosphere

IV - 13. Results of process control analyses after 109 days of simulation using the Pesticide Root Zone Model (PRZM) (Carsel et al., 1984) for TCE applied to soil at the Miscellaneous Chemicals Basin at the Savannah River Site under vegetated and nonvegetated conditions 


\section{LIST OF FIGURES}

1 - 1. Gross morphology of two root types; a fibrous root system (left) and a tap root system (right) in soil. (Adapted from Stern, 1982).

II - 1. Reductive dechlorination of chlorinated ethylenes under anaerobic (methanogenic) conditions

II - 2. Aerobic microbial degradation of trichloroethylene (TCE)

III - 1. Diagram of the Miscellaneous Chemicals Basin showing selected soil gas sampling locations, the original solvent disposal pit, and soil gas concentrations of tetrachloroethylene and trichloroethylene in October, 1986. (Adapted from Microseeps Ltd., 1986)

III - 2. Experimental flasks used to measure the fate of ${ }^{14} \mathrm{C}$-TCE in soil-plant systems

III - 3. Glass exposure chambers used to regulate environmental conditions and quantify ${ }^{14} \mathrm{C}$ released by the plants in whole plant experiments

III - 4. System used to trap ${ }^{14} \mathrm{C}$-volatiles and ${ }^{14} \mathrm{CO}_{2}$ during whole plant experiments

III - 5. Efficiency determination of the AquasolTM used to trap ${ }^{14} \mathrm{C}$-volatiles during whole plant experiments. A syringe was used to flush the headspace of a flask containing ${ }^{14} \mathrm{C}$-TCE through the trapping system at 0.5 and 1.5 hours

III - 6. Efficiency determination of the AquasolTM used to trap ${ }^{14} \mathrm{C}$-volatiles during whole plant experiments. A peristaltic pump was used to flush the headspace of a fiask containing ${ }^{14} \mathrm{C}$-TCE through the trapping system at $0.5,1$, and 24 hours.

III - 7. Efficiency determination of the Carbosorb used to trap ${ }^{14} \mathrm{CO}_{2}$ during whole plant experiments. A syringe was used to flush the headspace of a flask containing acidified ${ }^{14} \mathrm{C}$-bicarbonate through the trapping system 
III - 8. Efficiency determination of the Carbosorb used to trap ${ }^{14} \mathrm{CO}_{2}$ during whole plant experiments. A syringe was used to flush the headspace of a flask containing acidified ${ }^{14} \mathrm{C}$-bicarbonate through the trapping system

III - 9. Efficiency determination of the Carbosorb used to trap ${ }^{14} \mathrm{CO}_{2}$ during whole plant experiments. A peristaltic pump was used to flush the headspace of a flask containing acidified ${ }^{14} \mathrm{C}$-bicarbonate through the trapping system

IV - 1. Carbon dioxide efflux from experimental and sterile soil collected from a nonvegetated/noncontaminated area of the Miscellaneous Chemicals Basin. Each datum point is the mean of three replicates. Bars indicate one standard deviation of the mean.

IV - 2. Carbon dioxide efflux from experimental and sterile soil collected from a nonvegetated/contaminated area of the Miscellaneous Chemicals Basin. Each datum point is the mean of three replicates. Bars indicate one standard deviation of the mean

IV - 3. Carbon dioxide efflux from experimental and sterile soil collected at the Miscellaneous Chemicals Basin from the rhizosphere of Lespedeza cuneata. Each datum point ir the mean of three replicates. Bars indicate one standard deviation of the mean

IV - 4. Carbon dioxide efflux from experimental and sterile soil collected at the Miscellaneous Chemicals Basin from the rhizosphere of Paspalum notatum. Each datum point is the mean of three replicates. Bars indicate one standard deviation of the mean

IV - 5. Carbon dioxide efflux from experimental and sterile soil collected at the Miscellaneous Chemicals Basin from the rhizosphere of Pinus taeda. Each datum point is the mean of three replicates. Bars indicate one standard deviation of the mean

IV - 6. Carbon dioxide efflux from experimental and sterile soil collected at the Miscellaneous Chemicals Basin from the rhizosphere of Solidago sp. Each datum point is the mean of three replicates. Bars indicate one standard deviation of the mean. 
IV - 7. Dendogram of cluster analysis results from phospholipd fatty acid profiles of mizosphere and nonvegetated soils from the Miscellaneous Chemicals Basin.

IV - 8. Rates of ${ }^{14} \mathrm{C}$-acetate incorporation into total microbial lipids of soil samples collected from rhizosphere and nonvegetated areas at the Miscellaneous Chemicals Basin

IV - 9. Incorporation of ${ }^{14} \mathrm{C}$-acetate into the lipids of microorganismis from nonvegetated soil collected at the Miscellaneous Chemicals Basin

IV - 10. Incorporation of ${ }^{14} \mathrm{C}$-acetate into the lipids of microorganisms from the rhizosphere of Lespedeza cuneata soil collected at the Miscellaneous Chemicals Basin

IV - 11. Incorporation of ${ }^{14} \mathrm{C}$-acetate into the lipids of microorganisms from the rhizosphere of Paspalum notatum soil collected at the Miscellaneous Chemicals Basin

IV - 12. Incorporation of ${ }^{14} \mathrm{C}$-acetate into the lipids of microorganisms from the rhizosphere of Pinus taeda soil collected at the Miscellaneous Chemicals Basin.

IV - 13. Incorporation of ${ }^{14} \mathrm{C}$-acetate into the lipids of microorganisms from the rhizosphere of Solidago sp. soil collected at the Miscellaneous Chemicals Basin.

IV - 14. Carbon dioxide efflux from nonvegetated/contaminated soil collected from the Miscellaneous Chemicals Basin and treated with 0,500 , and $1000 \mu \mathrm{g} / \mathrm{g}$ (ppm) trichloroethylene. Each datum point is the mean of three replicates. Error bars represent one standard deviation of the mean.

IV - 15. Carbon dioxide efflux from Lespedeza cuneata rhizosphere soil collected from the Miscellaneous Chemicals Basin and treated with 0,500 , and $1000 \mu \mathrm{g} / \mathrm{g}(\mathrm{ppm})$ trichloroethylene. Each datum point is the mean of three replicates. Error bars represent one standard deviation of the mean.

IV - 16. Carbon dioxide efflux from Paspalum notatum rhizosphere soil collected from the Miscellaneous Chemicals Basin and treated with 0,500 , and $1000 \mu \mathrm{g} / \mathrm{g}(\mathrm{ppm})$ trichloroethylene. Each datum point is the mean of three replicates. Error bars 
represent one standard deviation of the mean.

IV - 17. Carbon dioxide efflux from Pinus taeda rhizosphere soil collected from the Miscellaneous Chemicals Basin and treated with 0,500 , and $1000 \mu \mathrm{g} / \mathrm{g}(\mathrm{ppm})$ trichloroethylene. Each datum point is the mean of three replicates. Error bars represent one standard deviation of the mean.

IV - 18. Carbon dioxide efflux from Solidago sp. rhizosphere soil collected from the Miscellaneous Chemicals Basin and treated with 0,500 , and $1000 \mu \mathrm{g} / \mathrm{g}(\mathrm{ppm})$ trichloroethylene. Each datum point is the mean of three replicates. Error bars represent one standard deviation of the mean.

IV - 19. Carbon dioxide efflux from nonvegetated/noncontaminated soil collected from the Miscellaneous Chemicals Basin and treated with 0,500 , and $1000 \mu \mathrm{g} / \mathrm{g}$ (ppm) tetrachlorsethylene. Each datum point is the mean of three replicates. Error bars represent one standard deviation of the mean.

IV - 20. Carbon dioxide efflux from nonvegetated/contaminated soil collected from the Miscellaneous Chemicals Basin and treated with 0,500 , and $1000 \mu \mathrm{g} / \mathrm{g}(\mathrm{ppm})$ tetrachloroethylene. Each datum point is the mean of three replicates. Error bars represint one standard deviation of the mean.

IV - 21. Carbon dioxide efflux from Lespedeza cuneata rhizosphere soil collected from the Miscellaneous Chemicals Basin and treated with 0,500 , and $1000 \mu \mathrm{g} / \mathrm{g}$ (ppm) tetrachloroethylene. Each datum point is the mean of three replicates. Error bars represent one standard deviation of the mean.

IV - 22. Carbon dioxide efflux from Paspalum notatum rhizosphere soil collected from the Miscellaneous Chemicals Basin and treated with 0,500 , and $1000 \mu \mathrm{g} / \mathrm{g}$ (ppm) tetrachloroethylene. Each datum point is the mean of three replicates. Error bars represent one standard deviation of the mean.

IV - 23. Carbon dioxide efflux from Pinus taeda rhizosphere soil collected from the Miscellaneous Chemicals Basin and treated with 0,500 , and $1000 \mu \mathrm{g} / \mathrm{g}$ (ppm) tetrachloroethylene. Each datum point is the mean of three replicates. Error bars represent one standard deviation of the mean.

IV - 24. Carbor dioxide efflux from Solidago sp. rhizosphere soil collected from the Miscellaneous Chemicals Basin and 
treated with 0,500, and $1000 \mu \mathrm{g} / \mathrm{g}(\mathrm{ppm})$ tetrachloroethylene. Each datum point is the mean of three replicates. Error bars represent one standard deviation of the mean.

IV - 25. Headspace concentrations of TCE in sterile, distilled water and soil slurries prepared from nonvegetated/ noncontaminated soil. The coefficient of variation [(standard deviation $\times 100$ )/mean] for measurements of TCE in the headspace of the water controls was $7.0 \%$

IV - 26. Headspace concentrations of TCE in sterile, distilled water and soil slurries prepared from nonvegetated/contaminated soil. The coefficient of variation [(standard deviation $x$ 100)/mean] for measurements of TCE in the headspace of the water controls was $7.0 \%$

IV - 27. Headspace concentrations of TCE in sterile, distilled water and soil slurries prepared fromı Lespedeza cuneata rhizosphere soil. The coefficient of variation [(standard deviation $\times 100$ )/mean] for measurements of TCE in the headspace of the water controls was $7.0 \%$

IV - 28. Headspace concentrations of TCE in sterile, distilled water and soil slurries prepared from Paspalum notatum rhizosphere soil. The coefficient of variation [(standard deviation $\times 100$ )/mean] for measurements of TCE in the headspace of the water controls was $7.0 \%$

IV - 29. Headspace concentrations of TCE in sterile, distilled water and soil slurries prepared from Pinus taeda rhizosphere soil. The coefficient of variation [(standard deviation $\times 100) /$ mean] for measurements of TCE in the headspace of the water controls was $7.0 \%$

IV - 30. Headspace concentrations of TCE in sterile, distilled water and soil slurries prepared from Solidago sp. rhizosphere soil. The coefficient of variation [(standard deviation $\times 100) /$ mean] for measurements of TCE in the headspace of the water controls was $7.0 \%$

IV - 31. Mineralization of ${ }^{14} \mathrm{C}$-TCE in sterile control soil, nonvegetated soil and soil containing Lespedeza cuneata. Data points for sterile control samples are the mean of two replicates whereas the nonvegetated and vegetated samples are the mean of three replicates. Error bars indicate one standard deviation of the mean. 
IV - 32. Mineralization of ${ }^{14} \mathrm{C}$-TCE in sterile control soil, nonvegetated soil, and soil containing Lespedeza cuneata. Data points for sterile control samples are the mean of two replicates whereas the nonvegetated and vegetated samples are the mean of three replicates. Error bars indicate one standard deviation of the mean

IV - 33. Mineralization of ${ }^{14} \mathrm{C}$-TCE in sterile control soil, nonvegetated soil, and soil containing Pinus taeda. Each; datum point is the mean of three replicates. Error bars indicate one standard deviation of the mean

IV - 34. Mineralization of ${ }^{14} \mathrm{C}$-TCE in sterile control soil, nonvegetated soil, and soil containing Pinus taeda. Each datum point is the mean of three replicates. Error bars indicate one standard deviation of the mean.

IV - 35. Mineralization of ${ }^{14} \mathrm{C}-\mathrm{TCE}$ ir sterile control soil, nonvegetated soil, and soil containing Solidago sp. Data points for sterile control samples are the mean of two replicates whereas the nonvegetated and vegetated samples are the mean of three replicates. Error bars indicate one standard deviation of the mean

IV - 36. Mineralization of ${ }^{14} \mathrm{C}$-TCE in sterile control soil, nonvegetated soil, and soil containing Solidago sp. Each datum point is the mean of three replicates. Error bars indicate one standard deviation of the mean

IV - 37. Mineralization of ${ }^{14} \mathrm{C}-\mathrm{TCE}$ in nonvegetated soil and soil containing Paspalum notatum from two different experiments .....

IV - 38. Mineralization of ${ }^{14} \mathrm{C}$-TCE in sterile control soil, nonvegetated soil, and soil containing Glycine max. Data points for sterile control samples are the mean of two replicates whereas the nonvegetated and vegetated samples are the mean of three replicates. Error bars indicate one standard deviation of the mean.

IV - 39. Mineralization of ${ }^{14} \mathrm{C}$-TCE in sterile control soil, nonvegetated soil, and soil containing Glycine max. Data points for sterile control samples are the mean of two replicates whereas the nonvegetated and vegetated samples are the mean of three replicates. Error bars indicate one standard deviation of 
the mean

IV - 40. Mineralization of ${ }^{14} \mathrm{C}$-TCE in sterile control soil, nonvegetated soil, and soil containing Pinus taeda. All samnles were respiked with ${ }^{14} \mathrm{C}$-TCE on day 10

IV - 41. Mineralization of ${ }^{14} \mathrm{C}$-TCE in sterile control soil and sterile soil containing a Pinus taeda seedling treated with $\mathrm{NaOCl}$. Each datum point is the mean of three replicates. Error bars indicate one standard deviation of the mean

IV - 42. Mineralization of ${ }^{14} \mathrm{C}$-TCE in sterile control soil and sterile soil containing a Pinus taeda seedling treated with $\mathrm{NaOCl}$. Each datum point is the mean of three replicates. Error bars indicate one standard deviation of the mean

IV - 43. Mineralization of ${ }^{14} \mathrm{C}$-TCE in sterile control soil, nonvegetated soil, and soil containing Glycine max grown under two different lighting conditions. Data points for sterile control samples are the mean of two replicates whereas the nonvegetated and vegetated samples are the mean of three replicates. Error bars indicate one standard deviation of the mean

IV - 44. Mineralization of ${ }^{14} \mathrm{C}$-TCE in sterile control soil, nonvegetated soil, and soil containing Pinus taeda grown under reduced light conditions. Each datum point is the mean of three replicates. Error bars indicate one standard deviation of the mean

IV - 45. Mineralization of ${ }^{14} \mathrm{C}$-TCE in sterile control soil, nonvegetated soil, and soil containing Lespedeza cuneata grown under reduced light conditions. Each datum point is the mean of three replicates. Error bars indicate one standard deviation of the mean 


\section{ACKNOWLEDGMENTS}

Several people in the Environmental Sciences Division at Oak Ridge National Laboratory have contributed to the success of this research in specific areas. Bob Luxmoore, Phil Jardine (soils and mode!ing); Pat Parr, Maureen Cunningham, Linda Mann, Gerry O'Neill, Rich Norby, Nelson Edwards, and Carla Gunderson (plants); Steve Herbes, Tony Palumbo and Mike Morrissey (bacteria and chemical analyses). In acidition, we are grateful to colleagues at the Institute for Applied Microbiology (Jim Guckert, David Ringleberg, Tommy Phelps) for help with bacterial community analysis. Dr. Terry Hazen of the Savannah River Laboratory (SRL) served as project officer for this work and provided helpful discussions and advice. Vergil Rogers (SRL) and John Knox (Savannah River Ecology Laboratory) helped with the pedon description and plant survey, respectively.

This research was sponsored by the Office of Technology Development, U.S. Department of Energy, under contract DE-AC05-84OR21400 with Martin Marietta Energy Systems, Inc. This research was conducted in the Environmental Sciences Division of Oak Ridge National Laboratory, which is managed by Martin Marietta Energy Systems, Inc. for the U.S. Department of Energy. Publication number 3809 of the Environmental Sciences Division. 


\section{ABSTRACT}

ANDERSON, T. A and B. T. WALTON: 1992. Comparative plant uptake and microbial degradation of trichloroethylene in the rhizospheres of five plant species--Implications for bioremediation of contaminated surface soils. ORNL/TM-12017. Oak Ridge National Laboratory, Oak Ridge, Tennessee. 206 pp.

The objective of this study was to collect data that would provide a foundation for the concept of using vegetation to enhance in situ bioremediation of contaminated surface soils. Soil and vegetation (Lespedeza cuneata, Paspalum notatum, Finus taeda, and Solidago sp.) samples from the Miscellaneous Chemicals Basin (MCB) at the Savannah River Site were used in tests to identify critical plant and microbiological variables affecting the fate of trichloroethylene (TCE) in the root zone.

Microbiological assays including phospholipid fatty acid analyses, and ${ }^{14} \mathrm{C}$-acetate incorporation were conducted to elucidate differences in rhizosphere and nonvegetated soil microbial communities from the MCB. The microbial activity, biomass, and degradation of TCE in mizosphere soils were significantly greater than corresponding nonvegetated soils. In addition, vegetation (both indigenous and nonindigenous) had a positive effect on microbial degradation of ${ }^{14} \mathrm{C}-\mathrm{TCE}$ in whole-plant experiments. Soils from the MCB containing Lespedeza cuneata, Pinus taeda, and Glycine max mineralized greater than $25 \%$ of the ${ }^{14} \mathrm{C}$-TCE added compared with less than $20 \%$ in nonvegetated soils. Collectively, these results provide evidence for the positive role of vegetation in enhancing biodegradation. Furthermore, biodegradation of TCE may be slower than degradation rates for less persistent 
waste chemicals such as nonhalogenated aromatics. Therefore, the data are likely to be conservative estimates of the potential for enhanced degradation of waste chemicals in the rhizosphere. In most of the whole plant experiments conducted, total uptake was minimal, ranging from $1 \%-21 \%$, and was related to water use and plant species. Because the experiments were designed to maximize plant uptake, these data may be overestimates of the potential TCE residues in plants grown in TCE-contaminated soil.

This dissertation represents a systematic approach to answering initial fundamental questions on the soil-plant-microbe-chemical relationship. The results presented provide strong evidence for the potential role of vegetation in remediation of surface soils contaminated with hazardous organic compounds. In addition, the reviewed literature on rhizosphere microbiology, accelerated degradation of agrochemicals in the root zone, and recent research on the fate of nonagricultural chemicals in the rhizosphere, all provide additional impetus for exploring the use of vegetation in bioremediation of contaminated surface soils. 


\section{CHAPTER I.}

\section{INTRODUCTION}

The use of indigenous microbial populations to restore chemically contaminated surface soils is potentially an effective remediation strategy, provided that a sufficient consortia of microorganisms capable of degrading the contaminant(s) are present and their activity is not limited by the existing environmental conditions. The highly versatile metabolic capabilities of fungi and bacteria have been employed to reclaim polluted ecosystems and minimize the potential adverse effects of hazardous chemicals released to the environment (Atlas and Pramer, 1990). Occasionally, environmental conditions onsite significantly hinder microbial degradation of toxicants. In such cases, the environmental conditions may be altered in an attempt to enhance microbial populations and/or their activity, such as through nutrient additions or aeration. The addition of external carbon sources may be especially important in such cases where the contaminant is degraded cometabolically.

The rhizosphere (Figure I - 1) is a zone of increased microbial activity and biomass at the root-soil interface (Curl and Truelove, 1986). The large microbial populations in the rhizosphere are sustained by exudation of carbohydrates and amino acids from the root and sloughing of root epidermis (Rovira et al., 1979). Although modification of the soil environment in the rhizosphere by plant root secretions is an important process that influences microbial populations, the actual structure of the plant root provides microorganisms with a large surface area for colonization (Lynch, 1982). The 


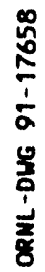

을

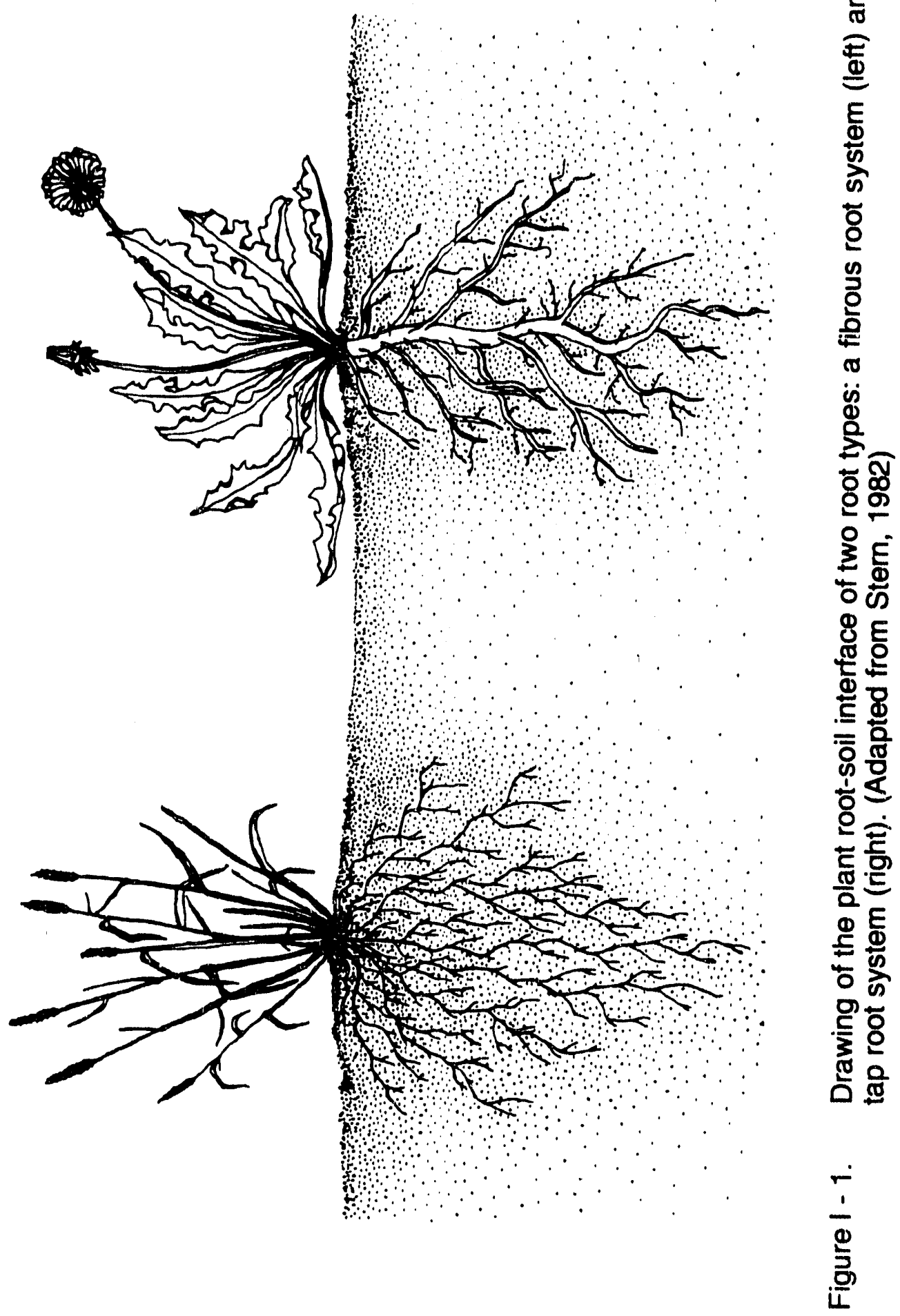


ihizosphere characteristics briefly described translate into typical microbial populations an order of magnitude or more above microbial populations in nonvegetated soil. In the most simplistic scenario, the increased microbial activity and biomass in the mizosphere would produce a faster degradation rate compared with nonvegetated soil. More complex scenarios could involve the role of plants in providing an extemal carbon source (exudates) in situations where the soil is contaminated with wastes that can be degraded cometabolically, such as trichloroethylene (TCE).

The specific use of vegetation to enhance the microbial degradation of surface and near-surface soils contaminated with hazardous wastes such as chlorinated solvents, polycyclic aromatic hydrocarbons (PAHs), or benzenetoluene-xylene (BTX) for example, is not known but could provide a costeffective remediation strategy for soils containing low to moderate concentrations of these compounds when engineering approaches to cleanup are not practical. In addition, establishing or selectively cultivating vegetation on a contaminated site are relatively simple site management techniques. Overall, vegetation has the potential for providing a cost-effective, lowmaintenance, aesthetically pleasing, in situ bioreactor.

The objective of this research was to determine whether vegetation could enhance microbial degradation of hazardous organic compounds in soils as a result of the rhizosphere effect. Trichloroethylene was used as a model compound in studies to identify critical environmental variables affecting the rate of TCE degradation in the root zone. Experiments were carried out using soils and plants from a TCE-contaminated field site. In addition, fundamental 
studies on thizosphere microbiology, microbial degradation of agricultural chemicals in the root zone, and recent research on the fate of non-agricultural chemicals in the rhizosphere are reviewed and presented as affirmation for the potential role of vegetation in enhancing remediation of sites contaminated with hazardous organic compounds. 
CHAPTER $\|$.

\section{LITERATURE REVIEW}

A. Physicochemical Properties of Trichloroethylene

Trichloroethylene (TCE) is a colorless, nonflammable, volatile liquid with a characteristic etheral odor that was commonly used as an industrial and drycleaning solvent, metal degreaser, and fumigant (Merck Index, 1989). These uses of TCE have contributed extensively to its occurance at waste sites and as

a contaminant of groundwater (U.S. EPA, 1982). Physicochemical properties of TCE are shown in Table $\| \cdot-1$.

TCE is only slightly soluble in water. Its hydrophobic nature causes it to partition into soils and sediments, both from the liquid and vapor phases. Peterson and coworkers (1988) found soil-liquid partition coefficients for TCE of $0.26 \mathrm{~cm}^{3} / \mathrm{g}$ on water-saturated synthetic soll (humic-coated alumina), $53.9 \mathrm{~cm}^{3} / \mathrm{g}$ on synthetic soil with $11.6 \%$ water content, and $207 \mathrm{~cm}^{3} / \mathrm{g}$ on synthetic soil with $8.2 \%$ water content. The above observation is consistent with the concept of water competing with organic compounds for sorption sites on soil, where decreasing water content leads to increasing sorption. The influence of moisture content on TCE sorption is further verified by Ong and Lion (1991). Lee et al. (1988) observed TCE sorption coefficients of $0.10 \mathrm{~mL} / \mathrm{g}$ on Borden aquifer material $(0.025 \%$ organic carbon) and $0.17 \mathrm{~mL} / \mathrm{g}$ on Lula aquifer material $(0.034 \%$ organic carbon). 
Table II - 1. Physicochemical properties of trichloroethylene (TCE).

\section{Propertles of TCE}

\begin{tabular}{lc}
\hline Molecular formula & $\mathrm{Cl}_{2} \mathrm{C}=\mathrm{CHCl}$ \\
Molecular weight & 132 \\
Boiling point & $87^{\circ} \mathrm{C}$ \\
Vapor pressure & $60 \mathrm{~mm} \mathrm{Hg}$ at $20^{\circ} \mathrm{C}$ \\
Solubility & $1.1 \mathrm{~g} / \mathrm{L} \mathrm{at} 25^{\circ} \mathrm{C}$ \\
Density & $1.46 \mathrm{~g} / \mathrm{mL}$ at $20^{\circ} \mathrm{C}$ \\
Log $_{10}$ octanol-water partition coefficient $\left(\log \mathrm{K}_{\text {ow }}\right)$ & $2.36^{A}$ \\
Henry's law constant (dimensionless) & $0.397^{8}$ \\
Log $_{10}$ adsorption coefficient $\left(\log \mathrm{K}_{\mathrm{oc}}\right)$ & $2.6-2.7^{\mathrm{B}}$ \\
\hline
\end{tabular}

A From Mailhot and Peters, 1988

B From Lee et al., 1988 
B. Mammalian Toxicity and Effects on Microorganisms

Mammalian Toxicity

Most chlorinated hydrocarbons are cytotoxic to the liver and kidney, and TCE is no exception (Williams and Weisburger, 1986). It induces liver neoplasms in mice and rats and can inactivate P-450 (mixed-function oxidase) catalyzed reactions by suicide inactivation (Sipes and Gandolfi, 1986). An enhanced TCE hepatotoxicity is observed after ethanol (Klaassen and Plaa, 1967), isopropanol, and acetone (Plaa et al., 1975) pretreatment. Necrosis and fatty liver are also signs of chronic TCE exposure (Plaa, 1986).

In mammalian systems, TCE undergoes microsomal oxidation via cytochrome P-450 (mixed-function oxidase) enzymes to a bloactivated epoxide metabolite (Miller and Guengerich, 1982). The epoxide intermediate of TCE metabolism may be mutagenic (Heath et al., 1977) and carcinogenic (Miller and Guengerich, 1982), but isolation has been difficult (Miller and Guengerich, 1983) Tue to its instability. The understanding of TCE metabolism via mixedfunction oxidases in mamallian systems has aided in elucidating the pathway for aerobic degradation of TCE by microorganisms employing monooxygenase enzymes.

\section{Effects on Microorganisms}

Adsorption of contaminants to soil can result in exposure to soil microorganisms and potential toxicity. Kanazawa and Filip $(1986,1987)$ have examined the effects of TCE, tetrachloroethylene, and dichloromethane on enzymatic activities, biomass, and microbial counts in soil. They found 
significant initial decreases in both ATP content and fungal counts in soil exposed to TCE at $1 \mu \mathrm{g} / \mathrm{g}$. TCE also initially inhibited aerobic bacteria and actinomycetes at $10 \mu \mathrm{g} / \mathrm{g}$, the highest concentration tested, although recovery orcurred. However, soils exposed to the highest concentration of TCE showed increased microbial counts two months after exposure. The authors did not differentiate between increased micrcbial counts caused by microorganisms using TCE or its metabolites as a carbon and energy source or to infusion of carbon from microorganisms killed by the TCE. Enzyme assays for $ß-$ glucosidase, B-acetylglucosaminidase, phosphatase, phosphodiesterase, and proteinase showed no effect from TCE exposure at $0.1 \mu \mathrm{g} / \mathrm{g}$. An initial inhibition was observed for B-glucosidase and B-acetylglucosaminidase at $1 \mu \mathrm{g} / \mathrm{g}$, however, both enzymes returned to normal or slightly higher than normal levels. Although TCE at $10 \mu \mathrm{g} / \mathrm{g}$ initially inhibited all enzymes tested, their activities had retumed to normal levels after two months. The authors did not determine whether residues of TCE were still present after two months.

Wackett and Householder (1989) measured the inhibition of cell growth and covalent modification of cellular macromolecules as indicators of the cytotoxic effects of TCE on Pseudomonas putida F1. Although this culture was capable of TCE degradation via the toluene dioxygenase pathway, initial degradation rates declined rapidly, possibly indicating the production of toxic intermediates. Exposure of TCE to mutant microorganisms lacking toluene dioxygenase activity showed no cytotoxic effects. Fractionation of $P$. putida $F 1$ cells exposed to ${ }^{14} \mathrm{C}$-TCE indicated most of the ${ }^{14} \mathrm{C}$ incorporated was associated with cell protein. Further chemical analyses of the protein fraction 
implicated glyoxylic acid and formic acid as components of the protein adducts. The authors speculated that the alkylation of cellular macromolecules by formic and glyoxylic acid produced the observed cytotoxic effects.

The toxicity of TCE to a mixed culture of methanotrophs has also been determined (Broholm et al., 1990). Results from these experiments showed that increasing TCE concentrations from 0 to $65 \mathrm{mg} / \mathrm{L}$ translated into decreased methane consumption and decreased bacterial growth as measured by protein concentration. Although the authors did not speculate whether the decreased methane consumption was due to competitive inhibition of methane monooxygenase with TCE or simply to a decline in the population of methanotrophs, these initial results provide an important start to determining the optimal concentrations of methane and TCE to achieve TCE degradation by methanotrophs. In addition, the data have important implications for remediation using methane to enrich for methanotrophs in contaminated soils and groundwater.

\section{Microbial Degradation of TCE}

Details of several studies involving TCE degradation are shown in Table II - 2. Where possible, complete information on the system involved as well as the experimental conditions employed are provided. In addition, discussions on the significant findings of the experiments are reported below.

The first laboratory experiments on the degradation of TCE failed to show conclusive results (Bouwer et al., 1981). Under both aerobic and anaerobic conditions, no appreciable degradation of TCE was observed, although 


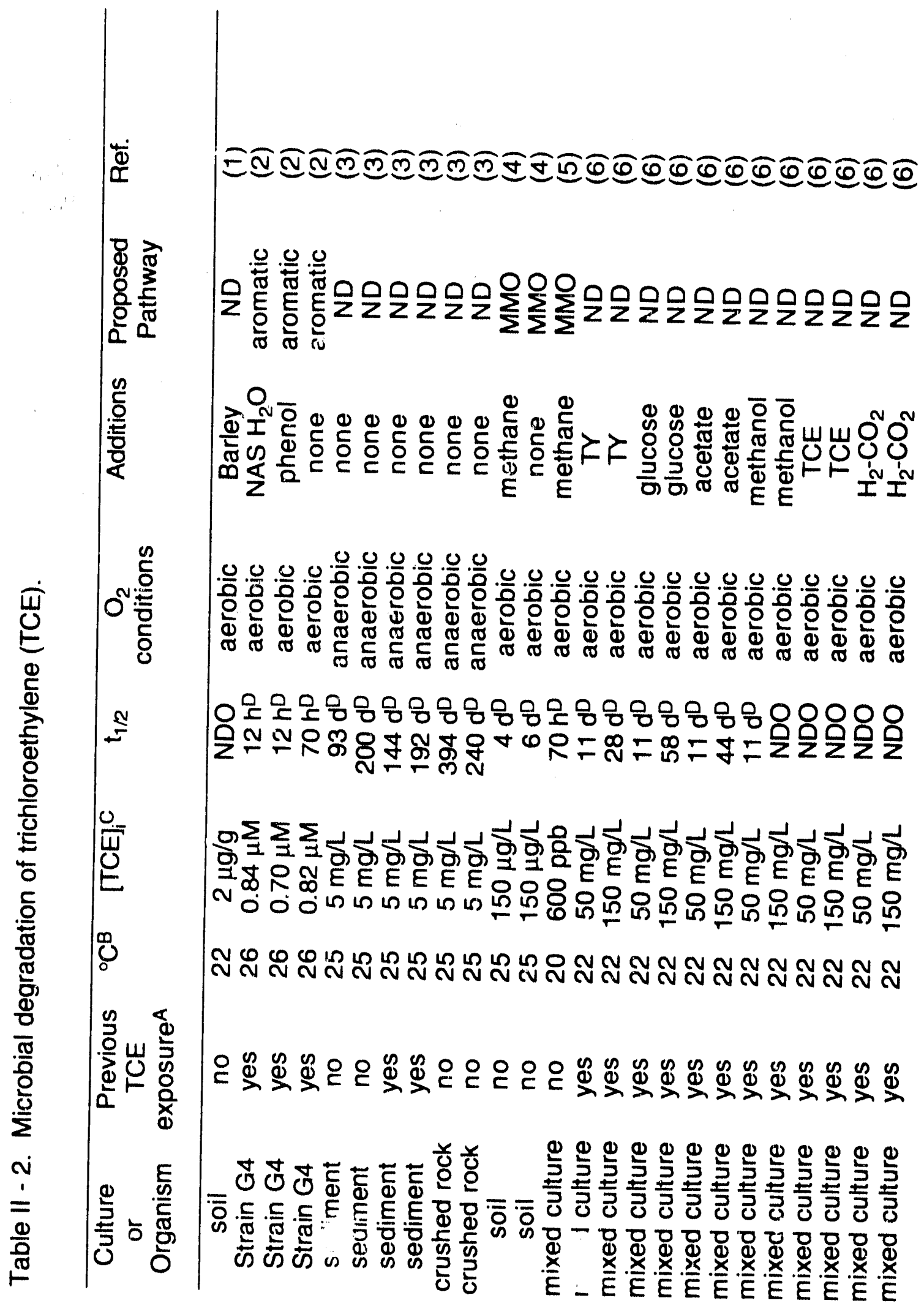




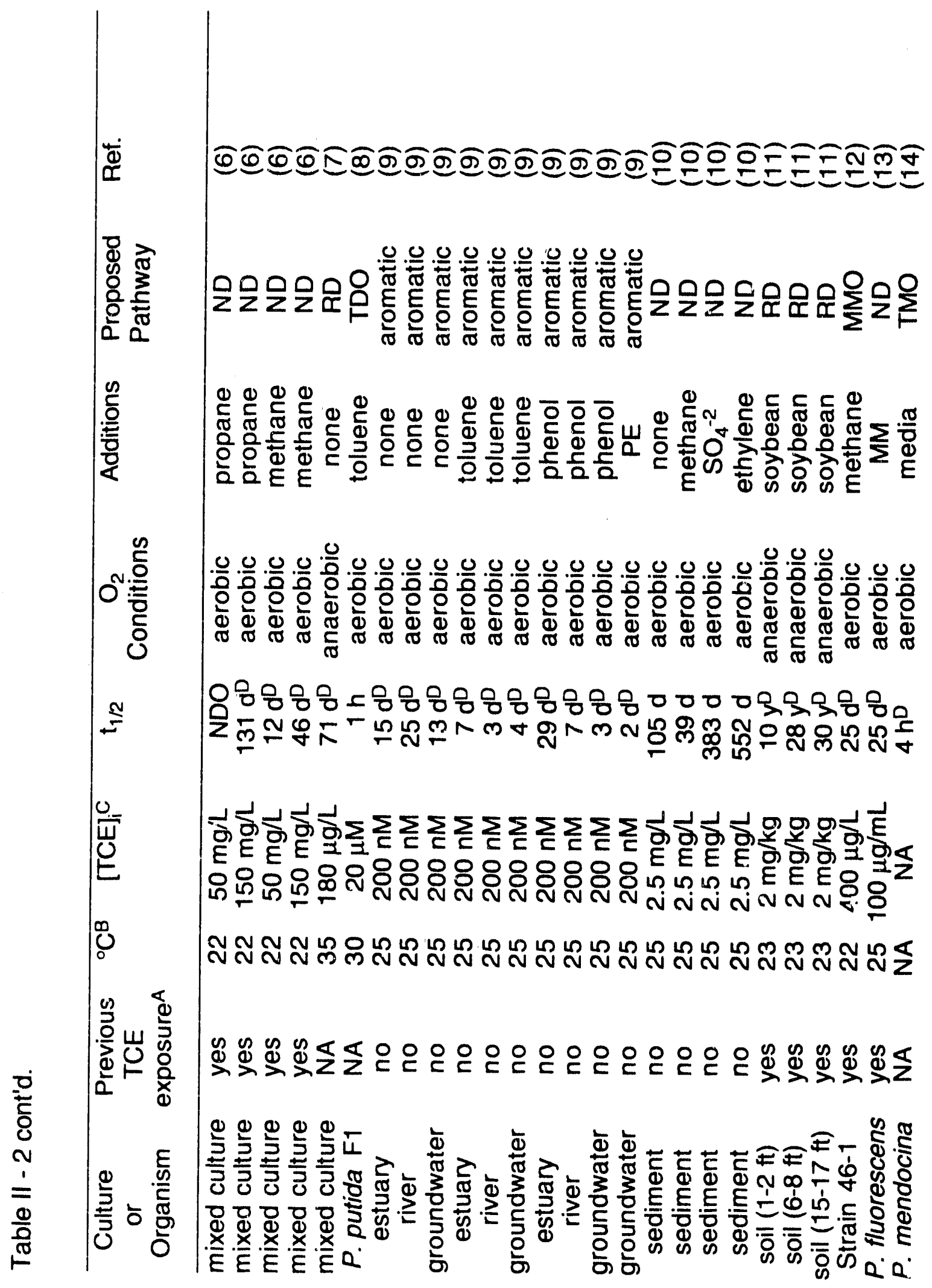




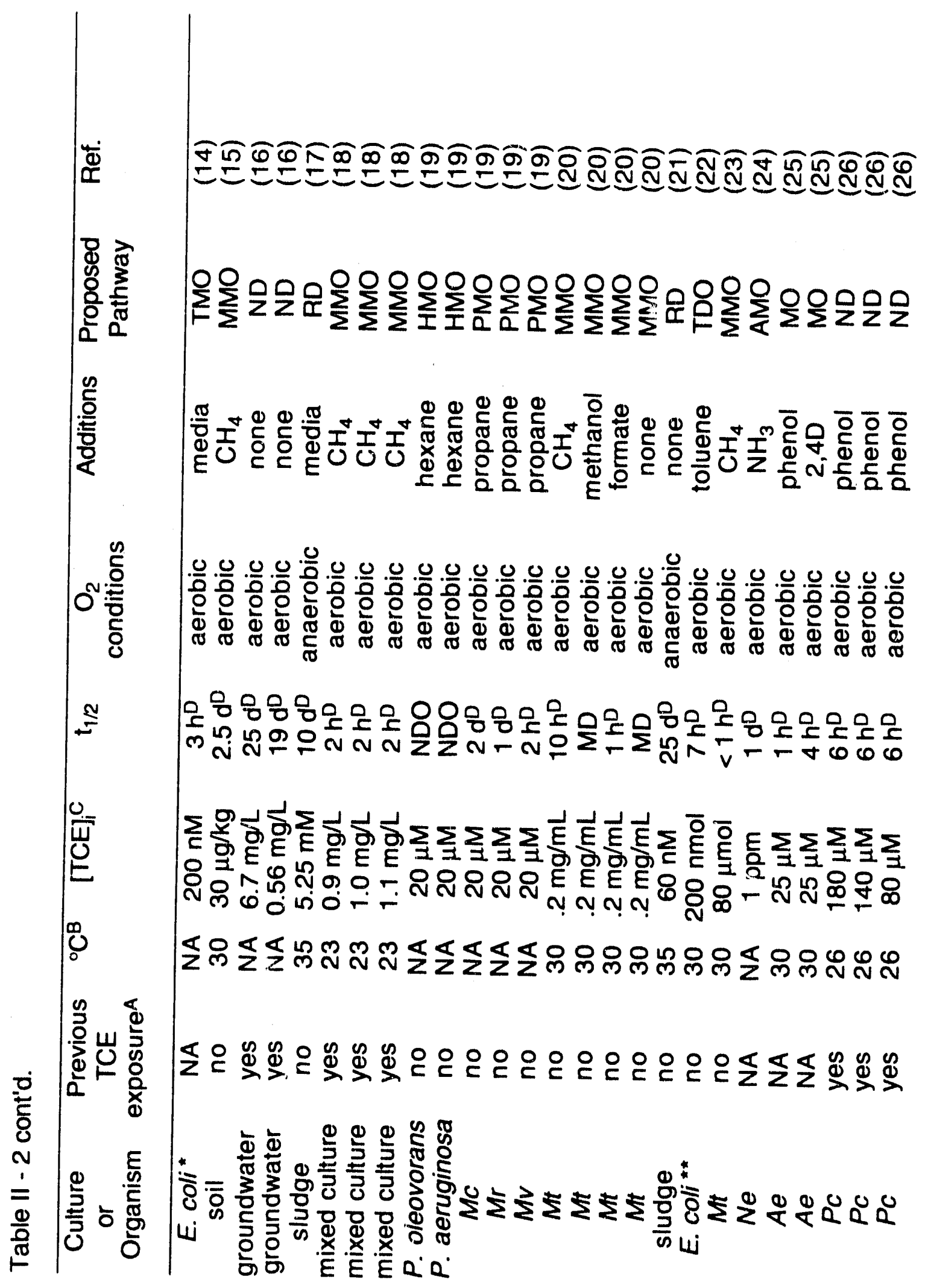




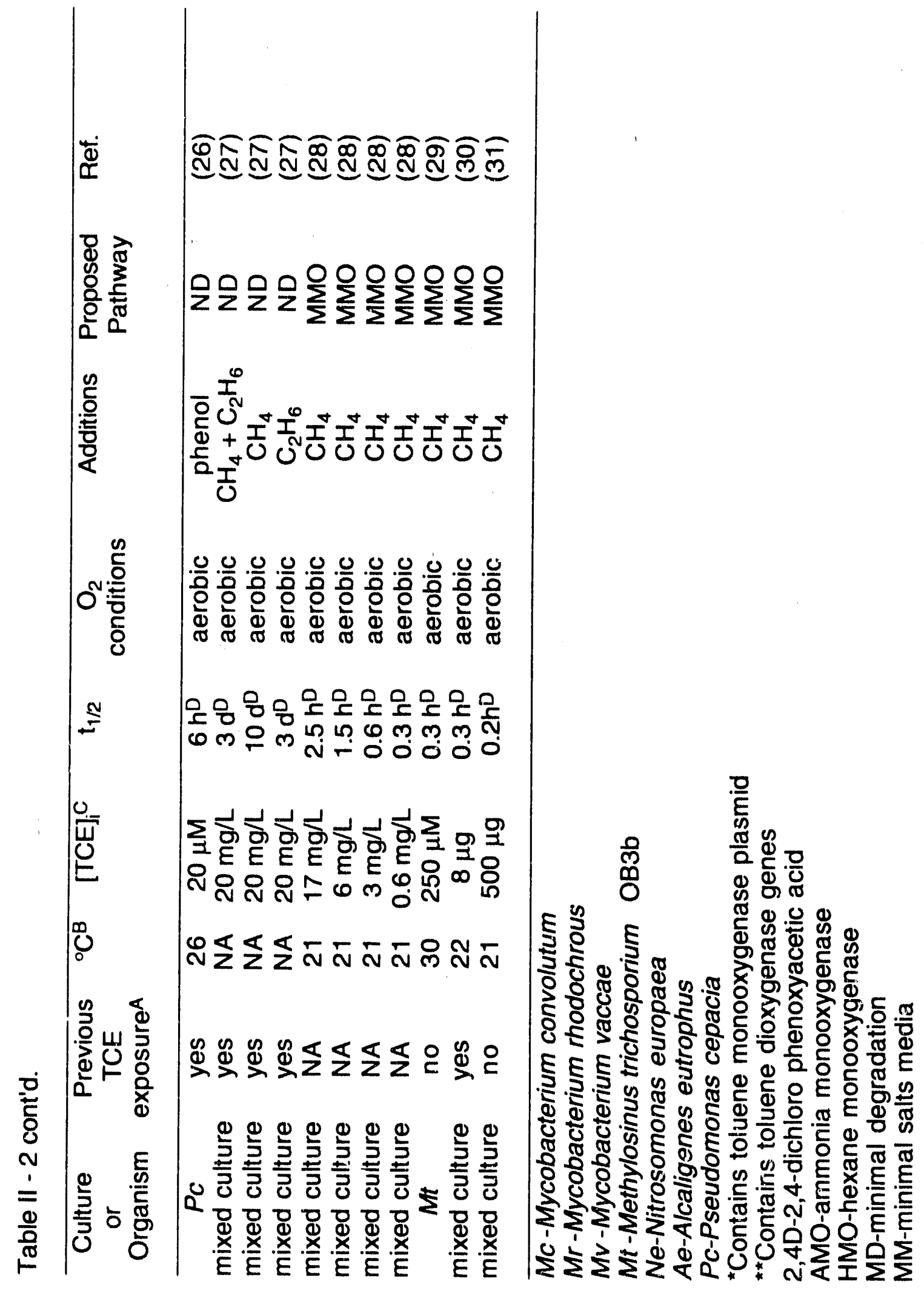




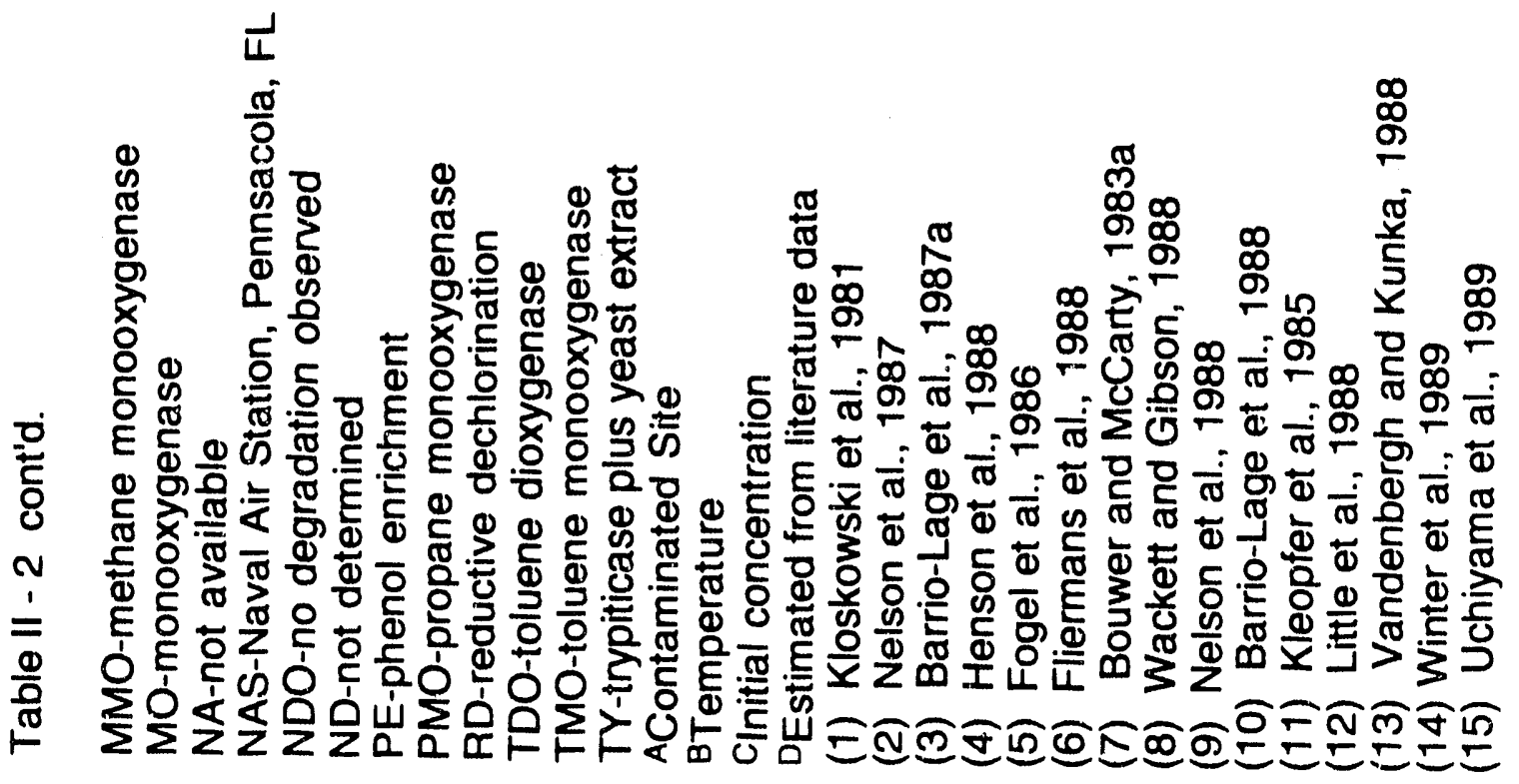




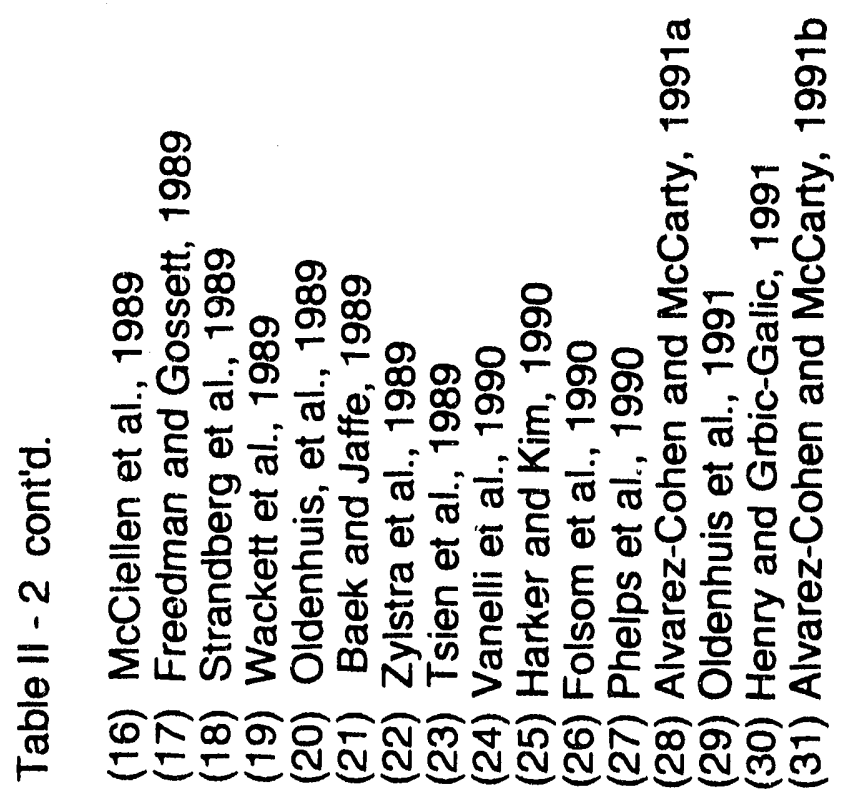


bromodichloromethane, dibromochloromethane, and chloroform were readily removed by mixed cultures from sewage effluent. These results were consistent with field observations at the Palo Ailto groundwater recharge project (Roberts et al., 1980), which documented the parsistence of TCE in groundwater. However, in subsequent experiments, Bouwer and McCarty (1983a) found that TCE could be degraded under methanogenic conditions in both batch and continuous flow reactors. It was not clear from this paper whether or not the reactors were seeded with cultures from a contaminated site to achieve the nearly $40 \%$ reduction of TCE that was observed after 8 weeks. No TCE was lost from sterile (un-innoculated) controls. The accumulation of dichloroethylene (DCE) in the reactor spiked with TCE supported the authors speculation of reductive dehalogenation as the mechanism of degradation. Tracer experiments using ${ }^{14} \mathrm{C}$-TCE were not performed to confirm the degradation pathway of TCE.

Further proof of reductive dehalogenation as a mechanism for the degradation of halogenated aliphatic compounds under anaerobic conditions came from Parsons and co-workers (1984) who observed the disappearance of tetrachloroethylene (PCE) with concommitant accumulations of TCE and cisand trans-DCE in freshwater organic sediment samples. These studies were initiated in part because of field observations describing the appearance of chloroethene and cis- and trans-DCE in groundwater from areas where these compounds were not used but TCE and PCE were previously used. Although anaerobic or nearly anaerobic concitions were presumed in the microcosms, dissolved oxygen content and redox potential in the samples was not determined. In a study utilizing a system less complex than the organic 
sediments, Parsons and Barrio-Lage (1985) used cultures of aquatic bacteria isolated from a TCE spill site to monitor TCE and PCE degradation. Reductive dehalogenation of TCE and PCE occurred, producing both isomers of 1,2-DCE; however, the cis isomer was produced in greater amounts. The authors speculated that the more polar cis isomer was preferentially formed because of the high polarity of the aqueous medium.

Kleopfer and co-workers (1985) used soil from a TCE spill site, ${ }^{13} \mathrm{C}$ labelled TCE, and gas chromotography/mass spectrometry to conclusively demonstrate reductive dechlorination of TCE in soil. Soybean meal was added to the soil samples to help produce anaerobic conditions although oxygen concentration in the samples was not determined. Only 1,2-DCE was produced from TCE dechlorination, however, the cis and trans isomers could not be differentiated. No 1,1-DCE was found in the samples. Interestingly, microorganisms in soils collected from three different depths in the soil profile were equally effective at dehalogenation of TCE. The authors speculated that in the field, TCE dehalogenation to DCE may be even faster due to the absence of an easily utilized carbon and energy source such as soybean meal.

However, the soybean meal may not have been appreciably metabolized under anaerobic conditions.

Vogel and McCarty (1985), using both small (2-day liquid retention time) and large (6-day liquid retention time) continuous-flow, fixed-film, methanogenic columns, observed $99 \%$ removal of PCE. In the small-column study, TCE was the major product formed whereas vinyl chloride was the major metabolite in the large-column study. The authors used both liquid scintillation spectroscopy 
and gas chromatography/mass spectroscopy to monitor reductive dehalogenation of ${ }^{14} \mathrm{C}-\mathrm{PCE}$ and PCE, respectively. These studies further implicated reductive dehalogenation as the degradative mechanism for chlorinated ethylenes in anaeroblc systems. In the tracer studies, ${ }^{14} \mathrm{CO}_{2}$ was detected, indicating complete mineralization of ${ }^{14} \mathrm{C}$-PCE. In addition, the authors proposed a pathway for reductive dehalogenation of PCE to $\mathrm{CO}_{2}$ by way of TCE, DCE, and vinyl chloride (Figure II - 1). Whether vinyl chloride could be converted to $\mathrm{CO}_{2}$ under anaerobic conditions is still speculative. However, because of its carcinogenicity (Williams and Weisburger, 1986), the eventual formation of vinyl chloride would not be desirable in situations where in situ remediation of groundwater and/or soils is the goal. Recent work on reductive dechlorination of chlorinated ethylenes has shown that PCE and TCE can be converted to ethylene through DCE and vinyl chloride (Freedman and Gossett, 1989) and vinyl chloride can be metabolized under aerobic conditions by actinomycetes (Phelps et al., 1991b). Unlike the results of Vogel and McCarty $(1985,1987)$ no significant amounts of $\mathrm{CO}_{2}$ were produced.

Although the studies described above showed reductive dechlorination of TCE under methanogenic conditions, it is important to note that these studies were undertaken using mixed cultures. Only recently has research on TCE degradation under methanogenic conditions with pure cultures of methanogens been conducted (Baek and Jaffe, 1989). These studies were important for elucidating the potential role of nonmethanogenic anaerobes in TCE degradation. Comparisons of vials innoculated with methanogens and vials innoculated with methanogens and nonmethanogenic anaerobes indicated 


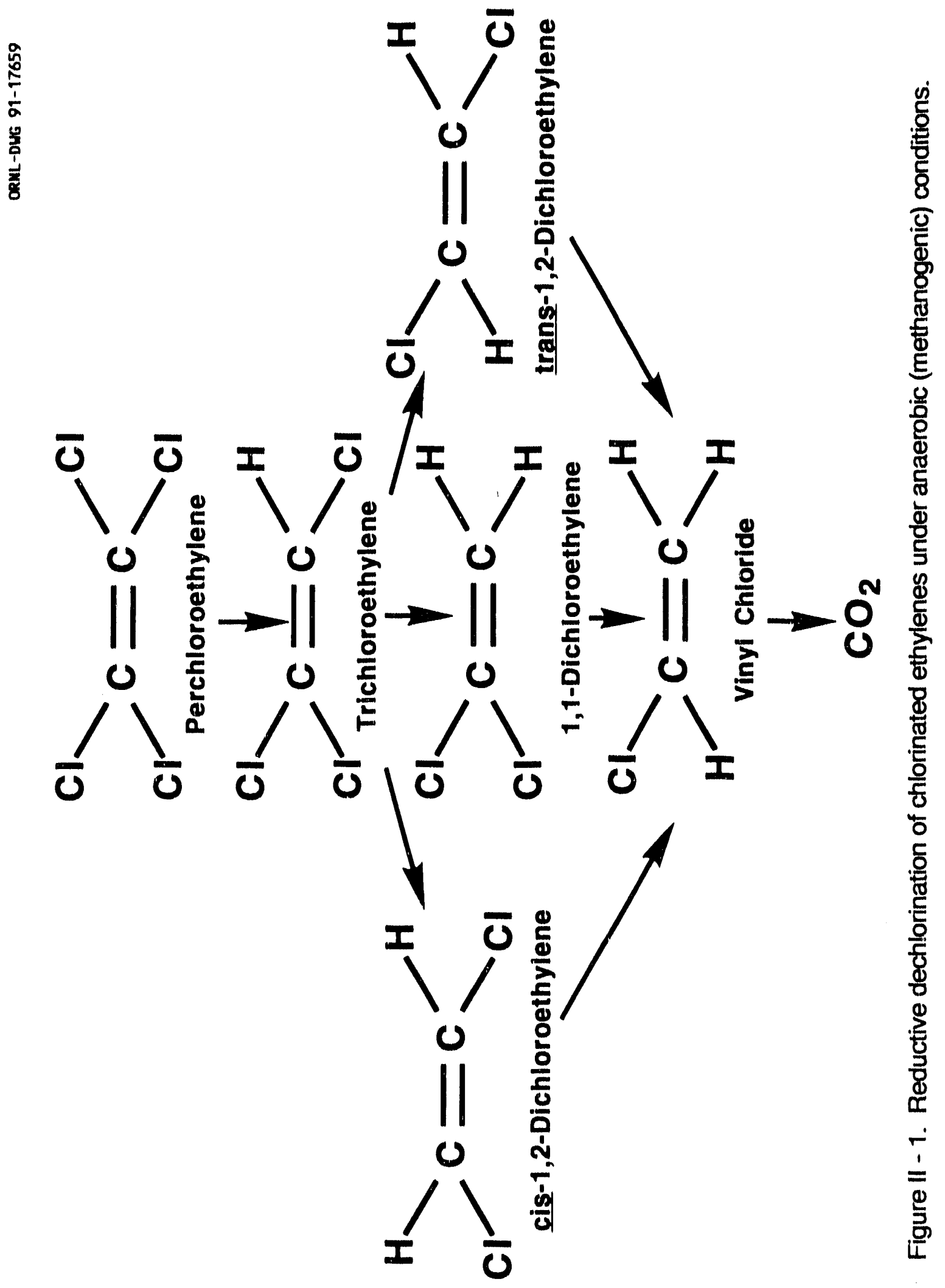


increased TCE degradation in the vials containing the nonmethanogenic anaerobes indicating their capability to also dechlorinate TCE.

Methane-oxidizing bacterla oxidize and dechlorlinate halogenated methanes via methane monooxygenase (Haber et al., 1983). This observation, coupled with the observation of ethylene epoxidation by propane-oxidizing bacteria (Hou et al., 1983) lead Wilson and Wilson (1985) to hypothesize that TCE transformation by methane- and propane-oxidizing bacteria might be possible and may proceed by these same mechanisms. They exposed soll columns to natural gas to enrich for methanotrophs and then compared the fate of TCE in these columns to unexposed soil columns. The $150 \mathrm{~cm}$-long soil columns were moistened daily with $\mathrm{H}_{2} \mathrm{O}$ containing TCE $(150 \mu \mathrm{g} / \mathrm{L})$. Less than $5 \%$ of the applied TCE passed completely through the natural gas-exposed soll column during the 2-week experimental period. Soil columns not previously exposed to natural gas showed no significant TCE degradation. The authors speculated that the TCE was transformed to $\mathrm{CO}_{2}$, and that the transformation was an aerobic process. This was the first observation of aerobic TCE metabolism. Because the soll used was sandy, low in organic carbor $(<0.45 \%)$, and not compacted, aerobic conditions were probably maintained throughout the study. Field applications of this technique may be hampered by the difficulty of maintaining aerobic conditions in the soll profile. However, in the field, water (and the TCE dissolved in it) would not be expected to percolate through the soll as quickly as is observed in packed laboratory soll columns. It is encouraging to note that TCE-degrading populations can be enriched in soil with no previous TCE exposure. Phospholipid ester-linked fatty acid (PLFA) 
analyses of the natural gas-exposed soll column indicated characteristic fatty acids typical of type II methanotrophic bacteria (Nichols et al., 1987). In a similar study, Henson and co-workers (1988) also exposed sandy soll to an atmosphere of $4 \%$ methane for 6 weeks prior to testing for TCE and PCE degradation. They found significantly greater degradation rates for TCE in the methane-enriched soll, further promoting the role of methanotrophic bacteria in TCE metabolism. In addition, once the soil was enriched with methane, its (methane) presence was not required except for removal of TCE below the detection limits (which were not reported). There was no significant difference between PCE degradation by the methane-enriched and control solls.

Recent research has shown that, in addition to soil, sediment samples may also be enriched with methanotrophic bacterla by exposure to methane (Fliermans et al., 1988; Barrio-Lage et al., 1988; Phelps et al., 1990).

Subsurface sediment samples collected from a solvent-contaminated area at the Savannah River Site near Alken, SC, were used by Fliermans et al. (1988) to determine TCE mineralization by heterotrophic enrichment cultures. They found that methane, methanol, acetate, glucose, and trypticase plus yeast extract stimulated the degradation of TCE (initial concentration $50 \mathrm{mg} / \mathrm{L}$ ) often leading to $99.8 \%$ removal. Degradation of TCE at higher concentrations varied from undetected to $37 \%$ among the different enrichments. Additional experiments with the cultures isolated from contaminated sediments at the Savannah River Site were cunducted in expanded-bed bioreactors (Phelps et al., 1990; Phelps et al., 1991a). Up to $95 \%$ of the TCE added was degraded in the reactors after 5 days. Phelps and coworkers also showed that pulse-feed 
reactors had higher TCE degradation rates compared with continuous-feed reactors. These results are very encouraging for groundwater remediation using pump and treat techniques. In similar experiments, Barrio-Lage et al. (1988) used sulfate, methane, and ethylene enrichments to study TCE degradation in sediment microcosms. Methane additions were found to increase the biotransformation rate of TCE, whereas sulfate and ethylene additions had the opposite effect.

Methane has also been used extensively in enrichments for methanotrophic bacteria in the liquid environments of culture flasks (for example, Fogel et al., 1986; Little et al., 1988) as opposed to soil. Fogel and coworkers (1986) used methane enrichment techniques to determine whether liquid cultures of methane-utilizing bacteria could degrade TCE and PCE. They found that $23 \%$ of the added TCE appeared as $\mathrm{CO}_{2}$ after 2 days. The remaining TCE was transformed to water-soluble products or incorporated as bacterial biomass. Additionally, acetylene, methanol, and 2-propanol inhibited the biodegradation of TCE. PCE transformation during 190 hours of incubation was not observed $(0.1 \mu \mathrm{g} / \mathrm{L}$ detection limit). The first observation of TCE biodegradation by pure cultures of methanotrophic bacteria was reported by Little et al. (1988). In addition, they determined the dependence of methane concentration and proposed a pathway for TCE degradation. Strain 46-1, a type I methanotroph, converted $40 \%$ of the added TCE after 20 days. The maximum rate of TCE degradation occurred during active cell growth and stopped after methane depletion. In addition, methanol was shown to stimulate biodegradation of TCE by strain 46-1. The pathway proposed by Little and co- 
workers (Figure II - 2) involves formation of TCE epoxide from TCE via methane monooxygenase (MMO). TCE epoxide then spontaneously breaks down to form dichloroacetic acid, glyoxylic acid, carbon monoxide, or formate. Previous research has shown that glyoxylic acid and dichloroacetic acid appear during decomposition of TCE epoxide (McKinney et al., 1955; Henschler et al., 1979). Ion chromotographic analysis of the culture medium following the TCE degradation experiments demonstrated the presence of both of these compounds. Strain 46-1 and other organisms from the methanotrophic consortia of Little et al. (1988) has also been used in packed-bed bioreactors (Strandberg et al., 1989) illustrating a possible use of this consortia in pump and treat applications.

The literature on TCE degradation by methanotrophic microorganisms is exciting because of the potential for field applications. Laboratory experiments have shown not only the TCE oxidation ability of these bacteria, but also that enrichment for methanotrophs is easily accomplished. Current research on TCE metabolism by methanotrophic organisms has focused attempts to identify the type(s) of methanotroph(s) (Type I versus. Type II) and enzymatic form(s) of methane monooxygenase (soluble MMO versus. particulate MMO) responsible for TCE degradation (Oldenhuis et al., 1989; Tsien et al., 1989; Uchiyama et al., 1989; Phelps et al., 1990) the influence of TCE toxicity to microorganisms on TCE degradation rates (Broholm et al., 1990; Alvarez-Cohen and McCarty, 1991a, 1991b, 1991d; Oldenhuis et al., 1991; Henry and Grbic-Galic, 1991a and 1991b) the influence of culture growth on treatment of contaminated groundwater in bioreactors (Alvarez-Cohen and McCarty, 1991c) and the fate of 


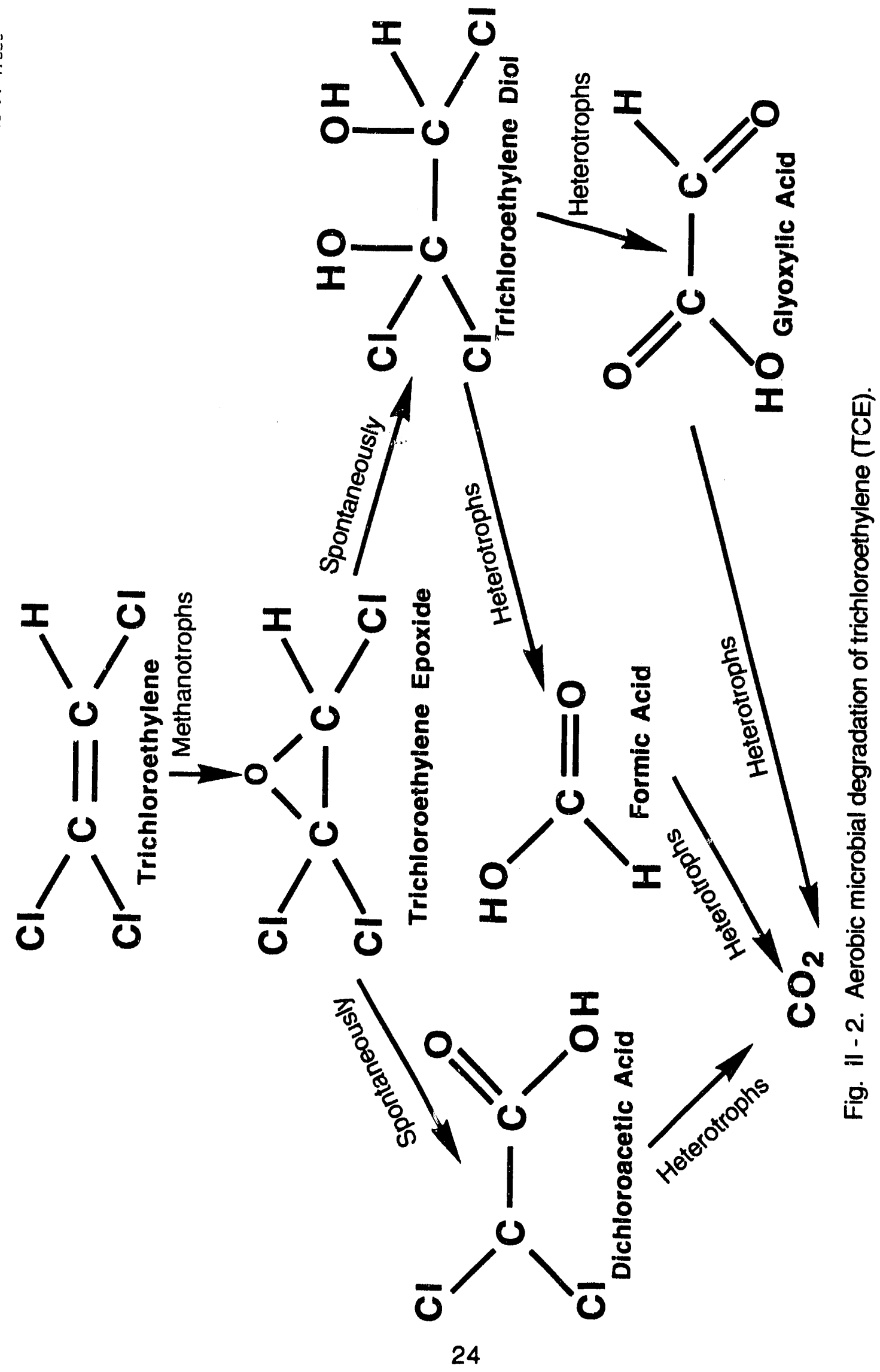


metabolic products of TCE oxidation in the environment (Newman and Wackett, 1991).

Barrio-Lage et al. (1987b) studied the influence of environmental factors other than TCE toxicity on TCE degradation in sediment samples. They observed a depletion of TCE with simultaneous production of cis-1,2-DCE (via reductive dechlorination) in all 3 types of sediment studied; muck, sand, and rock. In sediments containing significant amounts of organic carbon ( $>2 \%)$, a nonlinear form of Michaelis-Menten kinetics modeled the TCE degradation. However, in the crushed rock microcosms low in organic carbon content $(<1 \%)$ the linear form of the Michaelis-Menten equation gave the best fit (Barrio-Lage et al., 1987a). The successful use of different kinetic models implies that the rate of TCE degradation varies under different organic carbon conditions.

Acetate additions had little or no effect on the rate of TCE degradation, leading the authors to speculate that methanogens were not involved in the disappearance of TCE. In addition, denitrifying bacteria were not involved in the reductive dehalogenation of TCE in this study as was observed earlier by Bouwer and McCarty (1983b).

In addition to the above research on aerobic TCE degradation by methanotrophic microorganisms, recent research has also implicated the enzymes and pathways involved in degradation of aromatic compounds by microorganisms for the metabolism of TCE (Nelson et al., 1986; 1987; 1988; Wackett and Gibson, 1988). Nelson and co-workers' (1986) observation that TCE was degraded only in the presence of water from an industrial waste treatment facility (U. S. Naval Air Station (NAS), Pensacola, Florida) lead them 
to speculate that some component of the NAS water was required for TCE metabolism. This component was later identified as phenol (Nelson et al., 1987). Subsequently, Nelson and co-workers demonstrated that toluene, $Q$ cresol, and $\mathrm{m}$-cresol also stimulated TCE degradaiion and that a pure culture of toluene degraders (Pseudomonas putida) could also metabolize TCE (Nelson et al., 1988). Mutant strains of $P$. putida lacking toluene dioxygenase activity could not degrade TCE; however, revertants regained the TCE-degradative ability. These results provided evidence for the involvement of the aromatic degradative pathway and toluene dioxygenase in TCE metabolism. In addition, these results were independently verified by Wacket and Gibson (1988) during research with $P$. putida F1. Comparison of TCE degradation rates for strain F1 and the methanotroph Methylosinus trichosporium OB3b revealed a significantly greater initial rate for strain $F 1$. This observation is based on inspection of graphed data only; the degradation rate for OB3b was never reported. Although the rapid TCE degradation rate by strain F1 is initially exciting, the fact that toluene must be added to induce the toluene dioxygenase activity makes it unattractive for in situ remediation. In addition, the initial rapid TCE degradation rate observed for strain F1 decreased dramatically with time such that a more sustained TCE degradation rate was obtained for OB3b. This observation is encouraging for groundwater or soil remediation applications based on the comparative ease of adding methane rather than toluene to an aquifer or contaminated soil. However, recent work with the Pseudomonads has illustrated their potential in bioreactors (Folsom and Chapman, 1991). 
The involvement of the aromatic degradative pathway in TCE metabolism was also illustrated by the results of Winter et al. (1989) in which a recombinant Escherichia coli culture containing the toluene monooxygenase (TMO) gene from Pseudomonas mendocina was capable of TCE metabolism. Although cultures of $P$. mendocina could metabolize TCE, toluene was required for TMO enzyme induction. Once the TMO gene was transferred to $E$. colli, the gene could be induced by a simple temperature change. This eliminated the need for toluene as an inducer of TCE metabolism in the recombinant $E$. coli cells and probably gave new impetus for exploring the potential for organisms that possess the TMO gene in contaminated site remediation. It certainly would have been unattractive to add toluene to a contaminated aquifer or bioreactor to induce TCE degradation.

Similar results on TCE degradation were obtained by Zylstra and coworkers (1989) using E. coli cells containing the cloned toluene dioxygenase (TDO) genes from Pseudomonas putida. The recombinant E. coli cells required isopropyl-B-D-thiogalactopyranoside for TDO enzyme induction. The authors did not speculate whether this chemical could be used in contaminated environments to induce TDO enzyme activity during in situ remediation, or whether it could be used to induce TDO activity in bioreactors.

Vandenbergh and Kunka (1988) have reported TCE degradation in vials containing a pure Pseudomonas fluorescens culture. Interestingly, no mechanism for TCE removal was proposed although the authors noted that the $P$. fluorescens culture was isolated from soil with a history of 1,2dichloroethane and 1,2-dichloropropane contamination. Although only $2 \%$ of 
the TCE was metabolized after 24 hours, these results are encouraging in that the capability to degrade TCE may not be as rare or confined to specialized groups of bacteria as initially expected based on the earlier studies of TCE degradation. The ability to oxidize TCE may be acquired through prolonged exposure to TCE or related compounds. These results are further emphasized by the work of McClellen et al. (1989), who made similar observations with a mixed culture from a TCE-contaminated site. Although no substrate other than TCE was added to the cultures, the microorganisms in the mixed culture were able to degrade $47 \%$ and $33 \%$ of the TCE at initial concentrations of $0.56 \mathrm{mg} / \mathrm{L}$ and $6.7 \mathrm{mg} / \mathrm{L}$, respectively.

With the wealth of information documenting TCE oxidation (in some cases very rapid TCE oxidation) in laboratory experiments, one wonders why TCE would be such a large environmental problem. It appears that conditions in the field (whether it be aeration, temperature, toxicity, etc.) are in some way hindering microbial degradation of TCE. Researchers have realized this, and thus some common themes of laboratory studies during the last two years (1990 and 1991) have been identifying new organisms and pathways for TCE metabolism (Harker and Kim, 1990; Vanelli et al., 1990) and environmental factors such as substrate interactions (Folsom et al., 1990), substrate toxicity and aeration (Alvarez-Cohen and McCarty, 1991a and 1991b), and electron donors (Henry and Gricic-Galic, 1991a) influencing TCE oxidation.

The literature on microbial degradation of TCE reviewed above illustrates some common themes. Under anaerobic (methanogenic) conditions, TCE is converted to vinyl chloride via dichlorethylene (1,1-dichloroethylene, cis-1,2- 
dichloroethylene, or trans-1,2-dichloroethylene) by reductive dechlorination (dehalogenation). Vinyl chloride can be converted to $\mathrm{CO}_{2}$ or ethylene. In contrast, under aerobic conditions, TCE can be converted cometabolically by a variety of oxygenases including methane monooxygenase (MMO), ammonia monooxygenase (AMO), toluene monooxygenase (TMO), toluene dioxygenase (TDO), and propane monooxygenase (PMO) to an epoxide intermediate (TCE epoxide). TCE conversion via MMO is carried out by methanotrophic microorganisms that depend on methane for carbon and energy. Methanotrophic organisms are divided into two groups (Type I and Type II) based on the morphology of there intracellular membranes (Large, 1983). The role that the different types of methanotrophs play in TCE metabolism is currently being debated. There is evidence in the literature for both groups; Type I (Little et al., 1988) and Type II (Wilson and Wilson, 1985; Phelps et al., 1990). In addition, the form of MMO (soluble or particulate) involved in TCE metabolism by methanotrophs is also a topic of discussion. The current consensus is that soluble $\mathrm{MMO}$ is the form of the enzyme responsible for the oxidation of TCE (Oldenhuis et al., 1989), although results are influenced by micronutrient concentrations (especially copper) in the culture medium. The propane- and ammonia-oxidizing bacteria that cometabolically degrade TCE accomplish the oxidation via PMO and $A M O$, respectively. The microorganisms involved in TCE oxidation through the aromatic degradation pathways use both TMO and TDO. These enzymes are induced by a variety of substrates including phenol and toluene. 
A shared motif among the oxygenases is their mechanism of action. All have a substrate binding site and an oxygen binding site. Production of the TCE epoxide is accomplished through creation of a reactive oxygen species which epoxidates the double bond between the carbon atoms of TCE. The epoxide intermediate formed from TCE by the variety of oxygenases described above, is very reactive and unstable. Subsequently, it spontaneously breaks down to water-soluble products (formic acid, glyoxylic acid) that can be readily metabolized by heterotrophic microorganisms. Occasionally, when formic acid and glyoxylic acid accumulate, cytotoxic effects are observed.

Continued exploration of the variables affecting TCE degradation including substrate interactions and the myriad of environmental conditions in the micro-environment of bacteria will help identify situations where microbial degradation of TCE is and is not possible. The discovery and identification of novel new microorganisms capable of TCE oxidation could also provide more information on the mechanisms involved as well as potentially supply researchers with more effective microorganisms to employ in site restoration. In addition, continued research on TCE oxidation in bioreactors and eventually field plots will help advance the concept of using bacteria to remediate TCEcontaminated environments.

\section{Rhizosphere Microbiology}

Plant roots affect the soil in which they grow in a multitude of ways. making the soil more conducive for microbial growth and activity. All roots are protected from abrasion by root cap cells which are sloughed off during root 
growth; sometimes as many as 10,000 cells per plant per day in the case of maize (Campbell, 1985). As the root grows downward, cells in the root cap known as dictysomes produce a gel that helps lubricate the root cap (Foster et al., 1983), allowing the root to force its way through the soll. This mucigel (Leiser, 1968), rich in carbohydrates and amino acids, along with other root excretions are classified as root exudate (Rovira et al., 1979). Both of these components, root cap cells and root exudates, are useful sources of nutrients for microorganisms surrounding the root. In addition, microorganisms in the root zone can act as sinks for exudates with the absence of bacteria leading to less production of this material (Campbell, 1985). First described for legumes by Hiltner (1904), the rhizosphere has been the focus of agricultural research for several years, primarily because of its influence on crop productivity. Several excellent comprehensive reviews on the rhizosphere are available (Brock, 1966; Gray and Parkinson, 1968; Campbell, 1985; Curl and Truelove, 1986). The extensive nature of these reviews will limit this review to discussing isolated findings on rhizosphere microbiology within the context of the problem at hand; using the rhizosphere to facilitate bioremediation of contaminated sites.

Continual change at the root-soil interface, both physical and chemical, produces constant alterations in the soil structure and microbial environment. Differences in carbon dioxide and oxygen concentrations, osmotic and redox potentials, pH, and moisture content exist between rizosphere and bulk soil (Foster et al., 1983). Although the modification of the soil in the rhizosphere by plant root secretions is an important process that influences microbial populations, it is the actual structure of the plant root that provides 
microorganisms with a large surface area for colonization (Russell, 1977; Lynch, 1982). Using both simple and electron microscopy, various researchers (Linford, 1942; Campbell and Rovira, 1973; Rovira et al., 1974) have described the increased abundance of microorganisms in the rhizosphere. This thizosphere effect is often quantifled as the ratio of microorganisms in rhizosphere soll to the number of microorganisms in non-rhizosphere soll, the R/S ratio (Katznelson, 1946). R/S ratios from 5 to 20 are common, but occasionally are as high as 100 and above (Katznelson, 1965; Gray and Parkinson, 1968). In the simplest of scenarios, this increase in microbial numbers would translate to increased degradation rates of organic compounds in the rhizosphere.

In addition to the increase in numbers of microorganisms associated with the plant root, the actual composition of rhizosphere microorganisms is dependent on plant species, plant age, and soll type (Campbell, 1985) as well as other selection pressures (Sandmann and Loos, 1984; Abdel-Nasser et al., 1979; Abueva and Bagaev, 1975; Gavrilova et al., 1983). Typically, the rhizosphere is colonized by a predominantly gram negative microbial community (Atlas and Bartha, 1987). The ability of the plants to select for different mizosphere microbial communities is intriguing from the standpoint of exploring whether this selection translates to differences in the rates of micobial degradation of organic compounds in the rhizosphere. If such relationships exist, it may then be possible to use this knowledge in management of sites contaminated with different types of hazardous organic compounds. 
E. Degradation of Organic Compounds in the Rhizosphere

Because of its importance in crop produotivity, research on mlcrobial transformations in the rhizosphere has been concerned mainly with agrloultural chemicals, such as pesticides and tertilizers. The phenomenon of enhanced microbial degradation of these compounds in the mizosphere was probable due to the increased density and diversity of microorganisms, their intense activity, and the existence of cometabollo transformations. Table II - 3 lists studies on the degradation of compounds in the rhizosphere. The data presented here, along with the research on mizosphere microblology and microbial degradation of TCE provide the foundation for an exploration of the use of vegetation to remediate sites contaminated with hazardous organic compounds.

Several researchers (Hsu and Bartha, 1979; Seibert et al., 1981; Reddy and Sethunathan, 1983; Sandmann and Loos, 1984; Lappin et al., 1985) have described an increased capacity for mineralization of various pesticides in the rhizosphere. Occasionally, this increased minerallzation capacity is correlated with increased numbers of pesticide-degrading microorganisms. Sandmann and Loos (1984) found an increase in the number if 2,4-D (2,4dichlorophenoxyacetate)-degrading bacterla in the rhizospheres of previously untreated African clover and sugarcane. Earlier work by Abdel-Nasser and coworkers (1979) showed higher microbial counts in the rhizospheres of com, beans, and cotton treated with temik [2-methyl-2(methylthio)propionaldehyde O(methylcarbamoyl)oxime]. Recently, Sato (1989) found an 8-fold increase in heterotrophic bacteria in rice rhizosphere after benthlocarb (S-p-chlorobenzyl 


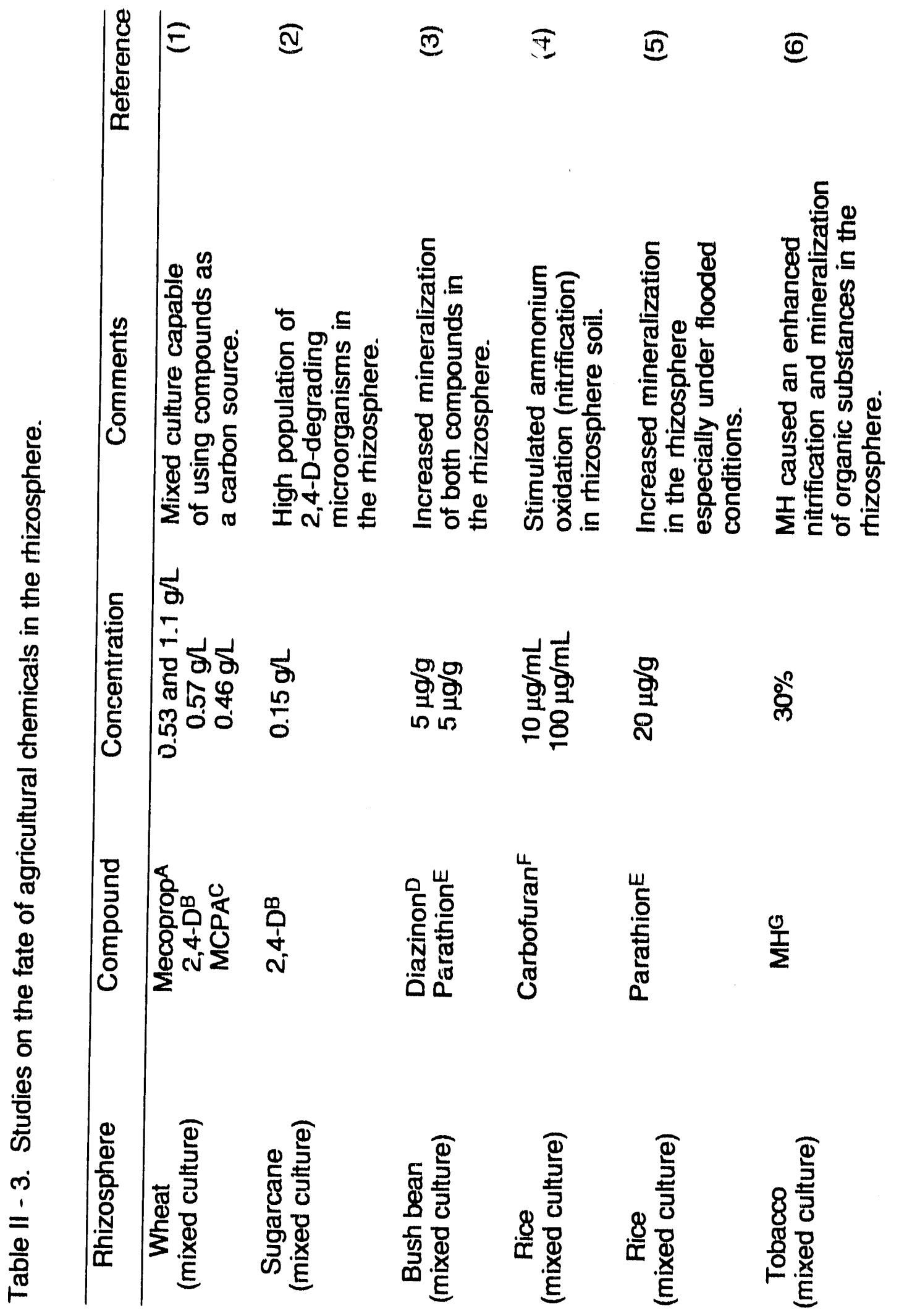




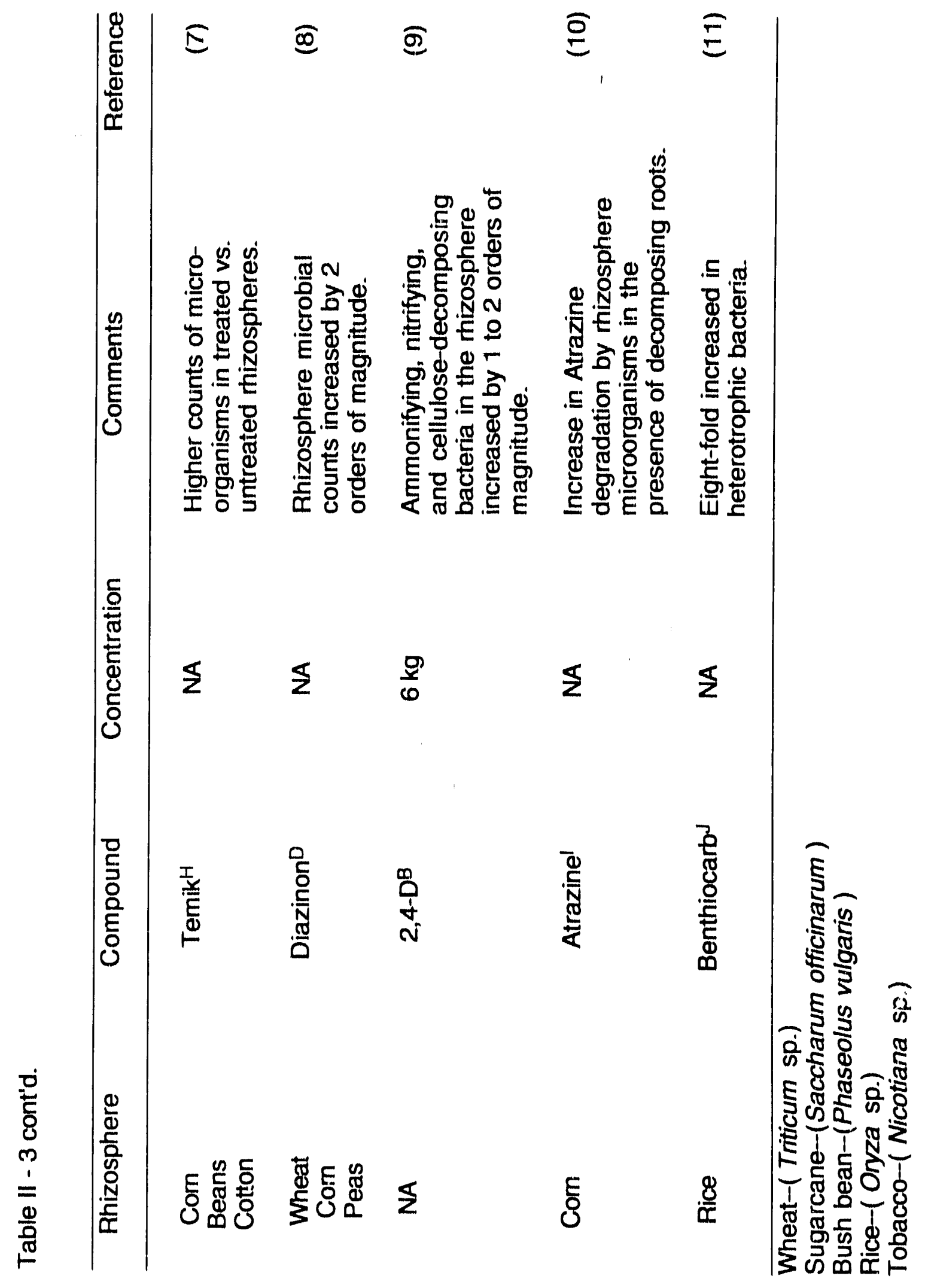




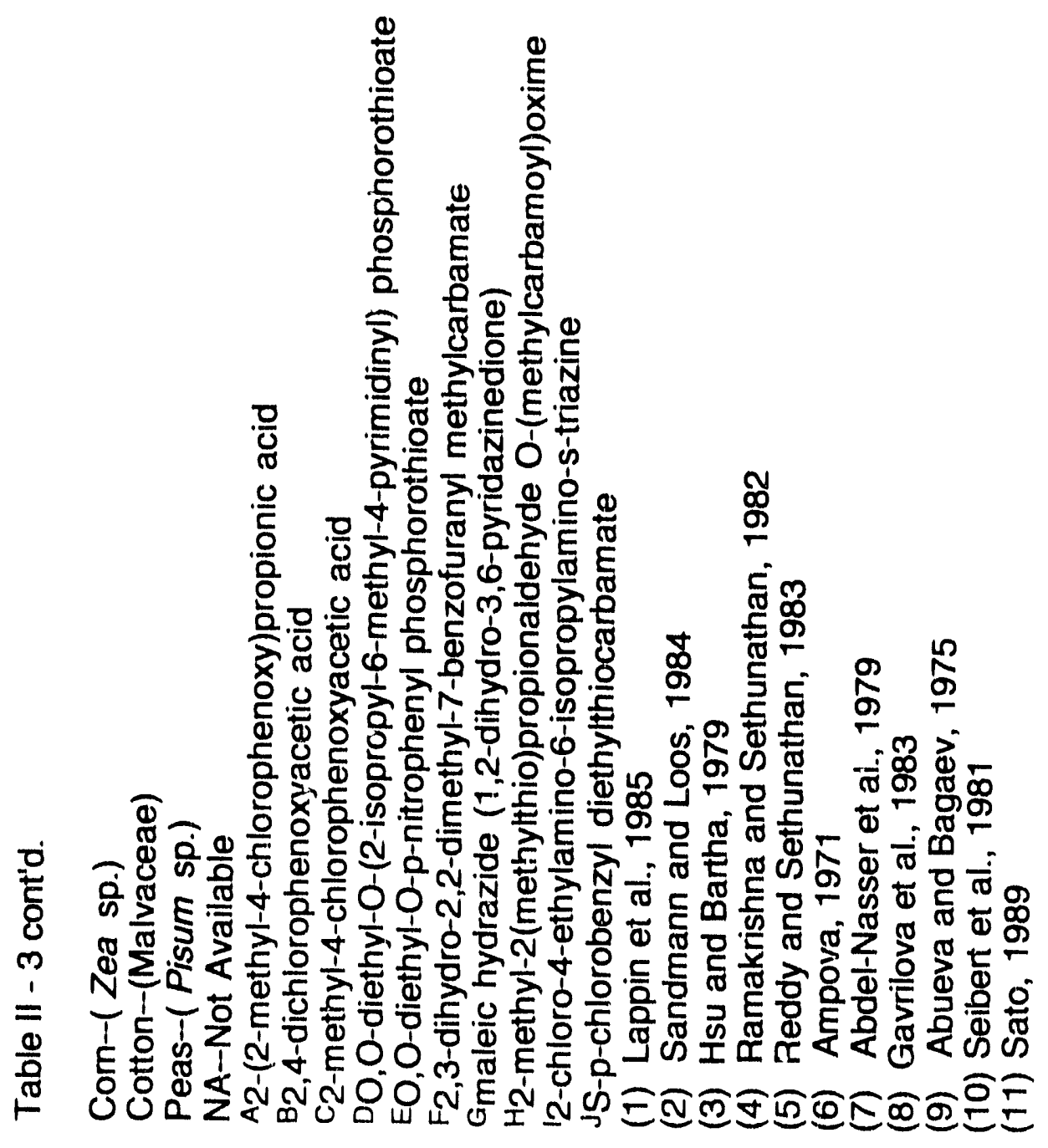


dlethylthlocarbamate) addition. The numbers of nitrifying bacterla also increased following benthlocarb exposure.

Seibert and co-workers (1981) observed an increase in atrazine (2chloro-4-ethylamino-6-isopropylamino-S-triazine) degradation by rhizosphere microorganisms in the presence of decomposing roots. They argued that this increase could be attributed to the higher dehydrogenase activity observed in the rhizosphere soil throughout the experimental period. Also, the concentration of unchanged atrazine was lower in the rhizosphere soil, and the concentration of hydroxyatrazine and two other hydroxylated metabolites were 3-fold higher than concentrations outside the rizosphere. Studies on labelled $\mathrm{CO}_{2}$ evolution from parathion (0,0-diethyl-O-p-nitrophenyl phosphorothioate) in rice rhizospheres indicated similar results (Reddy and Sethunathan, 1983). Only $5.5 \%$ of the ${ }^{14} \mathrm{C}$ in the parathion was evolved as ${ }^{14} \mathrm{CO}_{2}$ in unplanted solls while $9.2 \%$ was evolved from rhizospheres under non-flodded conditions. The rice variety in this experiment grew better in flooded soil, thus when flooded conditions prevailed, $22.6 \%$ of the radiocarbon was evolved as $14 \mathrm{CO}_{2}$. Reddy and Sethunathan argued that the close proximity of the aerobic-anaerobic interface in rice rhizosphere under flooded conditions favored the ring cleavage of parathion.

Parathion and diazinon [0,0-diethyl 0-(2-isopropyl-4-methyl-6pyrimidinyl) phosphorothioate] appear to be degraded in soil initially by cometabolic attack (Gunner et al., 1966; Daughton and Hsieh, 1977), a process that requires the preserice of a growth substrate other than the compound being degraded. As indicated earlier, root exudates provide microorganisms with a 
wide range of organic substrates for use as carbon and energy sources. These factors lead Hsu and Bartha (1979) to hypothesize that the rhizosphere would be especially favorable for cometabolic transformations of pesticides. Using radiolabelled diazinon and parathion, they were able to show accelerated mineralization of these compounds in bean rhizospheres. Beans were chosen because of their published inability to metabolize diazinon (Gunner et al., 1966). Approximately $18 \%$ of the parathion and $13 \%$ of the diazinon were mineralized in the bean rhizospheres compared with $7.8 \%$ and $5.0 \%$ in the rootfree soil for parathion and diazinon, respectively. Similar results with diazinon were previously found by Gunner and co-workers (1966), although they did not observe an increase in microbial biomass in the rhizosphere after diazinon application. Rather, the diazinon exerted a selective effect, which translated into the enrichinent of a particular isolate capable of diazinon metabolism.

Lappin et al. (1985) found that a microbial community isolated from wheat roots was capable of growth on the herbicide mecoprop [2-(2-methyl 4chlorophenoxy)propionic acid] as the sole carbon and energy source. The authors isolated five species, none of which was capable of growth on mecoprop individually. This microbial community was also shown to degrade 2,4-D (2,4-dichlorophenoxyacetic acid) and MCPA (2-methyl-4-chlorophenoxy acetic acid).

The increased mineralization capacity of the rhizosphere is not limited to pesticide degradatisi. Molla and co-workers (1984) showed that phosphate mineralization was maximized in the rhizospheres of wheat and ryegrass while Nakas and Klein (1980) reported an increase in glucose degradation 
associated with the rhizospheres of a shortgrass prairie ecosystem. In addition, Ramakrishna and Sethunathan (1982) found enhanced autotrophic ammonium oxidations in rice rhizospheres exposed to carbofuran (2,3-dihydro-2,2dimethyl-7-benzofuranyl methylcarbamate) and Ampova (1971) observed a stimulation of nitrification and mineralization of organic substances in tobacco rhizospheres exposed to maleic hydrazide (1,2-dihydro-3,6-pyridazinedione).

The increased degradative capability of the rhizosphere is not limited to terrestrial plants. Federle and Schwab (1989) and Federle and Ventullo (1990) have made similar observations of the increased microbial degradation of surfactants in the rhizospheres of aquatic plants. Mineralization of linear alkylbenzene sulfonate (LAS) and linear alcohol ethoxylate (LAE) was more rapid in the mizosphere of cattails (Typha latifolia) than in root free sediments (Federle and Schwab, 1989). Surprisingly, the source of the cattails (plants were obtained from a pristine pond and a pond receiving laundromat wastwater) had no significant influence on the rates of LAS and LAE degradation. Similar results on microbial degradation of LAS and LAE by the microbiota of submerged plant detritus were obtained by Federle and Ventullo (1990).

Although most of the studies described above have dealt with agricultural chemicals, they provided evidence for the accelerated inicrobial degradation of organic compounds in the rhizosphere and also gave an incentive for exploring the possibility of similar results with hazardous organic compounds. Two recent studies have detailed the accelerated disappearance of nonagricultural chemicals in the root zone; a series of polycyclic aromatic hydrocarbons in 
prairie grass rhizospheres (Aprill and Sims, 1990), and the increased degradation of oil residues by microorganisms isolated from oil-polluted rice rhizospheres (Rasolomanana and Balandreau, 1987).

Rasolomanana and Balandreau (1987) appear to be the first researchers to show enhanced microbial degradation of nonagricultural chemicals by rhizosphere microorganisms. These observations were serendipitously discovered while studying the improved growth of rice in soil to which oil residues had been applied. The authors hypothesized that the increased growth was brought about by the initial "removal" of the oil residues from the rhizosphere by capable microorganisms and isolated a Bacillus $\mathrm{sp.}$ with the ability to grow on the oil residues, but only in the presence of the rice root exudates.

The use of eight prairie grasses for stimulating microbial degradation of four PAHs, benz[a]anthracene, chrysene, benzo[a]pyrene, and dibenz[a,h]anthracene, in soil columns was evaluated by Aprill and Sims (1990). Based on residue analysis of the soil columns, PAH disappearance was consistently greater in the vegetated columns compared with unvegetated controls. Although sterile soil controls were not included in the experiments, the authors speculated that microbial degradation may account for the increased disappearance of the PAHs in the vegetated columns. However, the rhizosphere effect may have been obfuscated by addition of manure to all soil columns during PAH addition. Root uptake of the PAHs may have also obscured the disappearance data. Nonetheless, this research does provide evidence for the accelerated disappearance of hazardous organic compounds 
in the rhizosphere and also presents a nice discussion on plant and root biology in relation to stimulating soil microbial activity and enhancing microbial degradation of organic compounds in the root zone.

The literature reviewed above illustrates the increased degradative capacity of the rhizosphere for pesticides and more recently, nonagricultural chemicals. In addition, the literature also provides strong evidence for the potential role of vegetation in remediation of surface and near surface soils contaminated with hazardous organic compounds and certainly suggests that the role of vegetation in remediation of chemically contaminated sites be further explored.

\section{F. Manipulation of Root Exudation}

Several factors are known to control the extent of root exudation in the rhizosphere (Rovira and Davey, 1974). Research in this area has primarily been conducted in the laboratory using seedling plants grown in axenic culture. Small-scale field investigations have been tried using ${ }^{14} \mathrm{CO}_{2}$ which is fixed by the plant and released as radiolabelled root exudate, allowing easier detection and more sensitive measurements in the field. In addition, microbial population responses to factors affecting exudation have been used as indirect endpoints (Curl and Truelove, 1986).

One of the important implications of controlling root exudation is testing whether the exudation can control or influence the rate of organic compound degradation in the rhizosphere. The ability to change environmental variables such as light or moisture and thus change root exudation will allow this 
hypothesis to be tested. If root exudation is found to have a positive influence on microbial degradation in the rhizosphere, it may be possible to duplicate this phenomenon in the fleld through site management.

Root exudation is dramatically different among plant species. Rovira (1959) found greater amounts of amino acids in tomato rhizospheres as compared to clover. Vancura (1964) found differences in root exudates between wheat and barley, primarily with regard to certain sugars. Bowen (1969) demonstrated the effect of plant nutrient status on root exudation using pine seedlings. More than 4 times as much root exudate was present in the complete nutrient solution as compared to the $\mathrm{N}$-deficient nutrient solutions. Rovira (1956) found greater amounts of root exudates during the first 10 days of growth.

Environmental factors controlling root exudation include light intensity and temperature (Rovira, 1959), soil moisture (Katznelson et al., 1955), and support medium (Boulter et al., 1966; Barber and Gunn, 1974). Increases in light intensity and temperature have resulted in increases in root exudation for tomatoes and clover, respectively. Katznelson and co-workers found that temporary wilting increased the release of root exudates (especially amino acids) from roots of peas, soybeans, wheat, barley, and tomato. Tremendous increases in root exudation were also observed in plants grown in sand, soil, or glass beads as opposed to liquid media. 


\section{G. Lipid Analysis in Microbial Ecology}

One of the most important aspects of characterizing a site for bioremediation is the microbial ecology. The density (biomass), diversity, and activity of the microorganisms at the contaminated site are important indices for assessing the potential for bioremediation. The traditional techniques for measuring microbial biomass in pure cultures, such as by filtration and dry weight determination, are usually inadequate for determining viable biomass in environmental samples. Incomplete recoveries from environmental matrices as well as bias viable count procedures illustrate some of the inadequacies (Vestal and White, 1989). In addition, early attempts to study the microbial community structure of natural samples were very cumbersome and suffered from the inadequacies described previously.

Specific biochemical methods have been developed to assay for indicators of microorganisms in soil and sediment samples. These indicators include, ATP (Jenkinson and Oades, 1979), and cell wall components (Millar and Casida, 1970). Membrane phospholipids are present in all cells, have a rapid turnover, and are easily extracted from environmental samples and quantified, making them ideal for determining viable microbial biomass. Essentially identical estimates of microbial biomass were found by the membrane phospholipid and direct count methods (Balkwill et al., 1988). The phospholipid fatty acid assay has been used to describe microbial communities from such environmental samples as plant mizospheres (Tunlid et al., 1985) and creosote-contaminated soils and sediments (Smith et al., 1986). In addition, the detection of specific phospholipid fatty acids can indicate the 
presence and abundance of certain groups of microcrganisms. For example, Nichols and coworkers (1987) found relatively high proportions of 18-carbon fatty acids relative to 16 -carbon fatty acids in a natural gas-exposed soil column capable of TCE degradation. This indicated the presence of a large population of type II methanotrophic bacteria, rather than type I methanotrophs. Marker fatty acids have also been discovered for, among others, sulfate-reducing bacteria, aerobes, anaerobes, and actinomycetes (Vestal and White, 1989). Phospholipid fatty acid assays (PLFA) also have the advantage of revealing metabolic changes in a microbial community. During nutrient deprivation and other environmental stresses, fatty acid ratios can shift. For example, Guckert et al. (1986) found increases in the trans:cis ratio of monoenoic 16-carbon fatty acids in Vibrio cholerae during nutrient starvation. In addition, the protocol used to extract the lipids from environmental samples simultaneously extracts other biochemical indicators of nutritional status in microbial communities (for example, poly-ß-hydroxyalkonoates).

The "Gaia hypothesis" (Lovelock, 1979) describes the important role microorganisms play in maintaining the environment in its current state through their metabolic activities. However, assessing that role in nature presents a difficult task. Nonetheless, several techniques for measuring microbial metabolic activity in the laboratory have been developed. Respiration (Atlas and Bartha, 1987), ATP energy charge (Davis and White, 1980), and incorporation of radiolabeled substrates into cellular components (Moriarty and Pollard, 1981; White et al., 1977) have all been used successfully to monitor heterotrophic microbial activity in sediments and soils. In addition, these types 
of activity measurements permit the evaluation of the effects of environmental factors, such as contaminants, on microbial activity.

Incorporation of ${ }^{14} \mathrm{C}$-acetate into microblal lipids is a simple yet useful technique for measuring heterotrophic microblal activity. The rate of acetate incorporation into microbial phospholipids has been shown to be an accurate and sensitive measure of growth in sediment samples (Moriarty et al., 1985). The technique has been used to measure activity in sewage sludge (McKinley and Vestal, 1984), marine sediments (White et al., 1977), antarctic rock microbiota (Vestal, 1988), and soils (White et al., 1979). Acetate incorporation into lipids has also been used to assess the effects of toxicants, both inorganic and organic, on microbial metabolic activity (Barnhart and Vestal, 1983).

\section{H. Uptake of Organic Chemicals by Plant Roots}

The magnitude of plant uptake is an important variable which must be known (or estimated) for using vegetation in site remediation. Although the possibility for microbial degradation of hazardous organic compounds is high in the rhizosphere, there is also the possibility of plant uptake of the chemical(s) acting as a competing process. In addition, movement of chemicals from soil to vegetation is potentially a critical exposure pathway for humans and wild life.

Research on the environmental chemistry of pesticides (especially herbicides) has made substantial contributions to our understanding of plant uptake of organic compounds. From this extensive database, some general principles have resulted. Root uptake of organic compounds from soil solution is affected by three factors; (1) physicochemical properties of the compounds, 
(2) environmental conditions, and (3) plant characteristics (Ryan et al., 1989;

Paterson et al., 1990). Assuming constant plant and environmental characteristics, root uptake from soll solution is directly proportional to the compound's octanol-water partition coefficient $\left(K_{o w}\right)$ or inversely proportional to its water solubility. Namely, that more lipophillic compounds readily partition into roots (Briggs et al., 1982). However, highly lipophilic compounds tend to remain in the roots and are not translocated to the shoots. One of the important competing processes for root uptake of lipophilic compounds from soil is sorption (Topp et al., 1986). Compounds with low water solubilities would be expected to readily sorb to soil, making them unavallable for root uptake.

In the context of the present study to explore the potential use of vegetation for remediating TCE-contaminated soil, root uptake and translocation within the plant may be most dependent on environmental conditions. The degradation products of TCE vary with existing environmental conditions in the system. Under aerobic conditions, water-soluble products are formed (Little et al., 1988), whereas under anaerobic (methanogenic) conditions, reductive dechlorination (to dichloroethylene and vinyl chloride) can take place (Vogel and McCarty, 1985). Although the water-soluble products formed from aerobic TCE metabolism can be readily degraded by a variety of heterotrophic organisms, they could be readily translocated to the plant shoots if taken up by the plant. In addition, the lipophilic products formed from reductive dechlorination of TCE under anaerobic conditions (dichloroethylene and vinyl chloride), could be readily taken up by the plant roots. 
CHAPTER III.

\section{MATERIALS AND METHODS}

A. Site Description and Sample Collection

Site History

The Miscellaneous Chemlcals Basin (MCB) at the U.S. Department of Energy's Savannah River Site, Alken County, South Carolina (Figure III - 1), was used as a chemical disposal site beginning around 1956 (Plckett et al., 1986). Originally the MCB was a small, shallow pit (approximately $6 \times 6 \times 0.3$ m) where waste chemicals (primarily solvents) were poured directly onto the soil. Fill material was added when chemical disposal stopped (around 1974), and the site was graded to an area of approximately 100 by $100 \mathrm{~m}$. Since the site was closed it has become naturally revegetated with weeds, grasses, and small pine trees.

Analyses of soil cores at the site ( $0.5 \mathrm{~m}$ depth) showed residues of TCE, tetrachloroethylene (PCE), and trans"1,2-dichloroethylene (DCE) (Pickett et al., 1986; and T. C. Hazen, Savannah River Site, personal communication). In addition, extensive soll gas analysis of the MCB, completed in 1986, confirmed the soil core analyses. Sediment cores to $100 \mathrm{~m}$ and subsequent monitoring wells revealed that the contaminants had not reached the water table and were confined to the upper $10 \mathrm{~m}$ of the vadose zone. A risk assessment of the MCB revealed no immediate threat to human health or the environment (Pickett et al., 1986). Thus, several characteristics of the site made it a favorable location for exploring the potential for vegetation to be managed as an integral part of site remediation. 

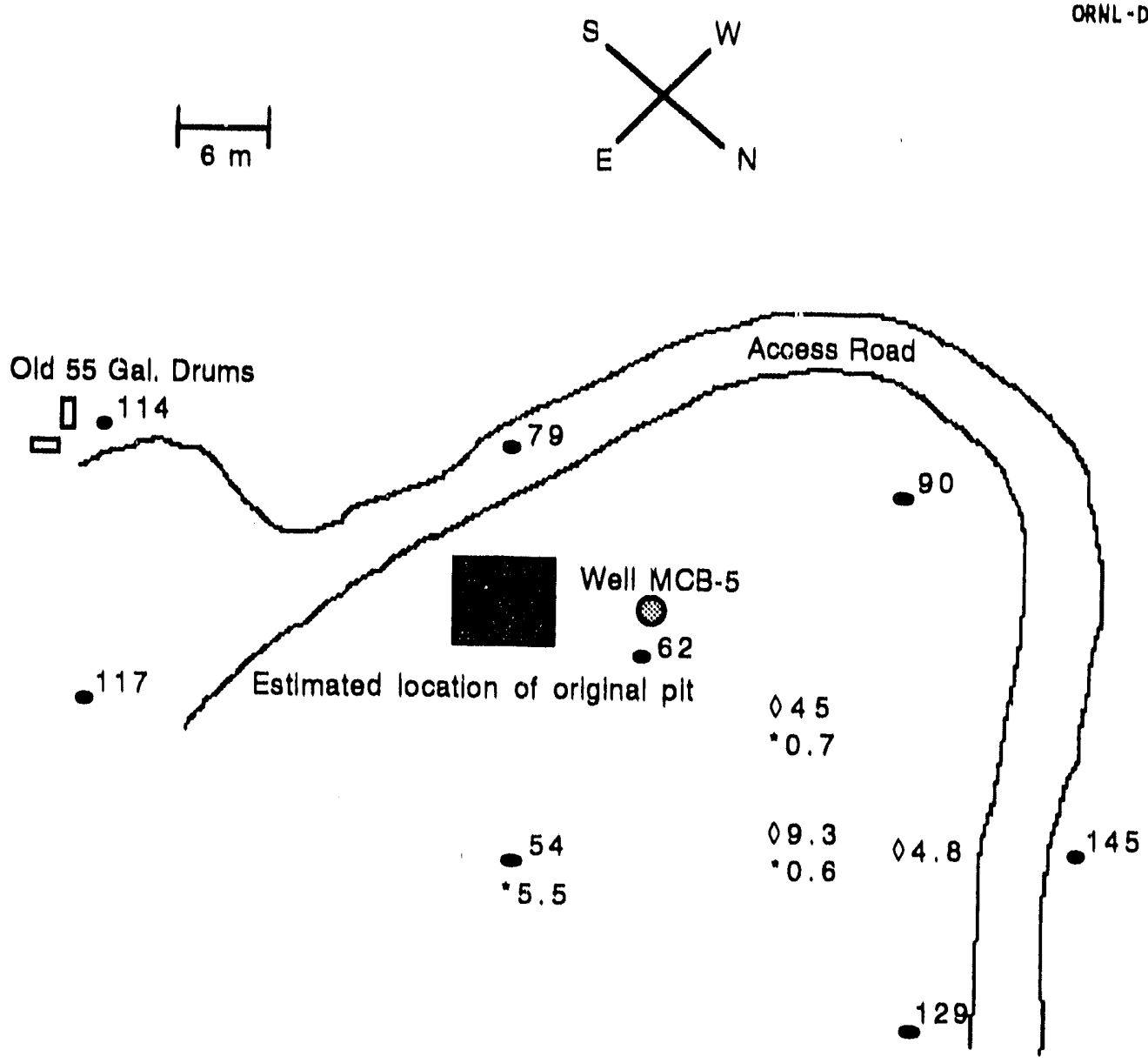

- Soll Gas Sampling Locations

- Tetrachloroethylene concentrations in soll gas, $\mu \mathrm{g} / \mathrm{g}(\mathrm{ppm})$

- Trichloroethylene concentrations in soll gas, $\mu \mathrm{g} / \mathrm{g}$ (ppm)

Figure III - 1. Diagram of the Miscellaneous Chemicals Basin showing selected soil gas sampling locations, the original solvent disposal pit, and soil gas concentrations of tetrachloroethylene and trichloroethylene in October, 1986. (Adapted from Microseeps Ltd., 1986) 
Speciflcally, the area is small and Inaccessible to the publlc, TCE and other hazardous chemicals are present in relatively low concentrations, and no Imminent human health hazard exists. Moreover, the MCB has become naturally revegetated during the $10^{+}$years since chemical dlsposal stopped; thus, sufficlent time has passed for populations or consortia of TCE-degrading microorganisms to be enriched in the rhizosphere.

Pedon Description and Soll Characterization of the MCB

Characterization of the soil and Identification of the plant specles at the MCB were conducted with the help of Mr. Vergil Rogers (U.S. Department of Agriculture) and Mr. John Knox (Savannah River Ecology Laboratory), respectively. Pedon descriptions were made down to $200 \mathrm{~cm}$ at nine sites within the MCB. This survey revealed that the area is mostly Typic Udorthents with firm substratum. In addition, the basin resulted from removal of much of the developed surface soil leaving a depression known as a borrow pit. The remaining material showed low water permeability and slow infiltration, conditions that produce a perched water table and anaerobic conditions within $1 \mathrm{~m}$ of the surface during the rainy season.

The $\mathrm{pH}$ and percent organic carbon $(\% \mathrm{OC})$ of soll samples were determined at Oak Ridge National Laboratory (ORNL). Carbon analyses were done in triplicate by using a Leco WR12 Carbon Determinator (St. Joseph, Mich.) equipped with an HF20 induction furnace (Nelson and Sommers, 1982). Inorganic carbon sources are insignificant in this soil type, therefore, total carbon represents organic carbon. Soll pH measurements were made in 
distilled water at a soll to water ratlo of $1 \mathrm{~g}: 2 \mathrm{~mL}$. Further characterization of a composite, nonvegetated soll sample from the MCB included determination of nitrogen $(N)$, phsophorus $(P)$, sulfur (S), and catlon-exchange capacity (CEC) by the Analytical Chemistry Division of ORNL. In addition, soil particle size distribution of the composite, nonvegetated soll collected from the MCB was done by the bouyoucos hydrometer method.

Vegetation Survey of the MCB

Plant species and relative abundance were described using a grid system at the site. The predominate herbaceous specles in this area were a grass, Paspalum notatum var. saurae Parodi; a legume, Lespedeza cuneata (Dumont); and a composite, Solidago sp. Loblolly pine (Pinus taeda L.) was also present. All of these species are plentiful in the area surrounding the MCB which is supportive of the idea that the MCB became naturally revegetated since its closure around 1974.

Sample Collection for Laboratory Experiments-Soil and Vegetation

Soll samples were taken from the root zones of the four predominant plant species at the MCB and from nonvegetated areas with TCE contamination and nonvegetated areas where TCE was not present. Herbaceous species were uprooted, and soil was tapped from the roots onto clean plastic sheets. Solls were collected from pine trees by scraping aside the top $1-2 \mathrm{~cm}$ and then using a trowel to remove soil adhering to and immediately surrounding the roots. Nonvegetated solls were sampled in a similar manner. Solls of each 
type were mixed to produce composite samples, then transferred to sterlle Whirl Pak ${ }^{\text {TM }}$ bags (NASCO, Fort Wilkinson, Wis.), sealed, and stored on ice for transport to ORNL. The solls, which were fine sleved $(2.0 \mathrm{~mm})$ prior to use, were stored in the dark at $4{ }^{\circ} \mathrm{C}$.

Vegetation samples were collected by coring around the base of the specific plant, removing the plant and attached soll and placing it in a plastic container. Water was added as needed during transport from the field site to ORNL. After arrival at ORNL, the vegetation samples were transferred to a greenhouse and maintained there until use in the experiments described below.

B. Microblal Biomass, Community Structure, and Metabolic Activity $\mathrm{CO}_{2}$ Biomass

Carbon dioxide efflux was measured from rhizosphere soils for four plant species and the two edaphosphere solls (TCE-contaminated and noncontaminated) to compare respiration among soil sample types and to estimaie microbial biomass. Triplicate soll samples $(50 \mathrm{~g})$ were moistened to $80 \%$ saturation with distilled, deionized water and incubated in the dark at 20 ${ }^{\circ} \mathrm{C}$ in 8- by 5 -cm glass jars. An infrared gas analyzer (LIRA Model 3000, Mine Safety Appliances Company, Pittsburgh, $\mathrm{Pa}$.) was used to monitor $\mathrm{CO}_{2}$ efflux (Edwards, 1982; Walton et al., 1989) at 24-h intervals for 7 days. Carbon dioxide respiration was used to calculate microbial blomass according to the method of Jenkinson and Powlson as modifled by Anderson and Domsch (Parkinson and Paul, 1982). 
Phospholipid Fatty Acid Analysis

\section{Materials}

Glass-distilled solvents (Burdick and Jackson, Muskegon, WI) were used in the extraction, fractionation, and derivitization procedures. Unisil silicic acid (100-200 mesh) was obtained from Clarkson Chemical Co., Williamsport, PA. Gas chromatography columns (fused silica capillary GLC Durabond DB-1) were purchased from J\&W Laboratories Inc., Rancho Cordova, CA.

\section{Lipid Extraction}

Sample extraction took place in Dr. David White's laboratory at the Institute for Applied Microbiology, The University of Tennessee, Knoxville. The extraction procedure, a modification of Bligh and Dyer (1959), was as follows: Weighed soil samples which had been frozen and lyophilized were extracted for $2 \mathrm{~h}$ in glass centrifuge tubes with 1.0:2.0:0.8, v/v/v chloroform:methanol:0.05 M phosphate buffer, $\mathrm{pH} 7.4$. Samples were centrifuged and decanted into 250$\mathrm{mL}$ separatory funnels. Equal amounts of chloroform and water were added to separate the extracts into organic and aqueous phases. The organic (chloroform) phase was filtered through a fluted filter into a round bottom flask and the chloroform was removed using a rotary evaporator.

\section{Lipid Fractionation}

Dried lipid extracts were re-dissolved in chloroform and loaded onto silicic acid columns for fractionation (Findlay and White, 1987). The columns 
were Pasteur pipettes packed with $0.5 \mathrm{~g}$ of activated (heated at $120^{\circ} \mathrm{C}$ for $2 \mathrm{~h}$ ) silicic acid. Neutral lipids, glycolipids, and phospholipids were eluted into test tubes with chloroform, acetone, and methanol, respectively. All lipid samples were dried under nitrogen. Neutral lipid samples were archived, glycolipid samples were stored for use in determining poly-B-hydroxyalkanoate (PHA), while phospholipid samples were derivatized as described below.

\section{Eatty Acid Derivitization}

The phospholipid samples were derivatized to phospholipid fatty acid methyl esters by mild alkaline methanolysis. Dried phospholipid samples were dissolved in $1 \mathrm{~mL}$ of toluene:methanol $(1: 1, \mathrm{v} / \mathrm{v})$. One $\mathrm{mL}$ of $0.2 \mathrm{M} \mathrm{KOH}$ in methanol was added, the samples were vortexed briefly, and heated for 30 minutes at $37^{\circ} \mathrm{C}$. Two $\mathrm{mL}$ of hexane:chloroform $(4: 1, \mathrm{v} / \mathrm{v})$ were added and the samples were neutralized with $0.2 \mathrm{~mL}$ of $1 \mathrm{~N}$ acetic acid and $2 \mathrm{~mL}$ distilled water. Samples were vortexed for 5 minutes, centrifuged for 10 minutes and the hexane:chloroform phase (top) was transferred into a clean screw-cap test tube. One $\mathrm{mL}$ of hexane:chloroform $(4: 1, \mathrm{v} / \mathrm{v})$ was added to the aqueous phase (bottom) and the vortex and centrifugation steps were repeated. The hexane:chloroform phase for each sample was pooled and dried under nitrogen.

\section{Quantification}

Analysis of phospholipid fatty acid methyl esters (FAME) was done using gas chromatography as described previously (Bobbie and White, 1980). The 
procedures and conditions are briefly described henceforth. A Hewlett-Packard 5880 gas chromatograph equipped with a splitless injector and a flame ionization detector was used to quantify FAME based on peak areas and comparisons to a FAME library. Dried FAME samples were re-dissolved in isooctane containing a 19-carbon fatty acid as an intemal standard.

Chromatographic conditions were as follows: injection volume, $1 \mu \mathrm{L}$; injector temperature, $270^{\circ} \mathrm{C}$; detector temperature, $290^{\circ} \mathrm{C}$; carrier gas, $\mathrm{H}_{2}$ at 1 $\mathrm{mL} /$ mirute, make up gas, $\mathrm{N}_{2}$ at $30 \mathrm{~mL} /$ minute; oven temperature, $80^{\circ} \mathrm{C}$ for 1 minute then ramped to $150^{\circ} \mathrm{C}$ at $10^{\circ} \mathrm{C} /$ minute, then to $240^{\circ} \mathrm{C}$ at $3{ }^{\circ} \mathrm{C} /$ minute, then to $280^{\circ} \mathrm{C}$ at $5{ }^{\circ} \mathrm{C} /$ minute and held for 5 minutes; column, fused silica capillary GLC Durabond DB-1.

\section{Data Analysis}

Total picomoles of phospholipid were converted to active microbial biomass using a conversion factor of $100 \mu$ moles phospholipid/g of bacteria the size of E. coli (Smith et al., 1989). Phospholipid fatty acid (PLFA) profiles of the different sample types were also constructed. A cluster analysis of the phospholipid fatty acid profiles of different rhizosphere and nonvegetated soil samples was performed to help in analyzing the different sample types. Interpretation of PLFA profiles was done with the help of Dr. Jim Guckert and Mr. David Ringleberg of the Institute for Applied Microbiology, The University of Tennessee. 


\section{Determination of poly-ß-Hydroxyalkanoates}

The glycolipid fraction from the total lipid extraction described above was used to determine the endogenous lipid storage products poly- $\beta$ hydroxyalkanoates (PHAs) using the techniques of Findlay and White (1987). Briefly, the glycolipid fraction (acetone) was dried to the side of a test tube under a stream of nitrogen. Lipids other than PHA were removed by washing with ethyl alcohol and diethyl ether. The constituent B-hydroxy acids from the PHA samples were ethanolyzed and converted to ethyl esters and analyzed by gas chromatography with flame ionization detection (Findlay and White, 1983). Verification of the constituent $\beta$-hydroxy acids was done by mass spectroscopy.

${ }^{14} \mathrm{C}$-Acetate Incorporation into Microbial Lipids

\section{Materials}

1.14C-Acetate (19.6 mCi/mmol) was purchased from Sigma Chemical Co., St. Louis, MO. Unisil silicic acid (100-200 mesh, Clarkson Chemical Co., Williamsport, PA) was a gift from Dr. Tom Phelps, Institute for Applied Microbiology, University of Tennessee. Chloroform (EM Science, Cherry Hill, NJ), methanol (Fisher Scientific, Fair Lawn, NJ), and acetone (Malinckrodt Inc., Paris, KY) were used as extraction solvents.

\section{${ }^{14} \mathrm{C}$-Acetate Incorporation}

Soil samples $(2 \mathrm{~g})$ from rhizosphere and nonvegetated areas at the MCB were placed in 15-mL polypropylene tubes together with $0.5 \mathrm{~mL}$ of sterile, distilled, deionized water. A syringe was used to add $5 \mu \mathrm{Ci}$ of $1{ }^{14} \mathrm{C}$-acetate in 
such a way as to minimize the disturbance artifact (Findlay et al., 1985). Samples were incubated in the dark at $20^{\circ} \mathrm{C}$. Samples were terminated at predetermined intervals and extracted using the procedure described below. Sterile controls for each sample type were prepared by autoclaving the samples, distilled water, and sample tubes in toto. Laminar-flow hoods were used during addition of the $1-14 \mathrm{C}$-acetate in the sterilized samples.

\section{Extraction}

Samples were extracted using a mixture of chloroform, methanol, and water as originally described by Bligh and Dyer (1959) with slight modifications. Briefly, soil samples were initially extracted for $2 \mathrm{~h}$ by pipetting $3 \mathrm{~mL}$ of methanol:chloroform:phosphate buffer $(2: 1: 0.1, \mathrm{v} / \mathrm{v} / \mathrm{v})$ into the sample tubes, vortexing them briefly, and holding them in the dark. After the $2 \mathrm{~h}$ extraction, samples were centrifuged at $1500 \mathrm{rpm}$ for 5 minutes and decanted into glass sample tubes. The extracts were then separated into organic and aque.; phases by the addition of $2 \mathrm{~mL}$ of chloroform:distilled water $(1: 1, v / v)$. The lipidcontaining chloroform (organic) phase was recovered for further use.

\section{Lipid Fractionation}

The chloroform phase was fractionated into neutral, glyco-, and phospholipid fractions using column chromotography (Findlay and White, 1987). The columns were Pasteur pipettes packed with $0.5 \mathrm{~g}$ of activated (heated at $120^{\circ} \mathrm{C}$ for $2 \mathrm{~h}$ ) silicic acid. The chloroform phase containing the total lipids was loaded 
onto the columns and neutral lipids, glycolipids, and phospholipids were eluted with chloroform, acetone, and methanol, respectively.

\section{Quantification}

Liquid scintillation spectrometry was used to quantify the radioactivity in the total lipid chloroform phase as well as the radioacticity in the 3 lipid fractions after separation on the silicic acid columns. Aliquots $(200 \mu \mathrm{L})$ were suspended in $10 \mathrm{~mL}$ of Aquasol and counted using a Packard 2000CA liquid scintillation spectrophotometer.

\section{Data Analyses}

Data from the experiments on acetate incorporation into total lipids were expressed as picomoles of ${ }^{14} \mathrm{C}$-acetate incorporated per gram of soil per hour by plotting cumulative radioactivity (disintegrations per minute) over time and determining a rate of incorporation from the plots. Graphs of the percentage of the total radioactivity contained in the 3 lipid fractions at each time point were constructed using Cricket Graph software on an Apple Macintosh Plus personal computer.

C. Toxicity of TCE and PCE to Soil Microorganisms

Successful microbial degradation studies require that the test chemicals be present at concentrations that are not toxic to the microorganisms. Carbon dioxide evolution was monitored as a simple, quick indication of chemical toxicity to soil microorganisms (Zelles et al., 1986; Walton et al., 1989). The 
respiration rates of treated and control solls were compared to select a concentration of chemicals that did not alter respiration. An infrared gas analyzer (LIRA Model 3000, Mine Safety Appliances Company, Pittsburgh, PA) was used to measure $\mathrm{CO}_{2}$ efflux over a $7-\mathrm{d}$ period from incubated $\left(20^{\circ} \mathrm{C}\right) 50 \mathrm{~g}$ soil samples according to the methods of Edwards (1982) as adapted by Walton et al. (1989). TCE or PCE was introduced into the soils gravimetrically (micrograms of chemical per gram of soil dry weight). However, soils were not mixed so that losses due to volatilization would be minimized. Every $24 \mathrm{~h}$ a flow of moist, $\mathrm{CO}_{2}$-free air was passed through the 8 - by $5-\mathrm{cm}$ incubation jars to measure $\mathrm{CO}_{2}$ efflux and also to maintain aerobic conditions. Toxicity determinations were based on whether microbial respiration in the treatment soils had returned to control levels by the end of the 7-d experiment. High concentrations $(500 \mu \mathrm{g} / \mathrm{g}$ and $1000 \mu \mathrm{g} / \mathrm{g})$ of TCE and PCE were chosen so that an effect could be observed.

\section{TCE Degradation in Soil Slurries}

Initial experiments to monitor the disappearance of TCE from the headspace of soil slurries were undertaken to provide an indication of whether biological degradation of TCE occurred in soil samples. Duplicate soil samples $(3 \mathrm{~g})$ from each of the four plant species, as well as from nonvegetated areas of the MCB, were placed in 40-mL glass bottles equipped with screw caps and polytetrafluoroethylene-lined septa. Distilled, deionized water $(20 \mathrm{~mL})$, spiked with TCE at either $35 \mu \mathrm{g} / \mathrm{mL}$ or $70 \mu \mathrm{g} / \mathrm{mL}$ was added. Sterile controls for each soil sample type and sterile water controls (no soil) were prepared by 
autoclaving samples for $1 \mathrm{~h}$ on each of three consecutive days prior to use. Samples were incubated in the dark at $20^{\circ} \mathrm{C}$ on a shaker table $(125 \mathrm{rpm})$. Headspace concentrations of TCE were determined with a Sigma 2000 capillary gas chromatograph (Perkin-Elmer Corp., Norwalk, Conn.) equipped with an electron capture detector. Chromatographic conditions were as follows: Column, SP-1000 (0.32 cm I.D. by $61 \mathrm{~cm})$; carrier gas, $\mathrm{N}_{2}(30 \mathrm{~mL} / \mathrm{min})$; injector temperature, $100^{\circ} \mathrm{C}$; column temperature, $100^{\circ} \mathrm{C}$; detector temperature, 350 ${ }^{\circ} \mathrm{C}$. Concentrations of TCE were quantified by integration of peak areas. The coefficierit of variation [(standard deviation $\times 100) /$ mean] for measurements of TCE in the headspace of the distilled, delonized water was $7.0 \%$.

\section{E. ${ }^{14} \mathrm{C}$-TCE Mineralization in Soil Samples}

The role of microorganisms in the biodegradation of TCE was further explored by comparing mineralization of ${ }^{14} \mathrm{C}$-TCE in soil from the root zone of one plant species ( $L$. cuneata) with that of the nonvegetated TCE-contaminated soil. Triplicate soil samples $(50 \mathrm{~g})$ for both treatment groups plus sterile controls (autoclaved for $1 \mathrm{~h}$ on three consecutive days) were moistened with sterile, distilled, deionized water to $80 \%$ saturation. The ${ }^{14} \mathrm{C}-$ TCE (specific activity $1.12 \times 10^{6} \mathrm{~Bq} / \mathrm{mmol}$, chemical purity $>99 \%$, Sigma, St. Louis, Mo.) was added to the soil at $70 \mu \mathrm{g} / \mathrm{g}$ soil (dry weight) in glass sample jars ( 8 by $5-\mathrm{cm}$ ) and closed with polytetrafluoroethylene-lined neoprene stoppers.

At 24-h intervals, filtered air was used to flush the sample jars and then passed sequentially through $7 \mathrm{~mL}$ ethylene glycol monomethyl ether (EGME) (Fisher, Fairlawn, N.J.) and $10 \mathrm{~mL}{ }^{14} \mathrm{CO}_{2}$ UNT SORB cocktail (Research 
Products Intemational, Elk Grove, III.) to trap ${ }^{14} \mathrm{C}$-volatiles and ${ }^{14} \mathrm{CO}_{2}$, respectively (Scheunert et al., 1987). Aliquots $(200 \mu \mathrm{L}$ ) of the EGME were counted in Aqueous Counting Scintillant (Amersham, Arlington Heights, III.) on a liquid scintillation spectrometer (Packard Tri-Carb $2000 \mathrm{CA}$ ). The ${ }^{14} \mathrm{CO}_{2}$ cocktall was counted directly. All samples were monitored for quenching using a quench curve.

\section{F. PCE Degradation in Soil Slurries}

Experiments monitoring the disappearance of PCE from the headspace of soil slurries with concomitant production of TCE were undertaken to determine whether biological reductive dechlorination of PCE occurred in soil samples from the MCB. Duplicate samples $(3 \mathrm{~g})$ of rhizosphere soils as well as nonvegetated/contaminated soil from the $M C B$, were placed in $40-\mathrm{mL}$ glass bottles equipped with screw caps and polytetrafluoroethylene-lined septa. Distilled, deionized water $(20 \mathrm{~mL})$, spiked with PCE at $50 \mu \mathrm{g} / \mathrm{mL}$ was added. Sterile controls for each soil sample type and sterile water controls (no soil) were prepared by autoclaving samples for 1 hour on three consecutive days prior to use. Resazurin (7-Hydroxy-3H-phenoxazin-3-one 10-oxide) was used as an indicator for reduced (anaerobic) conditions. Samples were incubated in the dark at $20^{\circ} \mathrm{C}$.

Initially, PCE and TCE concentrations were determined by headspace analysis with a Sigma 2000 capillary gas chromatograph (Perkin-Elmer Corp., Norwalk, Conn.) equipped with an electron capture detector. Chromatographic conditions were as follows: Column, Carbopak B/1\% SP-1000 (0.32 cm I.D. by 
$61 \mathrm{~cm})$; carrier gas, $\mathrm{N}_{2}(30 \mathrm{~mL} / \mathrm{min})$; injector temperature, $100^{\circ} \mathrm{C}$; column temperature, $100^{\circ} \mathrm{C}$; detector temperature, $350^{\circ} \mathrm{C}$. Concentrations of PCE and TCE were quantified by integration of peak areas and checked with external standards containing PCE and TCE. Problems with the Sigma 2000 initiated new analytical methods development in which a Perkin-Elmer $3920 \mathrm{~B}$ gas chromatograph with a flame ionization detector was brought on line. New chromatographic conditions were as follows: Column, Carbopak B/1\% SP. $1000(0.32 \mathrm{~cm}$ I.D. by $60 \mathrm{~cm})$; carrier gas, $\mathrm{N}_{2}(26 \mathrm{~mL} / \mathrm{min})$; injector temperature, $170^{\circ} \mathrm{C}$; column temperature, $160^{\circ} \mathrm{C}$; detector temperature, $190^{\circ} \mathrm{C}$. External standards of PCE and TCE were used to test the procedure and calibrate the instrument. Because of the decrease in sensitivity in moving from the Sigma 2000 to the 3920 B, headspace analysis could not be employed. Rather, 24 hour methylene chloride extractions were undertaken to remove residual PCE. and any TCE (or other metabolites) produced during the experiments and a portion of these extracts was anlayzed.

\section{G. Fate of ${ }^{14} \mathrm{C}$-TCE in Soil-Plant Systems}

Sample Flasks

Specially-designed Erlenmeyer flasks (Figure III - 2) were used for monitoring the fate of ${ }^{14} \mathrm{C}$-TCE in soil-plant systems. To minimize exposure of TCE to reactive substances, the flasks were equipped with ground-glass joints and stainless steel sampling ports. In addition, all flasks were wrapped with white electrical tape to eliminate the possibility of photooxidation of ${ }^{14} \mathrm{C}$-TCE. With the exception of G. max, and P. notatum, plant seedlings were placed in 


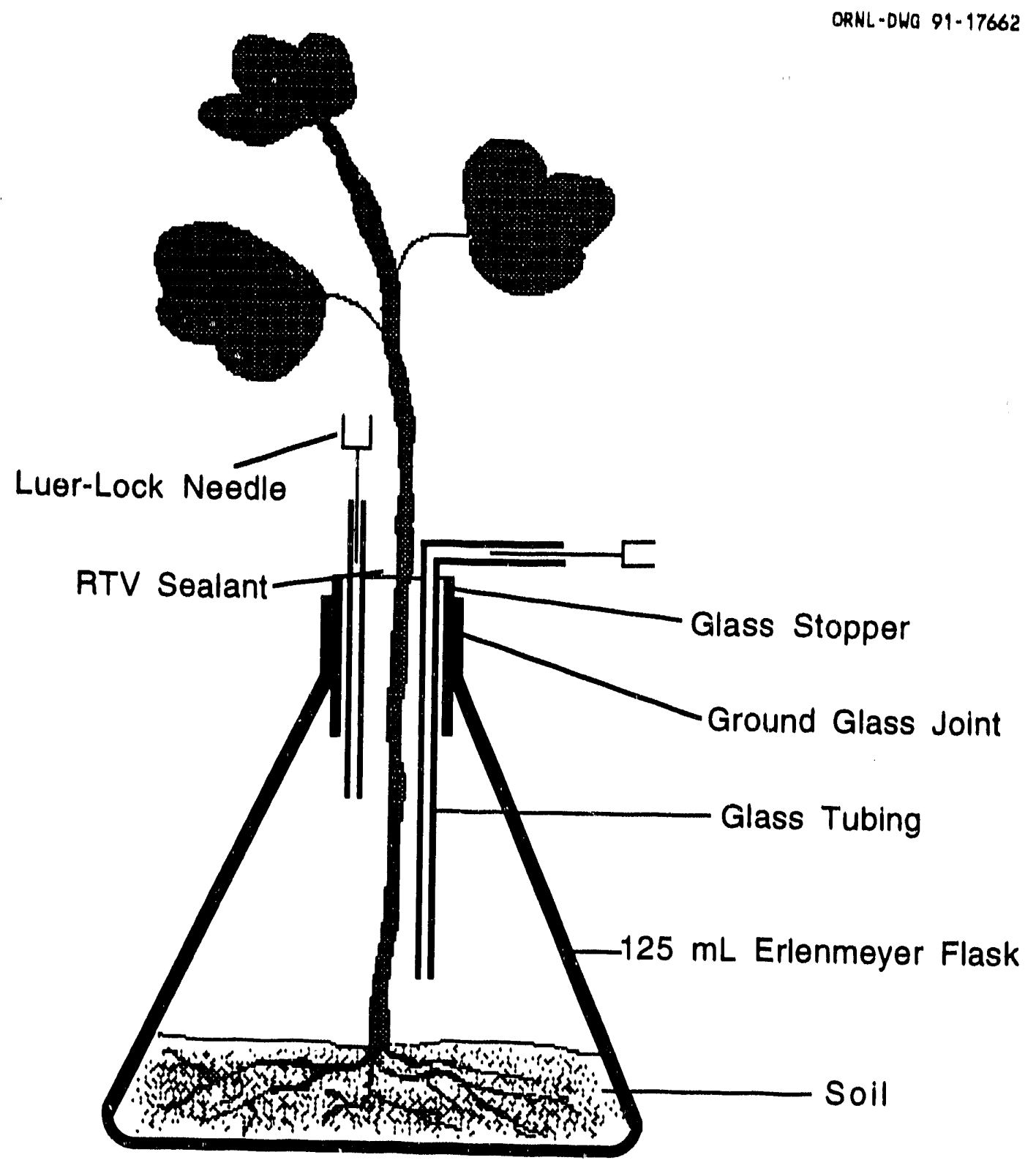

Figure III - 2. Experimental flasks used to measure the fate of ${ }^{14} \mathrm{C}$-TCE in soilplant systems. 
the flasks and the roots were covered with nonvegetated soll from the fleld site. These seedlings were acclimated in the greenhouse for two days, followed by two more days in the environmental chamber (described below). Seeds of G. max were germinated directly in the flasks and grown in the greenhouse for 12 days, and acclimated in the environmental chambers for two days before Initiation of the experiments. Because of its morphology, experiments with $P$. notatum were conducted in $125-$ by $65-\mathrm{cm}$ glass crystallization dishes in which the soil surface was open to the atmosphere. In addition to the vegetated soil samples, nonvegetated and sterlle (autoclaved for 1 hour on three consecutive days) soll samples were also part of each experiment. The ${ }^{14} \mathrm{C}-\mathrm{TCE}$ (Sigma Chemical Co., St. Louls, MO, specific activity, $1.12 \times 10^{6} \mathrm{~Bq} / \mathrm{mmol}$; chemical purity, > 99\%) was added directly to the soil and the flasks were sealed by coating a nonreactive silicone rubber sealant (Stotzky et al., 1961; Hsu and Bartha, 1979) between the plant and the flask. Sterile, distilled $\mathrm{H}_{2} \mathrm{O}$ was added to help distribute the ${ }^{14} \mathrm{C}$-TCE within the soll and adjust the soll to field capacity moisture content (water potential, $-33 \mathrm{kPa}$ ).

\section{Exposure and Environmental Chambers}

The Erlenmeyir flasks were placed in two air-tight, glass exposure chambers (Figure III - 3). Air within the exposure chambers was continuously evacuated and passid through charcoal (6-14 mesh, Fisher Scientific, Fair Lawn, NJ) filters to remove any ${ }^{14} \mathrm{C}$-compounds that had been taken up by the plant roots, translocated through the plant and released into the exposure chamber atmosphere with the evapotranspiration stream. The experimental 


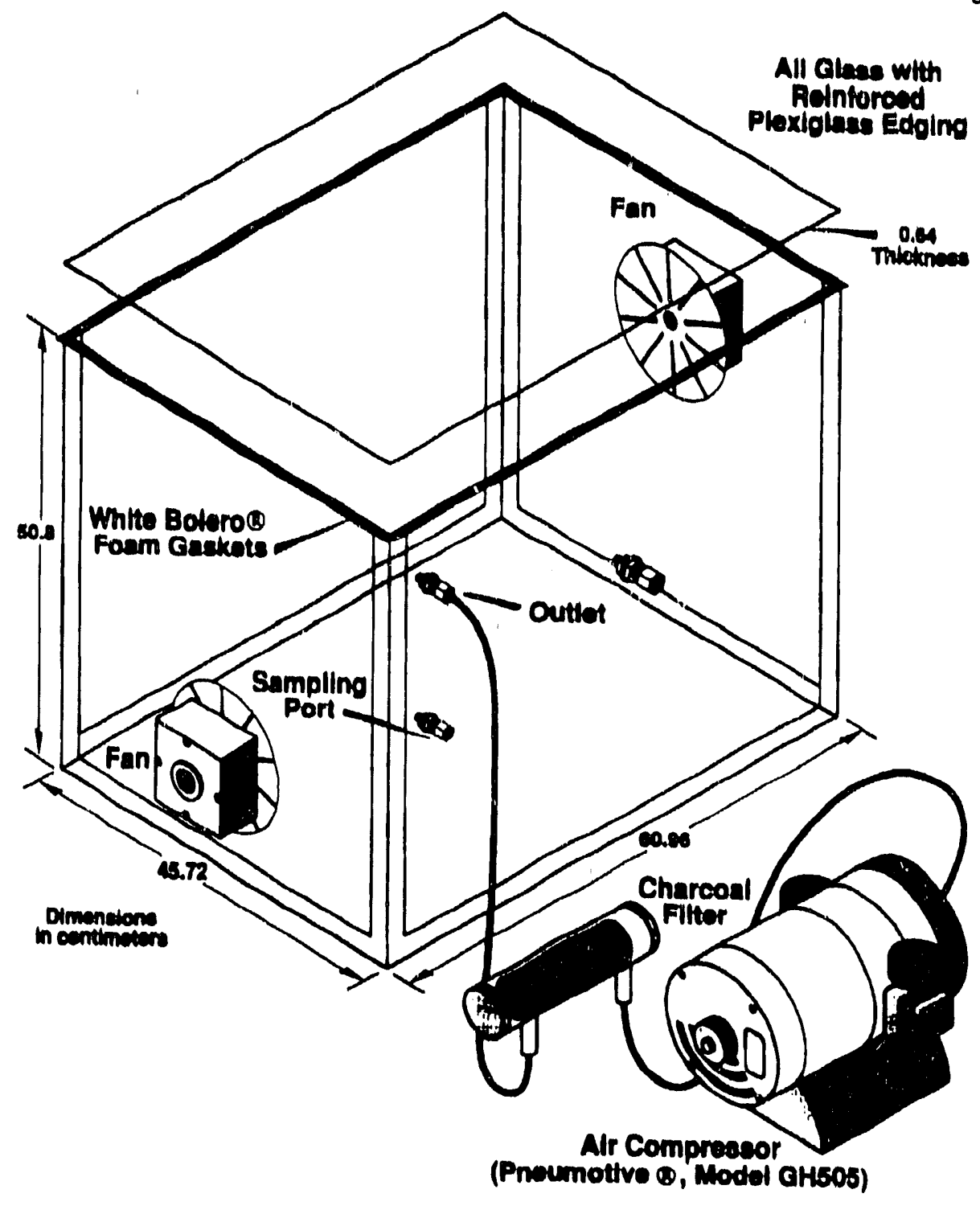

Figure III - 3. Glass exposure chambers used to regulate environmental conditions and quantify ${ }^{14} \mathrm{C}$ released by the plants in whole plant experiments. 
design was modifled slightly for the experiments with $P$. notatum. In these experiments, the air within the exposure chambers was continuously evacuated and passed through 2 gas-washing bottles containing $0.5 \mathrm{M} \mathrm{KOH}$ for trapping ${ }^{14} \mathrm{CO}_{2}$ and a charcoal filter for removing volatile ${ }^{14} \mathrm{C}$. The exposure chambers were contained within a controlled-environment chamber with a 14-h photoperlod. Diurnal temperatures were $30 / 22{ }^{\circ} \mathrm{C}$ and the $\mathrm{CO}_{2}$ concentration was amblent (approximately $370 \mu \mathrm{L} / \mathrm{L}$ ). Daytime relative humidity and approximate photosynthetic photon flux density in the exposure chambers was $74 \%$ and $365 \mu$ Moles $/ \mathrm{m}^{2} \mathrm{~s}$, respectively.

\section{Dally Sampling Procedure}

At 24-h intervals, the flasks were flushed with air to help maintain aerobic conditions and determine ${ }^{14} \mathrm{CO}_{2}$ produced from degradation of ${ }^{14} \mathrm{C}$-TCE. Originally, a 25-mL syringe was used to flush the air inside the flasks through a series of trapping solutions at approximately $10 \mathrm{~mL} / \mathrm{m}$. Subsequently, a peristaltic mini-tubing pump was used to provide more accurate air flow control. The exit air from the flasks passed through a trapping system (Hsu and Bartha, 1979) (Figure III - 4) containing an Aquasol (New England Nuclear Corp.) trap to remove ${ }^{14} \mathrm{C}$-compounds other than ${ }^{14} \mathrm{CO}_{2}$, which was trapped in a vial containing Carbosorb ( $330 \mathrm{~mL} / \mathrm{L}$ phenethylamine, $50 \mathrm{~mL} / \mathrm{L}$ distilled water, 400 $\mathrm{mL} / \mathrm{L}$ toluene, $220 \mathrm{~mL} / \mathrm{L}$ methanol, $5.0 \mathrm{~g} / \mathrm{L}$ 2,5-Diphenyloxazole, $0.3 \mathrm{~g} / \mathrm{L}$ 1,4-bis2-[5-phenyloxazolyl]-benzene). Radioactivity in the trapping solutions was determined using a liquid scintillation spectrophotometer (Packard Model $2000 \mathrm{CA}$ ). The efficiency of the Aquasol trap was determined by using ${ }^{14} \mathrm{C}$-TCE. 


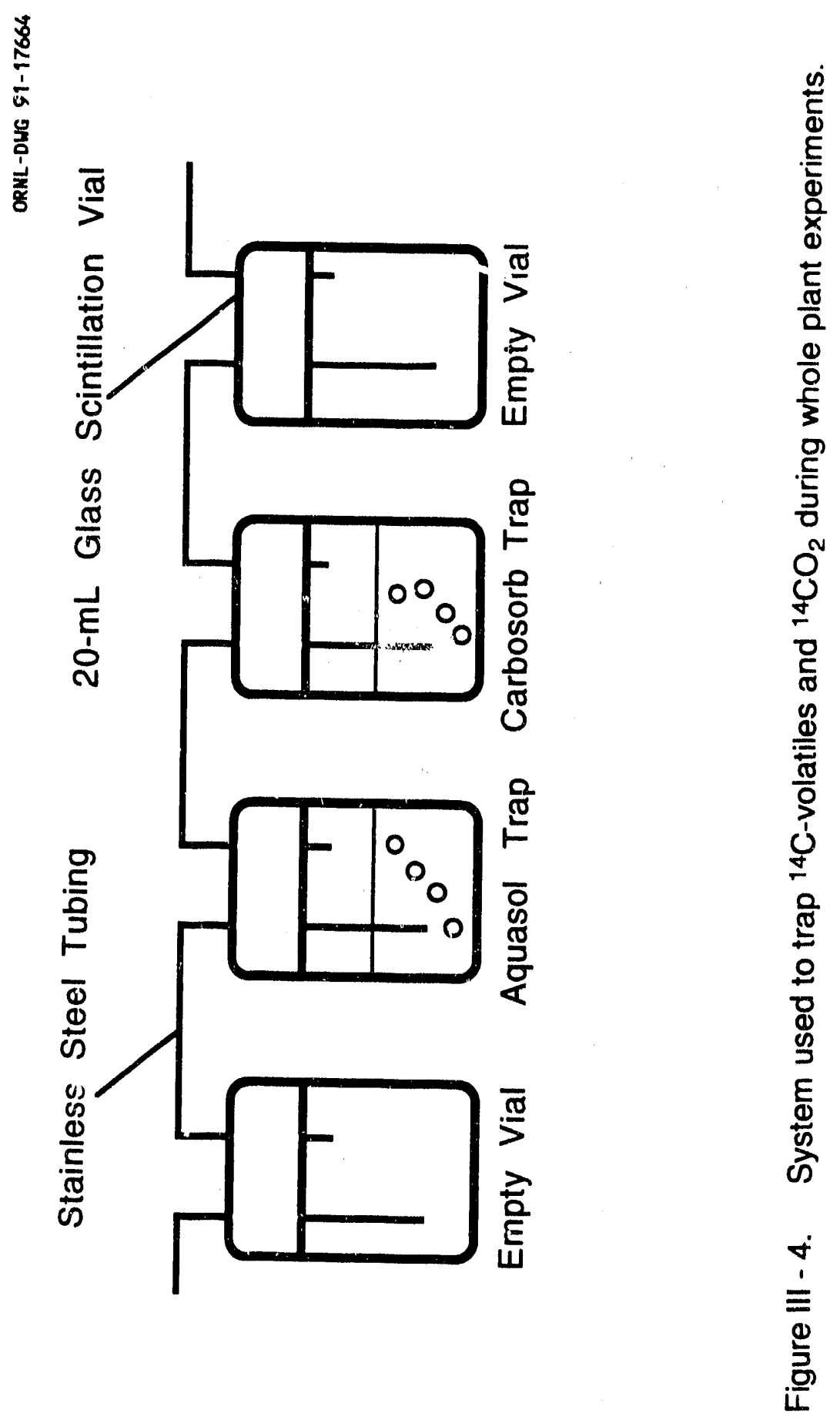


Originally, a syringe was used to flush the headspace of a flask containing ${ }^{14} \mathrm{C}$. TCE through the trapping system at 0.5 and 1.5 hours and the radioactive counts (expressed as a percentage of the total counts evolved from the flask) in the Aquasol trap were determined (Figure III - 5). Since subsequent experiements were conducted using a peristaltic pump to flush the flasks, the efficiency of the Aquasol trap was also determined for the flow of air provided by the pump (Figure III - 6). Similarly, the efficiency of the Carbosorb trap was determined using ${ }^{14} \mathrm{C}$-bicarbonate. A syringe was used to flush the headspace of a flask containing acidified ${ }^{14} \mathrm{C}$-bicarbonate through the trapping system and the radioactive counts in the carbosorb trap (expressed as a percentage of the total counts evolved) were determined. Acidification of the ${ }^{14} \mathrm{C}$-bicarbonate was done using two different volumes of $\mathrm{HCl}$ to be certain of complete acidification (Figures III - 7 and III - 8). As with the Aquasol trap, the efficiency of the Carbosorb trap was also determined for air flow provided by the peristaltic pump (Figure III - 9). The mean efficiency of the Aquasol trap for all determinations was approximately $92 \% \pm 4 \%$, while that of the Carbosorb trap was approximately $77 \% \pm 7 \%$. All samples were monitored for quenching and auto-fluorescence using a quench curve in the liquid scintillation spectrophotometer.

\section{Soil Extraction Procedures}

At the conclusion of each experiment, experimental soil was extracted in toto to determine extractable ${ }^{14} \mathrm{C}$ remaining in the soil. A modified Bligh- $\Gamma$ yer (1959) extraction procedure using $55 \mathrm{~mL}$ of methanol:chloroform $(2.7: 1, \mathrm{v} / \mathrm{v})$ 


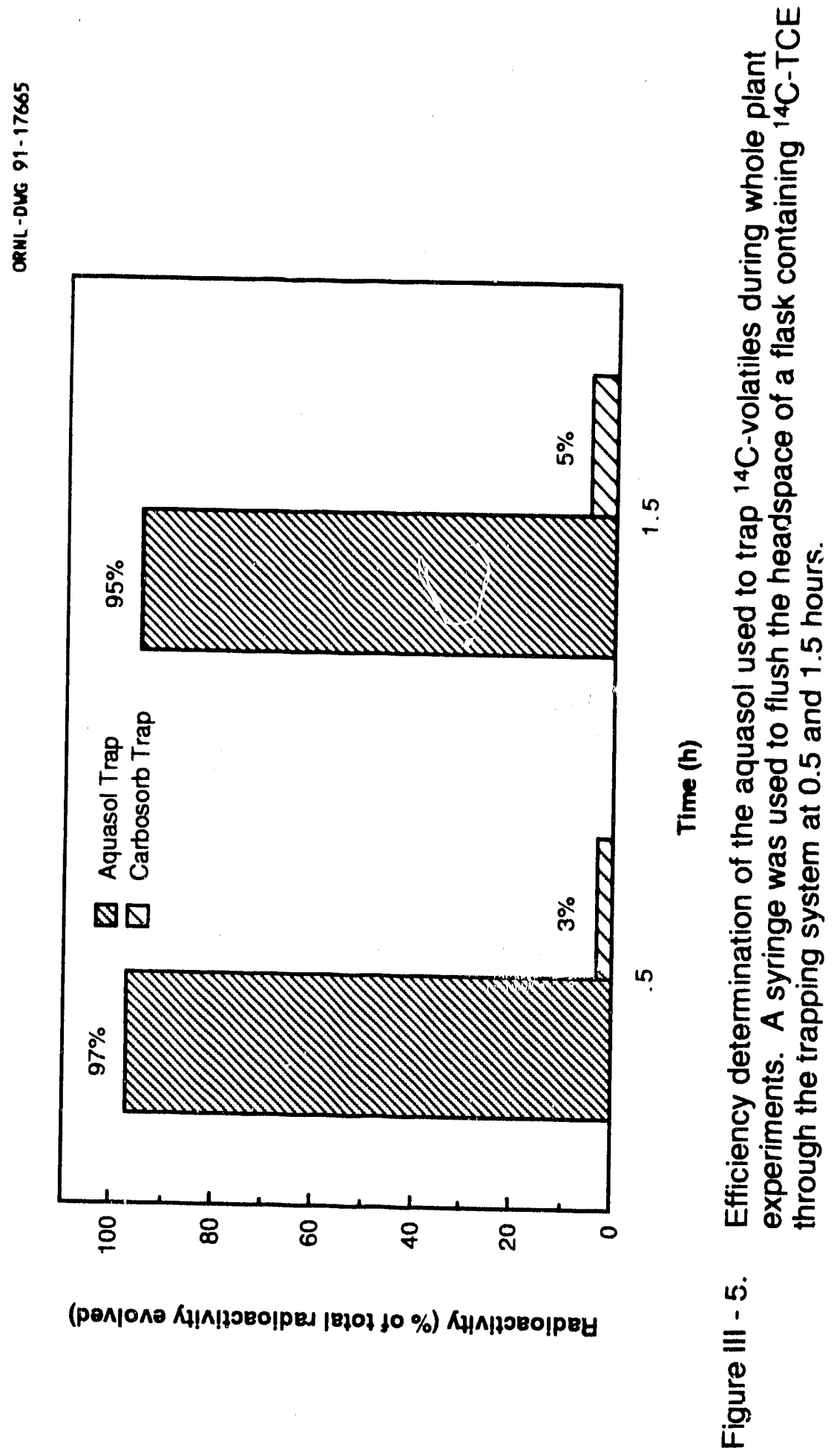




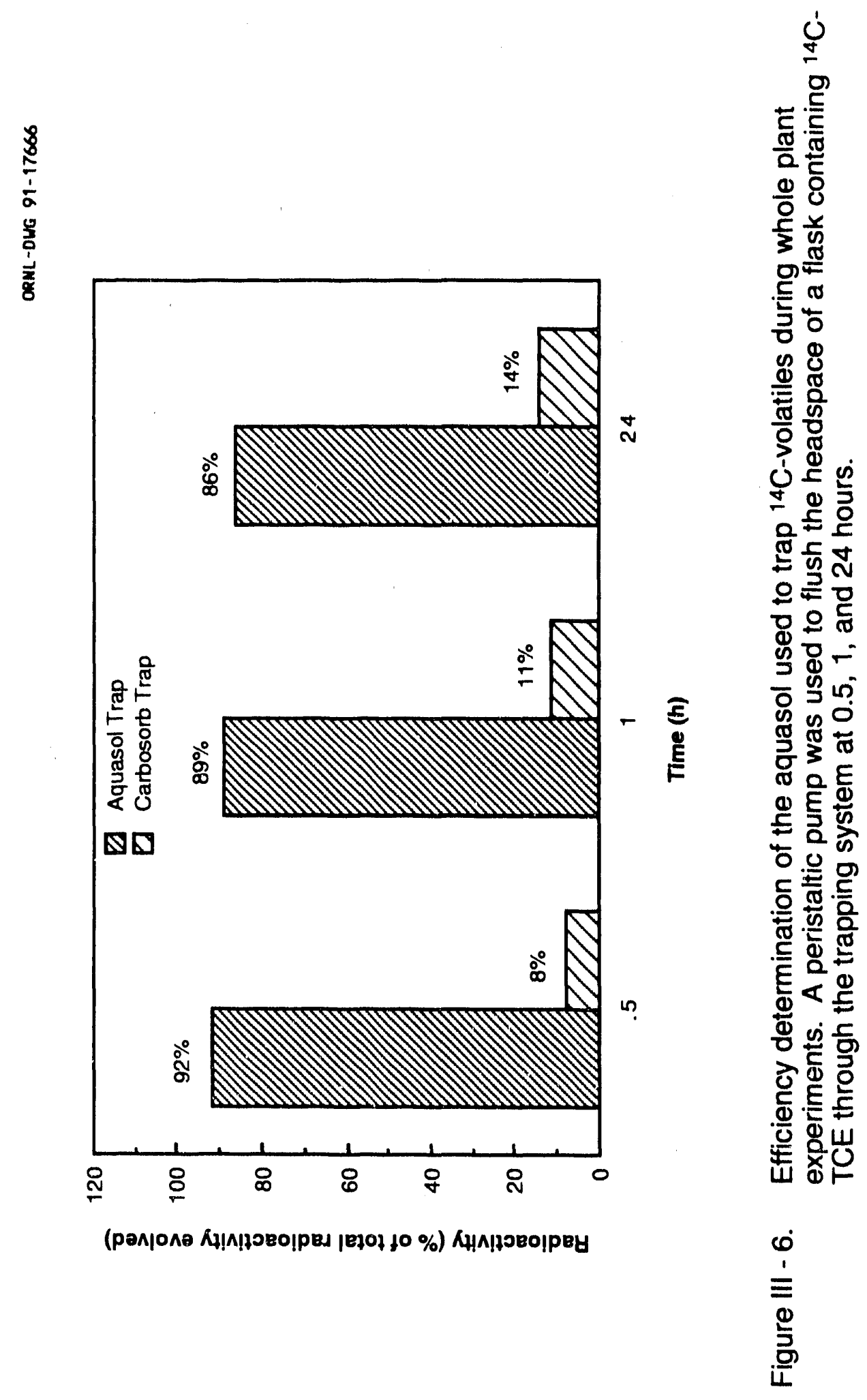




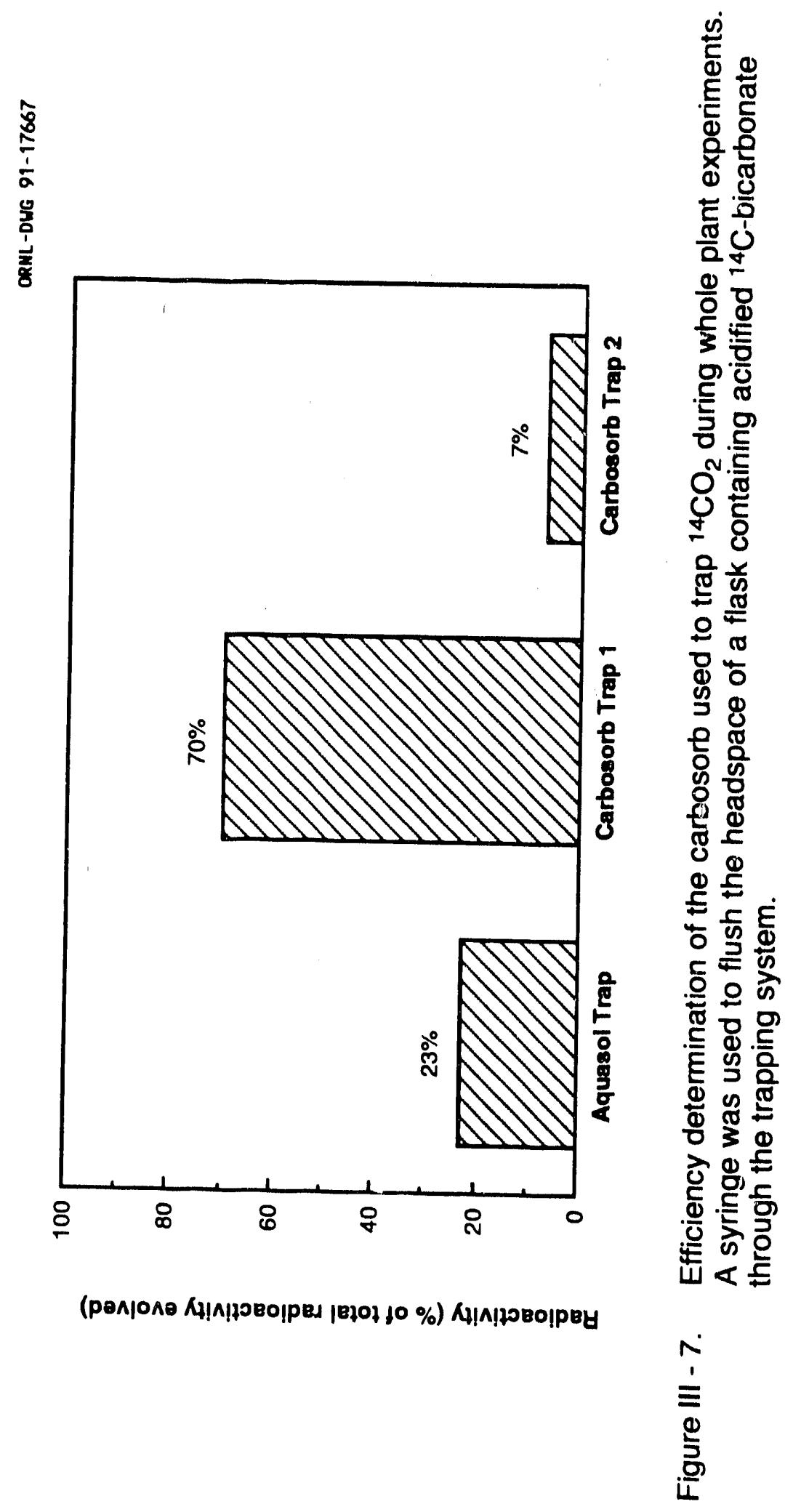




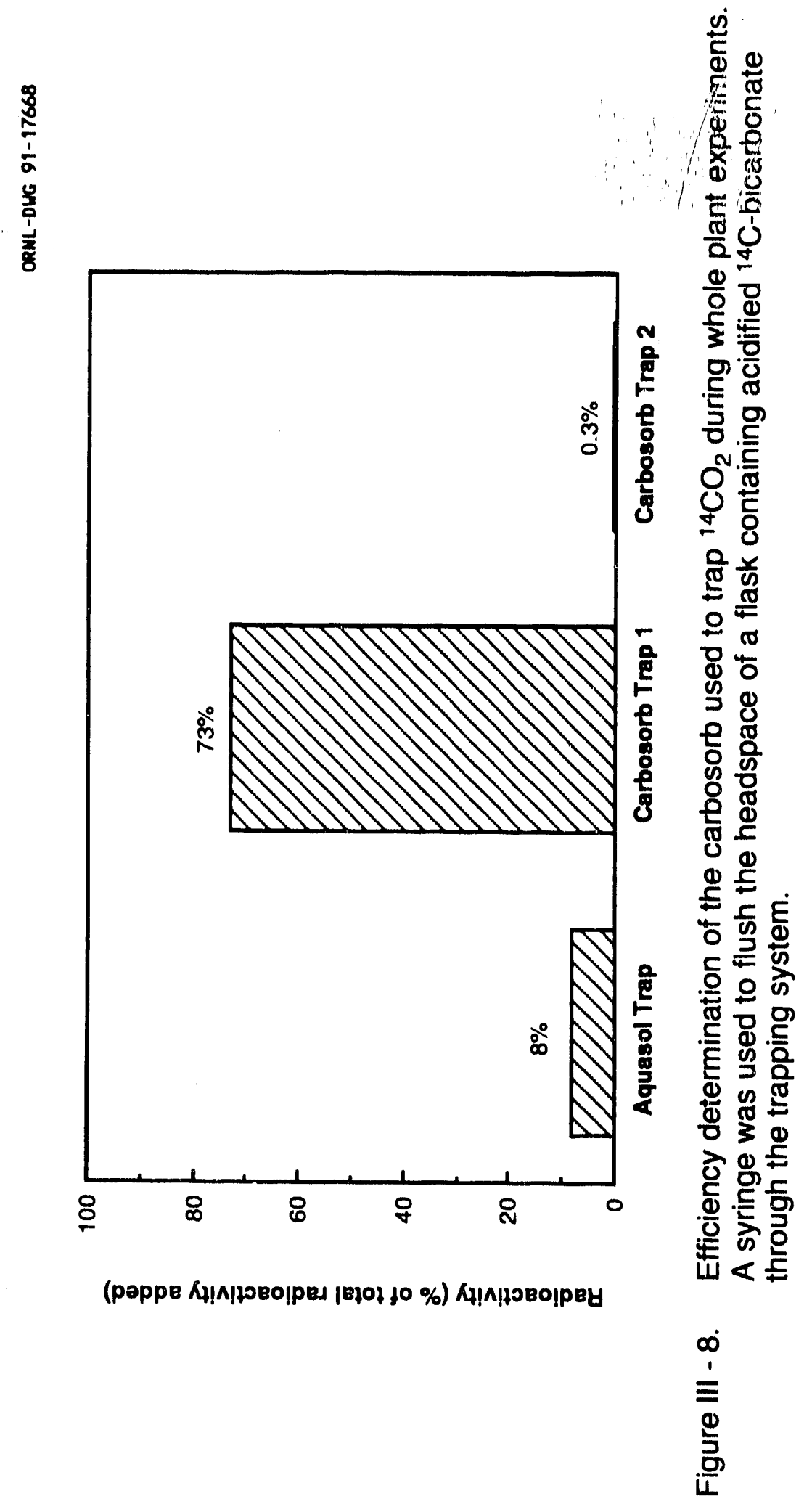




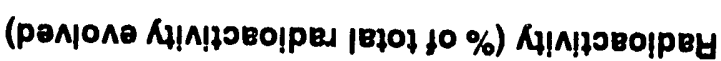

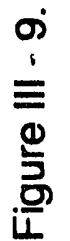


was employed. Soils were extracted in the sample flasks for at least two hours before being transferred to $110-\mathrm{mL}$ glass bottles equipped with polytetrafluoroethylene-lined caps. The bottles were centrifuged and $10 \mathrm{~mL}$ of the supernatant was decanted into a polypropylene vial. The supernatant was split into two phases (aqueous and organic), by adding $5 \mathrm{~mL}$ of chloroform and $5 \mathrm{~mL}$ of distilled water, and allowed to stand for $24 \mathrm{~h}$. Aliquots $(200 \mu \mathrm{L})$ of each phase were added to Aquasol and analyzed for ${ }^{14} \mathrm{C}$. A portion of the soil pellet from the centrifugation step was removed for use in the alkaline extraction procedure described below. Different ratios of methanol:chloroform and sequential extractions did not increase recovery of ${ }^{14} \mathrm{C}$ from the soil (data not shown). The solvent-extracted soil samples from the centrifugation step described above were weighed, and then extracted with $0.5 \mathrm{M} \mathrm{NaOH}$ overnight, and radioactivity in aliquots of each $\mathrm{NaOH}$ extract was determined. All samples were monitored closely for quenching (physical and chemical) and autofluorescence.

Plant Analysis for ${ }^{14} \mathrm{C}$

In order to determine ${ }^{14} \mathrm{C}$ in plant tissues for describing uptake and calculating a mass balance, plant tissue samples were combusted using a Thomas Ogg Infrared Ignitor (Thomas Scientific). Weighed samples of leaf, stem, and root tissue were enclosed in black paper sample wrappers (Thomas Scientific), placed in platinum baskets, and combusted in specially designed sealed flasks. Leaf and stem samples were combusted fresh, however, root samples were air dried before combustion. After cooling, an alkaline 
scintillation cocktail (described as Carbosorb above) was introduced into the flasks. The cocktail remained in the flasks for approximately 1 hour before being transferred to scintillation vials and counted using a Packard $2000 \mathrm{CA}$ Liquid Scintillation Spectrometer. Methyl methacrylate ${ }^{14} \mathrm{C}$ standards were used to determine the efficiency of the combustion procedure.

\section{Data Analysis}

In most cases, data from the whole plant experiments was expressed as a percentage of the total recovered radioactivity at the conclusion of each experiment. For example, mineralization of ${ }^{14} \mathrm{C}$-TCE over time is expressed as the percentage of the total radioactivity contained in the carbosorb traps. Data from all the experiments were recorded using an Apple Macintosh Plus personal computer and Cricket Graph software.

H. Influence of Root Exudation on ${ }^{14} \mathrm{C}$-TCE Mineralization

The potential role that exudation rate plays in ${ }^{14} \mathrm{C}$-TCE mineralization in rhizosphere soils was tested using materials and methods identical to the whole plant experiments described above with one major deviation. The light intensity (photosynthetic photon flux density) in chamber one was reduced to 249.4 $\mu$ Moles $/ \mathrm{m}^{2} \mathrm{~s} \pm 6.0$. This represented a statistically signficant reduction $(p<0.05)$ in light intensity compared with chamber two $\left(387.8 \mu \mathrm{Moles} / \mathrm{m}^{2} \mathrm{~s} \pm 9.2\right)$. Importantly, temperature within the two chambers varied only slightly $\left(29.2^{\circ} \mathrm{C} \pm\right.$ 0.2 and $29.9^{\circ} \mathrm{C} \pm 0.3$ for chambers 1 and 2 , respectively) and was not 
significantly different $(p>0.05)$. Experiments were conducted using G. max, $P$. taeda, and L. cuneata.

I. Pesticide Root Zone Model (PRZM)

The Pesticide Root Zone Model (PRZM) is an interactive software program developed for estimating the movement and fate of pesticides and other hazardous organic compounds within and below the plant root zone (Carsel et al., 1984). The model allows the user to input soil, chemical, and environmental data based on calculated, literature, and/or experimental measurements. Output from the model simulations is assessed based on both abiotic and biotic factors. Data from the whole plant experiments described above were incorporated into the PRZM to estimate the fate of TCE at the MCB under vegetated and nonvegetated conditions. 
CHAPTER IV.

\section{RESULTS}

A. Site Description and Sample Collection

Soil at the MCB

The soil samples from the Miscellaneous Chemicals Basin (MCB) proved to be low in organic carbon and slightly acidic (Table IV - 1), which is typical of areas where rainfall is abundant and warm, humid conditions prevall. Percent organic carbon was lower $(p \leq 0.05)$ for the nonvegetated soils (non-TCE contaminated, $0.20 \%$ OC; TCE contaminated, $1.06 \%$ OC) than for the inizosphere soils, which ranged from $1.20 \%$ to $1.43 \%$ OC. With the exception of Solidago sp., the mizosphere soils had higher pHs than the nonvegetated soils. Differences in these parameters (especially,$D C$ ) were expected and were consistent with the fact that some soils received waste solvent input and were vegetated whereas others were not. Because the primary purpose of the experiments was to determine whether degradation of TCE was enhanced in the rhizosphere, without regard at this time for the specific factors controlling such an effect, no attempt was made to normalize differences in $\% O C$ or $\mathrm{pH}$ between soil samples.

Further soil characterization of the composite, nonvegetated soil sample (Table IV - 2) used in the experiments on the fate of ${ }^{14} \mathrm{C}$-TCE in soil-plant systems provided additional confirmation of the initial pedon description. Namely, the MCB soil is dominated (>90\%) by sand ( $>67 \%$ ) and clay ( $>23 \%$ ). Cation-exchange capacity of the composite soll was $13.5 \pm 0.52 \mathrm{cmol}(+) / \mathrm{kg}$ while nitrogen, sulfur, and phosphorus content were $10.02 \% \pm 0.001 \%, 26.7$ 
Table IV - 1. Percent organic carbon (\%OC) and $\mathrm{pH}$ of soll samples from the Miscellaneous Chemicals Basin at the Savannah River Site.

\begin{tabular}{|c|c|c|}
\hline Soll source & $\begin{array}{c}\% \text { OC } \pm S D \\
(n=3)\end{array}$ & $\begin{array}{l}p H \pm S D \\
(n=3)\end{array}$ \\
\hline Nonvegetated, noncontaminatedA & $0.20 \pm 0.04 B$ & $5.20 \pm 0.10^{B}$ \\
\hline Nonvegetated & $1.06 \pm 0.08^{B, C}$ & $6.39 \pm 0.09 B$ \\
\hline L. cuneata & $1.35 \pm 0.01 B, D$ & $6.81 \pm 0.01 E$ \\
\hline Solidago sp. & $1.20 \pm 0.05^{D}$ & $5.53 \pm 0.15^{B}$ \\
\hline P. notatum & $1.43 \pm 0.05^{B, D}$ & $6.75 \pm 0.05^{E}$ \\
\hline P. taeda & $1.26 \pm 0.03^{D}$ & $6.87 \pm 0.09 E$ \\
\hline \multicolumn{3}{|c|}{$\begin{array}{l}\text { ANo detectable TCE; however, trace dichloroethylene was detected. } \\
\text { BSignificantly different from all other soils ( } p \leq 0.05 \text { ) } \\
\text { CSignificantly greater than nonvegetated, noncontaminated soil ( } p \leq 0.05 \text { ). } \\
\text { DSignificantly greater than nonvegetated soil and nonvegetated, } \\
\text { noncontaminated soil ( } p \leq 0.05 \text { ). } \\
\text { ESignificantly different from the Solidago sp., nonvegetated soil, and } \\
\text { nonvegetated, noncontaminated soil ( } p \leq 0.05 \text { ). }\end{array}$} \\
\hline
\end{tabular}


Table IV - 2. Selected physical and chemical properties of the composite, nonvegetated soll from the Miscellaneous Chemicals Basin at the Savannah River Site.

\begin{tabular}{lc}
\hline Parameter & Value \\
\hline Sand $(\%)$ & 67.5 \\
Silt $(\%)$ & 9.0 \\
Clay $(\%)$ & 23.5 \\
Cation-exchange capacity $[\mathrm{cmol}(+) / \mathrm{kg}]$ & $13.5 \pm 0.52$ \\
Nitrogen $(\%)$ & $10.02 \pm 0.001$ \\
Sulfur $(\mu \mathrm{g} / \mathrm{g})$ & $26.7 \pm 9.3$ \\
Phosphorus $(\mu \mathrm{g} / \mathrm{g})$ & $99.0 \pm 5.1$ \\
\hline
\end{tabular}


$\mu \mathrm{g} / \mathrm{g} \pm 9.3 \mu \mathrm{g} / \mathrm{g}$, and $99.0 \mu \mathrm{g} / \mathrm{g} \pm 5.1 \mu \mathrm{g} / \mathrm{g}$, respectively. Determination of soll physical and chemical properties in this study was used strictly for soil characterization. No additional nutrients were added to the soll used in these experiments.

Vegetation at the MCB

Results of the vegetation survey of the Miscellaneous Chemicals Basin conducted in August, 1988, are summarized in Table IV - 3. As described earlier, the predominant plant species aie a legume, Lespedeza cuneata (Dumont); a grass, Paspalum notatum var. saurae (Parodi); and a composite, Solidago sp. The estimated cover for these three species was greater than $84 \%$ of the total area of the MCB. In addition, approximately 500 trees (mostly loblolly pine, Pinus taeda with diameters at breast height ranging from $<1$ to 20 $\mathrm{cm}$ ) were found throughout the MCB. Miscellaneous vegetation, which covered about $7 \%$ of the total area of the MCB included broom sedge (Andropogon virginicus), dwarf sumac (Rhus copallina), and consumption weed (Baccharis halimifolia). Nonvegetated areas at the MCB were estimated at $8 \%$ of the total area.

B. Microbial Blomass, Community Structure, and Metabolic Activity

Carbon dioxide efflux from incubated soils collected in August, 1988, (late summer) illustrated a pattern consistent with the enhanced microbial activity in the plant rhizosphere, in that higher respiration rates $(p \leq 0.05)$ were observed in all soils from the rhizosphere compared to soils from nonvegetated 
Table IV - 3. Vegetation survey of the Miscallaneous Chemicals Basin at the Savannah River Site.

\begin{tabular}{lcl}
\hline $\begin{array}{c}\text { Species } \\
\text { (common name) }\end{array}$ & Estimated \% CoverA & Comments \\
\hline $\begin{array}{c}\text { Lespedeza cuneata } \\
\text { (sericea) }\end{array}$ & 46 & $\begin{array}{l}\text { Tap root system } \\
\text { Leguminous }\end{array}$ \\
$\begin{array}{c}\text { Paspalum notatum var. saurae } \\
\text { (bahia grass) }\end{array}$ & 32 & Fibrous root system \\
$\begin{array}{c}\text { Solidago sp. } \\
\text { (goldenrod) }\end{array}$ & 6.5 & Tap root system \\
$\begin{array}{c}\text { Miscellaneous } \\
\begin{array}{c}\text { B } \\
\text { Pinus taeda } \\
\text { (loblolly pine) }\end{array}\end{array}$ & 7 & Tap root system \\
\hline
\end{tabular}

AThe vegetation survey of the MCB was conducted in August, 1988.

Nonvegetated areas within the MCB were estimated at $8 \%$ of the total area.

BMiscellaneous vegetation included Eupatorium capillifolium (dog fennel), Andropogon virginicus (broom sedge), Pteridium aquilinum (bracken fern), Baccharis halimifolia (consumption weed), Rhus copallina (dwarf sumac), and Hypericum sp.

CTrees were almost exclusively loblolly pine with $<10$ trees being long-leaf pine (Pinus australis) 
areas within the MCB (Figures IV - 1 through IV - 6). For example on day 3 of soil incubation, $\mathrm{CO}_{2}$ efflux was from 4 to 9 times greater in mizosphere soils than in nonvegetated soils (Table IV - 4). Consequently, the calculated biomass based on $\mathrm{CO}_{2}$ efflux was consistently higher in rhizosphere soils than in nonvegetated soils (Table IV - 4).

Microbial biomass measurements based on $\mathrm{CO}_{2}$ efflux from nonvegetated soils collected in March, 1989, (spring) were elevated over nonvegetated soils from the previous summer (Table IV - 5). In addition, biomass estimates for rhizosphere soils collected in March, 1989, also varied slightly from previous estimates (Table IV - 5). Microbial biomass estimates calculated from phospholipid fatty acid (PLFA) analysis were fairly consistent with the estimates based on $\mathrm{CO}_{2}$ efflux and also illustrated the increased microbial biomass associated with the rhizosphere soils (Table IV - 5). Consistency between biomass based on PLFA and other techniques has been previously reported (Balkwill et al., 1988). Vestall and White (1989) believe that PLFA gives a better indication of viable biomass because phospholipids are a cellular component common to all cells of the microbiota and are quickly degraded on cell death.

In addition to microbial biomass, PLFA analysis was also used to determine the microbial community structure of the soil samples frorn the MCB. Phospholipid fatty acid profiles of the different rhizosphere and nonvegetated soil samples are shown in Table IV - 6. The most abundant PLFA among both mizosphere and nonvegetated soils was palmitate (16:0), a common saturated fatty acid. It was also concluded that the communities of both sample types 

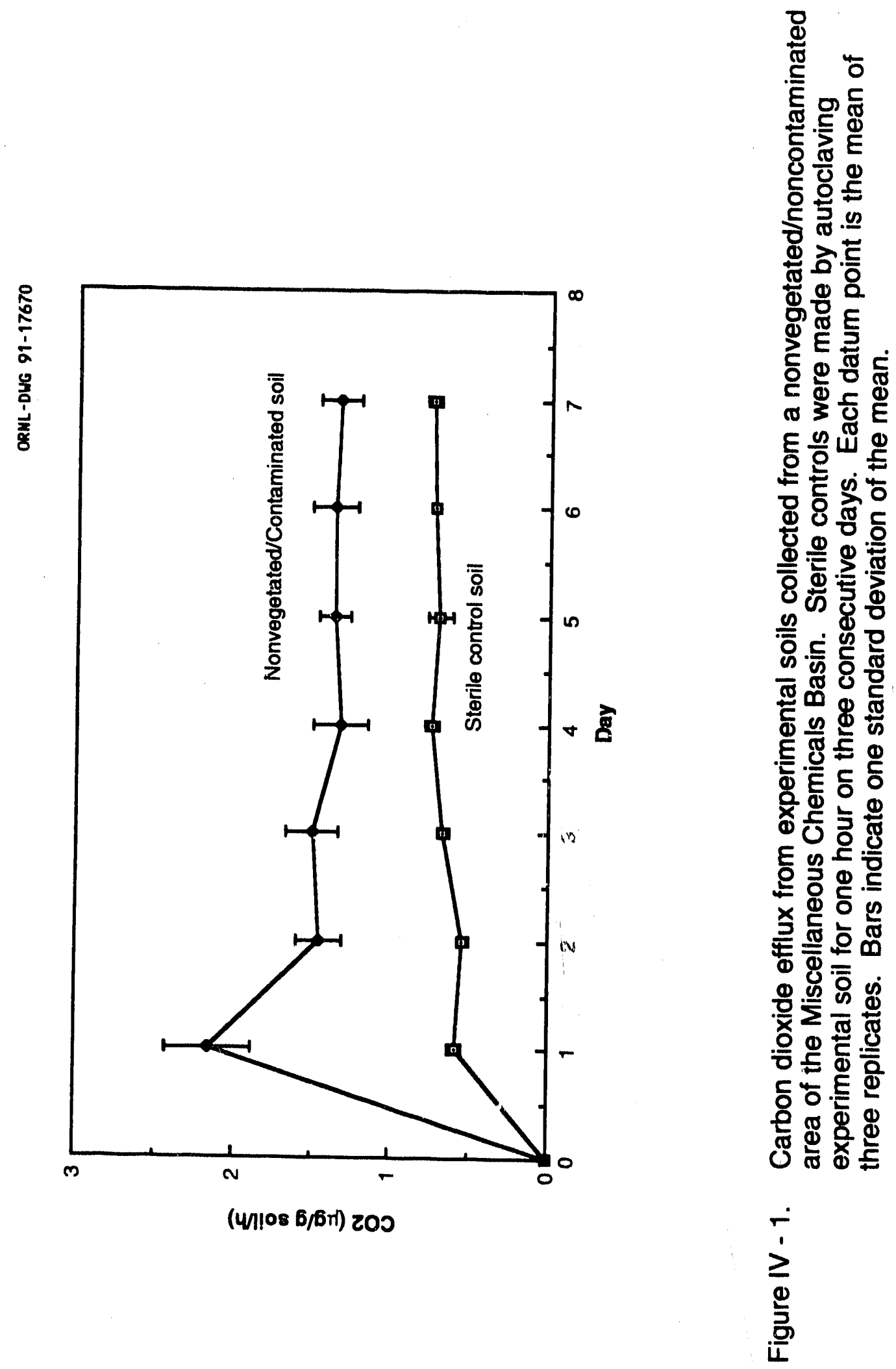


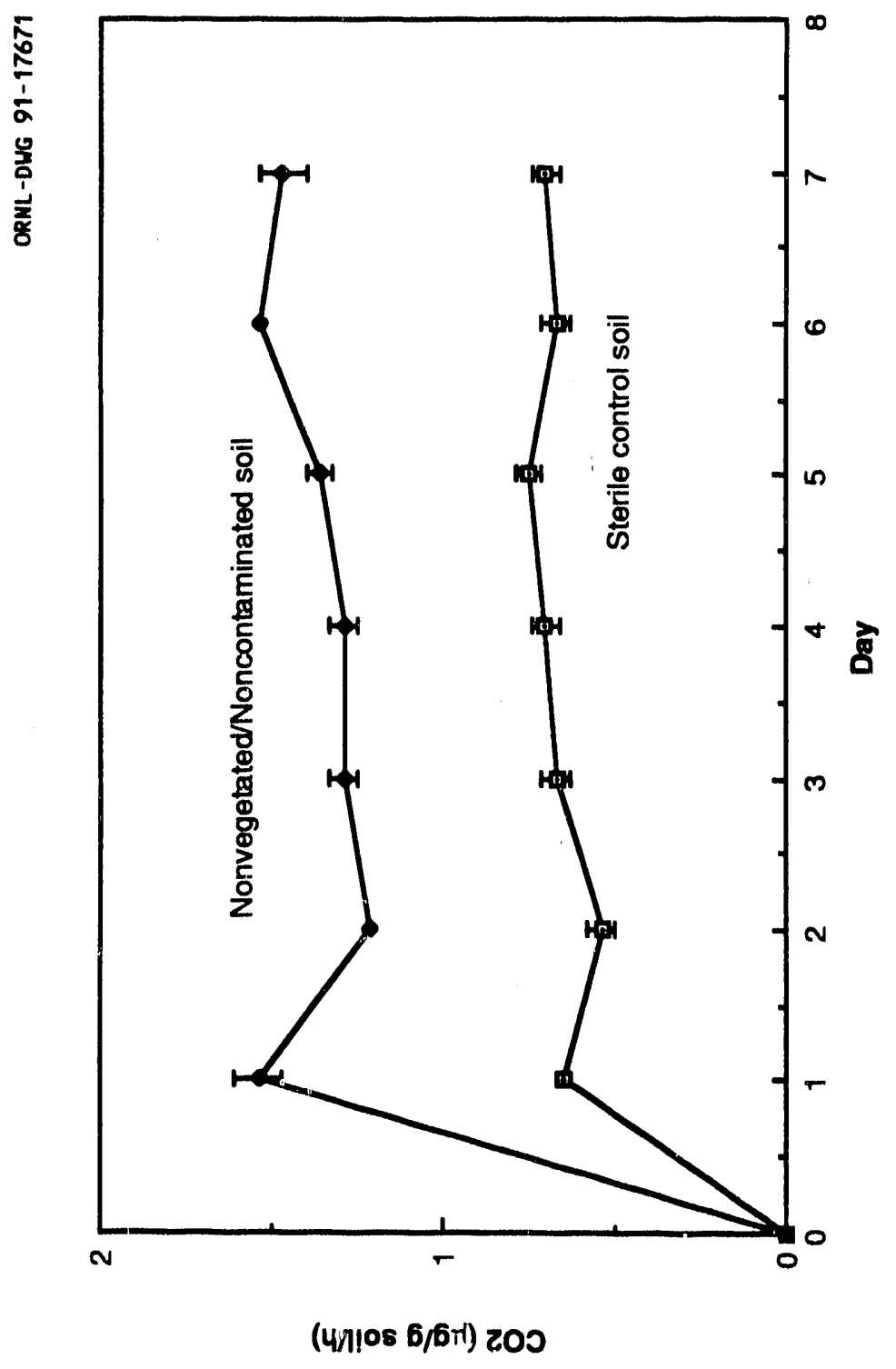

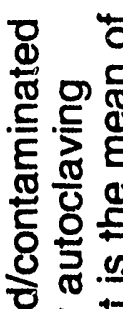

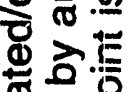

屯

ช్

$\Phi$ ह

잉 行宁

¿

๙ $3 \varepsilon$

통응

我此

割

잉

西

Ф

के ठु

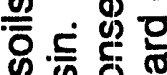

(d 0

要品

舟电

대요

ब등

事

ख约 专

통 오으음

웅

x

言舟

论

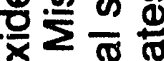

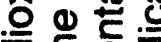

吅

ᄃㄴ․ㅌ․

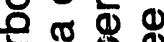

ऽั

$(4 / 1086 / 611) 200$

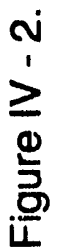




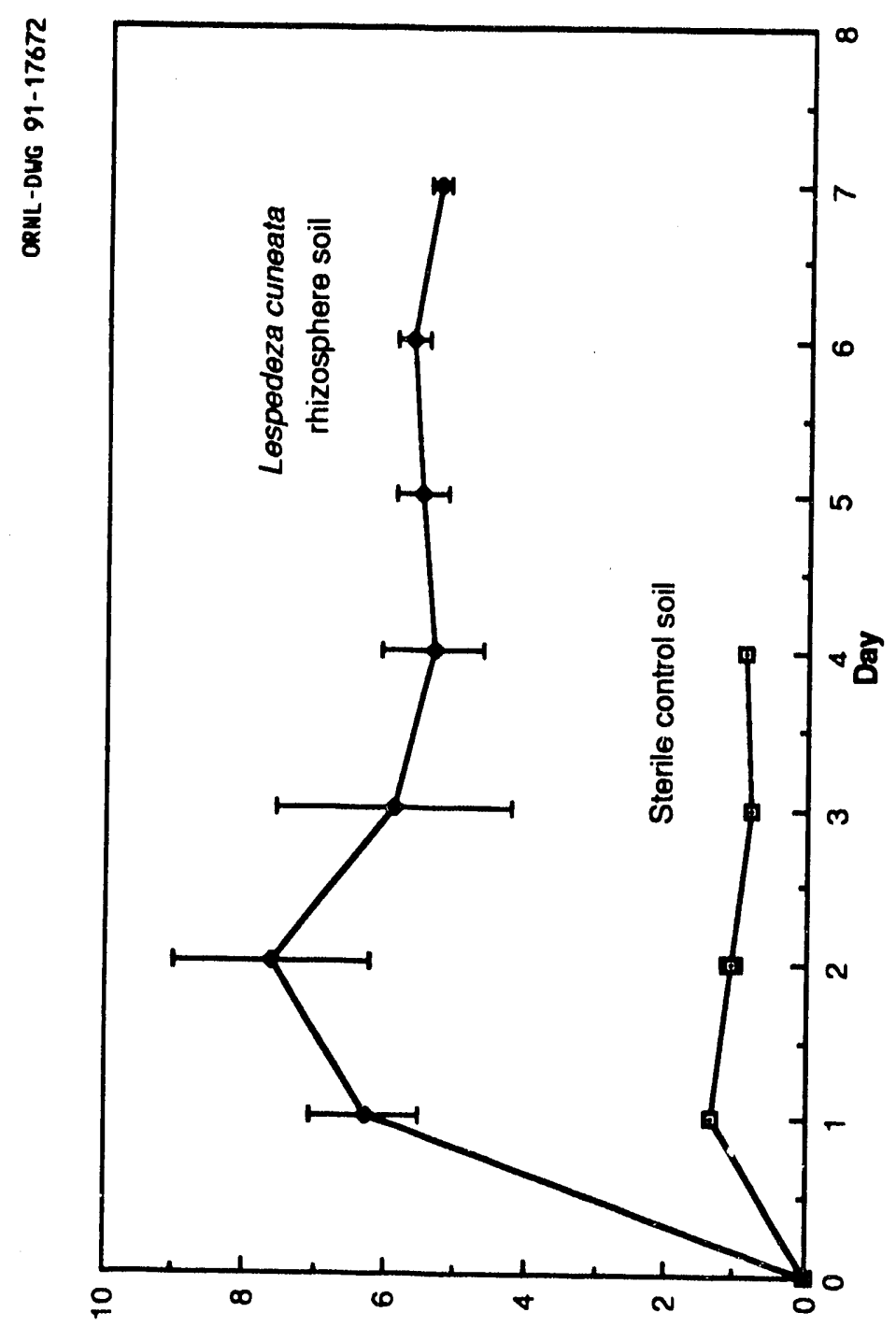

$(4 / 1 ! 086 / 6 \pi) 200$ $\frac{5}{\sqrt{3}}$

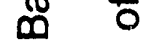

용 융

ह

도용

U

옹 그등

$\Phi$

雨

స ह

他 要

¿

उ

ฆํㅡㅇ

สัธ

잉 중은

넝응

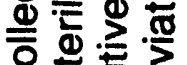

ठ心志

ำ

施

त 80

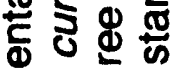

E

응 동

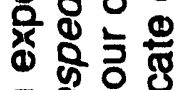

통 오흠

농

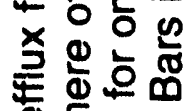

屯

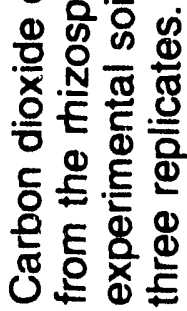

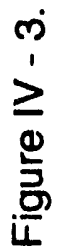



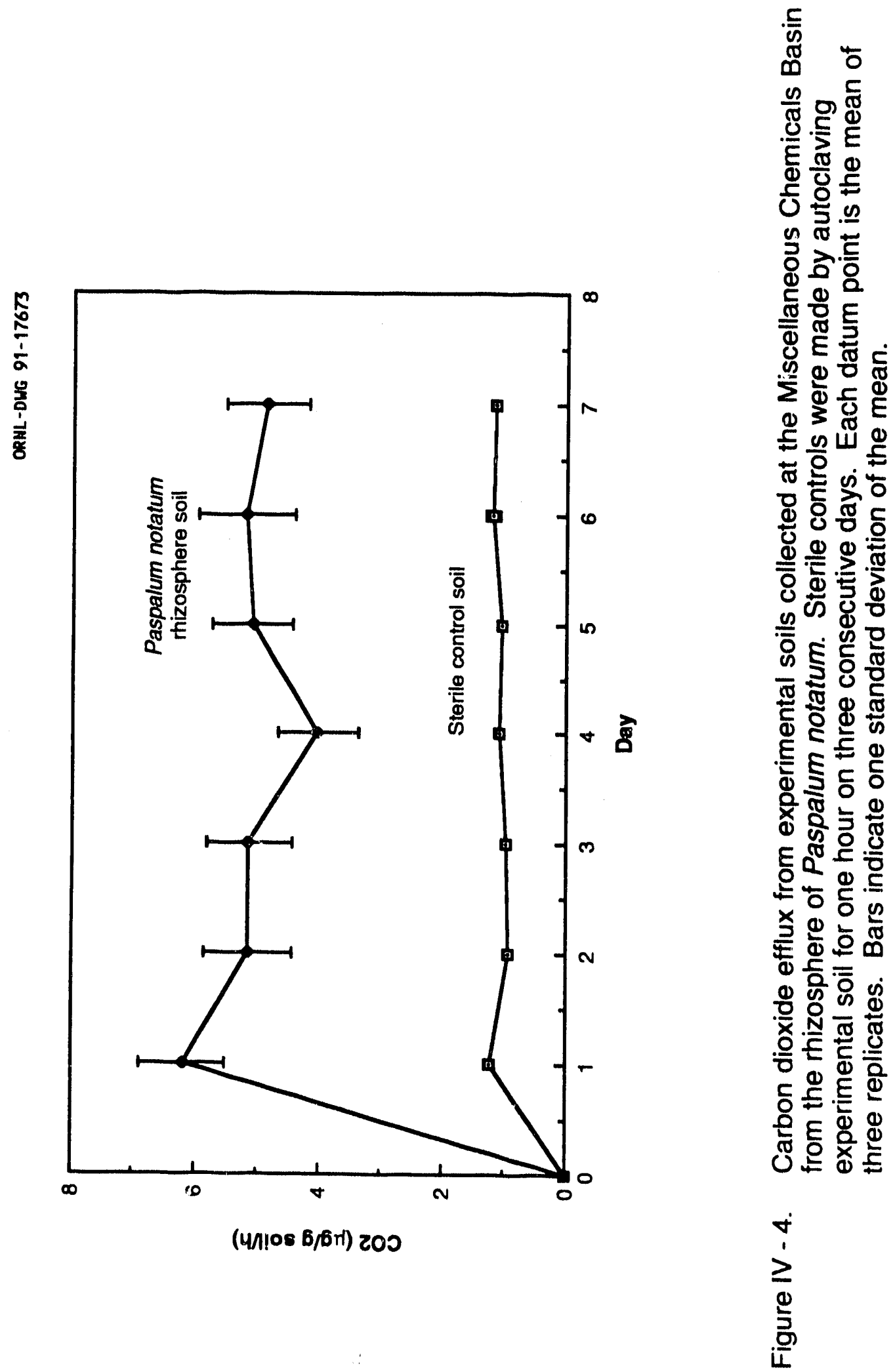


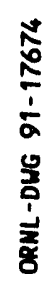

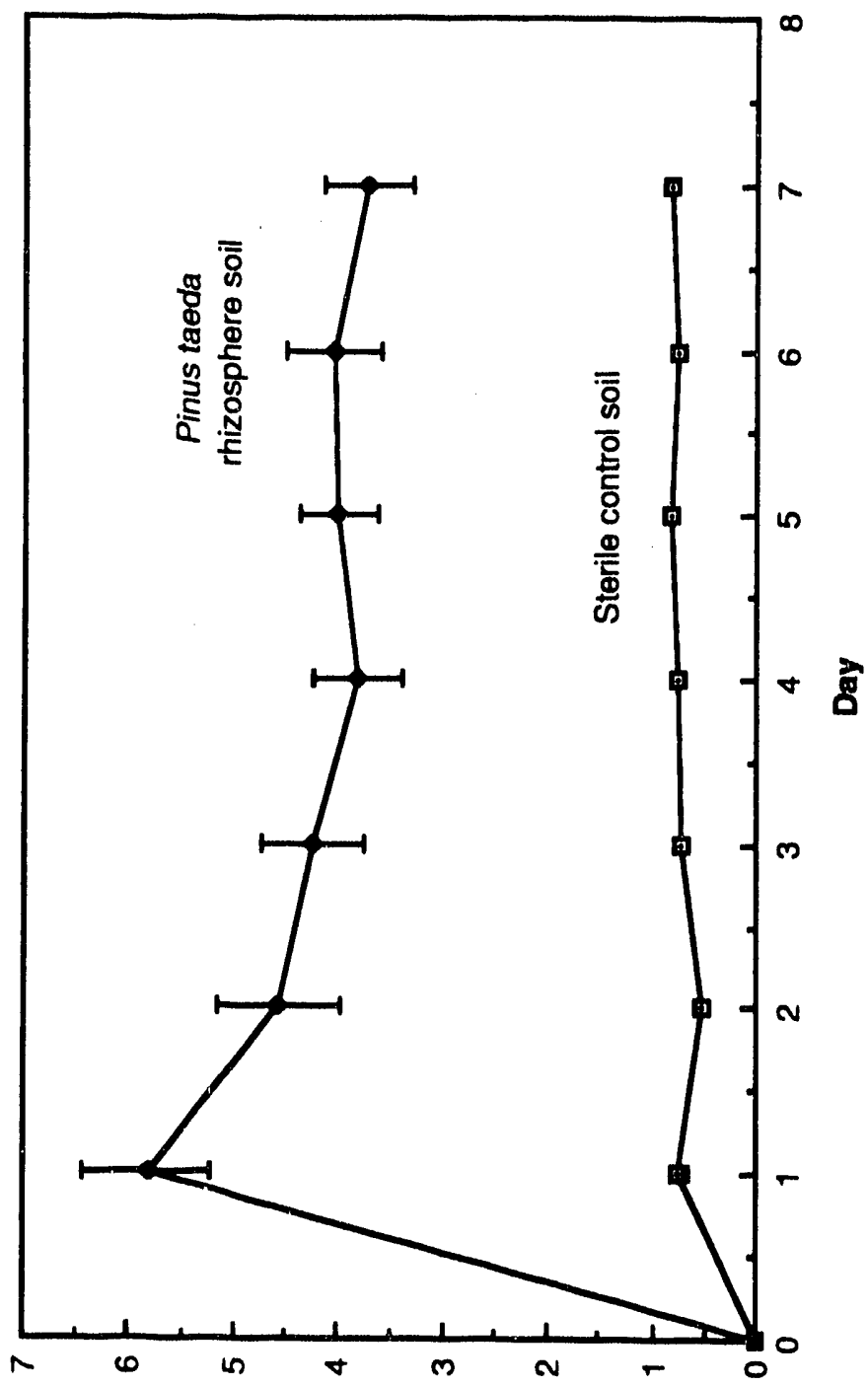

$(4 / 11086 / 6 \pi) 200$

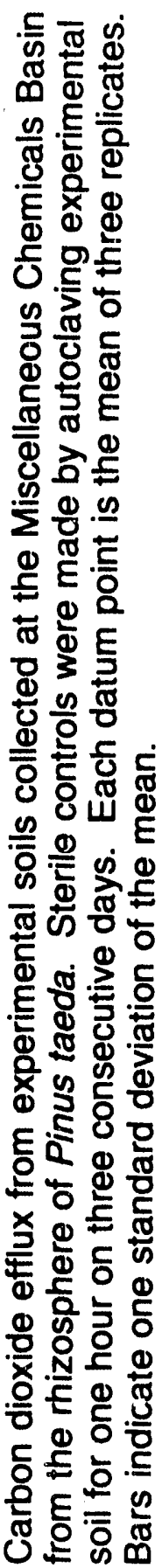

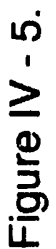




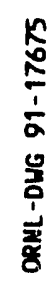
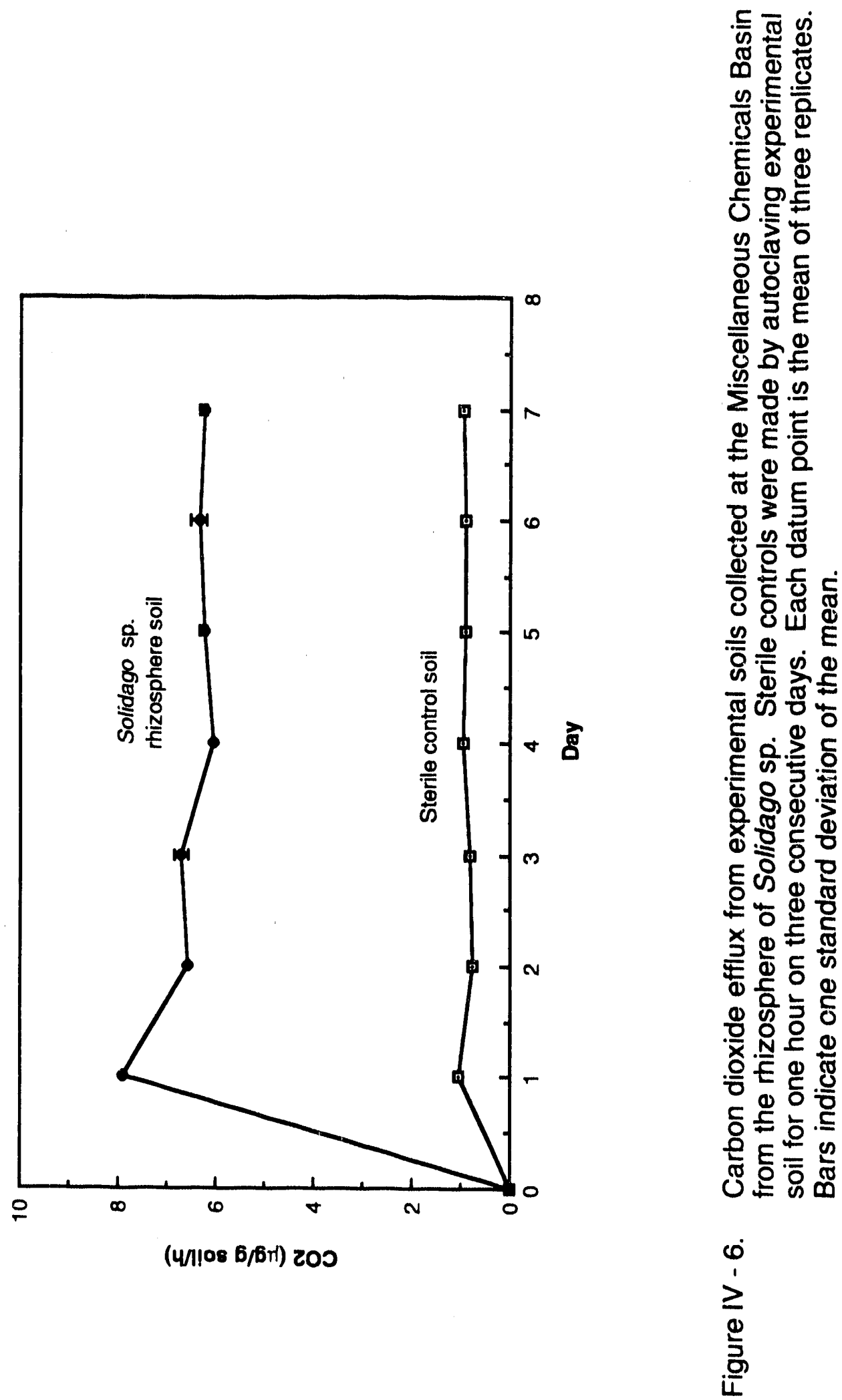
Table IV - 4. Carbon dioxide efflux on day 3 of incubation from rhizosphere and nonvegetated soils collected at the Miscellaneous Chemicals Basin at the Savannah River Site.

\begin{tabular}{|c|c|c|}
\hline Soil source $A$ & $\begin{array}{l}\text { Net } \mathrm{CO}_{2} \text { efflux } \\
(\mu \mathrm{g} / \mathrm{g} \text { of soil per } h) \\
\pm \operatorname{SD}(n=3)\end{array}$ & $\begin{array}{c}\text { Microbial } \\
\text { Biomass } \\
(\mu \mathrm{g} / \mathrm{g} \text { of soil)c }\end{array}$ \\
\hline Nonvegetated, noncontaminated $\mathrm{D}$ & $0.62 \pm 0.04$ & 372 \\
\hline Nonvegetated & $0.83 \pm 0.17$ & 498 \\
\hline L. cuneata & $4.93 \pm 1.66 \mathrm{E}$ & 3072 \\
\hline Solidago sp. & $5.90 \pm 0.14 E$ & 3540 \\
\hline P. notatum & $4.17 \pm 0.68 E$ & 2502 \\
\hline P. taeda & $3.52 \pm 0.49 \mathrm{E}$ & 2112 \\
\hline
\end{tabular}

AAll samples were collected from the MCB in August, 1988.

BNet $\mathrm{CO}_{2}$ efflux $=\mathrm{CO}_{2}$ efflux from sieved soil sample (triplicate determinations) $\mathrm{CO}_{2}$ efflux from matched, sterile (autoclaved) soil (triplicate determinations).

CMicrobial biomass was calculated according to methods in Parkinson and Paul, 1982.

DNo detectable TCE; however, trace dichloroethylene was detected.

ESignificantly greaier than $\mathrm{CO}_{2}$ efflux from nonvegetated soil and nonvegetated, noncontaminated soil $(p \leq 0.05)$. 


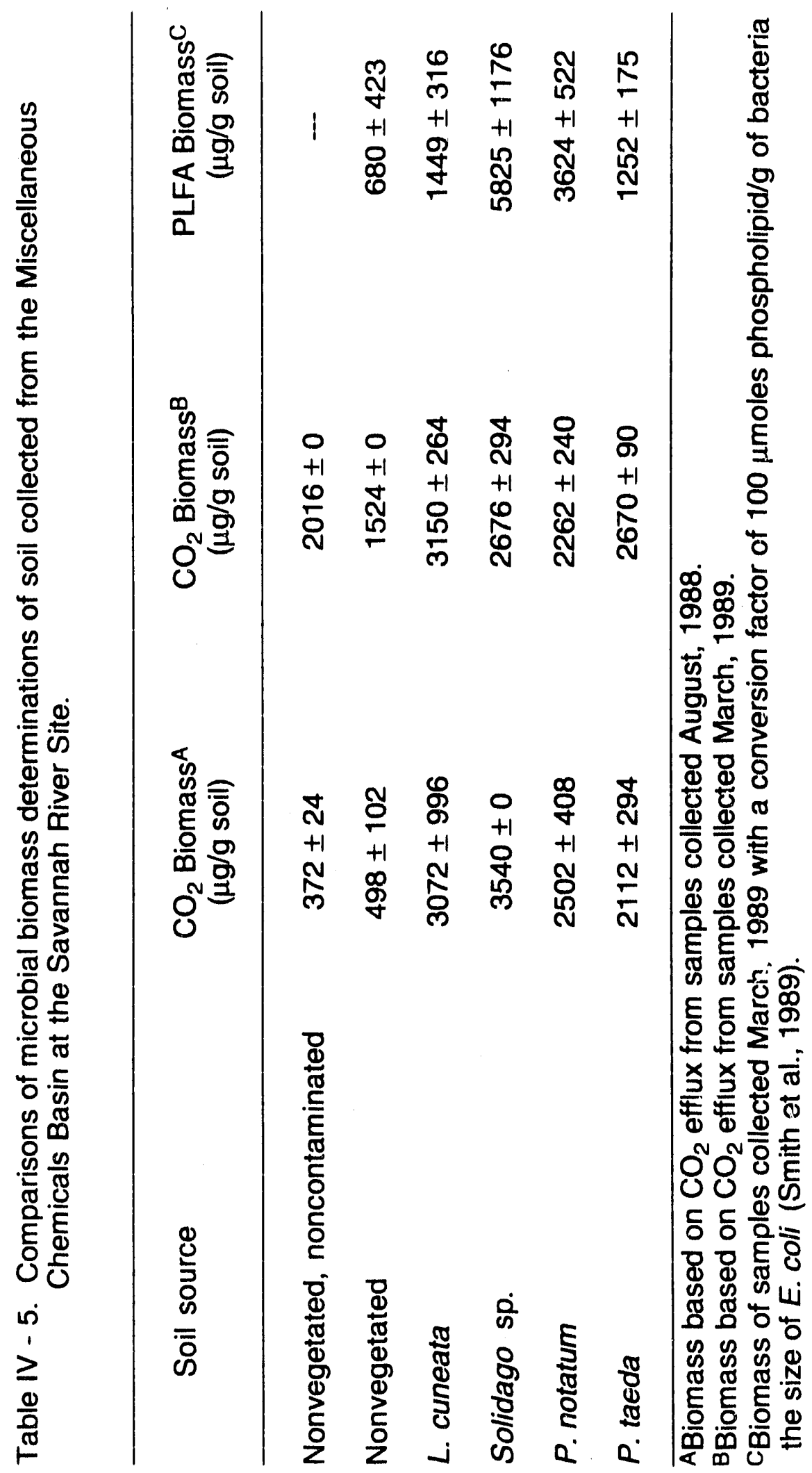




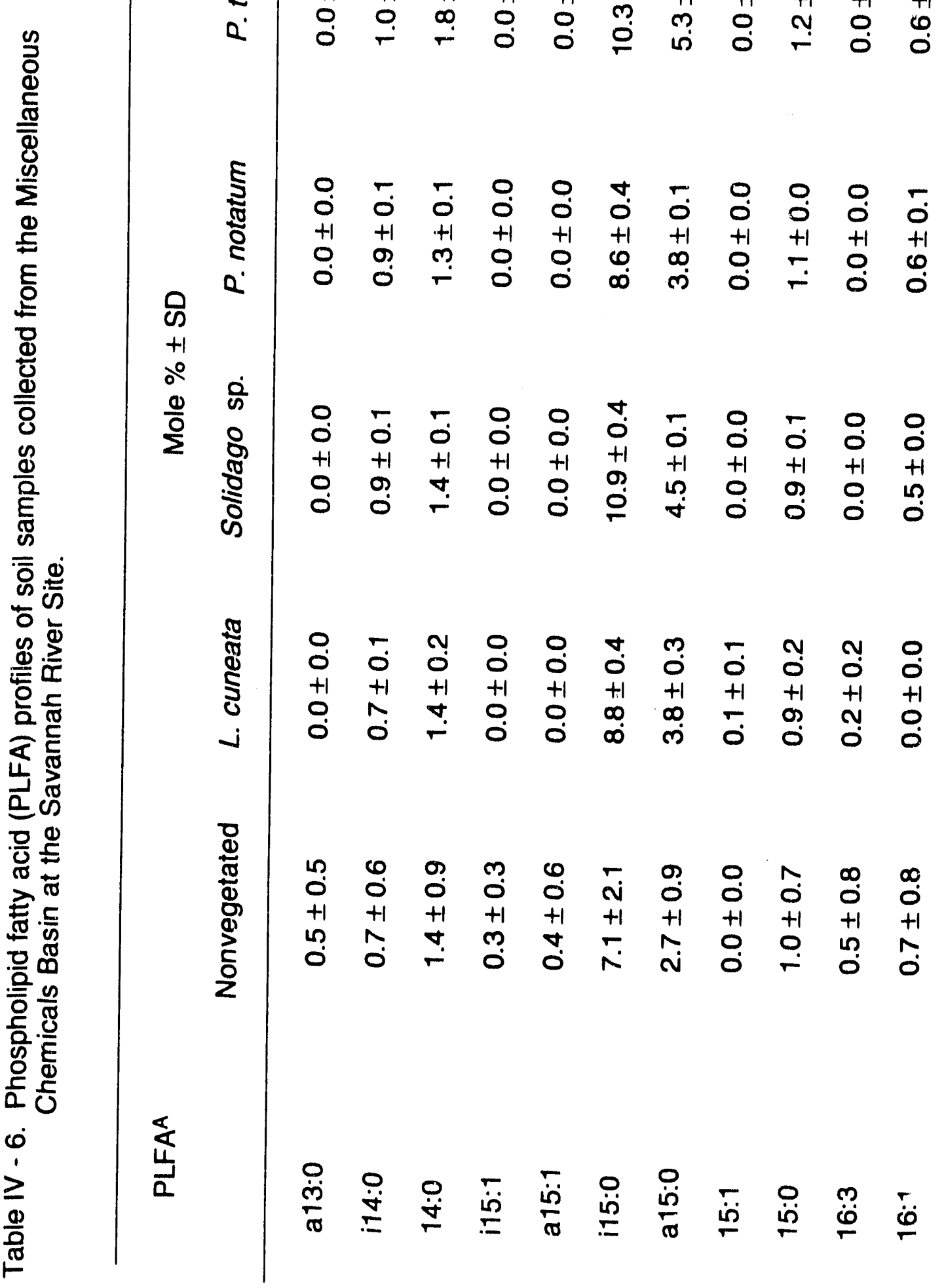




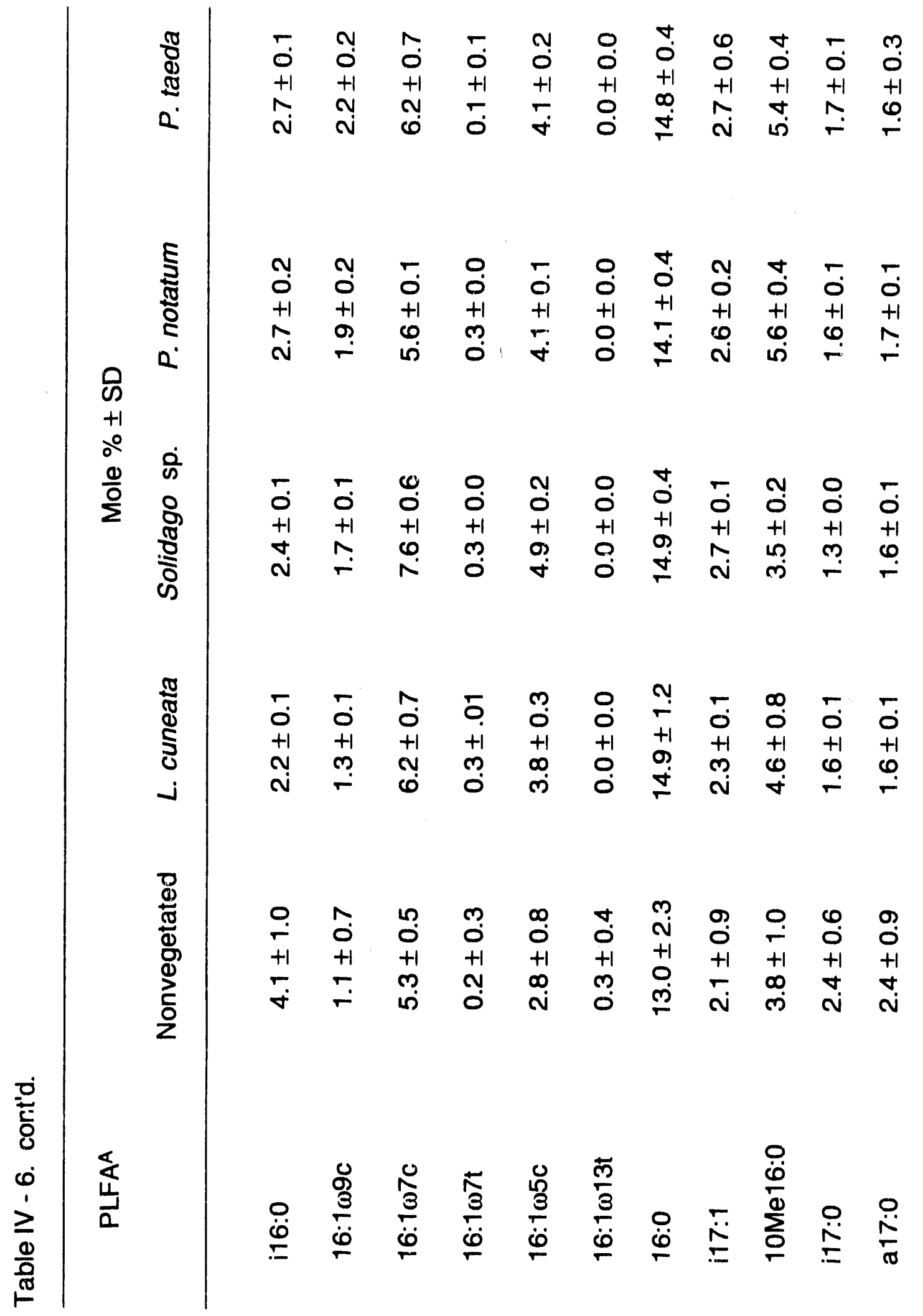




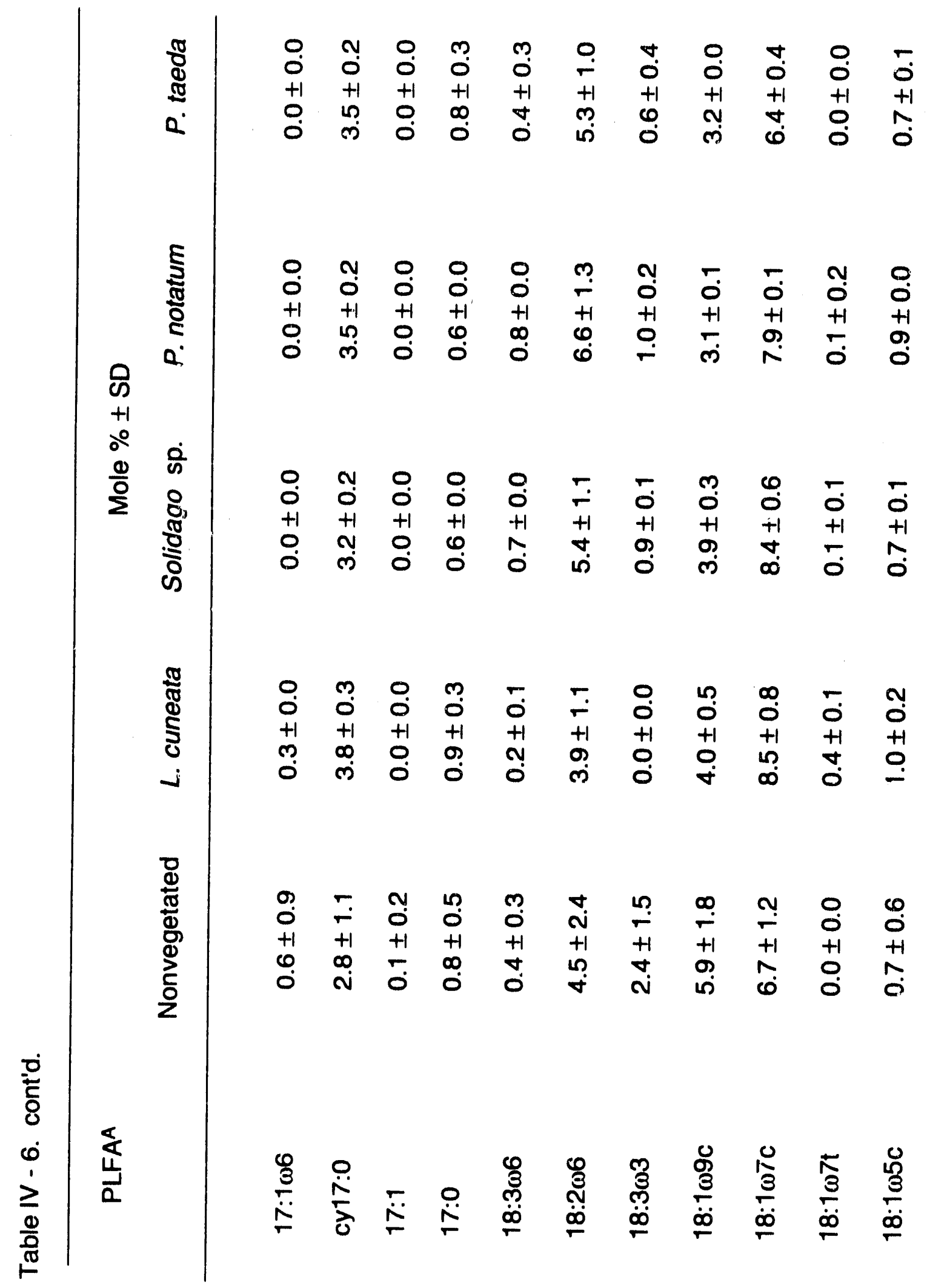




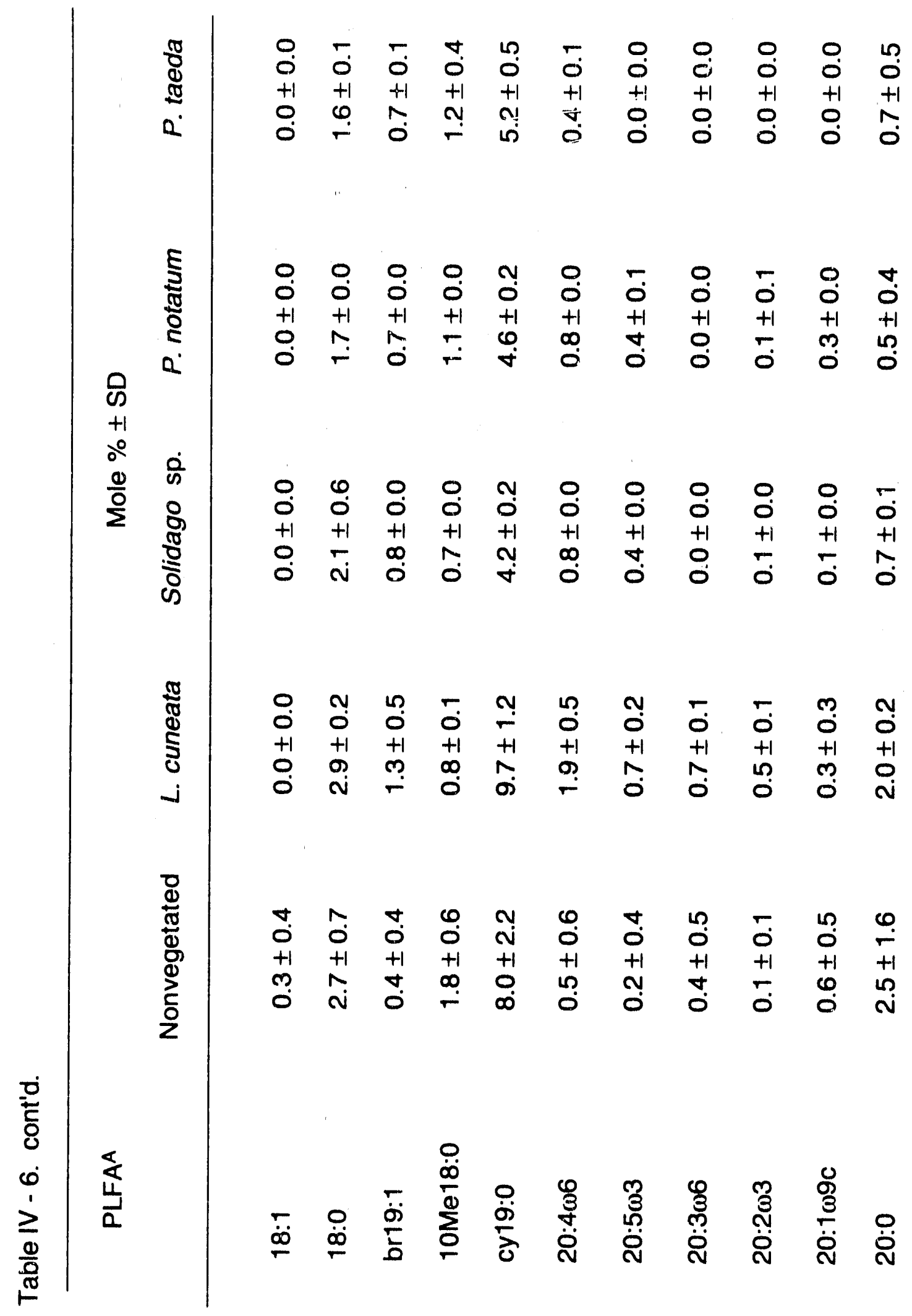




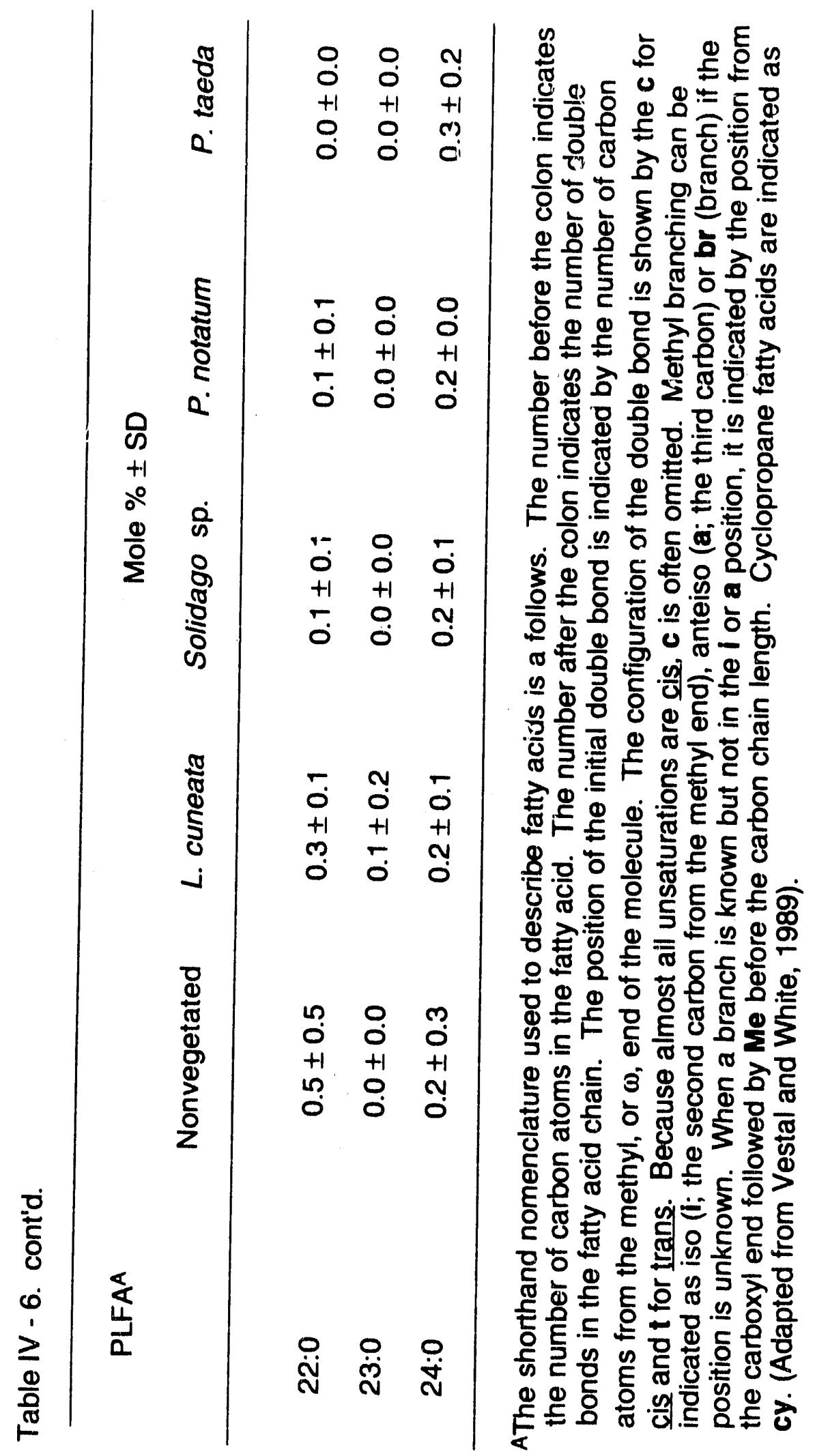


(hizosphere and nonvegetated) are composed of gram negative and gram positive microorganisnis in approximately equal atundance as indicated by the strong presence of monounsaturated $(16: 1 \omega 7 \mathrm{c}$ and $18: 1 \omega 7 \mathrm{c})$ and branched phospholipid fatty acids (i15:0 and i16:0 for example), respectively, in the samples. Further review of the PLFA profiles indicated that ratios of cis fatty acids to trans fatty acids (specifically $16: 1 \omega 7 \mathrm{c}$ to $16: 1 \omega 7 \mathrm{t}$ and $18: 1 \omega 7 \mathrm{c}$ to

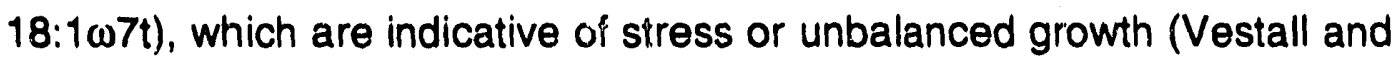
White, 1989), were not significantly different among the rhizosphere and nonvegetated soils. In addition, cyclopropyl fatty acids such as cy17:0 and cy 19:0, which are indicative of unbalanced growth and/or anaerobic microorganisms (Guckert et al., 1985), were present in all sample types. These results are probably best explained by the soil conditions at the MCB. Namely that the soil is low in organic carbon and fluctuates between aerobic and anaerobic conditions.

Additional evaluation of the PLFA frofiles of rhizosphere and nonvegetated soils from the MCB was done using standard cluster analysis techniques. A dendogram of the cluster analysis results is shown in Figure IV 7. The figure illustrates the primary clustering of nonvegetated soil samples with Lespedeza cuneata soil samples and Solidago sp. soil samples with Pinus taeda soil samples and Paspalum notatum soil samples. Secondary clustering occurred between Pinus taeda soil samples and Paspalum notatum soil samples. A principal components analysis indicated that the fatty acid which most determines the primary clustering (separation of the nonvegetated soil and L. cuneata mizosphere soil from the others) was cy19:0. The secondary 


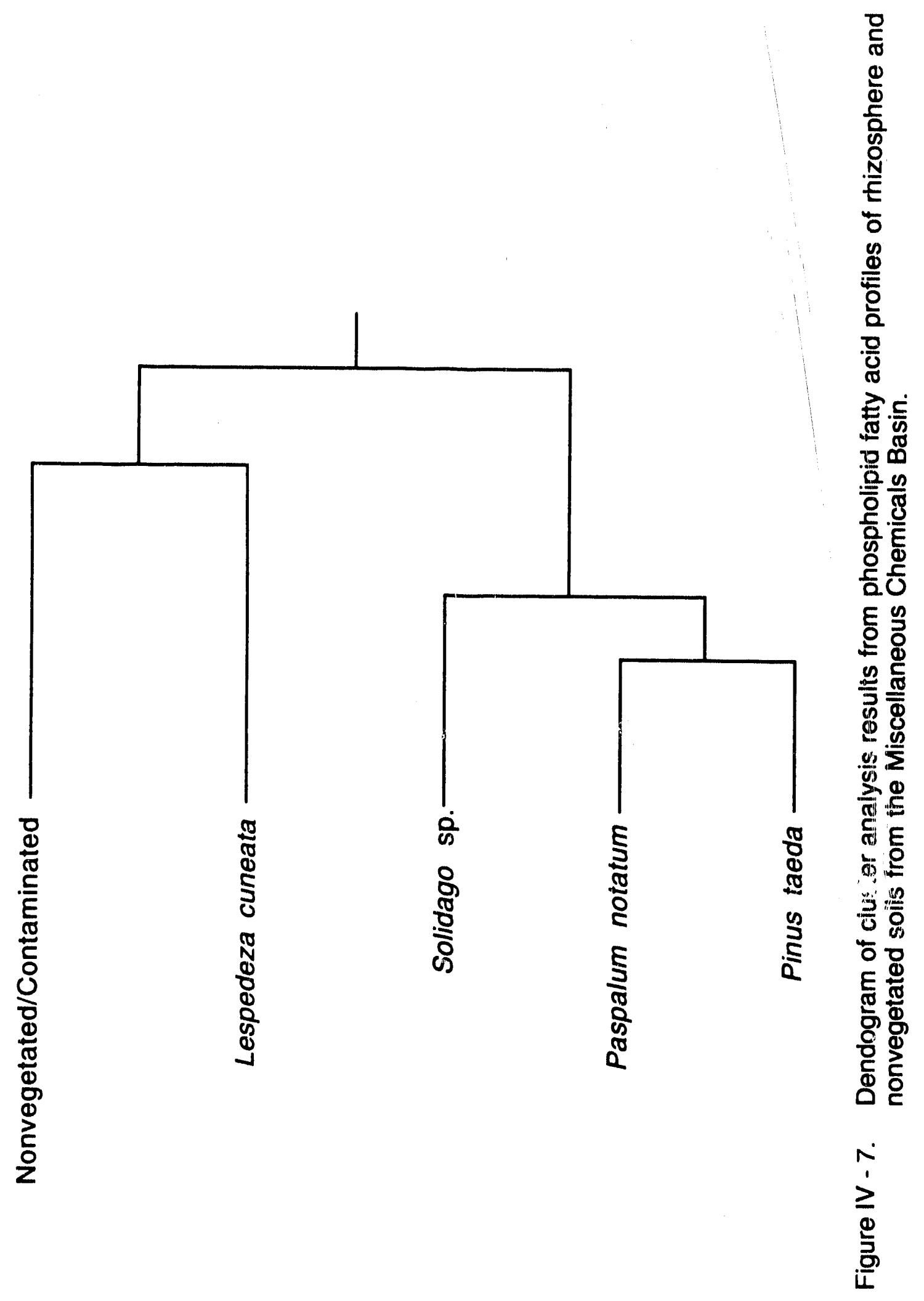


clustering which separates $P$. notatum and $P$. taeda from Solidago sp. was explained by the greater presence of 10Me16:0 and 10Me18:0 in samples of $P$. taeda and $P$. notatum rhizosphere soil. These fatty acids (10Me16:0 and 10Me18:0) are characteristic of Actinomycetes (Vestall and White, 1989).

The microbial metbolic activity of soil samples from the MCB was determined by measuring the incorporation of ${ }^{14} \mathrm{C}$-acetate into cellular lipids. In initial studies, the rate of ${ }^{14} \mathrm{C}$-acetate incorporation into cellular lipids (pMoles/g soil/h) was determined for the four rhizosphere soils and the nonvegetated soil (Figure IV - 8). The metabolic activity of the four mizosphere samples, as determined by ${ }^{14} \mathrm{C}$-acetate incorporation rate, was significantly greater $(p \leq$ $0.05)$ than metabolic activity in the nonvegetated soil $(1407 \pm 10,905 \pm 35,599$ $\pm 33,1727 \pm 180 \mathrm{pMoles} / \mathrm{g}$ soil/h for L. cuneata, $P$. taeda, $P$. notatum, and Solidago sp., respectively vs. $445 \pm 86 \mathrm{pMoles} / \mathrm{g}$ soil/h for the nonvegetated soil). In addition, ${ }^{14} \mathrm{C}$-acetate incorporation rates among thie four mizosphere samples were significantly different $(p \leq 0.05)$ from each other, with Solidago sp. rhizosphere soil having the highest rate. The results indicating greater metabolic activity among the rhizosphere samples is consistent with the biomass estimates reported earlier and also consistent with what traditionally has been observed in thizosphere samples.

In addition to monitoring acetate incorporation into total microbial lipids, the incorporation of ${ }^{14} \mathrm{C}$-acetate into the three lipid classes (neutral lipids, glycolipids, and phospholipids) was also determined for rhizosphere and norvegetated soils from the MCB (Figures IV - 9 through IV - 13). Soil from nonvegetated areas within the MCB incorporated ${ }^{14} \mathrm{C}$-acetate predominantly 


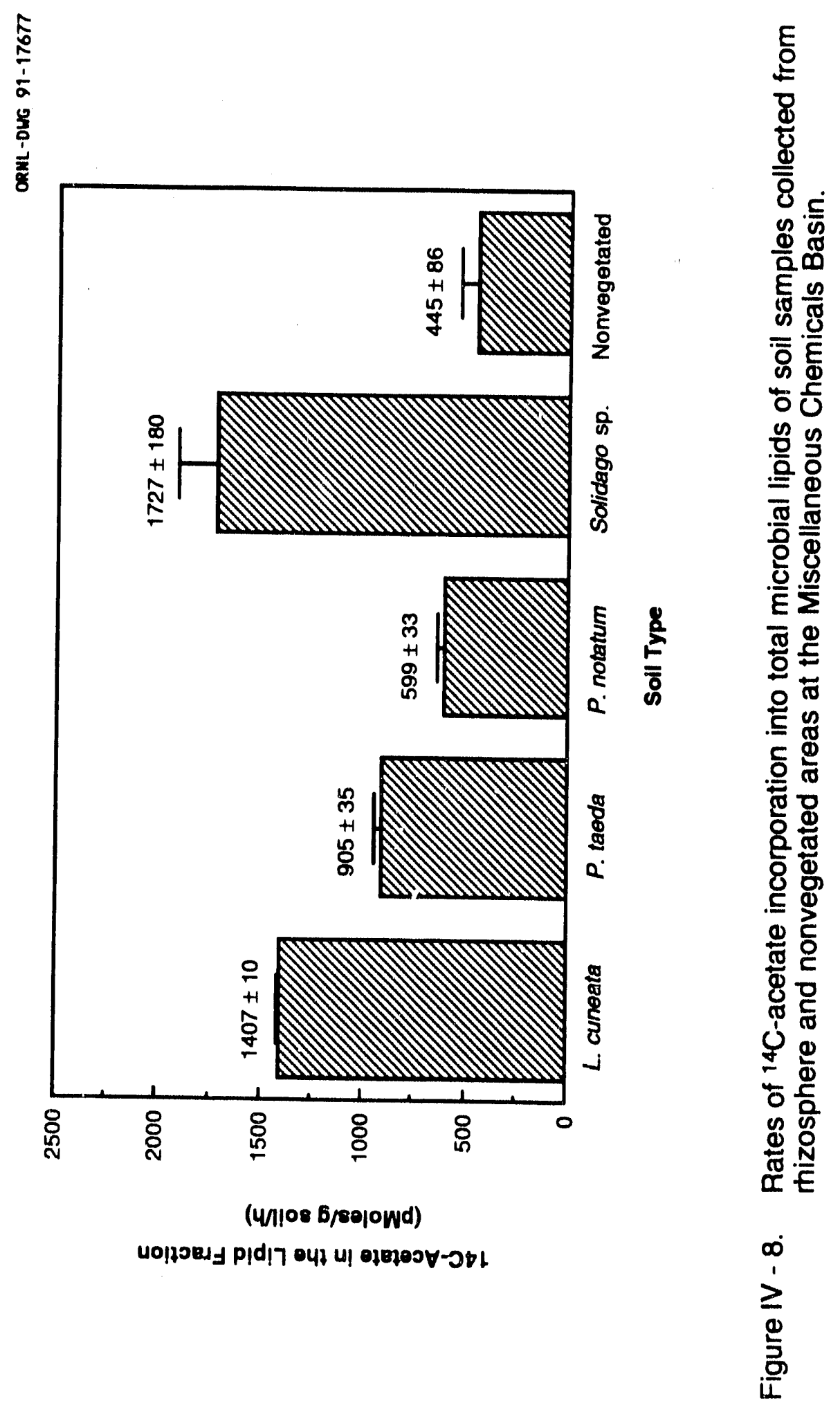




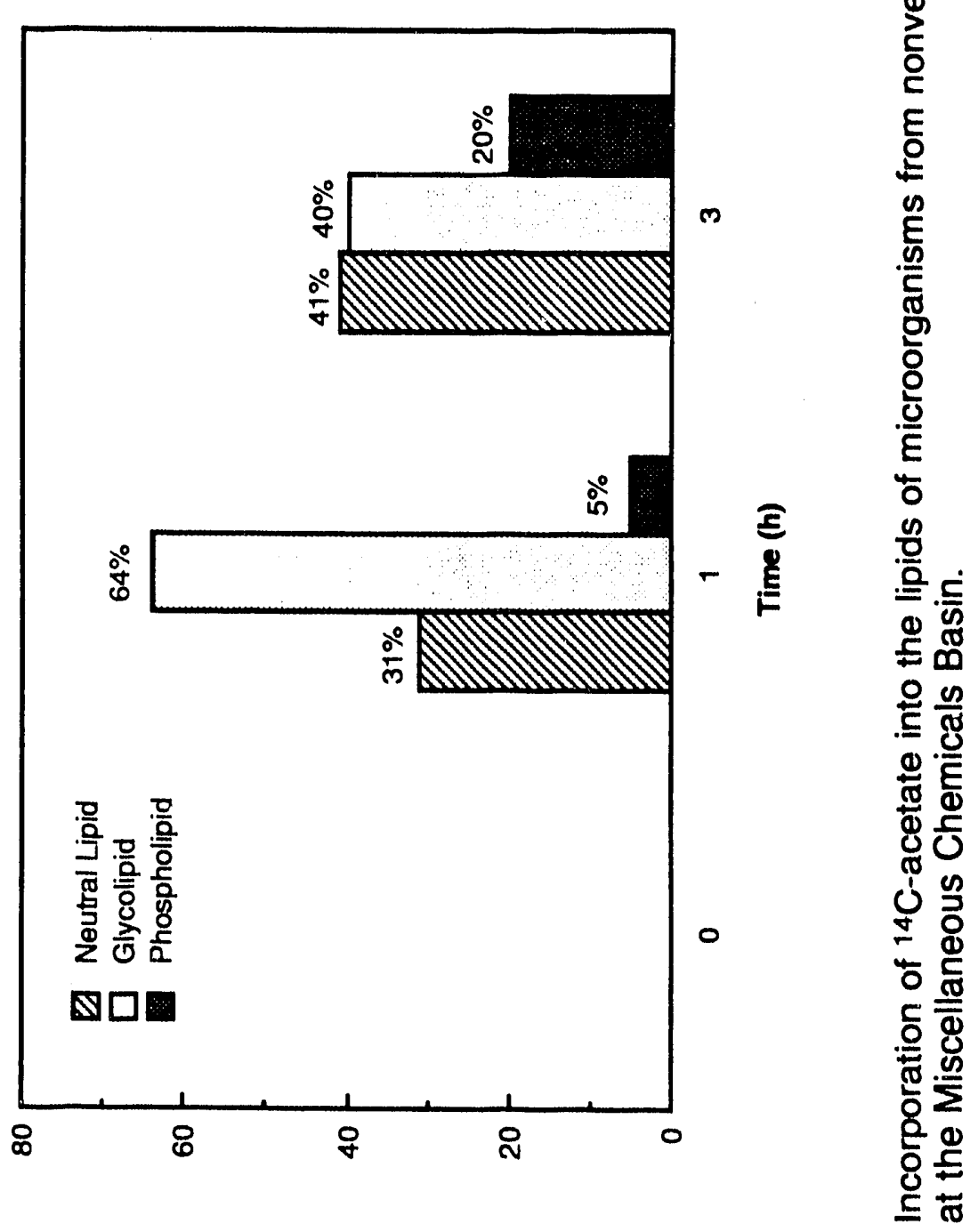

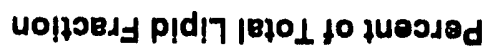

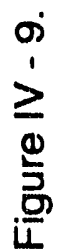


$\frac{8}{0}$
$\frac{1}{\alpha}$
$\frac{0}{0}$
$\frac{1}{1}$
$\frac{1}{2}$
8

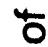

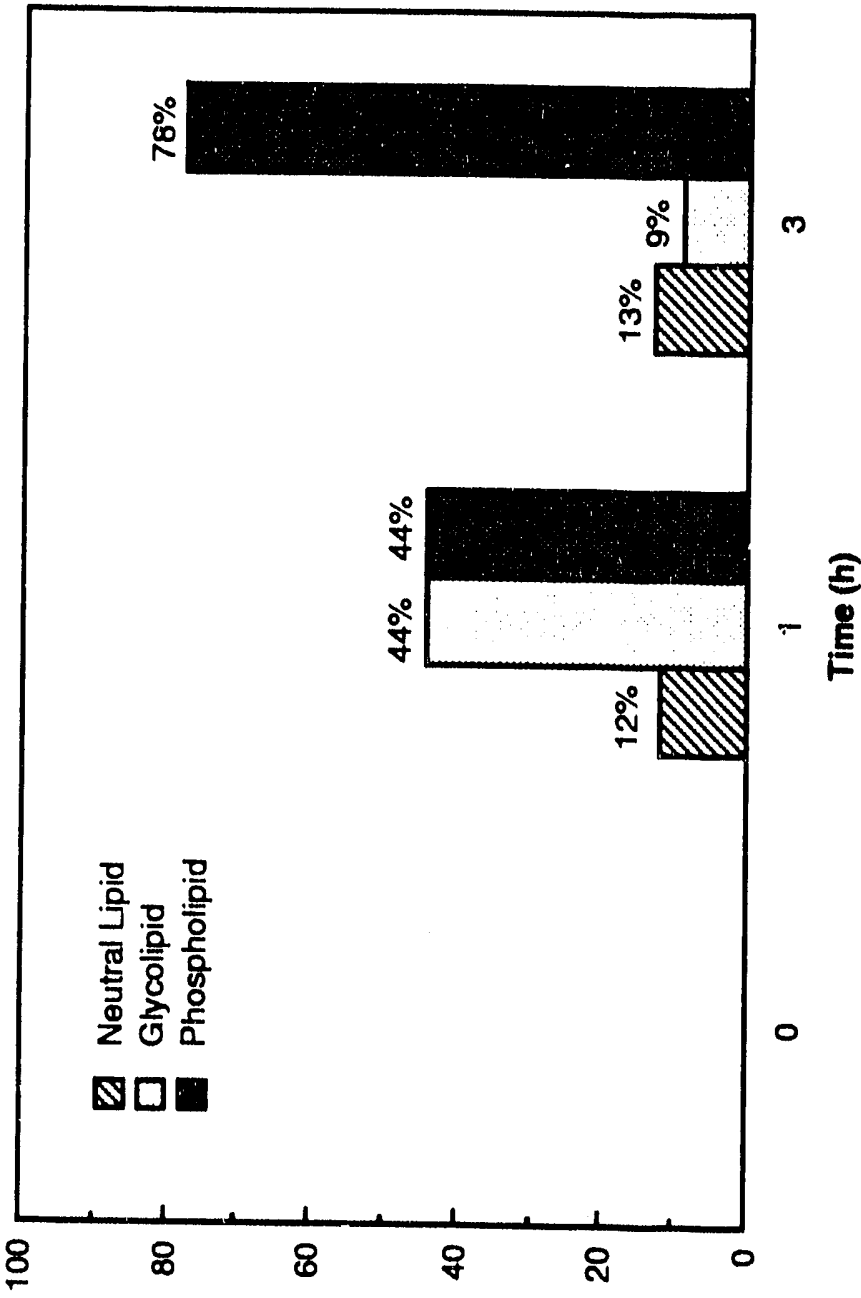

ڤั)

而邱

$\stackrel{\infty}{\infty}$

ह $\frac{\text { c }}{\mathbb{D}}$

을

ต

. $\frac{1}{0}$

똥

항

을

$E$

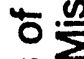

\& 0

드늘

ब市

\%

을 웜

竞

ষे

郘

守焉

요

더

ํㅠㄴ

ㅇํㅇ

\&

ठํ के

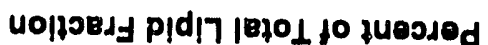

은 


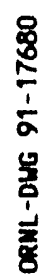

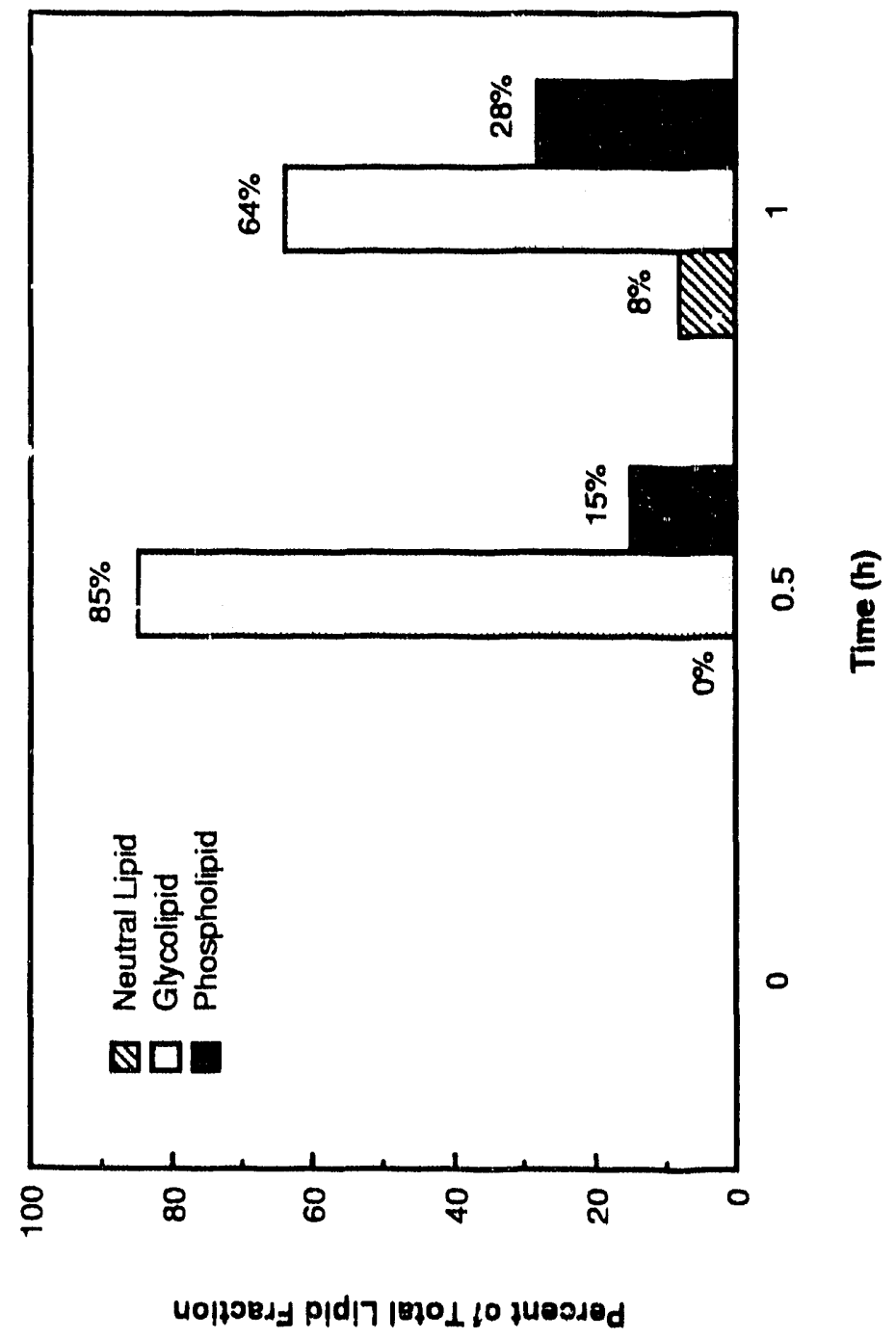

ธ

这

$E$.

क

톤 $\frac{\infty}{\mathbb{8}}$

을

है $\frac{E}{\Phi}$

등

목

88

을 음 58

○

용

을오

元

용

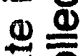

응

음

乌ీ

S

닌

동

는

음

등 웅

증

$\frac{1}{2}$ 
$\overline{8}$
$\frac{8}{1}$
$\frac{1}{2}$
$\frac{9}{0}$
$\frac{1}{80}$

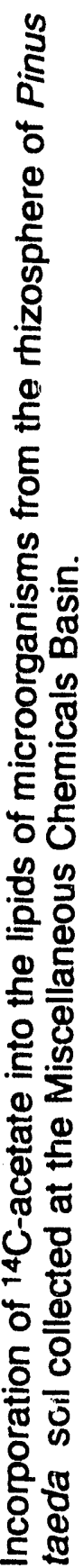

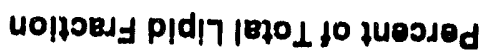

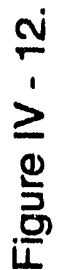


$\frac{8}{8}$
$\frac{1}{\alpha}$
$\frac{1}{0}$
$\frac{1}{0}$
$\frac{1}{8}$

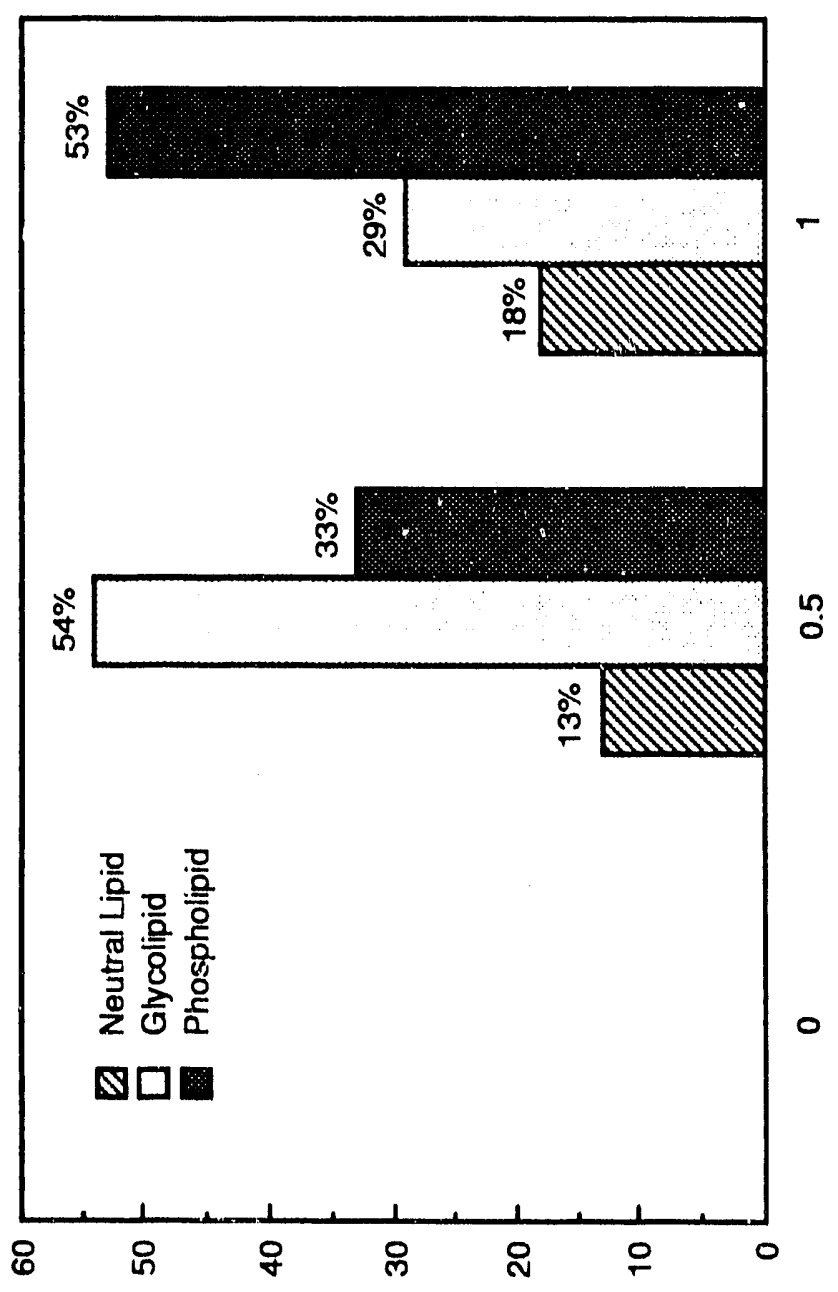

$\stackrel{\infty}{\rightleftarrows}$

돈 co

है

동.을

잉

हू.

es $\frac{1}{80}$

菓

응

禹

율

๘

๘

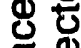

它

엉

“등

든 过

징

을

응

巨ஸ

Uo!fordy p!d!

$\frac{\stackrel{2}{2}}{\geq}$ 
into neutral and glycolipids (storage lipids) during the first three hours of incubation possibly indicating unbalanced growth of the microbial community in this soil. Only about $20 \%$ of the radioactivity was found in the phospholipid (membranes) fraction after 3 hours (Figure IV - 9). In contrast, solls from $L$. cuneata (Figure IV - 10), P. taeda (Figure IV - 12), and Solidago sp. (Figure IV 13) incorporated the acetate into membrane lipids (phospholipids). Radioactivity in the phospholipid fraction for P. taeda and Solidago sp. rhizosphere soll was greater than $50 \%$ of the total radioactivity in all lipid fractions after 1 hour and greater than $80 \%$ for L. cuneata rhizosphere soil after 3 hours. Soils collected from $P$. notatum rhizosphere soll incorporated most of the ${ }^{14} \mathrm{C}$-acetate into the glycolipid fraction after 1 hour (Figure IV - 11), similar to the results of the nonvegetated soil.

Production of the endogenous storage lipids, polybetahydroxyalkanoates (PHAs) was also used as an indicator of the nutritional status of rhizosphere and nonvegetated soils from the MCB. Mass spectroscopy revealed that almost all of the constituent beta-hydroxy acids from the PHAs was betahydroxybutyrate (PHB) although very small amounts of betahydroxy hexanoate were also detected. All samples tested contained significant amounts of PHA, however, PHA levels varied among sample types (Table IV 7). Consistently greater amounts of PHA were detected in rhizosphere soils compared with the nonvegetated soils, although the amounts were significantly greater $(p \leq 0.05)$ only for soils from Paspalum notatum rhizosphere. The ratios of phospholipid fatty acid (PLFA) to PHA were also determined for the 


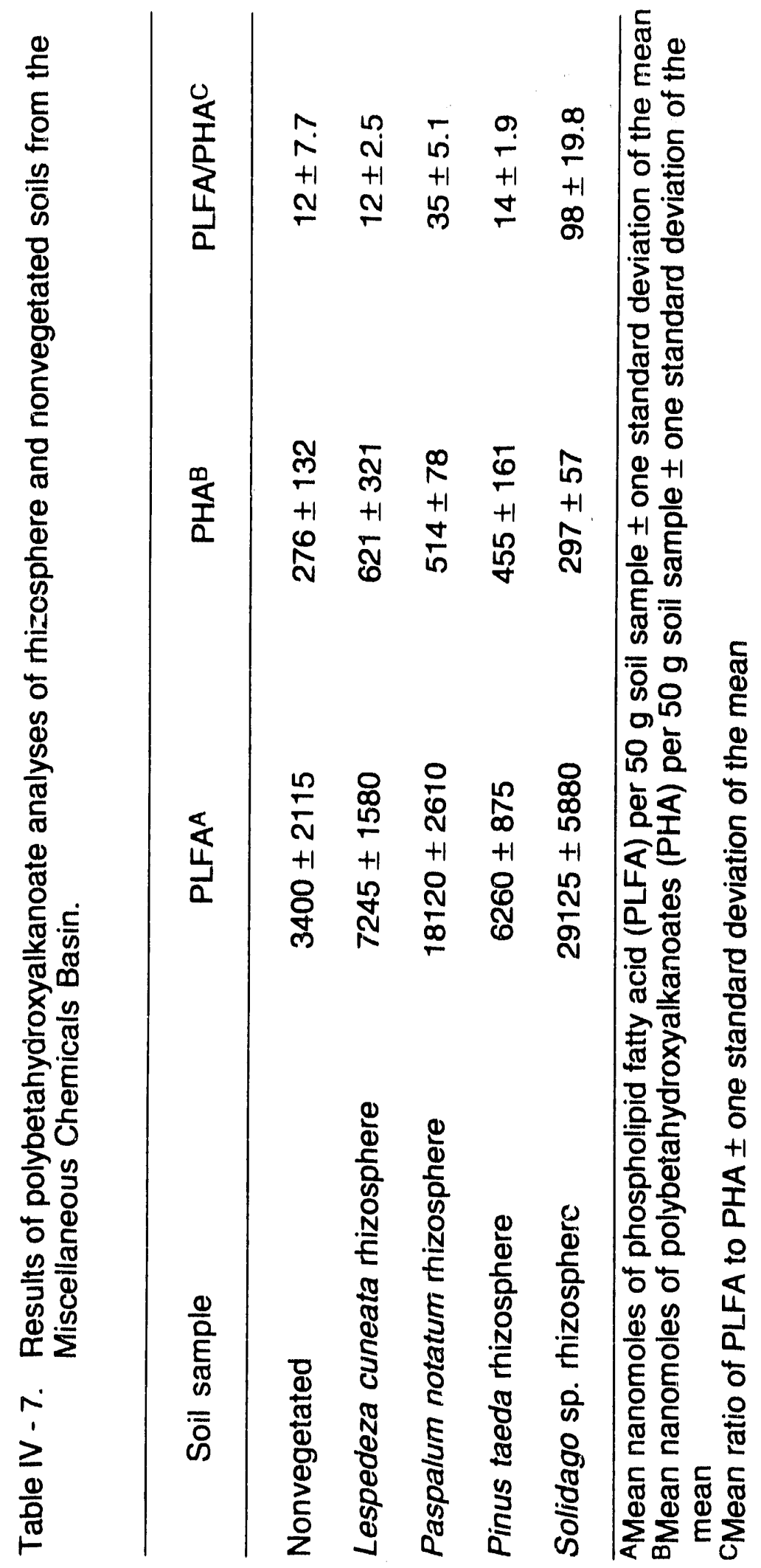


rhizosphere and nonvegetated soils as an indicator of the relative amounts of these membrane (PLFA) and storage (PHA) lipid components (Table IV - 7).

C. Toxicity of TCE and PCE to Soil Microorganisms

The influence of TCE on $\mathrm{CO}_{2}$ efflux (used as an indicatur of toxicity) in soil samples collected from the MCB varied with TCE concentration and sample type (Figures IV - 14 through IV - 18). Only the Solidago sp. rhizosphere soil showed a statistically significant decrease ( $p \leq 0.05$ at $1000 \mu \mathrm{g} / \mathrm{g}$ TCE) in $\mathrm{CO}_{2}$ efflux (Figure IV - 18) although P. notatum mizosphere soil (Figure IV - 16), and the nonvegetated soil (Figure IV - 14) also showed decreased respiration at $1000 \mu \mathrm{g} / \mathrm{g} \mathrm{TCE}$, and $500 \mu \mathrm{g} / \mathrm{g}$ and $1000 \mu \mathrm{g} / \mathrm{g}$ TCE, respectively. Respiration in L. cuneata (Figure IV - 15) or P. taeda (Figure IV - 17) rhizosphere soils was not affected by TCE at the two concentrations tested.

Toxicity to soil samples from the MCB was also determined for tetrachloroethylene (PCE) (Figures IV - 19 through IV - 24). Soil gas concentrations of PCE at the MCB are higher than all of the other chlorinated solvents and it was hypothesized that PCE may be inhibiting TCE degradation because of its toxicity. Nonvegetated soil samples collected from an area within the MCB shown in earlier soil gas analyses to be uncontaminated showed a significant decrease $(p \leq 0.05)$ in $\mathrm{CO}_{2}$ efflux at PCE concentrations of 500 and $1000 \mu \mathrm{g} / \mathrm{g}$ (Figure IV - 19) while nonvegetated soils collected from contaminated areas showed no statistically significant effect (Figure IV - 20). Tetrachloroethylene concentrations of $500 \mu \mathrm{g} / \mathrm{g}$ and $1000 \mu \mathrm{g} / \mathrm{g}$ had a stimulatory effect on $\mathrm{CO}_{2}$ efflux from L. cuneata (Figure IV - 21) and Solidago 
M
$\frac{8}{2}$
$\frac{1}{a}$
0
$\frac{1}{0}$
$\frac{1}{z}$
$\frac{8}{8}$

为至

宁 $\frac{1}{0}$

过

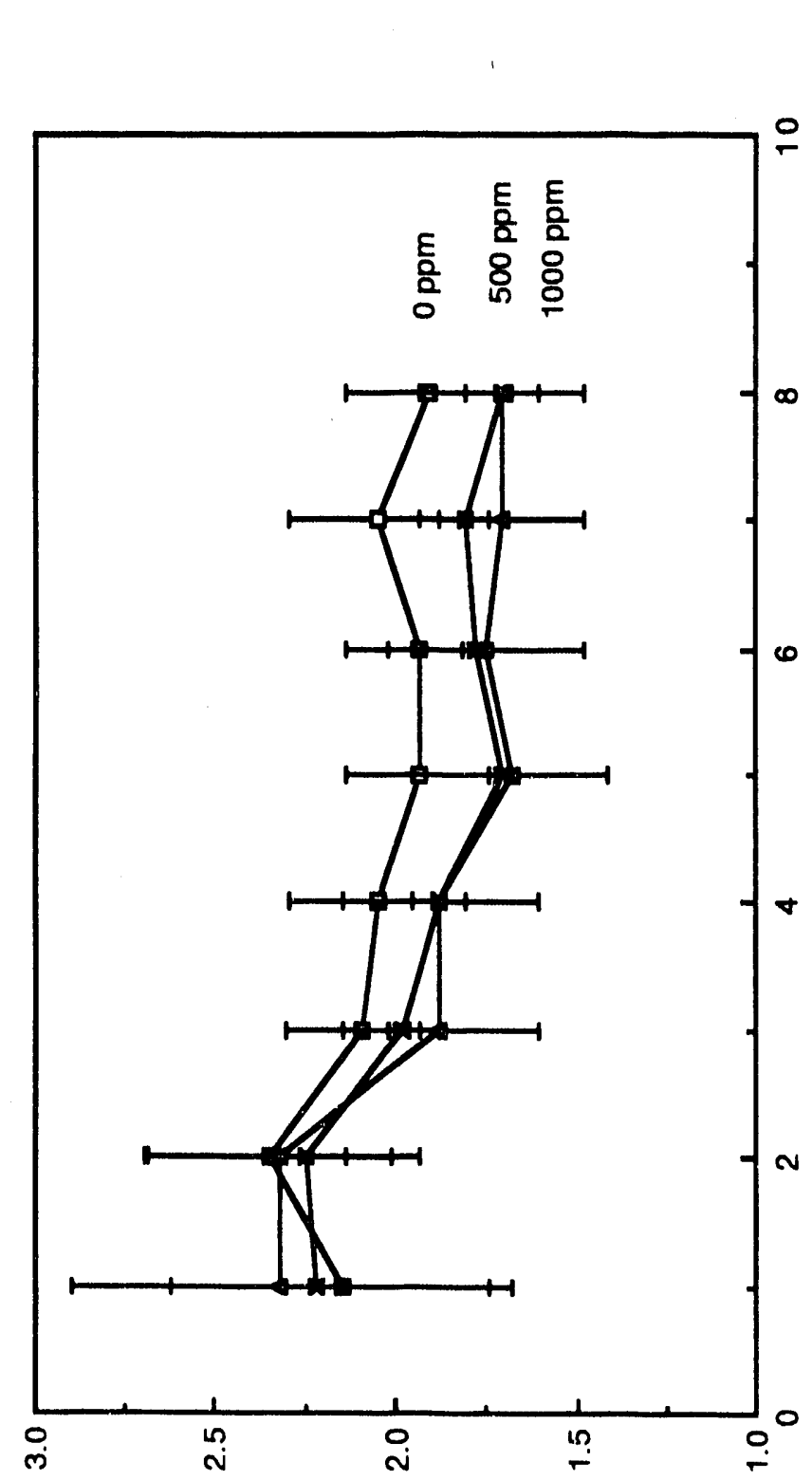

요옹

ఏ ․ㅗㅇ

E

은 은

응 중

헌든

흐웜ㅇ

으을 흥

웅

뜨응

토옹

둥

등을 용

은

官

옹는

ذ๐

$\Phi=$

도을

응웡

E

은 은

종흔

本

0.5

을 है

음 욤

도ㅇㅡㅡㄹ 으

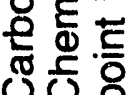

\%

$(4 / 1086 / 6 \pi) 200$

\pm
$\geq$
$\frac{1}{2}$
$\frac{0}{2}$ 


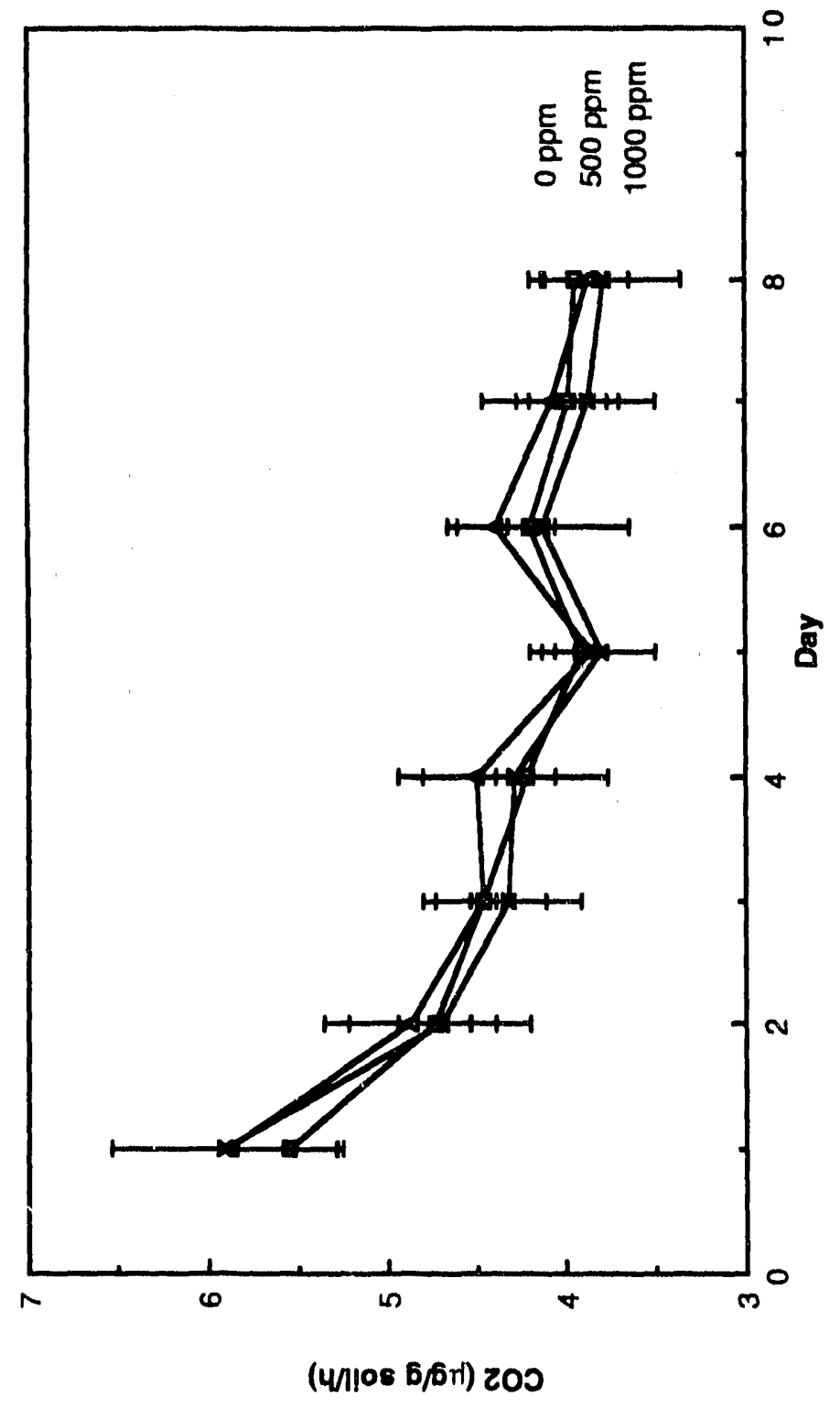

틍 은은

하넨

흥

88

응

은 응

क 인

흥용

유은

동은

을 在

II

ऽ

ठ

$\mathbb{N}=$

응

屯 흥

कू. 동 등

赵

E용

은융ㄷㅇㅇ

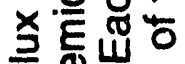

需起 은

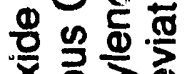

응ㅎㅀ

등 웡

额产递要

官 
盟
$\frac{1}{5}$
$\frac{1}{0}$
$\frac{1}{0}$
$\frac{1}{8}$
$\frac{8}{8}$

@

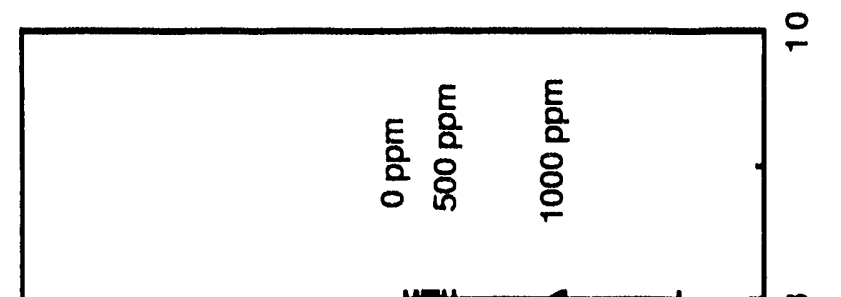

Eิํㅇ용

은

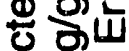

응용

응

的흠

๑ $\frac{5}{\sigma} \Phi$

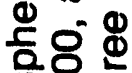

की

NO

E雪

క

密

웡

돈든.

2

की

엉어

Eڤ유

은 $\frac{0}{8}=$

틍

牙㝴

乌

응

은 훙

ᄃ응 응

인 에응 응

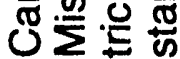

$\frac{0}{1}$
$\geq$
$\frac{0}{3}$
욘 
8
$\frac{8}{6}$
$\frac{1}{2}$
5
$\frac{5}{0}$
$\frac{1}{8}$
8

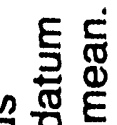

옹

\&

๘ั

Ф

之 $\frac{\omega}{2}$

象

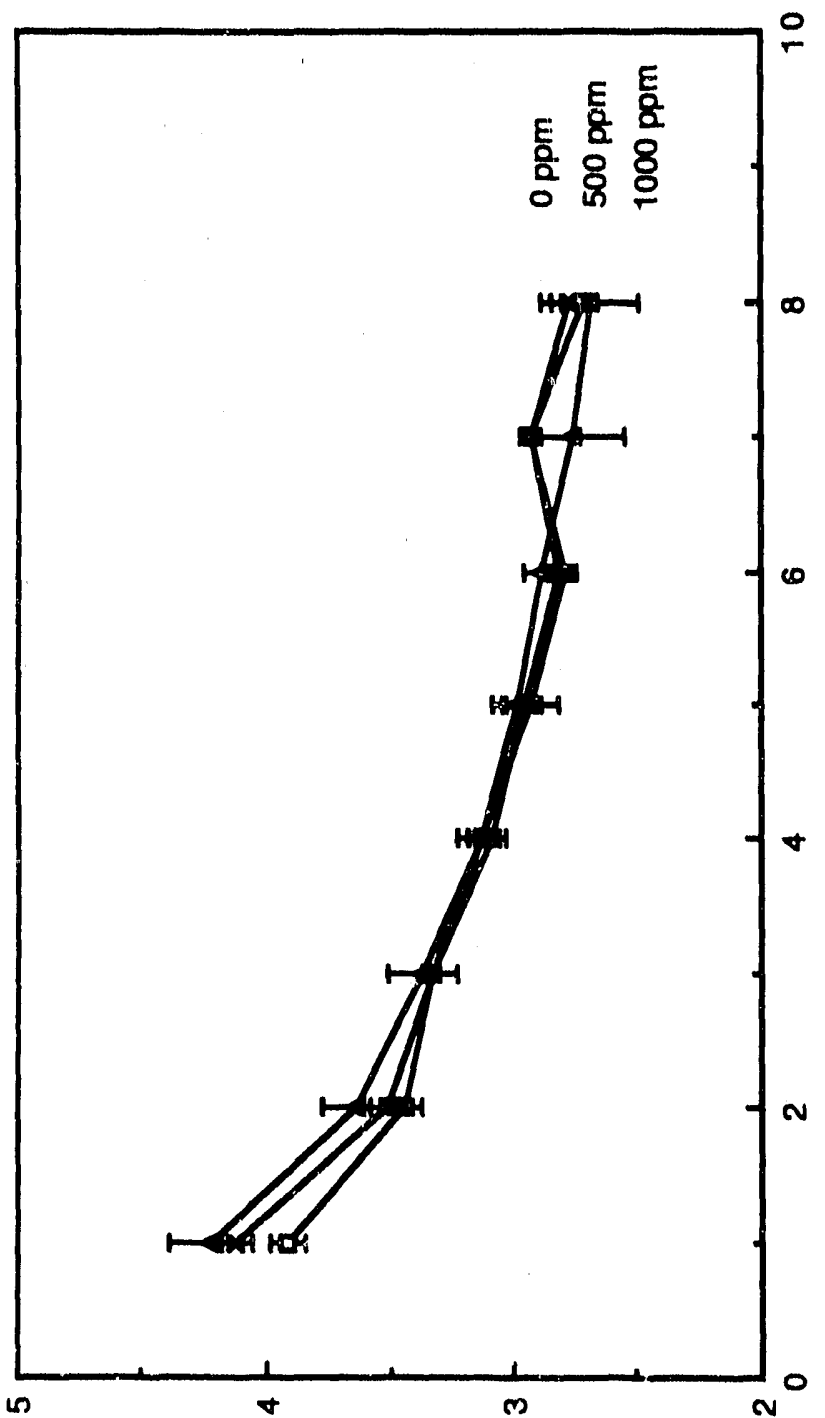

통응 융

능 등

छृ

흥흥명

ธ워

엉

항혀

둥ㅇㅇ

웅

충

웅문

$\frac{7}{8}$

ฮั

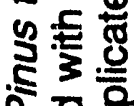

영

등

는

공뭉

드드

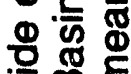

×

음 옹

둥.

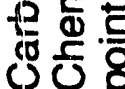

: 


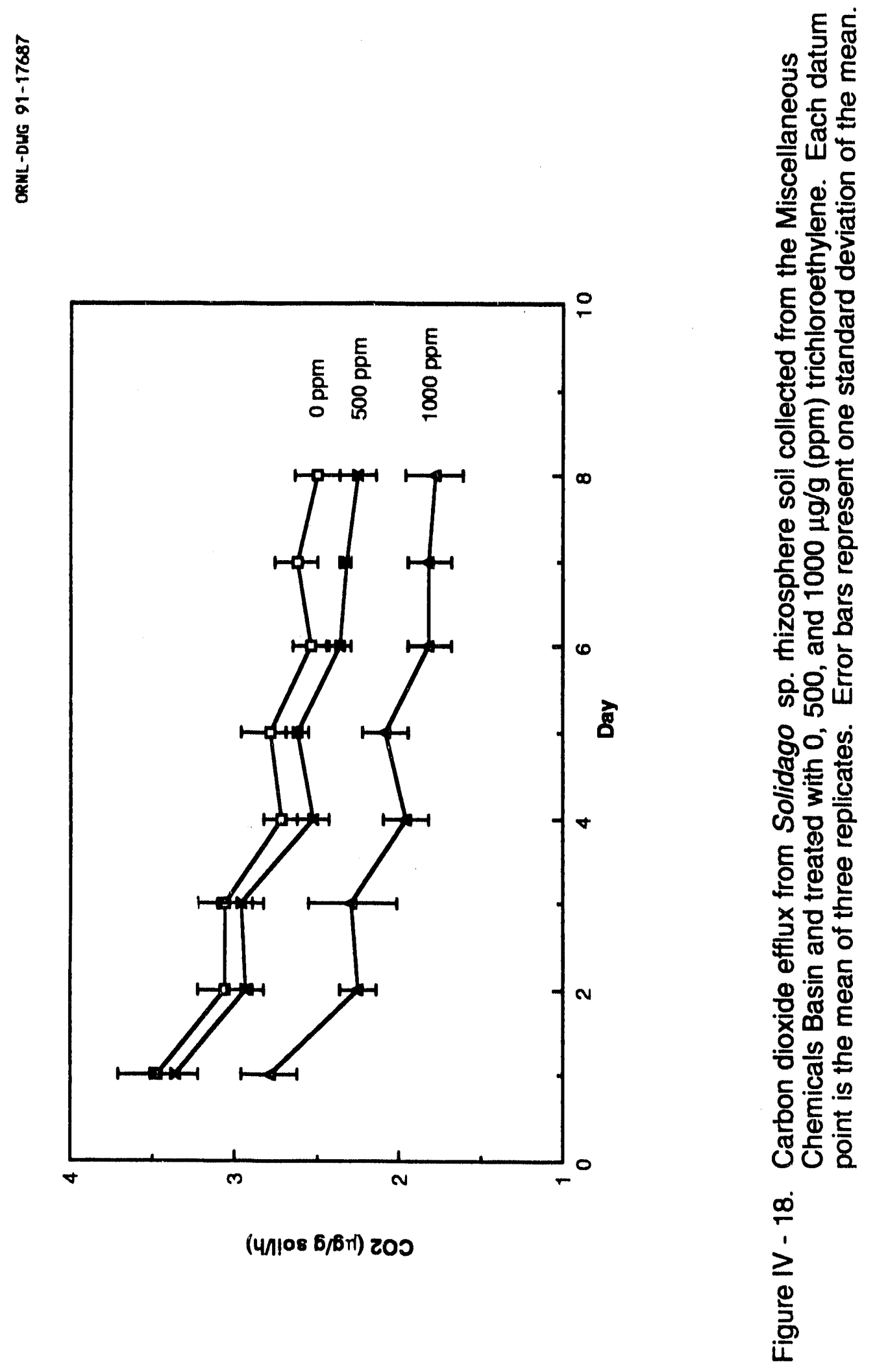


8
$\frac{8}{2}$
$\frac{1}{2}$
5
$\frac{1}{0}$
$\frac{1}{8}$
8
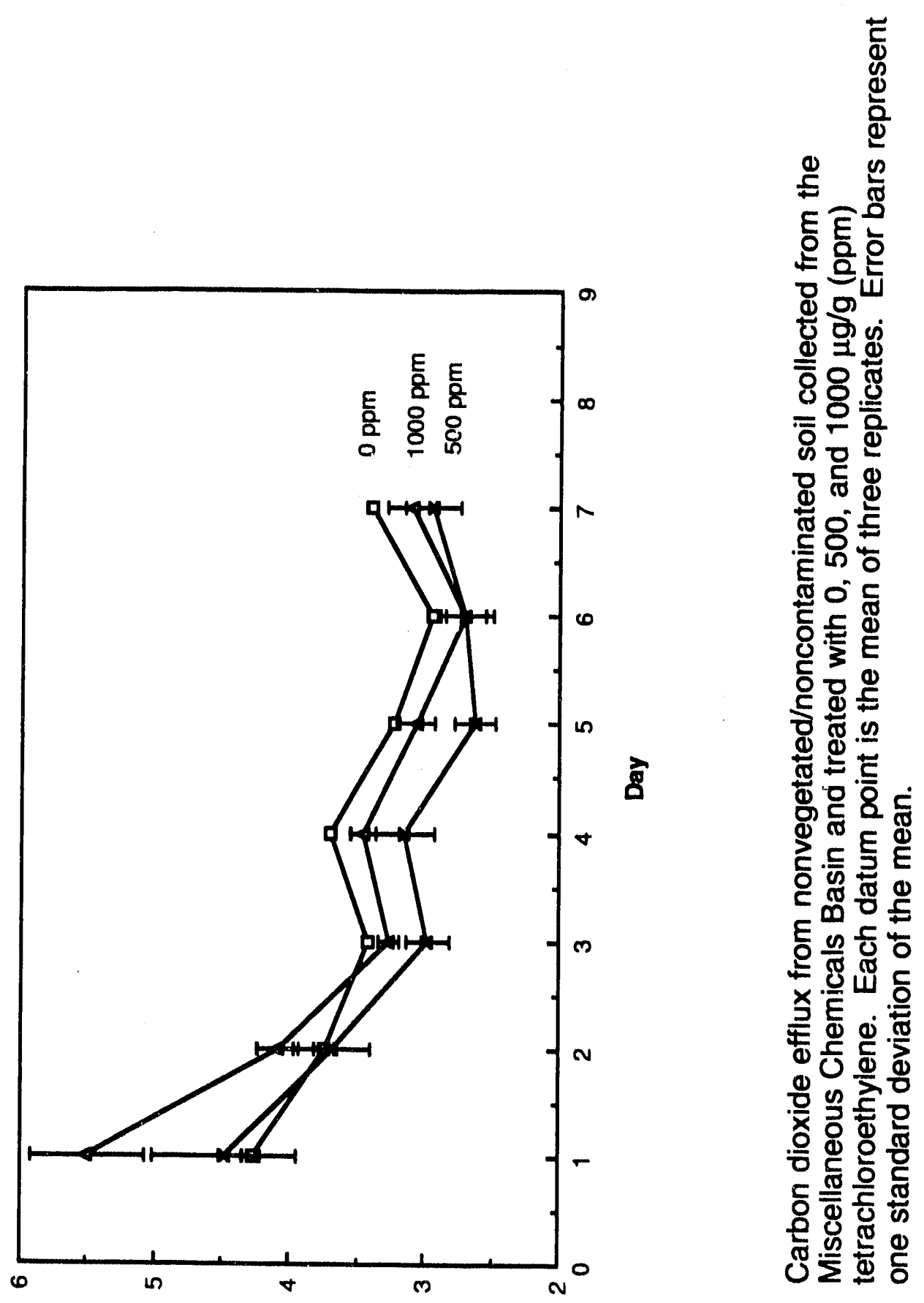

(4/108 6/6rl) zO०

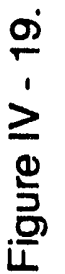




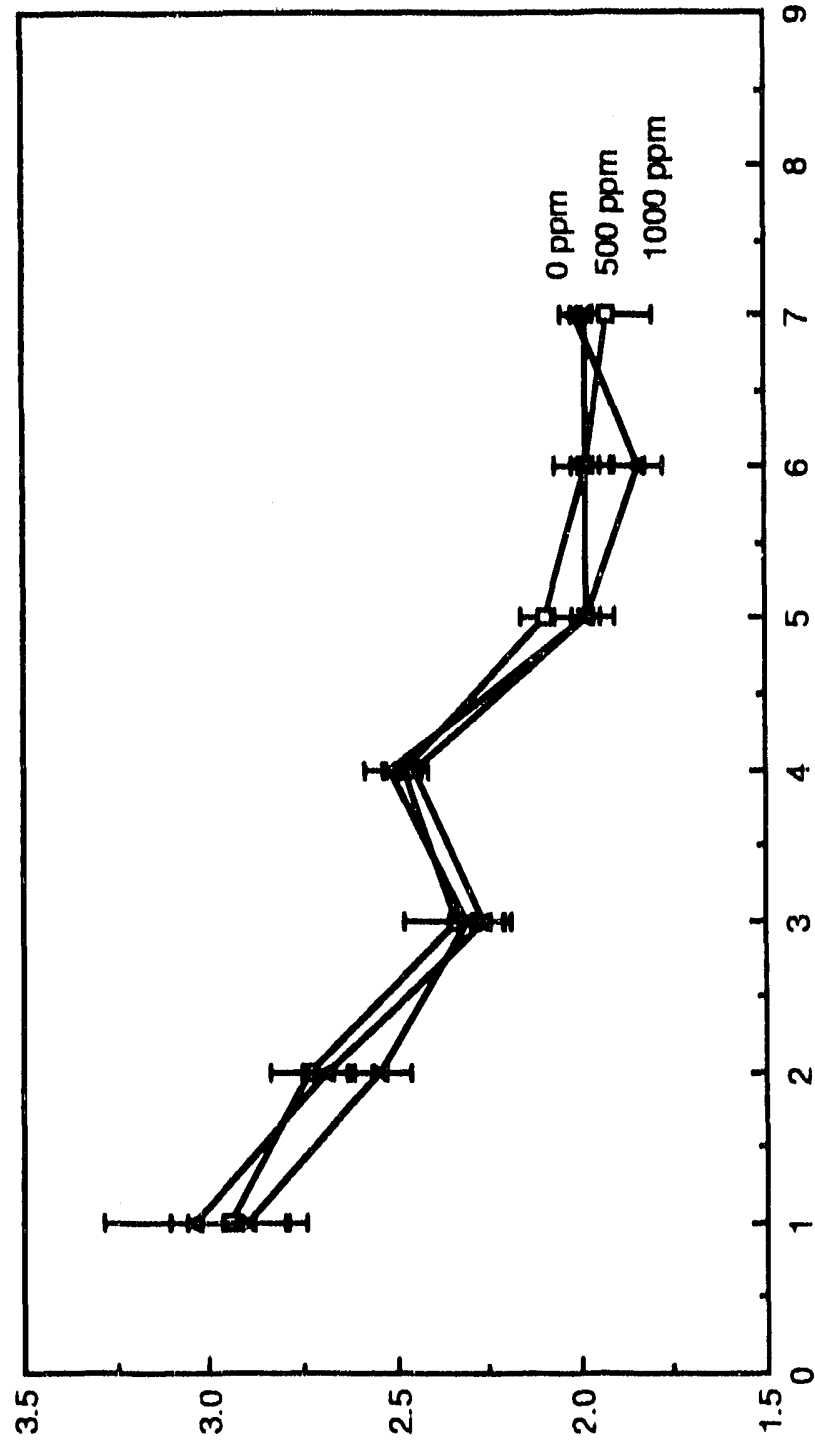

$(4 / 108$ 6/6r $) 200$

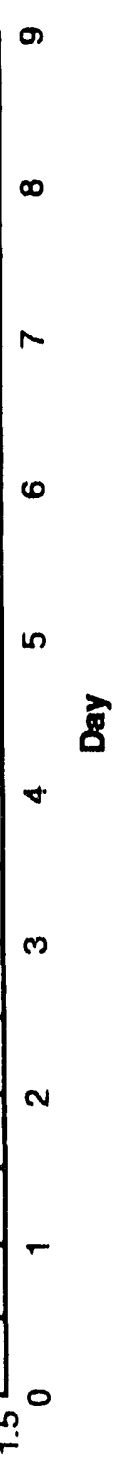

E

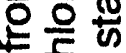

웡

छั屯

으웛

흐응 응

क व

었 임

잉

동은

진대

당 당

ఫัه

車烦.

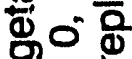

\&

동

은온

E空

은

즐 을

(1)

( )

용.

ชั㐅ิ

음 능

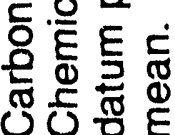

ฉ

$\frac{1}{\geq}$ 


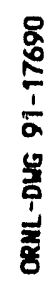

(2)

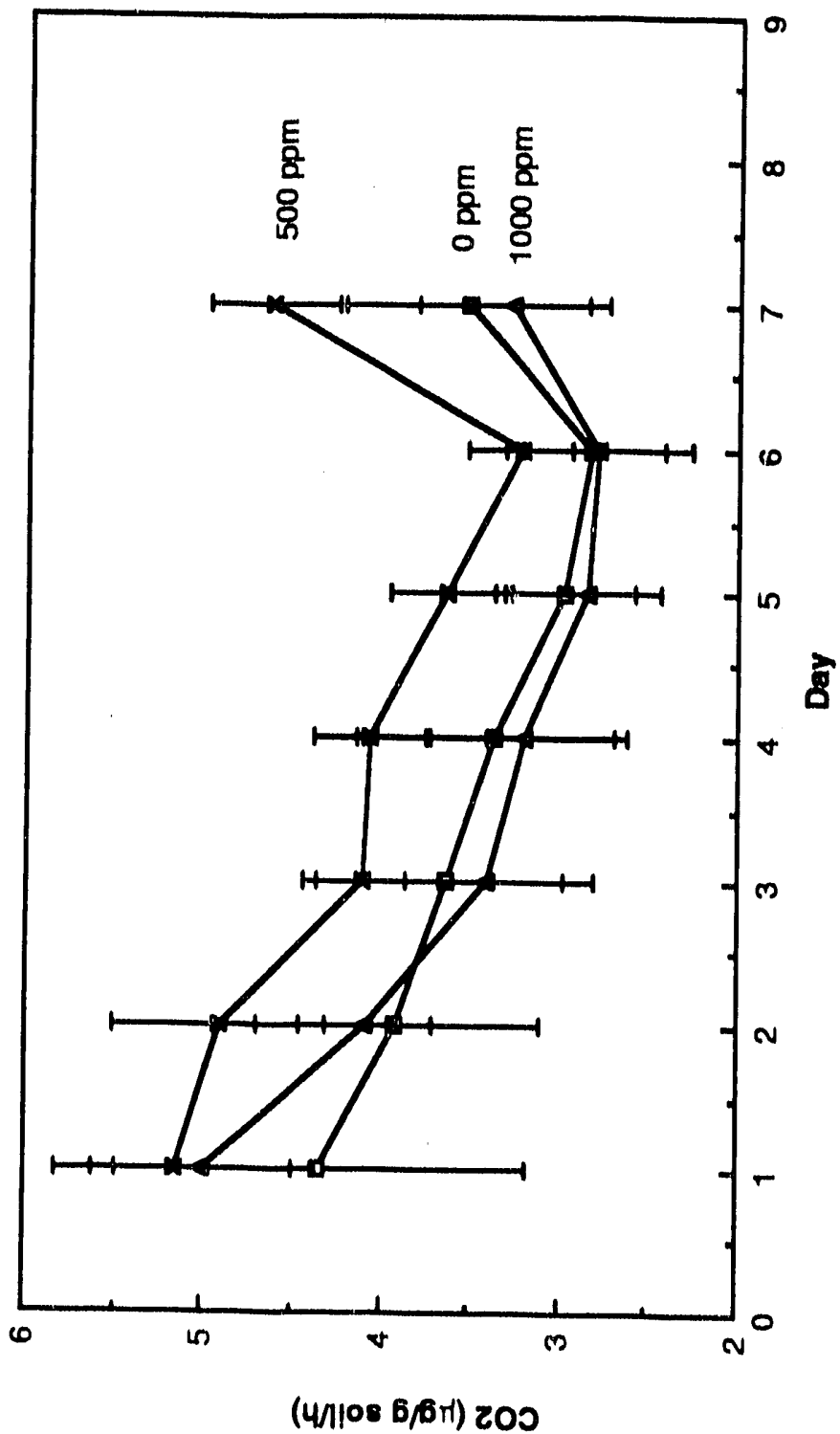

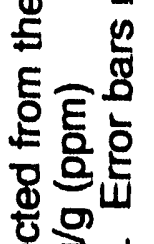

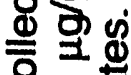

80

행으믐

인

๘

용ㅎ

0

응

ख

\%

$5 \mathrm{~d}$

$0 . \underline{0}$

ช

웡응

ब

के. 돌

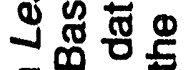

동은

肴然要

需

े ब

은 웅

음 웅

등흔

융

需总总

ำ 


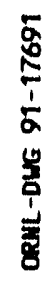
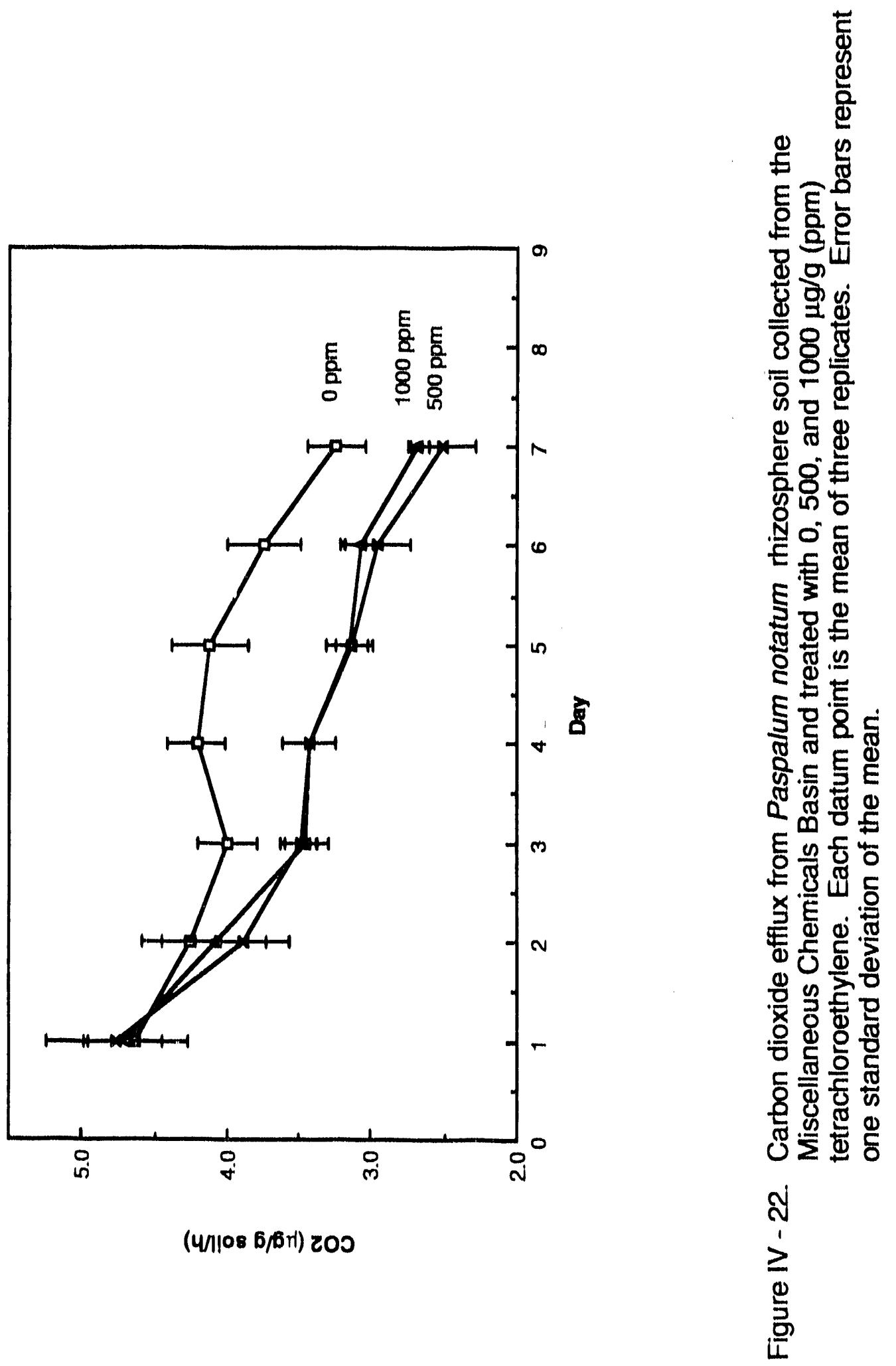


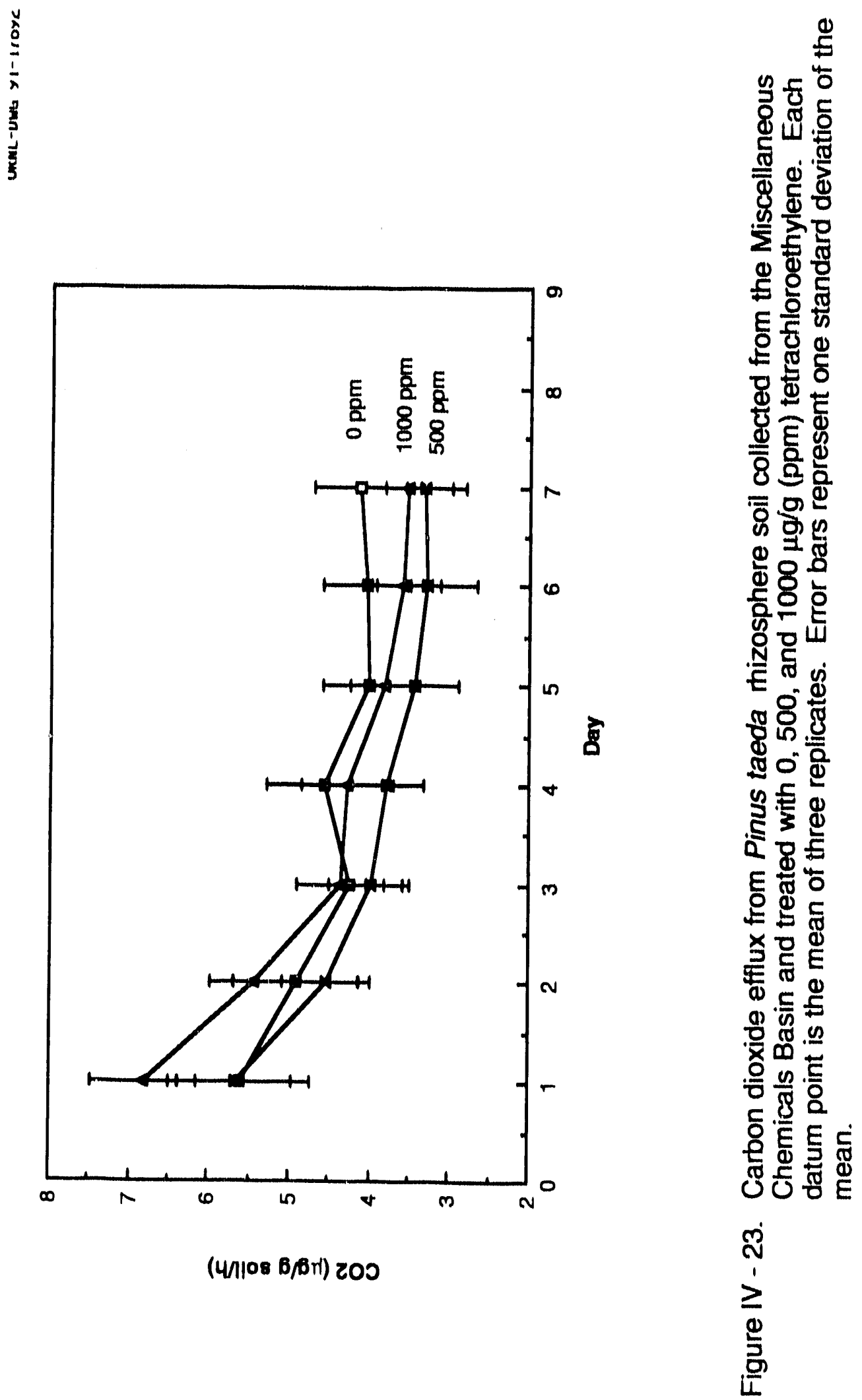


草

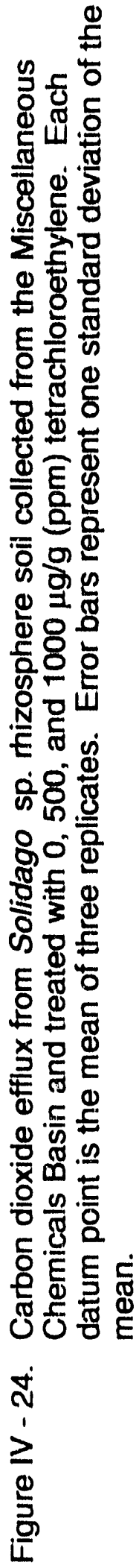


sp. (Figure IV - 24) rhizosphere soils, respectively. Although PCE concentrations of 500 and $1000 \mu \mathrm{g} / \mathrm{g}$ caused a decrease in $\mathrm{CO}_{2}$ efflux from $P$. notatum (Figure IV - 22) and P. taeda (Figure IV - 23) rhizosphere soils, only the decrease observed in P. notatum rhizosphere soil was statistically significant $(p \leq 0.05)$. The toxic effect of TCE and PCE to soil samples from the MCB were not similar as illustrated by results from Solidago $\mathrm{sp}$. Although respiration in Solidago sp. rhizosphere was significantly depressed by TCE at $1000 \mu \mathrm{g} / \mathrm{g}, \mathrm{PCE}$ at the same concentration had a stimulatory effect on $\mathrm{CO}_{2}$ efflux. The fact that high concentrations of TCE are toxic to microorganisms in soil samples from nonvegetated areas and Solidago sp. and Paspalum notatum rhizosphere could provide an explanation for the decreased degradative ability of these soils should such an observation be made. In addition, the lack of a toxic effect (or stimulatory effect) from TCE and/or PCE exposure could be used to help interpret results on TCE degradation in the laboratory as well as describing field situations where toxicity may affect degradation rates. Results from these toxicity experiments with TCE and PCE will be discussed further following the presentation of results on microbial degradation of ${ }^{14} \mathrm{C}$-TCE in soil plant systems.

\section{Degradation of TCE in Soil Slurries}

Analysis of the headspace above aqueous soil slurries spiked with TCE showed that the solvent was lost from the headspace of rhizosphere soils more quickly (Figures IV - 27 through IV - 30) than from nonvegetated soils (Figures IV - 25 and IV - 26) in all cases as evidenced by TCE concentrations on the last 


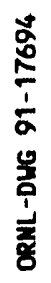

통

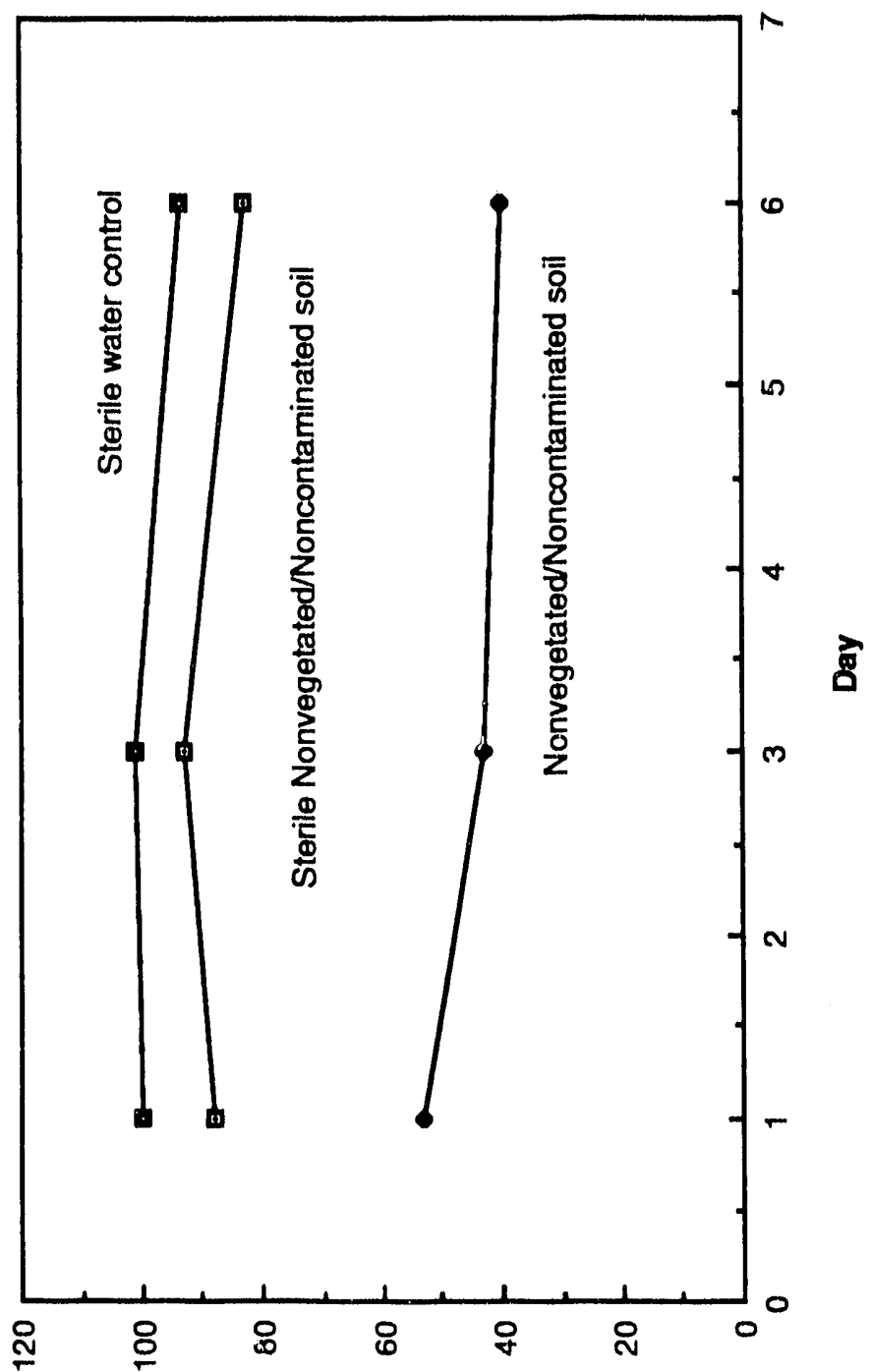

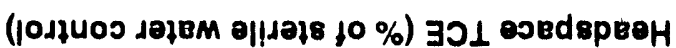

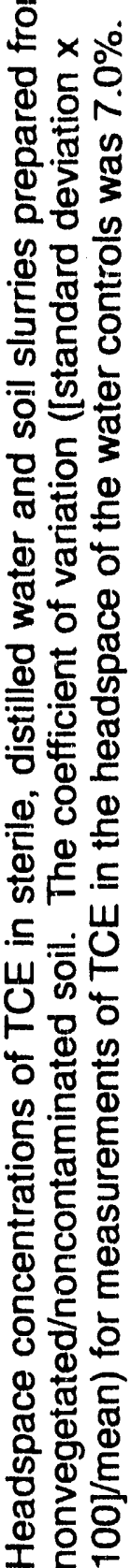

مُ 


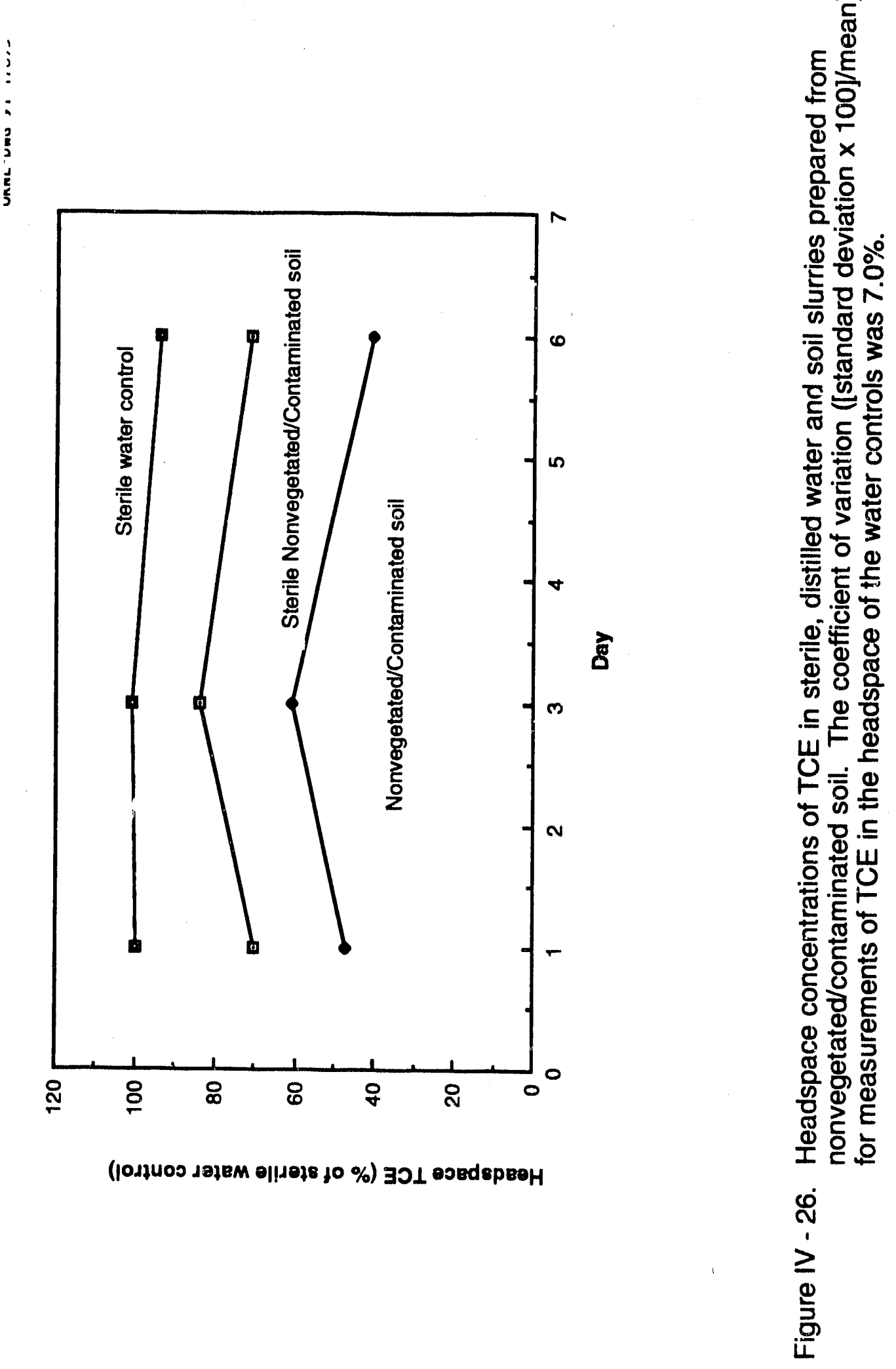



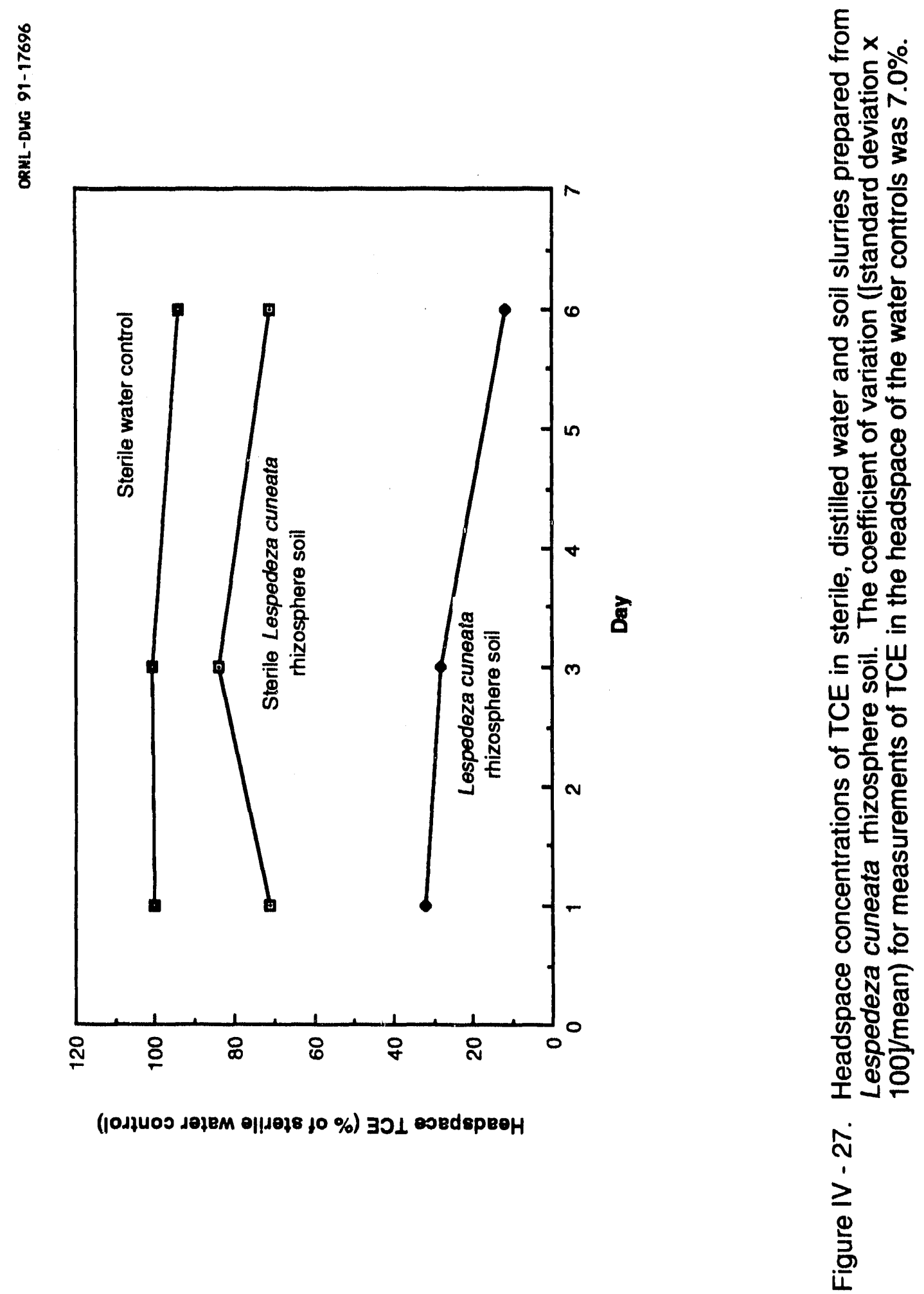


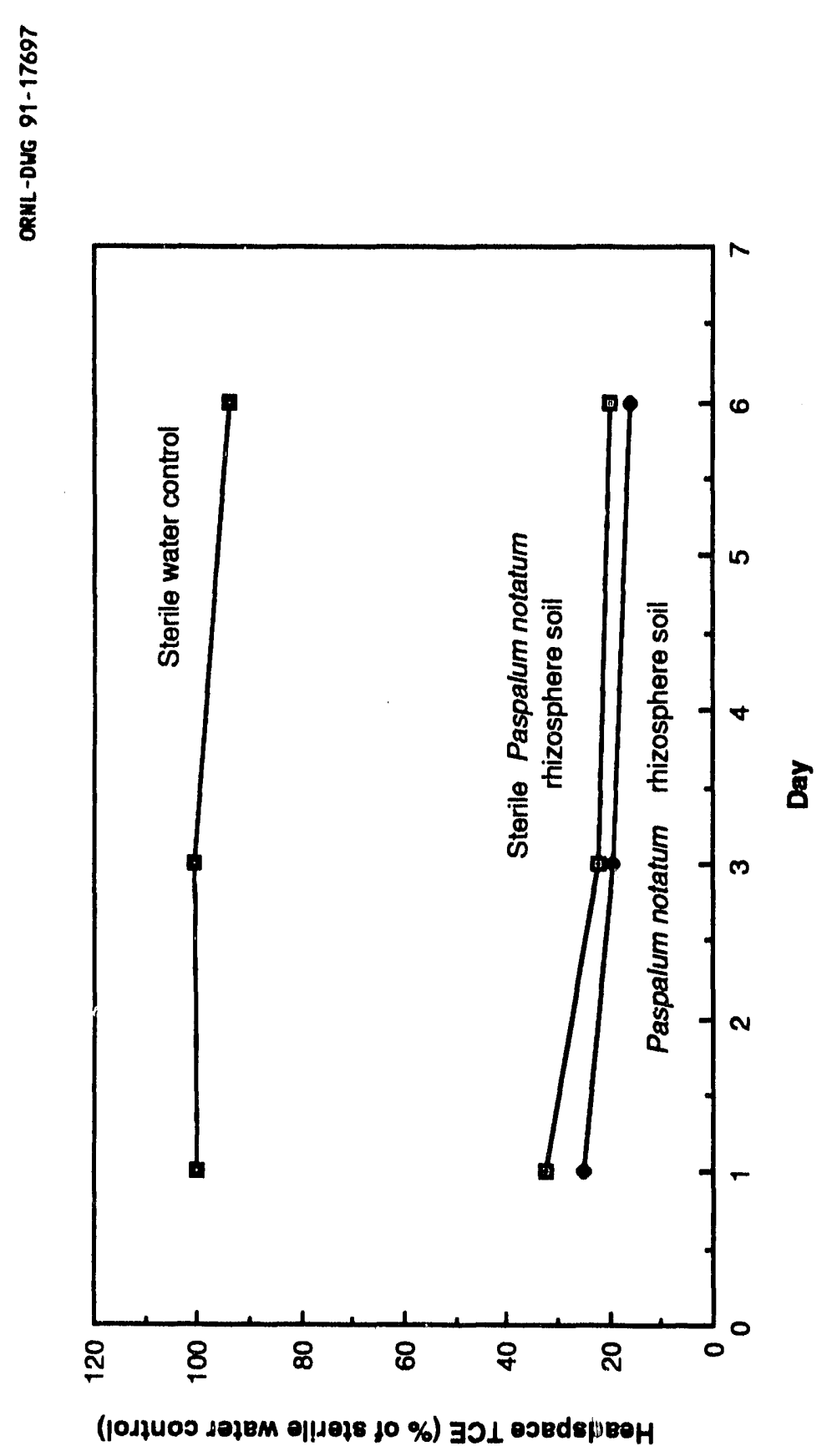

E

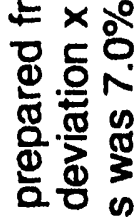

क 응

는 응 등

的

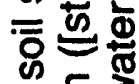

돈

ㅇ․ㄹ

可

는 8

엉둥

此 응

要

Ф

氖和

드

ш 행

00

ธ这

응

응오

준

통

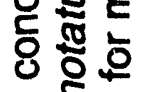

U드드

응

速

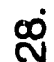

$\geq$

造 


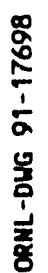

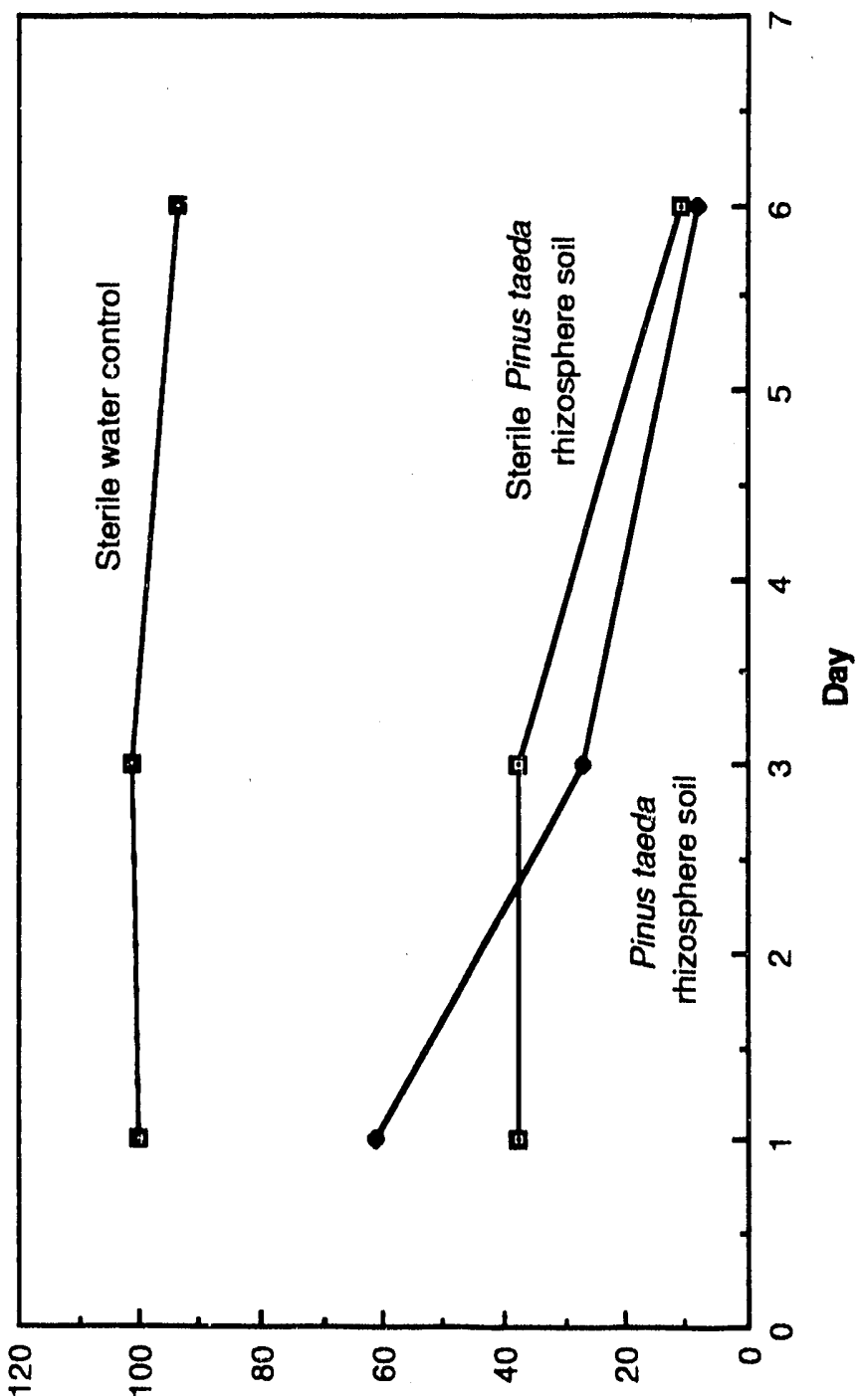

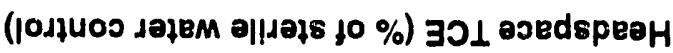

ธั้

E

$\stackrel{2}{2}$

옹

을

등

๕

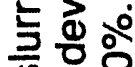

कํ.

ㅎํㅇ

○ $\frac{\mathrm{C}}{3}$

焉 $\frac{\infty}{0}$

힝

은 응

๑ั

要施要

응 응

D.

क象

등

嵌

U上正

등

क

등․ㄷ

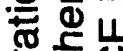

흔

ठㅇํㅇ

동를

\&

(

은ํำ

马

政

श्र

$\geq$

옥 
8
$\frac{0}{5}$
$\frac{1}{2}$
$\frac{1}{0}$
$\frac{1}{2}$
$\frac{1}{8}$

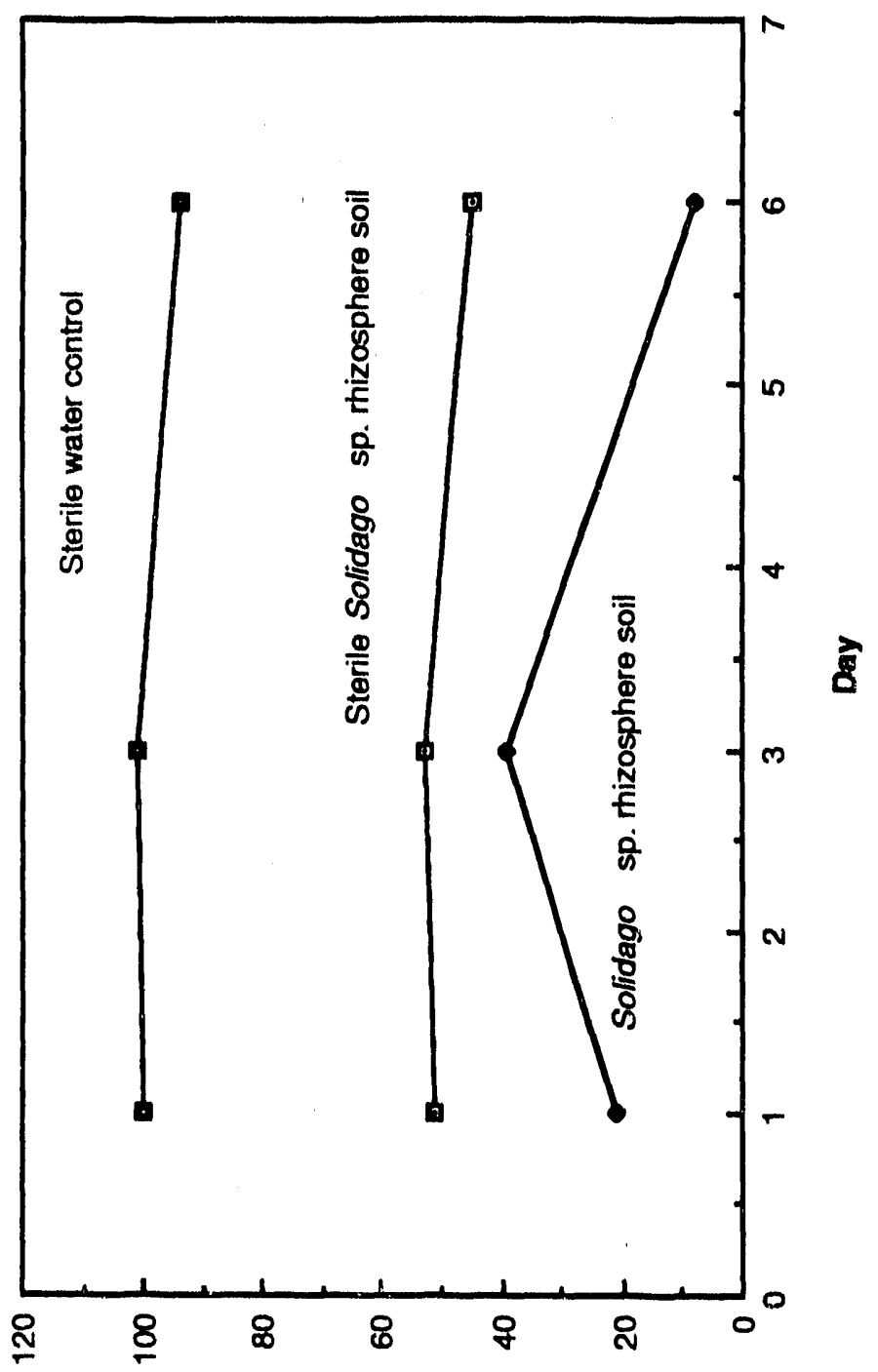

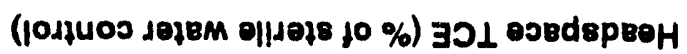

토용

$\sqrt{8}$

든

을

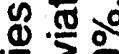

늘

क

$\overline{0} \frac{\pi}{8}$

"

응 웡

西

๘ 58

잉

3.

유

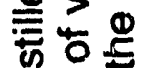

믄드

๑.

당 앙

$\Phi$

ᄃ 8

$\leq \mathbb{0}$

U上E

-

능

드원

它

웅

ఏ용

든

8 을

क के

( 0 ⿹

응

ชิ

吕

ถ

$\frac{1}{2}$ 
sampling day. Throughout the 6-day sampling period, TCE concentrations were higher in the sterile water controls (no soil) than in sterile soil slurries for all soils indicating either nonbiological transformation of TCE or simply sorption of TCE to the soil. The fact that TCE concentrations decreased rapidly from day 0 to day 1 but changed only slightly from day 1 to day 6 in all sterile soil samples indicates that abiotic losses occurred rapidly in the first day of the experiment but contributed very little to losses thereafter. This observation is consistent with sorption as the predominant abiotic loss process.

Biological transformation of the TCE was most evident as an important loss process in L. cuneata (Figure IV - 27) and nonvegetated, noncontaminated soils (Figure IV - 25), because the TCE loss from the soil was greatest compared with the matched sterile control for each of these samples. On day 6, there was $55 \%$ less TCE in the headspace of the L. cuneata soil compared to its matched sterile control (Figure IV - 27), whereas, the nonvegetated, noncontaminated soil showed $40 \%$ less TCE in the headspace compared to its matched sterile control (Figure IV - 25) on day 6. These differences can be attributed directly to biological transformation of TCE in each soil.

Differences in TCE concentrations were marked but less pronounced between sterile and nonsterile soil slurries of Solidago sp. (Figure IV - 30) and nonvegetated, contaminated soil (Figure IV - 26). Once again the faster disappearance of TCE from the nonautoclaved soils indicates that biological processes contribute to the disappearance of TCE. Rapid loss of TCE was also observed for $P$. taeda (Figure IV - 29) and $P$. notatum (Figure IV - 28); however, the contribution of microbial transformation could not be inferred because TCE 
was also lost from the headspace of matched, sterile soils. Nonetheless, the rate of TCE disappearance from $P$. taeda and $P$. notatum exceeded that of nonvegetated soils (Figures IV - 25 and IV - 26). Thus, enhanced microbial degradation may still occur in these rhizosphere soils, but microbial degradation may not be distinquishable from other losses unless a higher TCE concentration is present.

\section{E. Mineralization of ${ }^{14} \mathrm{C}-\mathrm{TCE}$ in Soil Samples}

The hypothesis that microbial degradation of TCE is faster in the rhizosphere than in nonvegetated soil was also supported by the comparison of ${ }^{14} \mathrm{C}$-TCE mineralization in L. cuneata and non-vegetated, TCE-contaminated soils. Mineralization to ${ }^{14} \mathrm{CO}_{2}$ occurred in both soils; however, a significantly greater amount of ${ }^{14} \mathrm{CO}_{2}(p \leq 0.05)$ was produced in the rhizosphere soil from L. cuneata (mean \pm one standard deviation $=3.1 \pm 0.42 \mathrm{ng} / 50 \mathrm{~g}$ soll over 30 days) than in the nonvegetated, TCE-contaminated soil $\left(1.3 \pm 0.68 \mathrm{ng}{ }^{14} \mathrm{CO}_{2} / 50\right.$ $\mathrm{g}$ soil). Moreover, ${ }^{14} \mathrm{CO}_{2}$ efflux from the latter soil was not significantly greater than its matched, sterile control or than the sterile L. cuneata control. Although these results were encouraging for providing further evidence for the role of mizosphere microorganisms in degrading TCE, experiments with other inizosphere types were not attempted. Rather, experiments exploring ${ }^{14} \mathrm{C}$-TCE mineralization in soil samples containing a living plant were conducted based on the hypothesis that the estimates of ${ }^{14} \mathrm{C}$-TCE mineralization in rhizosphere soil samples were conservative due to the absence of a living plant. 


\section{F. Degradation of PCE in Soll Slurries}

Initial results on microblal degradation of tetrachloroethylene (PCE) in rhizosphere and nonvegetated solls from the MCB were somewhat encouraging although equivocal (Table IV - 8). Reductive dechlorination of PCE to trichloroethylene (TCE) was observed in both nonvegetated and Solidago sp. rhizosphere soll as determined by gas chromatography after 2 days. However, more TCE was produced through reductive dechlorination in the rhizosphere soil. Control (sterile) samples for both the nonvegetated and Solidago sp. rhizosphere soll produced 0.0 and $0.1 \mathrm{mg}$ of TCE, respectively. In addition, no TCE was produced in the sterile water controls. Somewhat troubling was the failure to detect PCE in all samples (sterile and nonsterile) on day 2. It was hypothesized that leaks in the sample vials, some type of reaction with the redox indicator (resazurin), or sorption may have lead to headspace concentrations of PCE below detection.

More rigorous experiments on PCE degradation failed to confirm the results of the initial tests (Table IV - 9). No TCE was detected in any of the samples tested over 18 days. Tetrachloroethylene concentrations remained constant in sterile water controls, nonvegetated soils (sterile and nonsterile) and Solidago sp. rhizosphere soil (sterile and nonsterile) throughout the 18-day experiment.

The PCE degradation experiments were conducted with nonvegetated soll and Solidago sp. rhizosphere soil simply because of their availability at the time. No additional experiments on microbial degradation of PCE in other rhizosphere soll samples from the MCB were attempted. Thus, it is possible that 


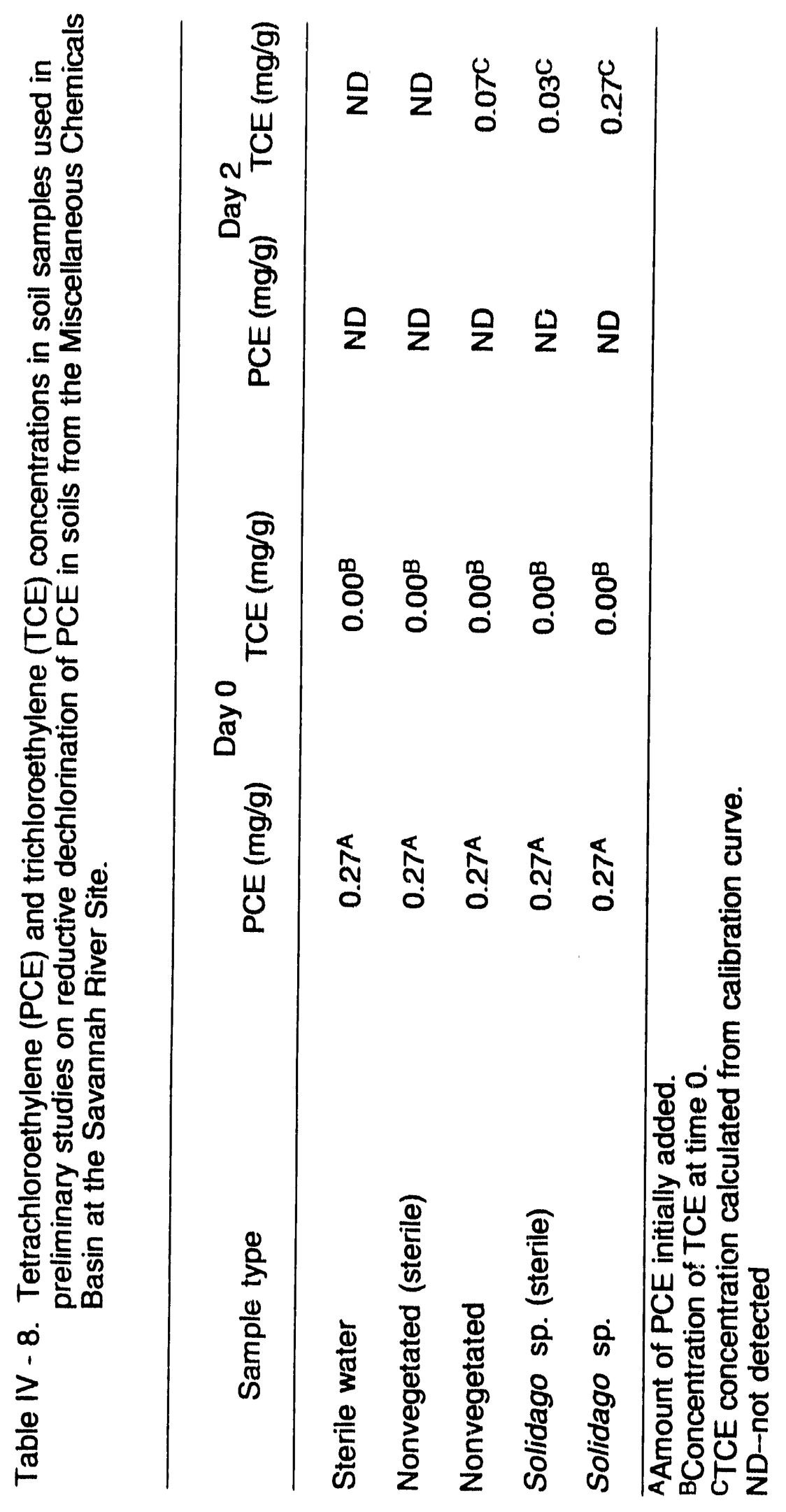




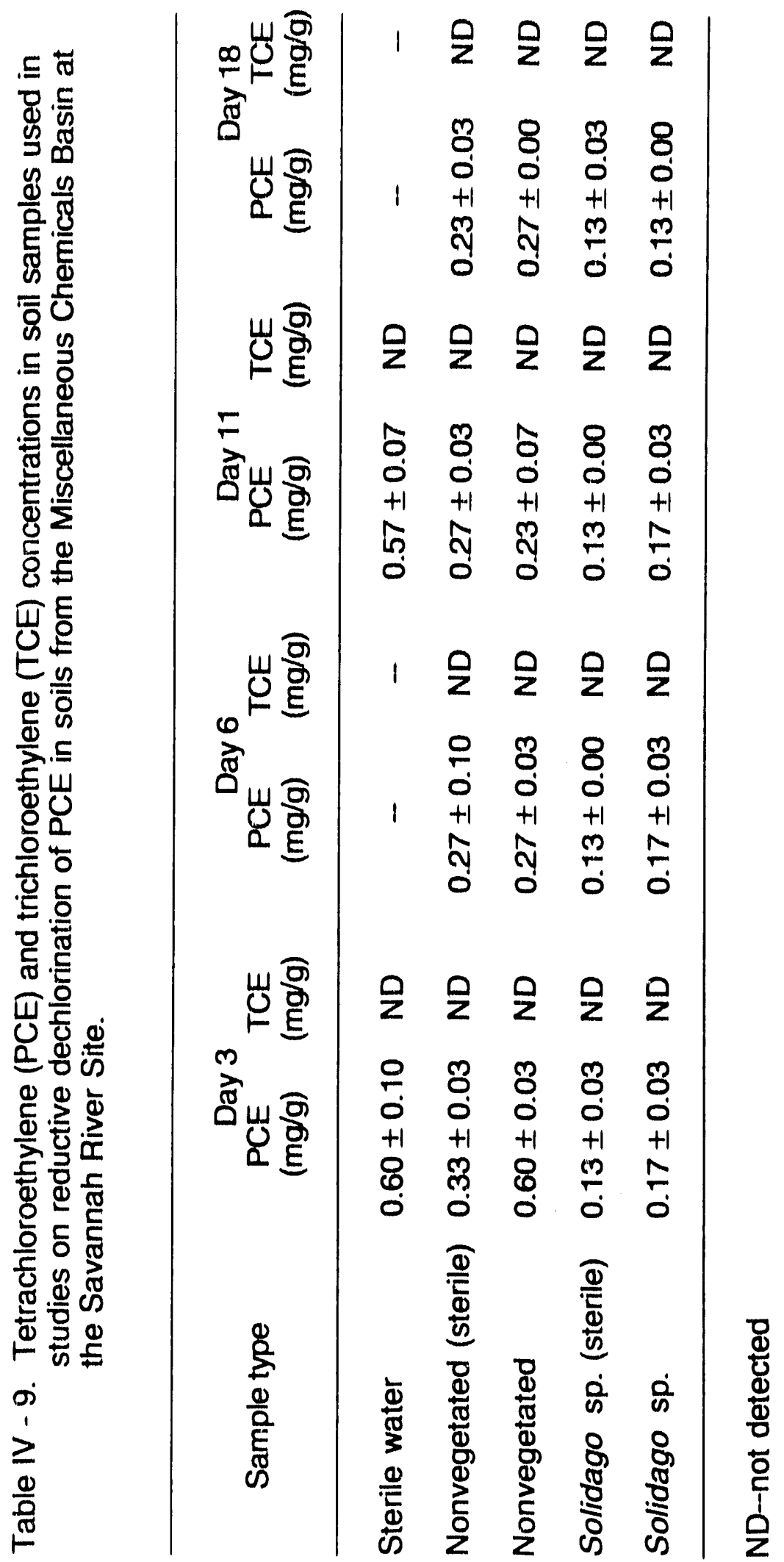


microblal degradatlon of PCE occurs in the untested solls. Certainly PCE degradation via reductive dechlorination is favorable in soll at the MCB because of the anaeroblc conditions that exist as a result of the solls poor dralnage. I addition, recent work by Kastner (1991) showed that reductlve dechlorination of TCE and PCE occurred in anaeroble solls only after the solls had gone from aeroblo to anaeroblc conditions. Solls under strlotly anaeroblc conditions failed to show any dechlorination of TCE or PCE. This phenomenon (fluctuation between aerobic and aneroblo conditions) certainly occurs at the MCB.

\section{G. Fate of ${ }^{14} \mathrm{C}$-TCE in Soll-Plant Systems}

The first goal of the ${ }^{14} \mathrm{C}$-TCE soll-plant experiments was to demonstrate the ability to achieve a good mass balance of ${ }^{14} \mathrm{C}$ in the experimental systems. Using the sampling, extraction, and plant analysis techniques described in the Materlals and Methods section, consistent recovery of $>70 \%$ (range $40 \%-96 \%$ ) of the total ${ }^{14} \mathrm{C}$ initlally added to the samples was achleved. Analysis of the Carbosorb traps from the whole plant experiments showed that ${ }^{14} \mathrm{CO}_{2}$ production in the vegetated solls was elevated compared with elther the nonvegetated soll or the sterile control soil (Figures IV - 31 through IV - 36). In the experiments with soils containing Lespedeza cuneata (Figures IV - 31 and IV - 32) and $P$. taeda (Figures IV - 33 and IV - 34), ${ }^{14} \mathrm{CO}_{2}$ production at the conclusion of the experiment was significantly greater $(p \leq 0.05)$ than ${ }^{14} \mathrm{CO}_{2}$ production in nonvegetated and sterlie (autoclaved) control solls. In experiments with solls containing Solidago sp. (Figures IV - 35 and IV - 36), 


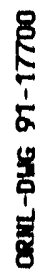
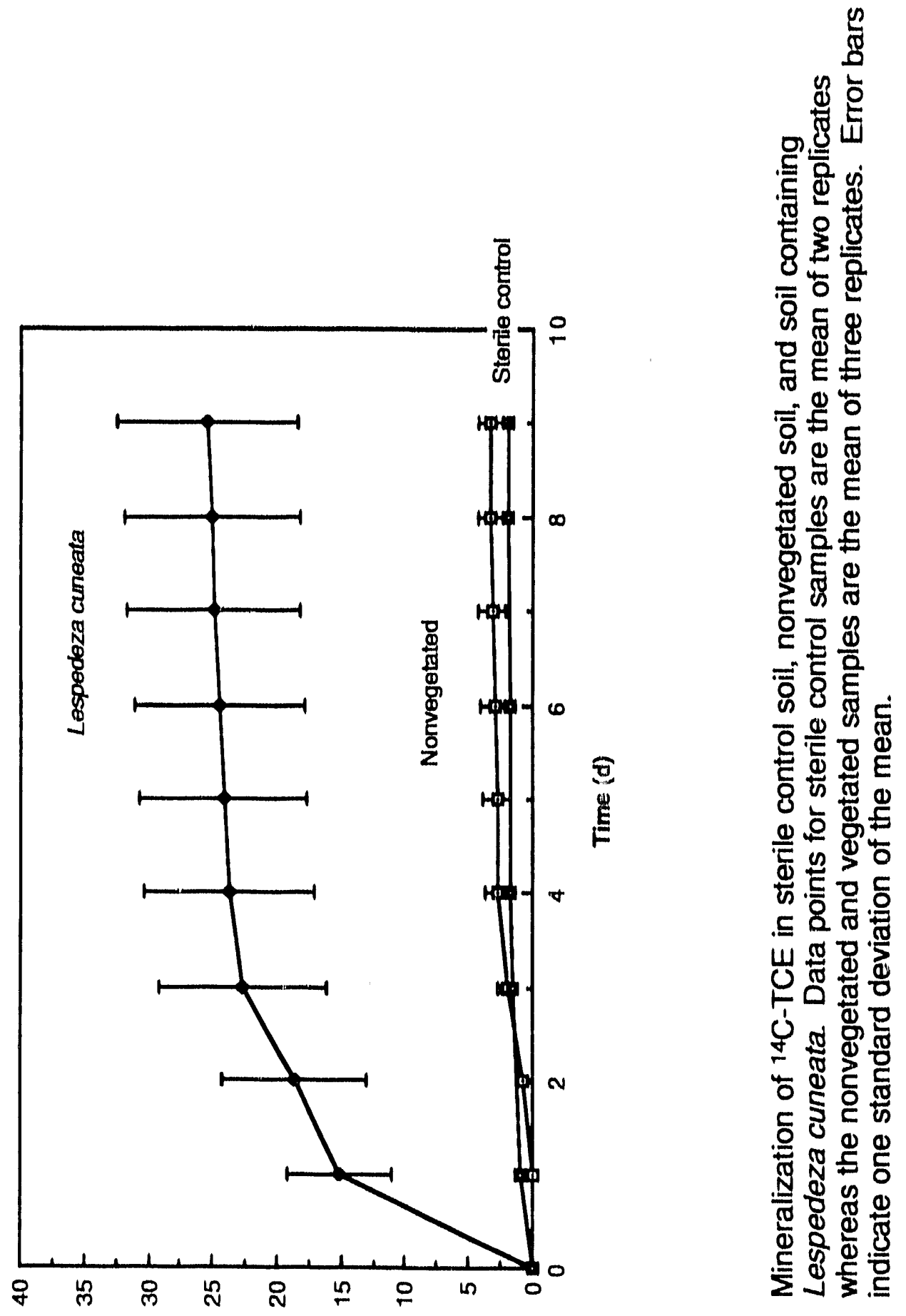

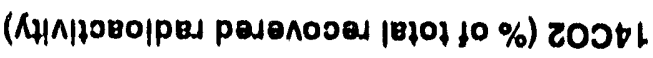

$\frac{n}{3}$ 


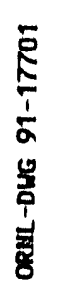

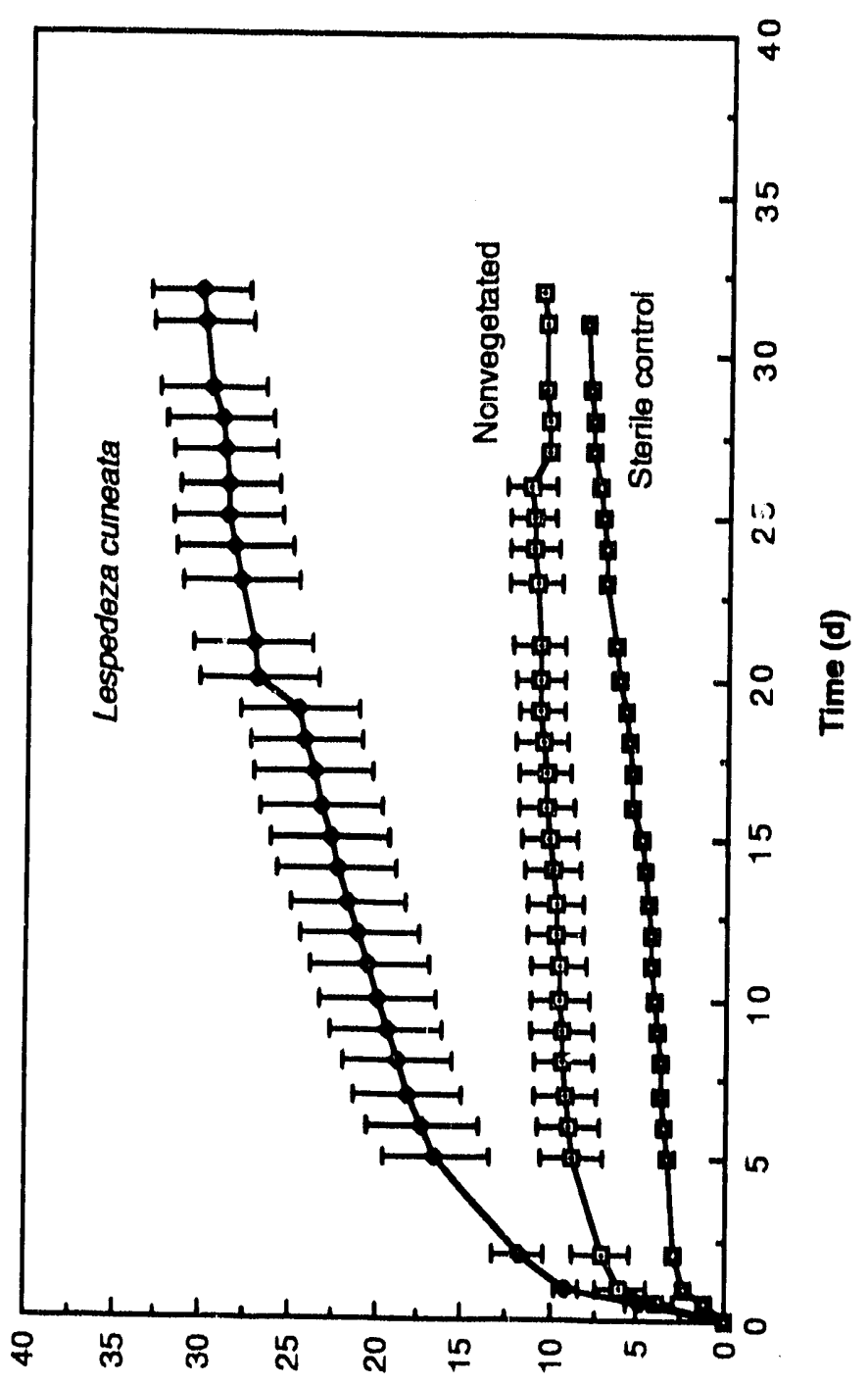

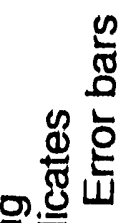

등

돈

동요

는

응

올

$=\underline{0}$

以

ช สิ

\$ิ

흥하

$\Phi$ 텅

ญ

응

흠

훙 ह

엉

뻐

क皆

0 吉

은 유

包\$它

๘.등응으

등

山 용

岕志焉

广西

ن

व

ㄴํㄴ 옹

등 둥

ํㅗㅇ 옹

응

तิ

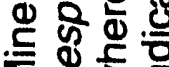

决吉的

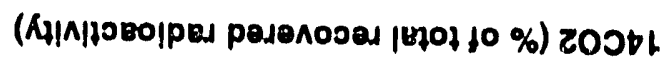

ก่
$\geq$
$\frac{1}{0}$
믁 


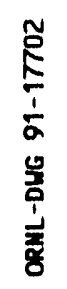

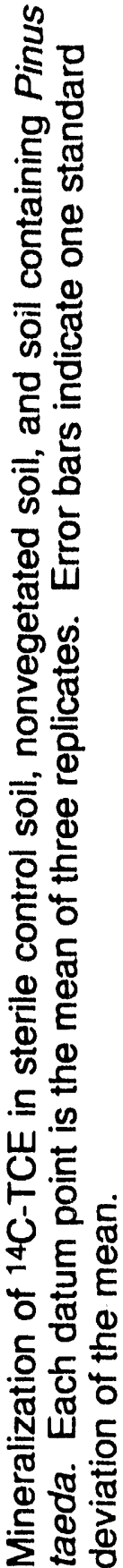

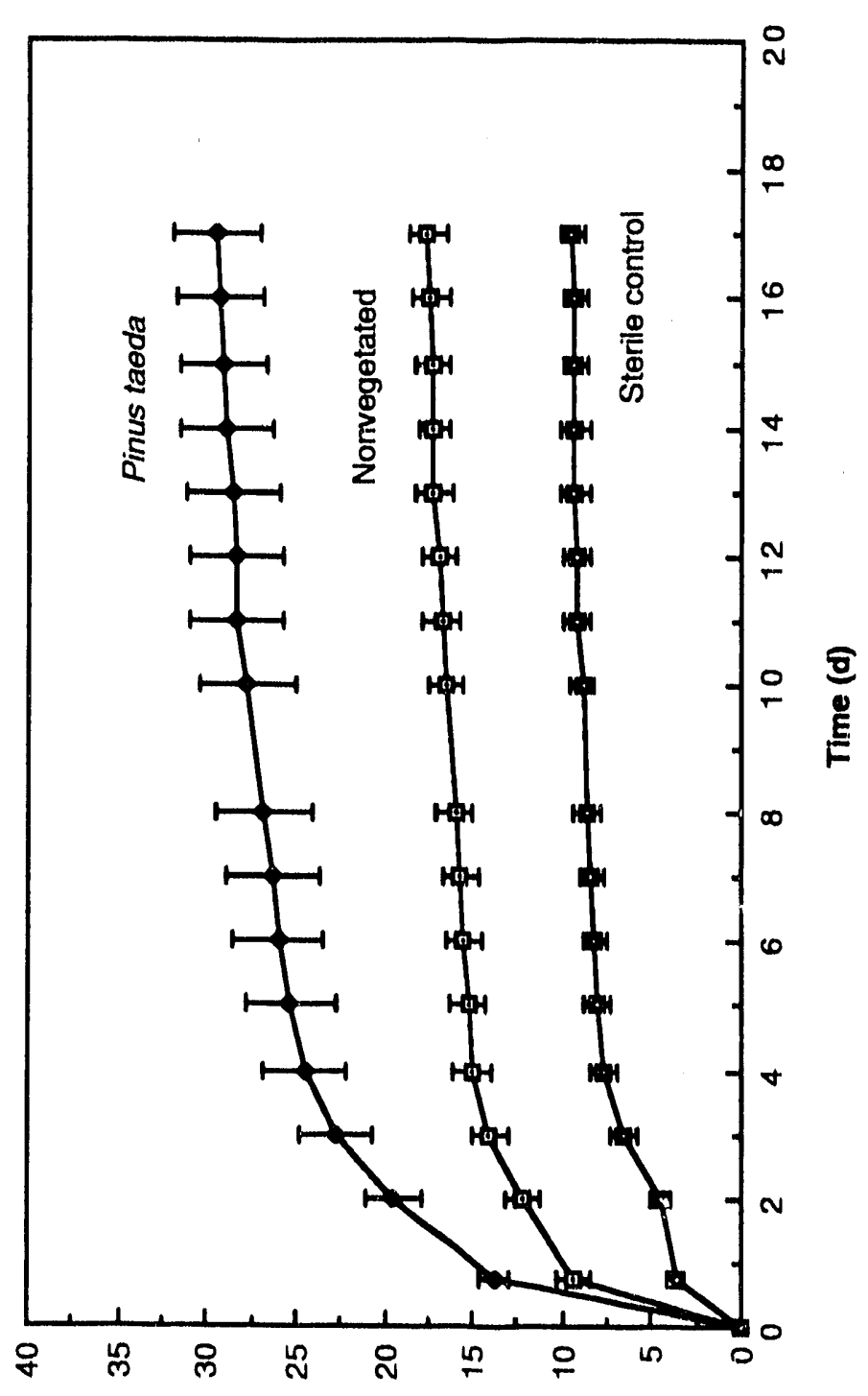

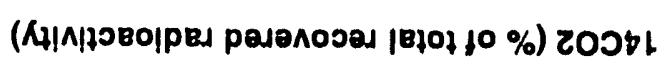

लं

递 


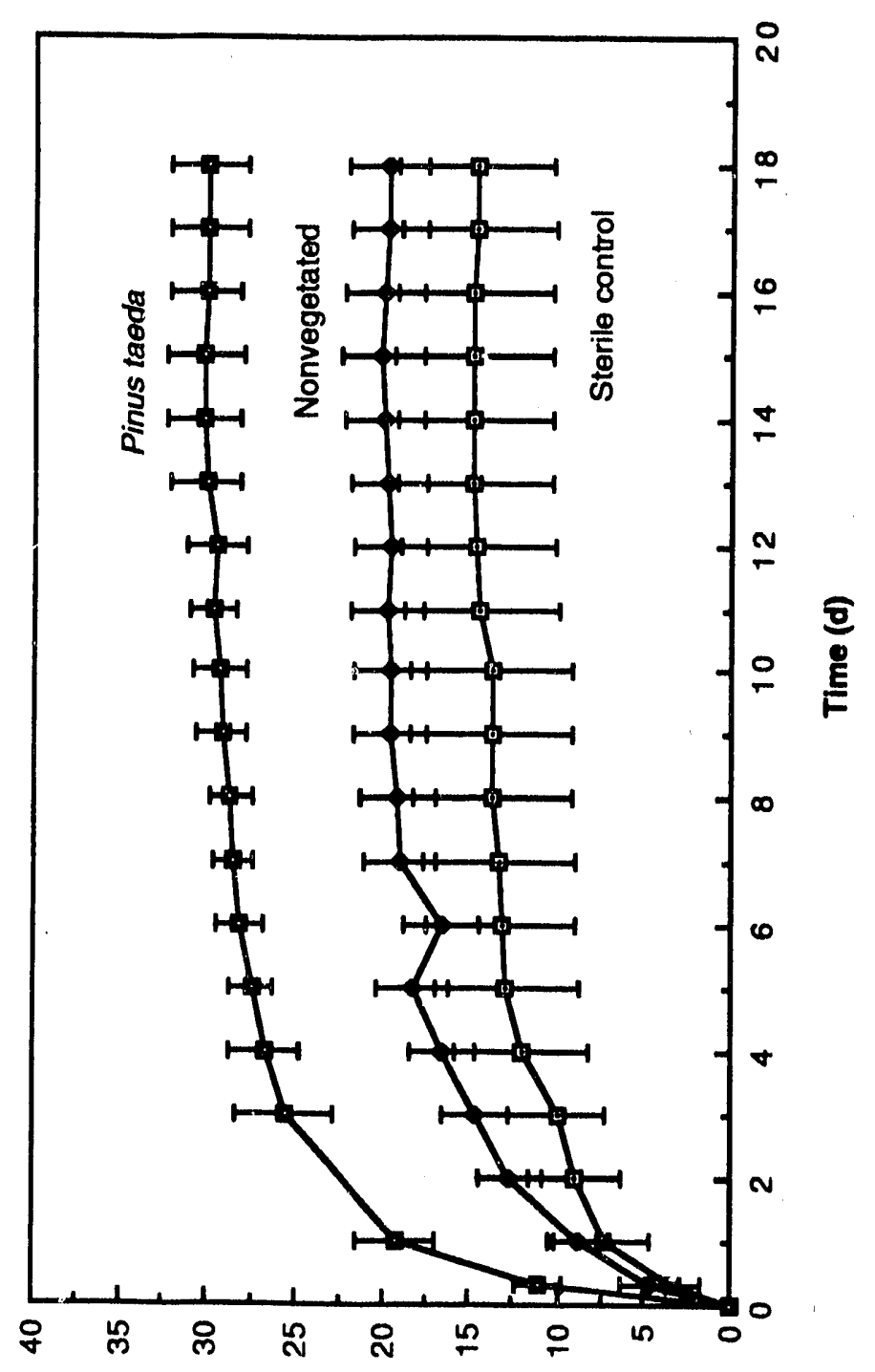

ס

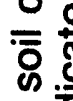

으ㄹㅡㅡ

ธิ

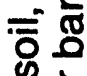

옹

䒹山

ธิ

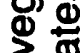

등 응

=

\%ั

을

등

8 당

Ф ఖ

Ф

ऊ岳

.$\subseteq \underline{\underline{n}}$

岂.

눙

่ำ

돌

ธ。

등도

읗둥 훙

Nㅡㄴ

전

要

도웡

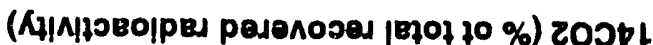

望 

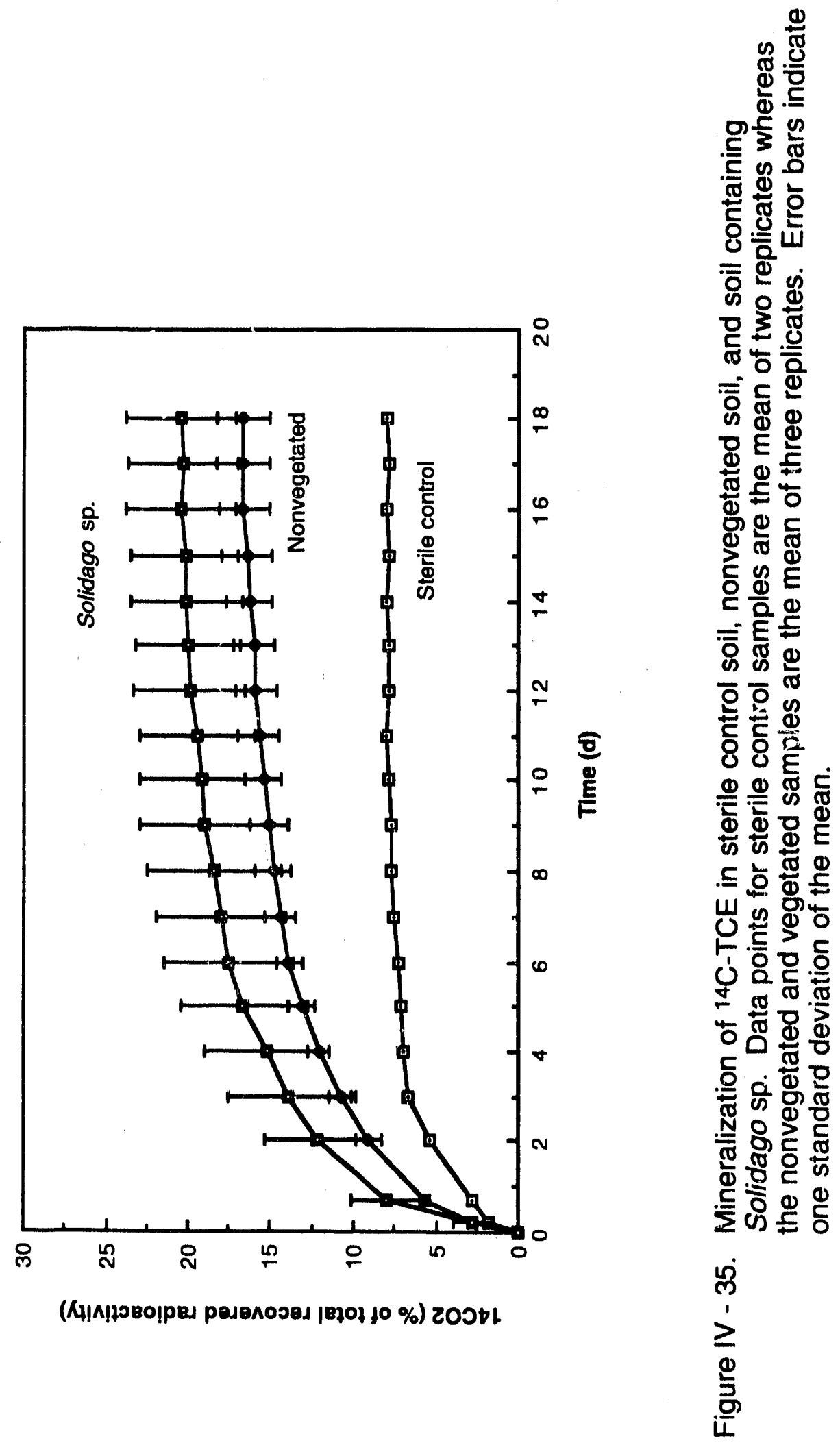


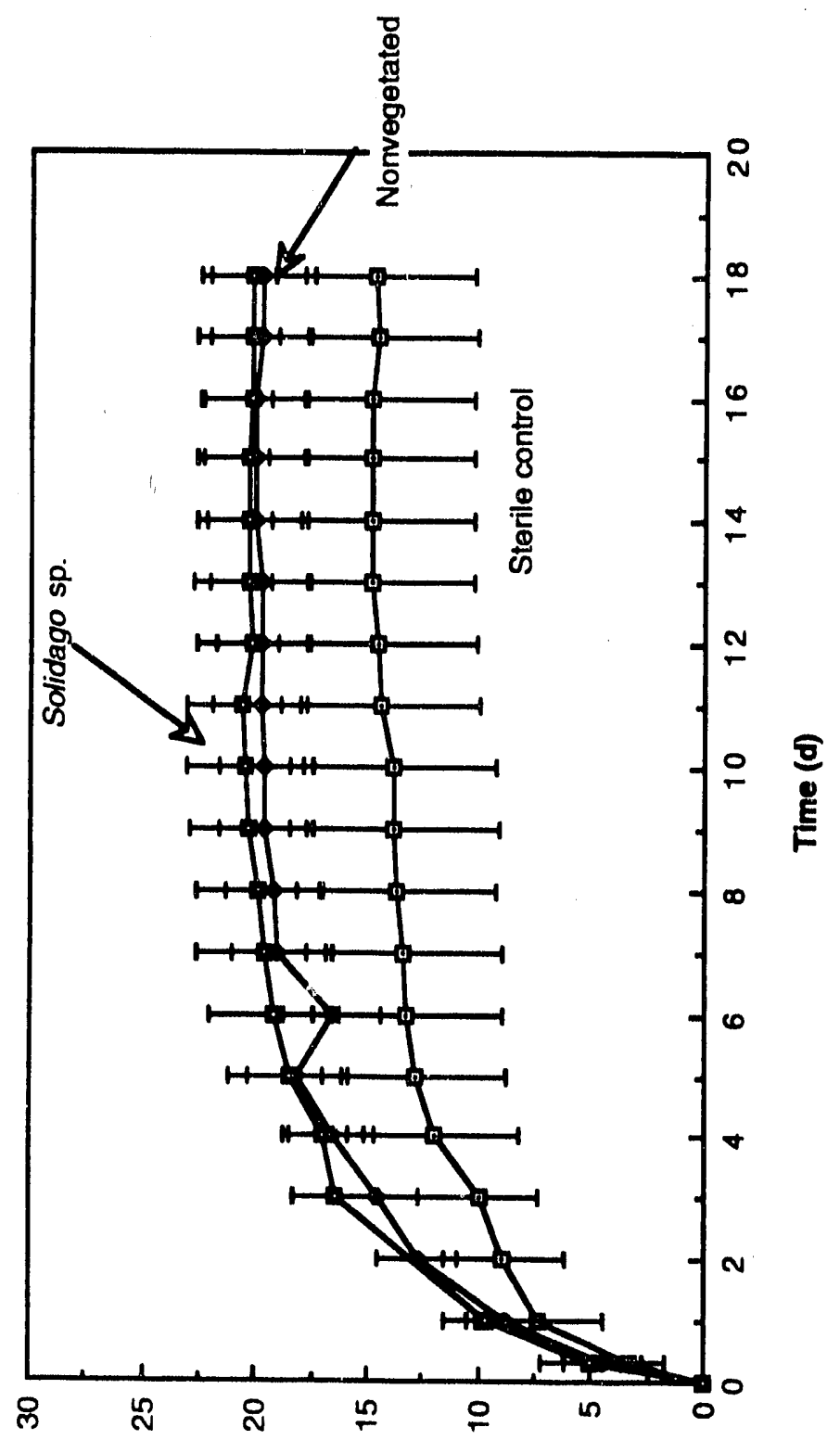

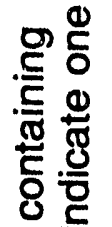

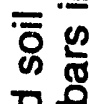

은 흔

ธิธี้

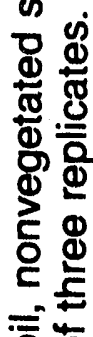

$\overline{\overline{0}}$

응 융

ठั

足点

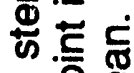

$\subseteq$ 응

山ᄐ

옥

نे

I

휴유

동

흥용

Nㅗㅇ은

진

흔

之心

g্户

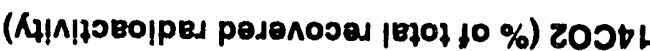

ำ 
${ }^{14} \mathrm{CO}_{2}$ production was elevated in the vegetated samples but not statistically different $(p \leq 0.05)$ from ${ }^{14} \mathrm{CO}_{2}$ production in the nonvegetated soil. Most of the ${ }^{14} \mathrm{CO}_{2}$ produced from ${ }^{14} \mathrm{C}$-TCE in the vegetated solls was evolved during the first three days of the experiment. This is in agreement with earlier observations on the initial rapid disappearance of TCE from the headspace above aqueous slurries of rhizosphere soil (Walton and Anderson, 1990). In addition, comparisons of the percentage of ${ }^{14} \mathrm{C}$-TCE mineralized in the whole plant systems with previous data on ${ }^{14} \mathrm{C}$-TCE mineralization in L. cuneata rhizosphere soil (Walton and Anderson, 1990), appeared to confirm the hypothesis that the mineralization rates based on soil slurries gave conservative estimates of mineralization rates that would occur in soil containing a live plant.

As described in the Materials and Methods section, slight modification of the experimental apparatus was necessary for the grass, Paspalum notatum, because of its different morphology, that is, the lack of a stem. Glass crystallization dishes were used to contain the plants. Although mineralization of ${ }^{14} \mathrm{C}$-TCE was detected in soil containing $P$. notatum during two different experiments, ${ }^{14} \mathrm{CO}_{2}$ production in the vegetated dishes was slightly less than ${ }^{14} \mathrm{CO}_{2}$ production in an identical dish containing soil but no vegetation (Figure IV - 37). However, these results should be taken with caution due to the low mass balance of radioactivity and the difficulty of measuring ${ }^{14} \mathrm{CO}_{2}$ production in these "open" systems.

Mineralization experiments were also conducted with soybean, Glycine max. These tests were done to obtain data on the fate of ${ }^{14} \mathrm{C}$-TCE in the 


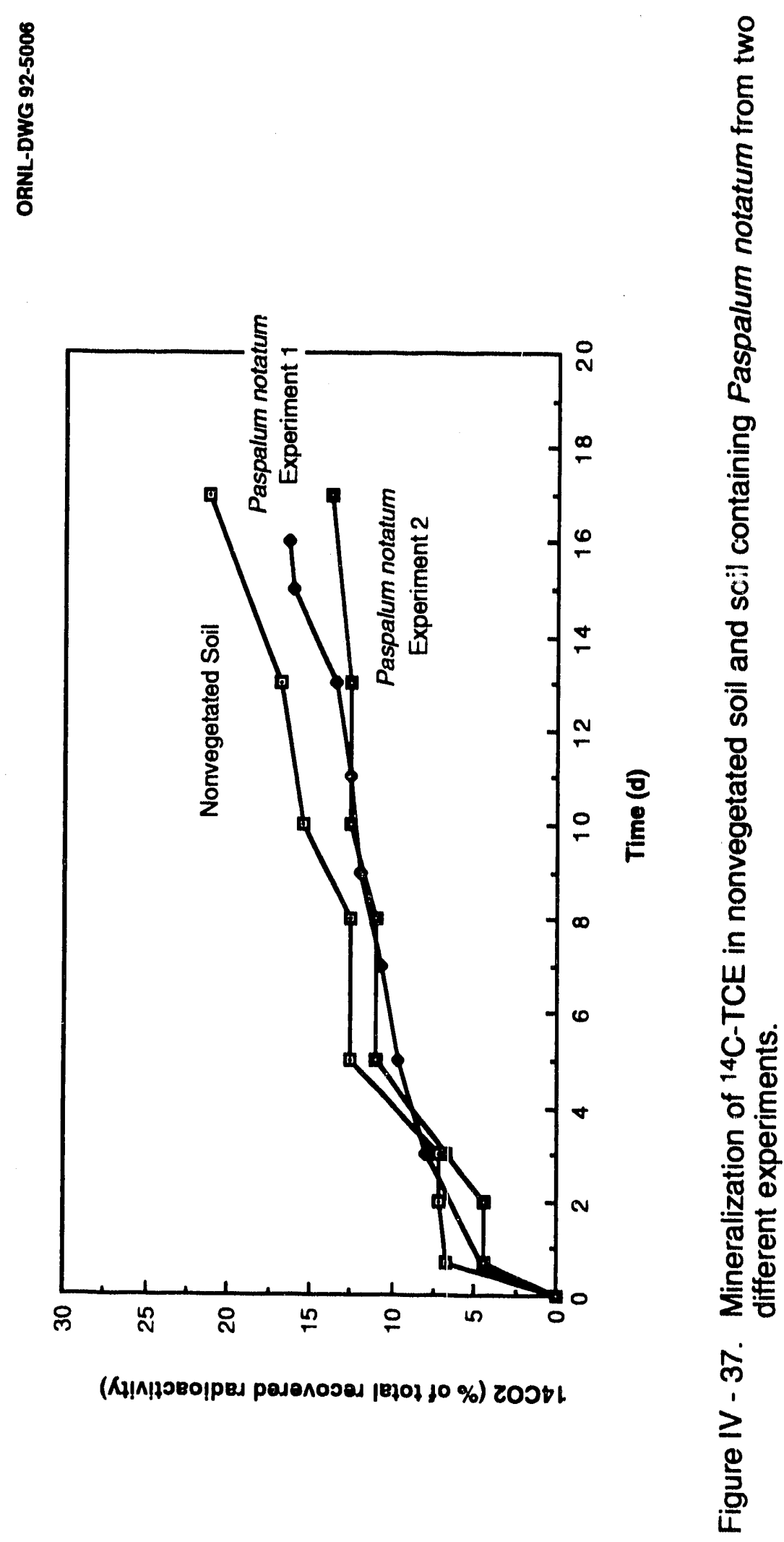


rhizosphere of a common experimental plant not indigenous to the MCB and also determine whether previous exposure of the plant to TCE was necessary for enhanced microbial degradation of ${ }^{14} \mathrm{C}$-TCE in the rhizosphere. Results of these tests were somewhat inconclusive. Although elevated levels of ${ }^{14} \mathrm{CO}_{2}$ were detected from flasks containing soybean plants compared with nonvegetated flasks and sterile control flasks (Figures IV - 38 and IV - 39), the ${ }^{14} \mathrm{CO}_{2}$ levels were significantly greater $(p \leq 0.05)$ in only the second experiment (Figure IV - 39). Although environmental conditions monitored were identical during both experiments, the soybean plants in the second experiment grew much better, as indicated by water use, visual estimates of foliage, and weight of the plant tissue at the conclusion of the experiment. Because one of the effects of increased growth can be increased root exudation, these results imply a possible role of root exudation in TCE degradation in the mizosphere. In addition, if the results of the second soybean experiment are correct, it appears that previous exposure of TCE to the plant may not be necessary for enhanced degradation of TCE to occur in the rhizosphere.

The initial rapid ${ }^{14} \mathrm{CO}_{2}$ production in soils containing vegetation as observed in previous tests, was further confirmed by respiking sterile control, nonvegetated, and vegetated (Pinus taeda) flasks with ${ }^{14} \mathrm{C}$-TCE after ${ }^{14} \mathrm{CO}_{2}$ production had leveled off. Once again, a burst of ${ }^{14} \mathrm{CO}_{2}$ production was observed, but only in the vegetated sample (Figure IV - 40). These results are consistent with the initial rapid mineralization of 14C-TCE observed previously. In addition, the results also provide evidence for the importance of bioavailability of the TCE, as would be the case in these respiked samples. 


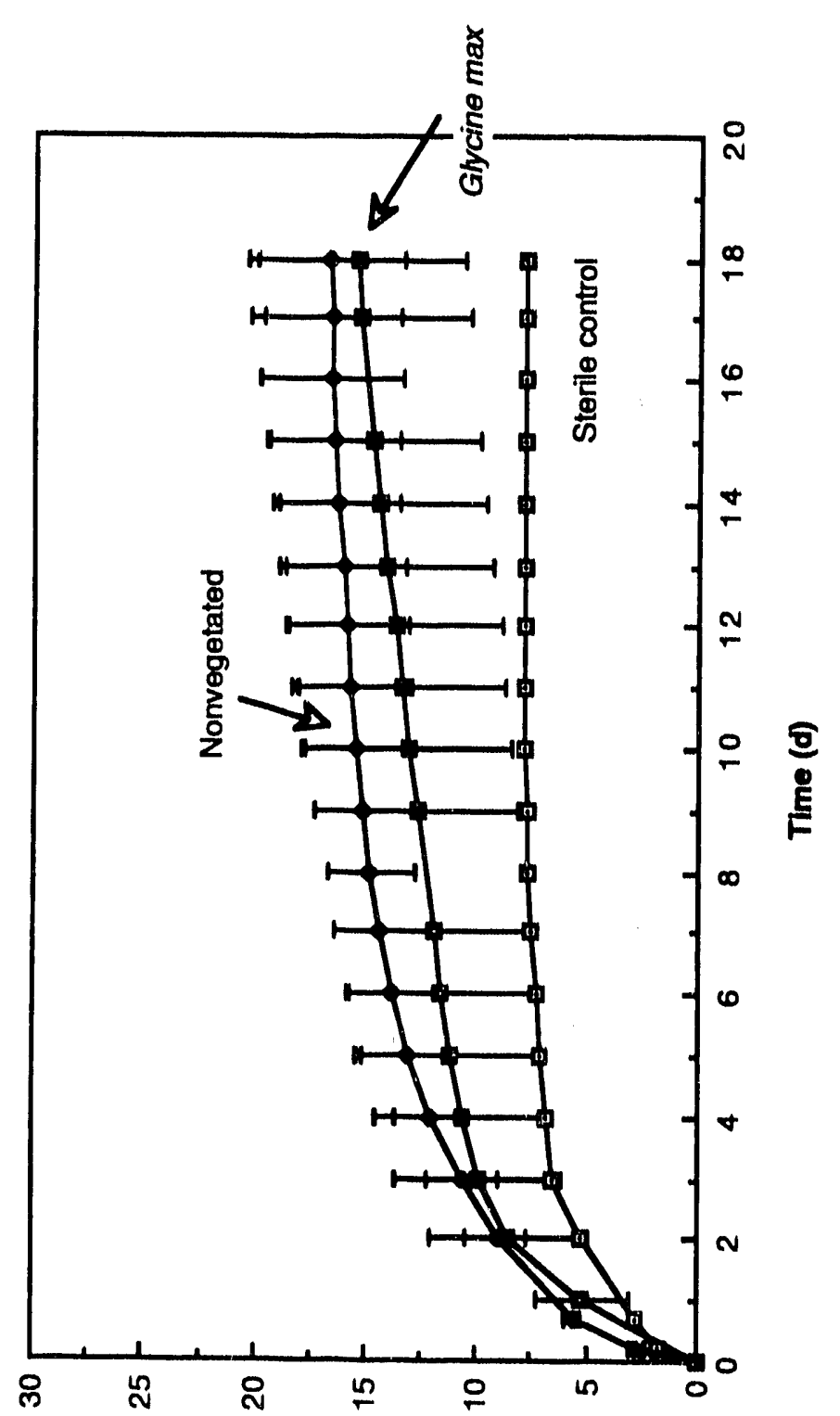

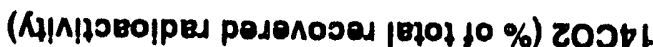

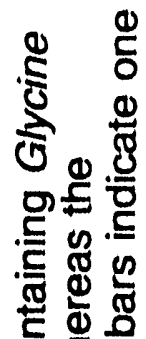

온은

온

o

สำ

후응

๙引는

$\Phi$

동

实

E

동

-

क षै

$\overline{0}$

을 을

ठํํㅇ

응 흥

融

$\subseteq$ 용

III $\Phi$

U要

的宁

نे

는든 은

등영웡

๙

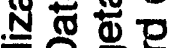

미유

Ф) 흐

次希焉

क्ष

ำ 


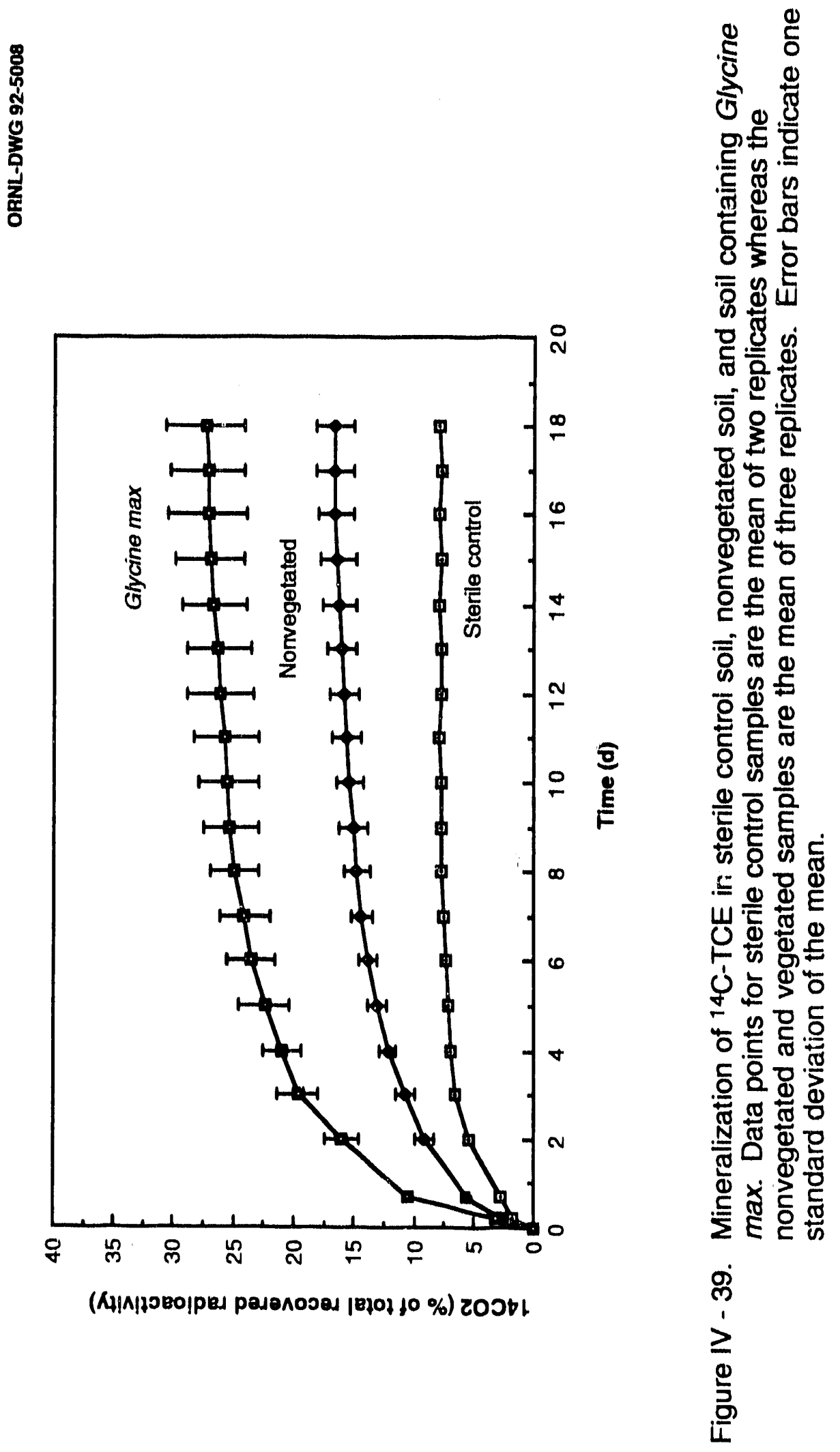


옳

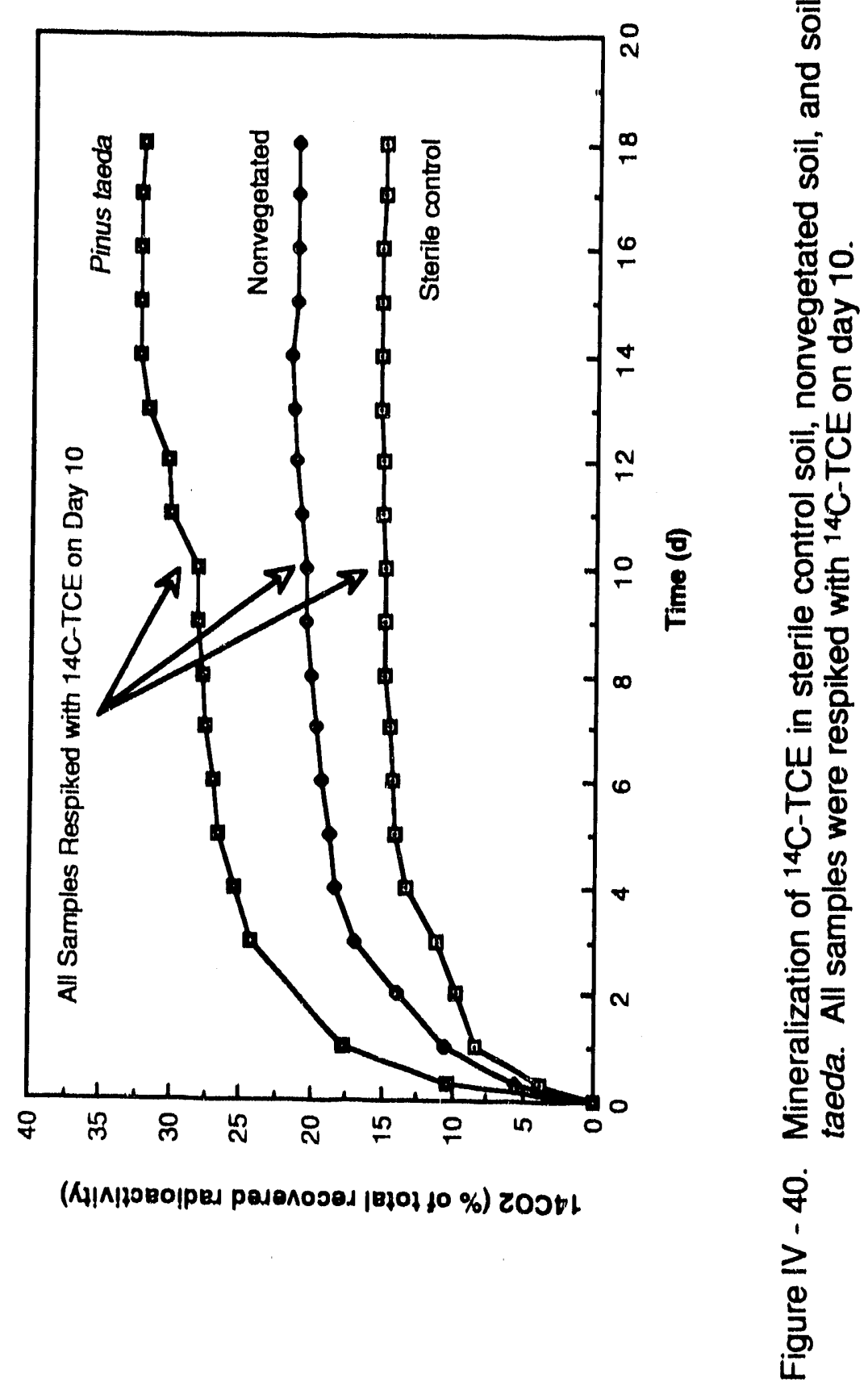


To further explore whether the enhanced degradation of ${ }^{14} \mathrm{C}$-TCE observed in vegetated samples was catalyzed by mloroorganisms or by the plant itself, fate experiments were conducted under sterile conditlons. The fate of ${ }^{14} \mathrm{C}$-TCE in flasks containing sterlle soil and flasks containing sterile soll and loblolly pine seedlings treated with $\mathrm{NaOCl}$ to reduce bacterial activity on the plant roots (Norby et al., 1987) was monitored. In two separate exferlments (Figures IV - 41 and IV - 42), ${ }^{14} \mathrm{CO}_{2}$ production in both samiple types was not significantly different $(p \leq 0.05)$. These results provide strong evidence for the role of soil micrnorganisms in the rhizosphere in microblal degradation of ${ }^{14} \mathrm{C}$ TCE.

H. Influence of Root Exudation on ${ }^{14} \mathrm{C}$-TCE Mineralization

In addition to monitoring microbial degradation of ${ }^{14} \mathrm{C}$-TCE in the rhizosphere, preliminary studies were also conducted on the influence of root exudation on microbial degradation of TCE. Specifically, root exudation was reduced (by reducing light intensity) to determine the effect on mineralization of ${ }^{14} \mathrm{C}$-TCE. Experiments were conducted with soils containing Glycine max, Pinus taeda, and Lespedeza cuneata. Although mineralization of ${ }^{14} \mathrm{C}$-TCE in soils containing $G$. max grown under the two different lighting conditions was significantly greater $(p \leq 0.05)$ than mineralization in the nonvegetated and sterile control soils, the two light intensities had no significant effect on mineralization in the vegetated samples (Figure IV - 43). Similar results were obtained in solls containing P. taeda (Figure IV - 44) and L. cuneata (Figure IV 45). Although plants grown under reduced light showed elevated levels of 


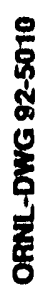

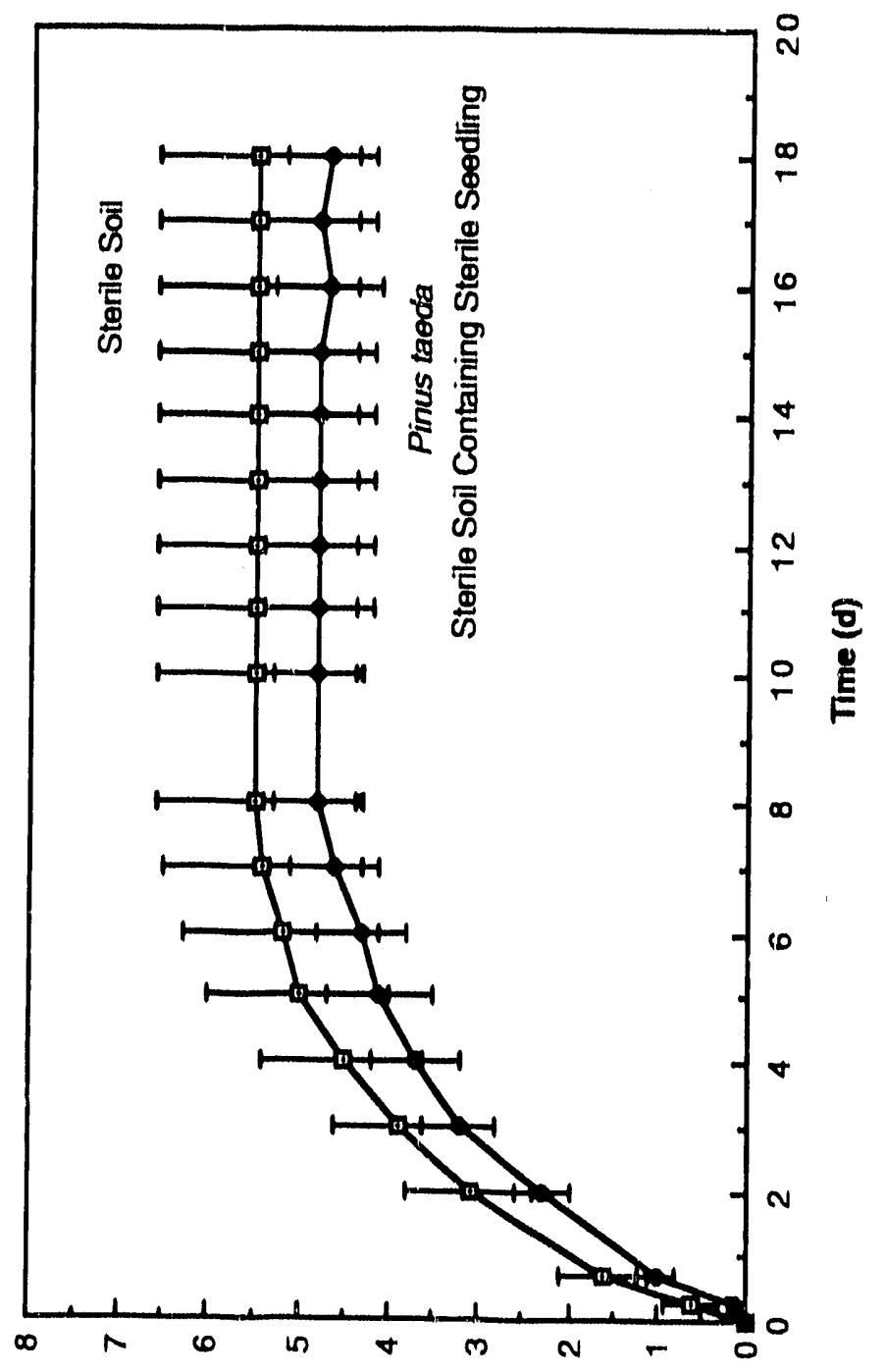

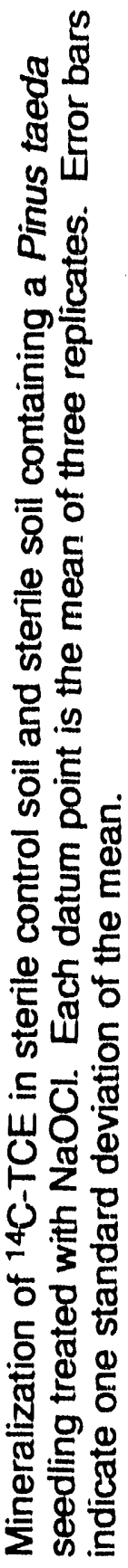

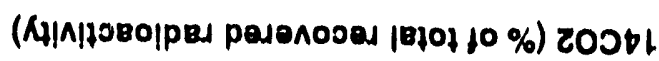

$\dot{8}$
$\geq$
$\frac{1}{0}$
$\frac{0}{2}$ 
造

¿

(1)

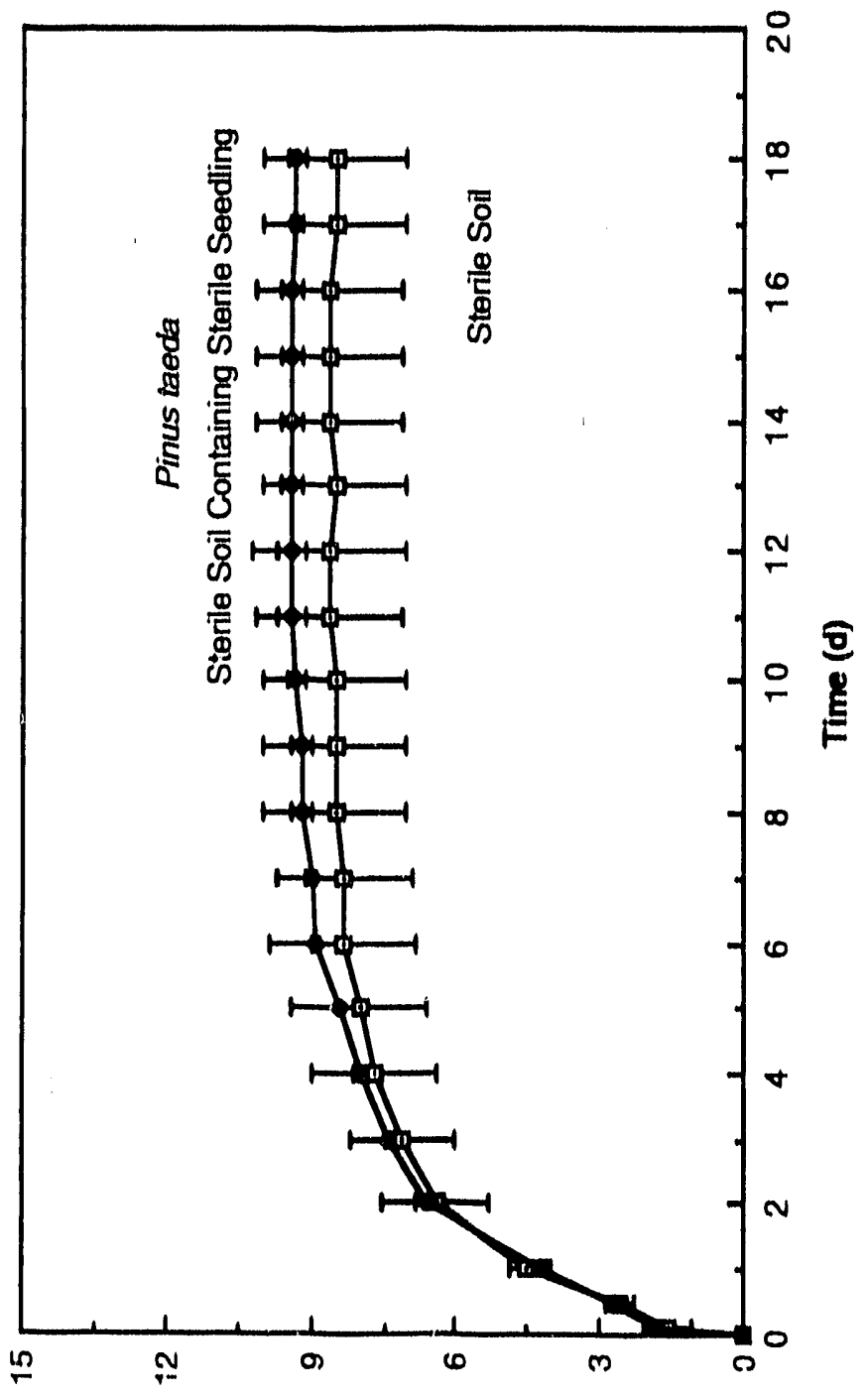

을을

$\overline{0}$

४ 동

옳

战市

응

흥

क

돌

8 ช

들 它

क虫

덩

山о >

인

住。

亭

-

듀

동

承过

은 음

Фํํㅇ

들 岕등

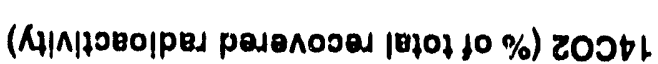

产 


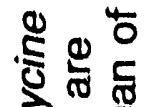

उิ \&

을

동

荧的㐫

8 这

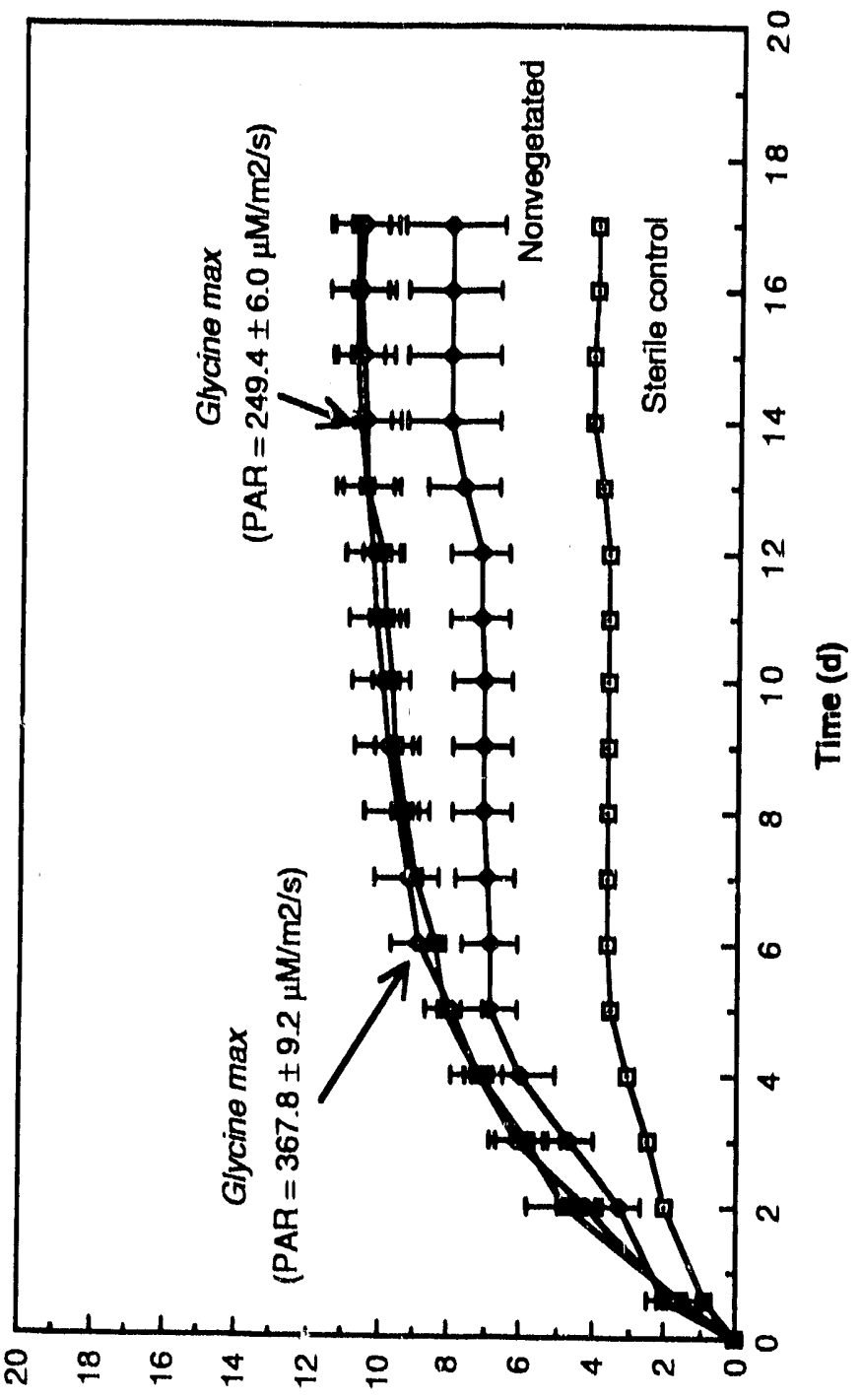

항응

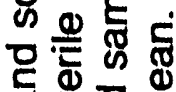

ণ

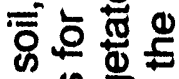

융 영

密

ชั ฮำ สำ

政

哽

ำ

言.

施吉

응ㅎㅇㅇ

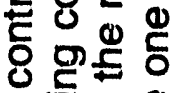

政

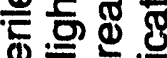

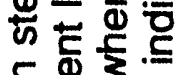

$\subseteq \Phi$ 岕必吕 는 늉

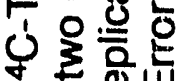

远政

ธ。

ᄃ

은

ูํㅇํำ

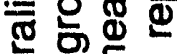

Ф

空造怘

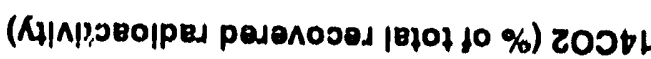

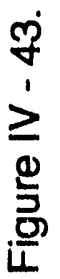




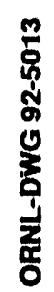

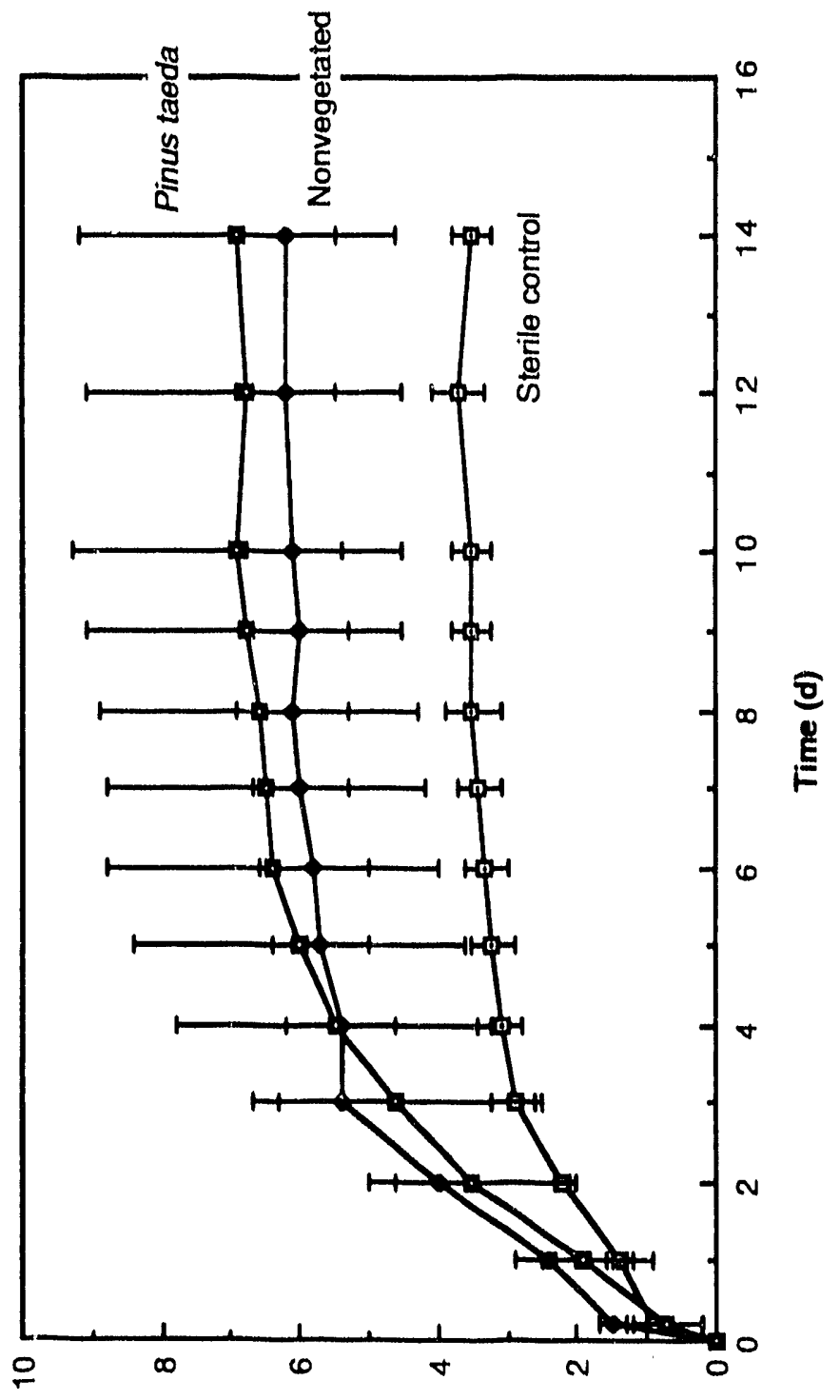

象

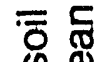

O E

है

胥

言, 吕

옹

$\Phi$

홍

$\geq$ 迈

둥

西

ర人

क

ত

등

8 을

잉

ब둥

๘高西

$\subseteq$ 중

山

仓部

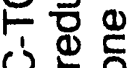

广े

券

5 $5: 0$

을.

赵合

충

西

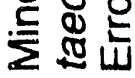

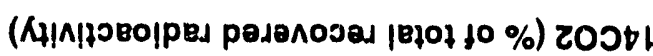

j
$\geq$
$\frac{1}{0}$
$\frac{9}{5}$ 

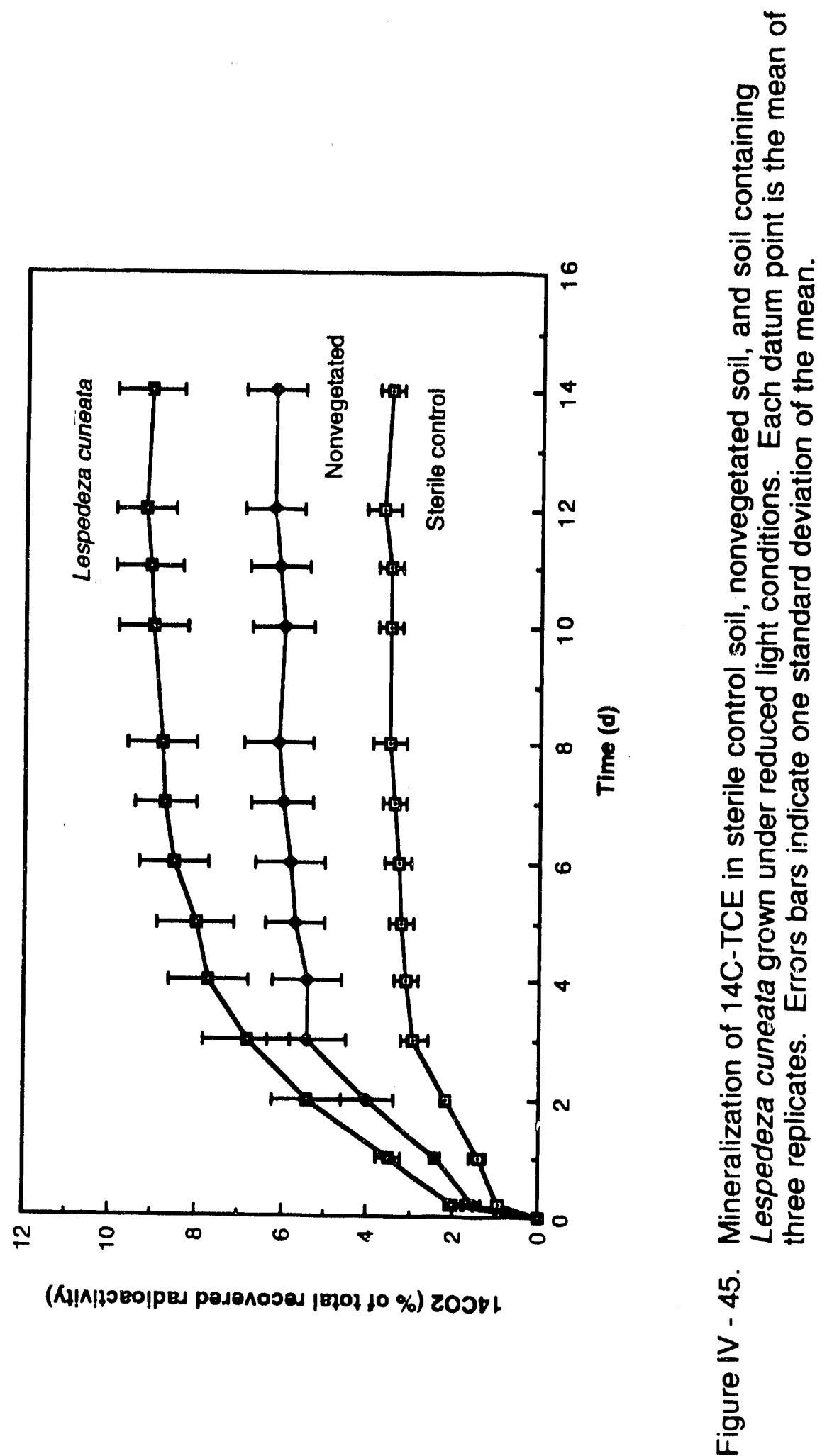
${ }^{14} \mathrm{CO}_{2}$ production (significantly elevated in the case of $L$. cuneata), the percentage of ${ }^{14} \mathrm{C}$-TCE mineralized was greater than $15 \%$ less than in previous tests with $P$. taeda and $L$. cuneata. Although preliminary, the results indicate that root exudation influences microbial degradation of ${ }^{14} \mathrm{C}-\mathrm{TCE}$ in the root zone. The implications of such an influence could be important for managing sites where vegetation is being used in bioremediation.

\section{Root Uptake of ${ }^{14} \mathrm{C}$-TCE-Derived Compounds}

The experimental apparatus used isolated the top portion of the plants from the bottom portion, thus enabling the determination of the route of entry of any radioactivity contained in the plant tissues. Root uptake of ${ }^{14} \mathrm{C}$ and translocation in plant tissues ranged from $1 \%$ to $22 \%$ for the total percentage contained in leaves (or needles), stems, and roots (Table IV - 10). It appeared that there were differences within a species from separate experiments, but when the uptake data was normalized for water use those differences disappeared, providing strong evidence for the direct relationship between water use and uptake. In only one case (soybean) did normalization for water use fail to explain the differences within a species (Table IV - 11). Consistently greater amounts of radioactivity were contained in the root tissue compared with the leaves (or needles) and stems. The last column of Table IV - 11 (charcoal) represents the percentage of recovered radioactivity in the exit air from the chamber. In cases where elevated water use within the same plant species from different experiments was observed, increased carbon 14 being released through evapotranspiration and captured in the charcoal trap was concomitantly 
Table IV - 10. Total root uptake of ${ }^{14} \mathrm{C}$-trichloroethylene-derived radioactivity in leaves (or needles), stems, and roots of plants used in studies on microbial degradation of ${ }^{14} \mathrm{C}$-TCE in the rhizosphere.

\begin{tabular}{|c|c|c|}
\hline Plant & TimeA & ${ }^{14} \mathrm{C}^{\mathrm{B}}$ \\
\hline L. cuneata & 9 & $2.5 \pm 2.1$ \\
\hline L. cuneata & 32 & $1.3 \pm 1.3$ \\
\hline P. taeda & 17 & $14.4 \pm 4.0$ \\
\hline P. taeda & 18 & $4.2 \pm 1.6$ \\
\hline G. $\max$ & 18 & $2.2 \pm 1.1$ \\
\hline G. $\max$ & 18 & $21.2 \pm 11.1$ \\
\hline G. $\max$ & 17 & $13.7 \pm 3.8$ \\
\hline$P$. notatum & 16 & $5.8 \pm 3.4$ \\
\hline P. notatum & 16 & $6.6 \pm 1.6$ \\
\hline P. notatum & 17 & $1.4 \pm 0.7$ \\
\hline Solidago sp. & 18 & $14.8 \pm 5.7$ \\
\hline Solidago sp. & 18 & $8.3 \pm 3.6$ \\
\hline
\end{tabular}

A Length of experiment in days

BRadioactivity ( $\%$ ot total recovered radioactivity \pm one standard deviation) contained in leaves, stem-, and roots 


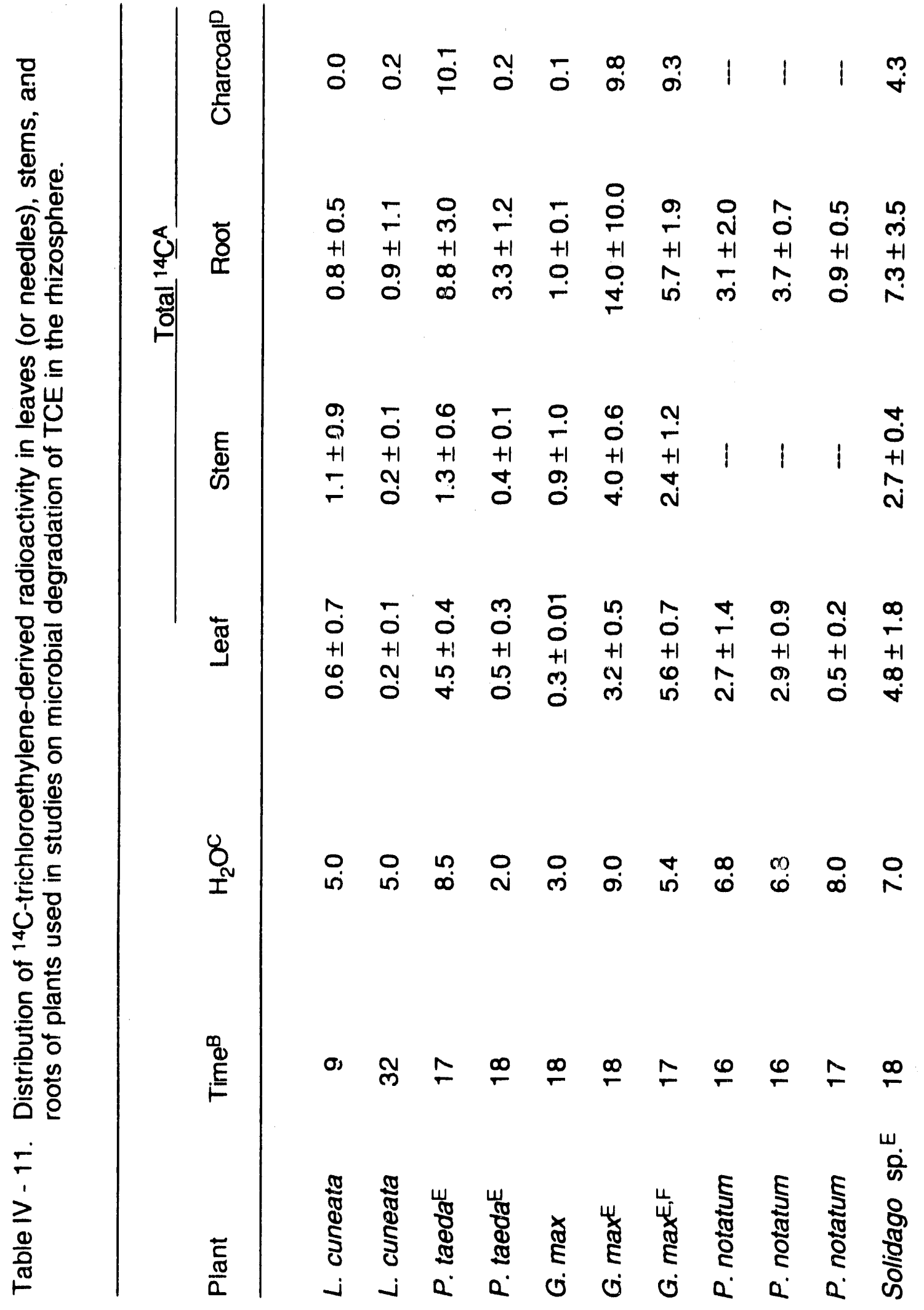




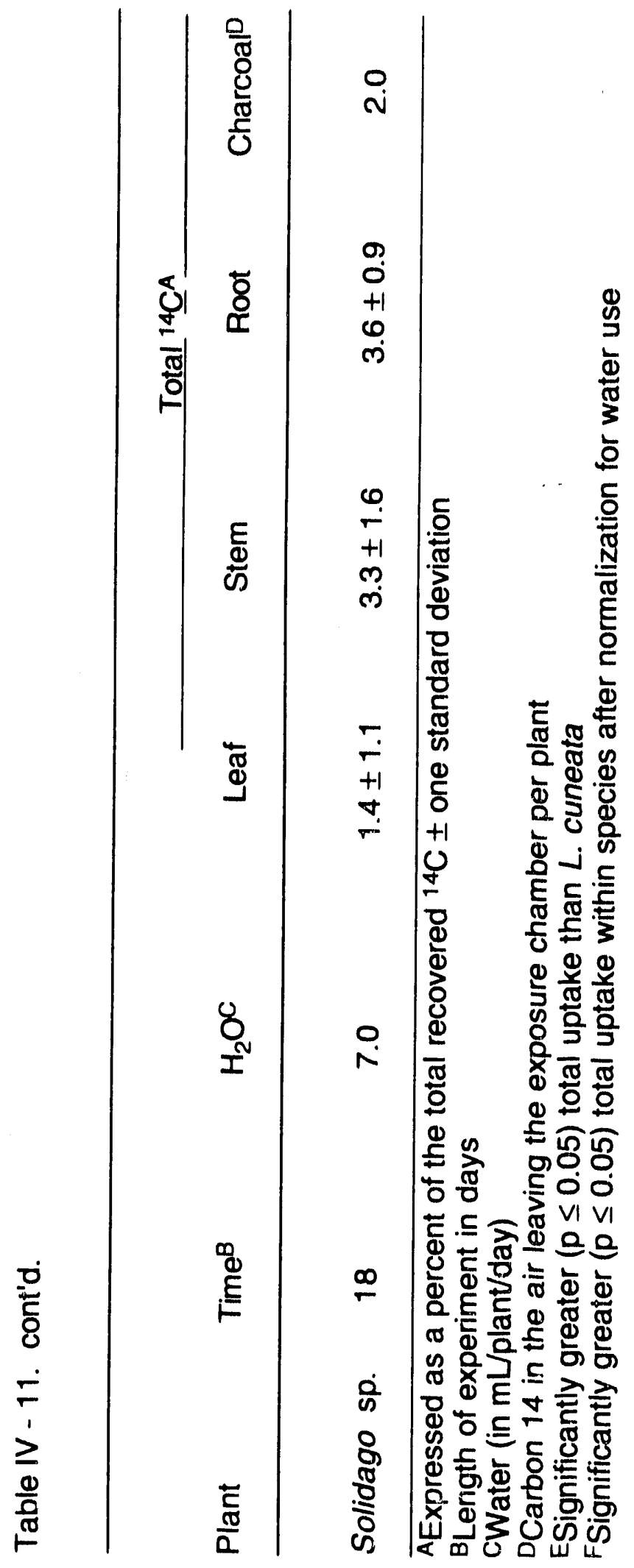


observed. The amount of ${ }^{14} \mathrm{C}$ in the plant tissues also appears to be dependent on plant species as illustrated by the significant differences in total uptake ( $p \leq$ 0.05 ) in $P$. taeda, G. max, and Solidago sp. compared with L. cuneata and $P$. notatum. No attempt was made to qualitatively identify the form of the ${ }^{14} \mathrm{C}$ in the plant tissues.

Although this system for monitoring uptake is more complex than most techniques employing plants or isolated roots in sterile nutrient solutions, simple relationships describing chemical uptake into plants can be developed from the soil-plant system. However, if environmental conditions are changed, the relationships became more complex as can be seen in Table IV - 12 Illustrating uptake data for plants grown under reduced light and in sterile soll. One of the effects of reduced light is decreased growth, which could have a negative effect on TCE uptake. However for $L$. cuneata and $P$. taeda, reduction of the light caused an increase in uptake of ${ }^{14} \mathrm{C}$ derived from ${ }^{14} \mathrm{C}$-TCE compared to identical plants grown under normal light. A possible explanation for this is that another effect of reduced light is decreased root exudation which could translate to decreased microbial activity and an increase in the amount of ${ }^{14} \mathrm{C}$ available for uptake due to the absence of microorganisms competing (through biodegradation) for the TCE. This explanation appears to be further illustrated by the increased uptake of ${ }^{14} \mathrm{C}$ in loblolly pine seedlings under sterile conditions. 


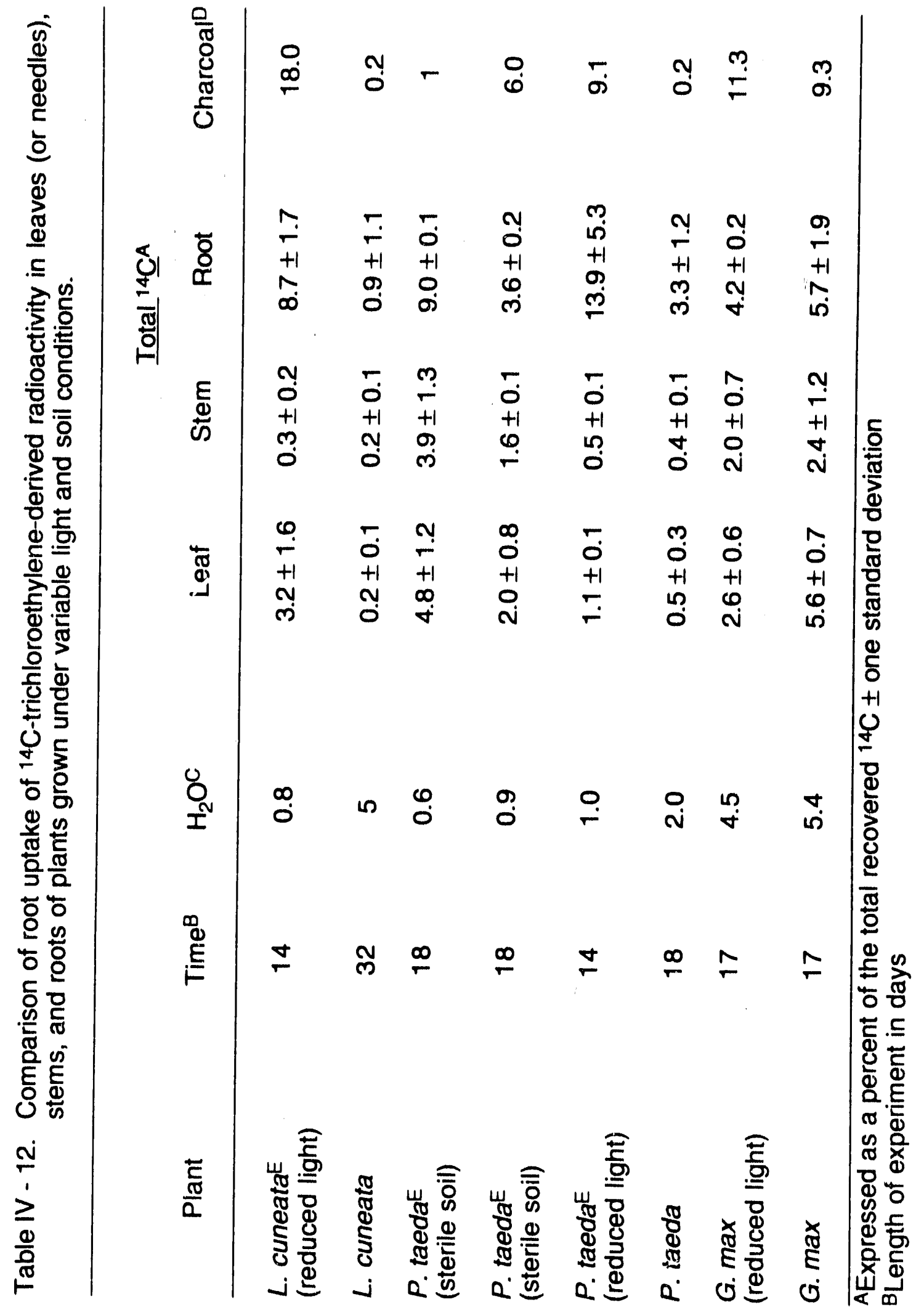




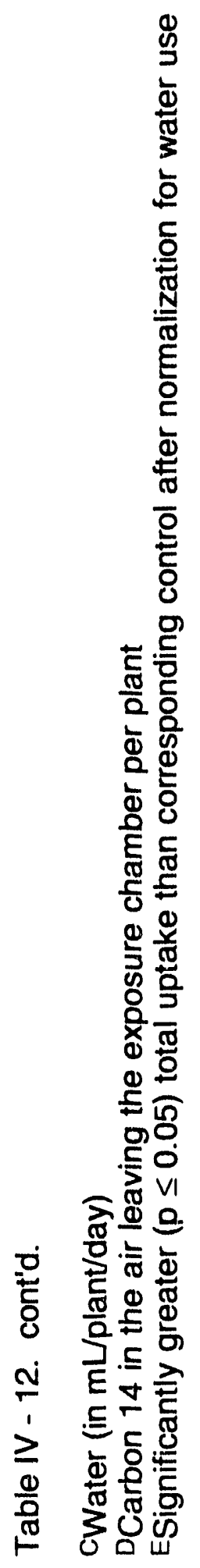




\section{J. Pesticide Root Zone Model (PRZM)}

The Pesticide Root Zone Model (PRZM) was chosen for its ability to simulate the decay and transport of pesticides in and below the plant root zone. Because the model was developed for monitoring the fate of nonvolatile compounds such as pesticides, it lacks the ability to simulate volatilization, a very important component of TCE fate. Although this presented no problem for actually conducting the simulation, the modeling results should be viewed with this shortcoming in mind. The complex matrix of input data included properties of TCE (such as sorption coefficient and degradation half-life), hydrology parameters for Aiken, SC (such as daily temperature and evapotranspiration), soll properties for the MCB (such as organic carbon content and bulk density), and vegetation characteristics (such as root depth and aerial coverage) for all four plant species and nonvegetated conditions.

In all of the simulations for the four plant species and nonvegetated conditions, the percentage of TCE remaining at the conclusion of the simulation (109 days) was consistently less under vegetated conditions (Table IV - 13). In plots planted with L. cuneata and P. taeda, the decay (The "decay" compartment in PRZM includes microbial degradation and losses due to runoff and erosion) of TCE was simulated as $>90 \%$, uptake into both plants was $<1 \%$, and $<0.1 \%$ of the TCE initially applied had migrated past the root zone $(40 \mathrm{~cm})$ after 109 days. For plots planted with Solidago sp. and $P$. notatum, the decay was $>75 \%$, while uptake was minimal but slightly larger (1.6\% and $1.4 \%$ for $P$. notatum and Solidago sp., respectively). In plots left unvegetated, $72 \%$ of the TCE initially added had decayed after 109 days. Although the presence or absence of 


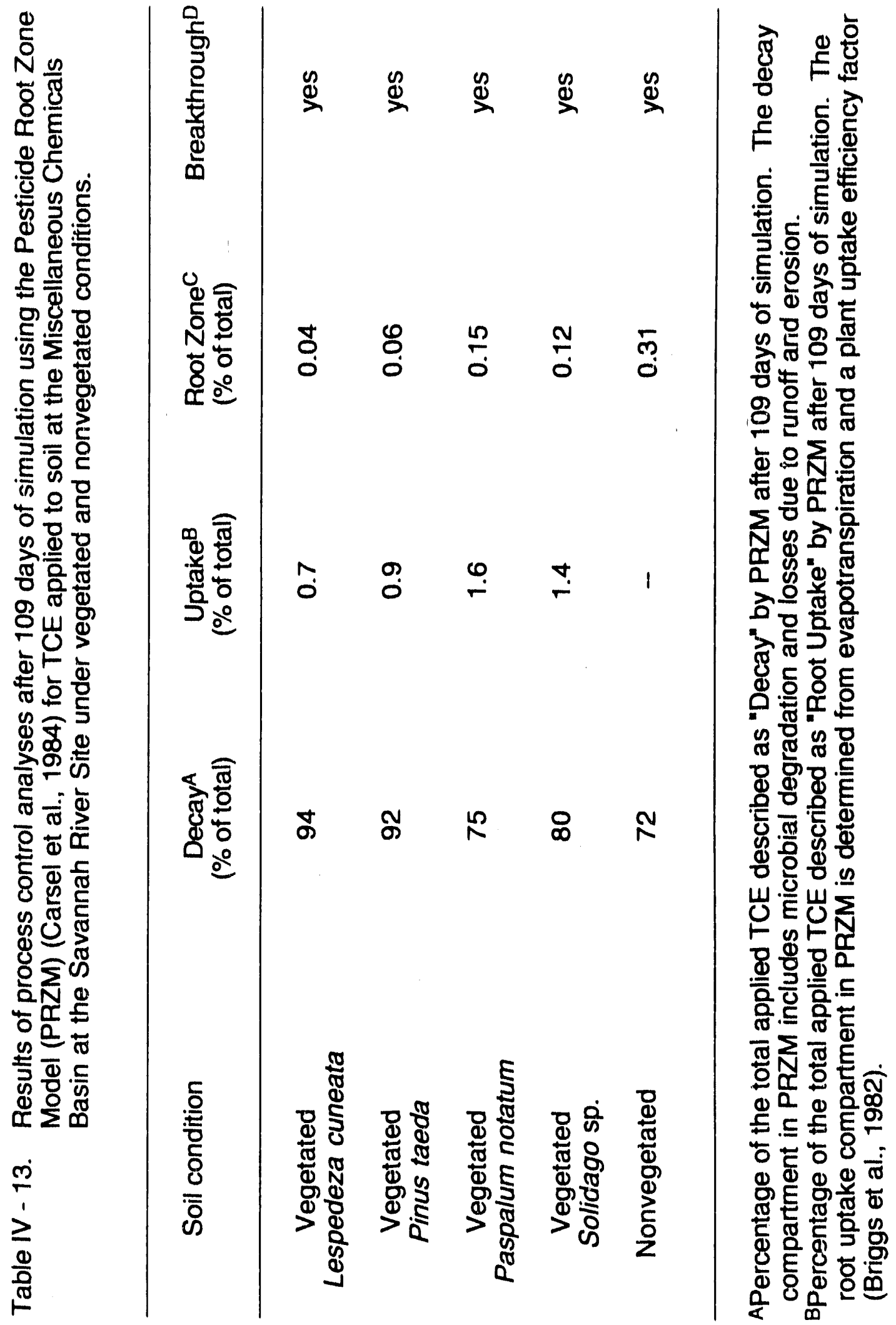




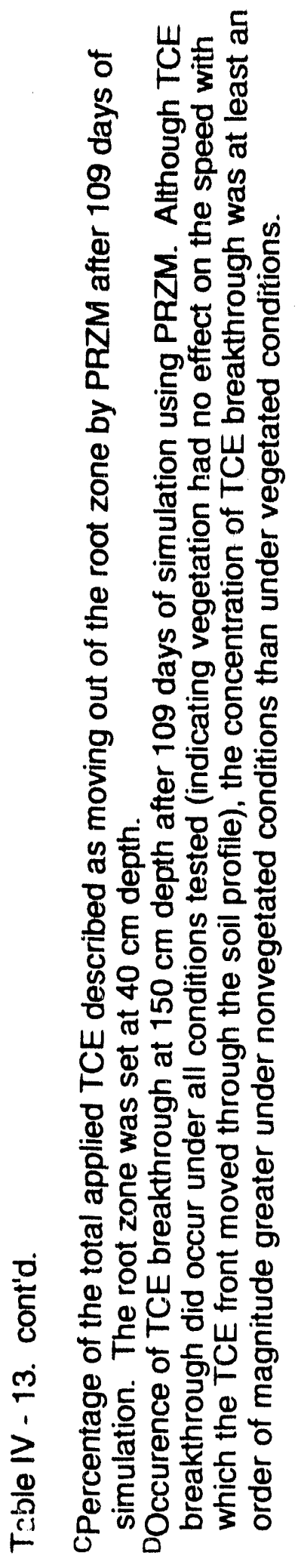


vegetation appeared to have no influence on the speed in which the TCE front migrated through the simulated soll profile $(150 \mathrm{~cm})$, concentrations of TCE breakthrough were at least one order of magnitude greater under nonvegetated conditions. 


\section{CHAPTER V. \\ DISCUSSION}

The iridices of microblal biomass and activity measured in the present study all provide evidence that microbial activity is greater in rhizosphere solls than in nonvegetated solls at the MCB. Results from two different techniques for measuring microblal blomass indicate that there is a substantial increase in microbial numbers associated with the plant rhizosphere. Although biomass estimates were uselful for describing the microblological properties of the MCB solls, they were not good predictors of TCE degradation. Rhizosphere soils from $P$. notatum and Solldago sp. had comparatively high levels of microbial blomass, yet both rhizosphere types did not degrade TCE as well as other samples with less microbial biomass.

Measurements of ${ }^{14} \mathrm{C}$-acetate incorporation rates, used as a measure of heterotrophic microbial activity, provide evidence for the increased microbial activity associated with the plant root zone. In addition, acetate incorporation also appeared to be a good predictor for the ability to degrade TCE in wholeplant experiments. Rhizosphere samples from L. cuncata and and $P$. taeda had relatively high rates of acetate incorportation and also had the highest TCE degradation rates, while samples of $P$. notatum rhizosphere and nonvegetated areas had lower acetate incorporation rates and lower TCE degradation rates.

In addition to providing biomass estimates, phospholipid fatty acid (PLFA) analysis also gave an indication of differences in the microbial community structure of nonvegetated and rhizosphere soil samples. Although taxonomic characterization of the microorganisms from the soil samples was not 
undertaken, it is possible to compare qualitative differences between the groups of microorganisms present using PLFA analysis. Both gram positive and gram negative microorganisms were present in all samples tested. In addition, cluster analysis of PLFA profiles indicated a stong presence of actinomycetes in samples from $P$. taeda and $P$. notatum inizospheres. Previous PLFA analysis of a TCE-degradading soll column enriched with natural gas (Wilson and Wilson, 1985) revealed the strong presence of type II methanotrophs as indicated by the fatty acid $18: 1 \omega 8 \mathrm{c}$ (Nichols et al., 1987). Because methanotrophs are likely to be found in zones that fluctuate between aerobic and anerobic conditions, such as surface soils that periodically flood and drain and subsurface solls at the capillary fringe, these bacteria are likely to be present at the MCB and also to contribute to TCE degradation in soils from the MCB. However, the characteristic fatty acid for type II methanotrophs (18:1 $108 \mathrm{c})$ was not detected in soll samples from the MCB. Nonetheless, these microorganisms are undoubtedly present based on their ubiquity in nature and the favorable conditions for their proliferation at the MCB.

Analyses for the endogenous storage lipid polybetahydroxyalkanoate (PHA) indicated its presence in all samples primarily as polybetahydroxybutyrate. Samples of $L$. cuneata and $P$. taeda rhizosphere soils contained elevated levals of PHA and were also very capable of degrading TCE in whole-plant experiments. Correlations between TCE degradation rate and PHA production have been observed previously in bioreactors (David Ringleberg and Dr. Tommy Phelps, Institute for Applied Microbiology, personal communication). Soil samples from Solidago sp. 
rhizosphere and nonvegetated areas within the MCB had the lowest levels of PHA and also degraded TCE more slowly in whole-plant experiments than rhizosphere soils of $L$. cuneata and $P$. taeda. Only soils from the rhizosphere of $P$. notatum failed to follow the correlation between degradation of TCE and production of PHA. Soils from P. notatum mizosphere had comparatively high levels of PHA but did not degrade TCE as well as soils from the rhizosphere of L. cunata and $P$. taeda.

Toxicity experiments witii TCE were very helpful in interpreting the data on biodegradation of TCE. Soil samples from P. notatum and Solidago sp. rhizosphere and nonvegetated areas had decreased respiration after exposure to TCE at $1000 \mu \mathrm{g} / \mathrm{g}$. These samples also had loweio ${ }^{14} \mathrm{C}$-TCE degradation rates campared with the thizosphere soil of $L$. cuneata and $P$. taeda. Both of these samples showed no effect from TCE at $100 \mu \mathrm{g} / \mathrm{g}$. Somewhat conflicting results were obtained from soxicity experiments with PCE indicating that only in certain cases may the PCE be influencing ${ }^{14} \mathrm{C}$-TCE degradation rates.

The results obtained from the degradation experiments indicate that the presence of vegetation enhances ${ }^{14} \mathrm{C}$-TCE mineralization in soil from a contaminated field site. Furthermore, these findings corroborate interpretations of earlier data indicating an initial rapid degradation of TCE in the rhizosphere soil slurries and mineralization of ${ }^{14} \mathrm{C}$-TCE in rhizosphere soil from $L$. cuneata (Walton and Anderson, 1990). In soils containing L. cuneata, P. taeda, and G. max, the levels of ${ }^{14} \mathrm{CO}_{2}$ produced were significantly greater than ${ }^{14} \mathrm{CO}_{2}$ production in both nonvegetated and sterile control soils. Radiolabelled $\mathrm{CO}_{2}$ production in soil containing Solidago sp. and $P$. notatum was elevated, 
however, there was no statistically significant difference from ${ }^{14} \mathrm{CO}_{2}$ produced in the respective nonvegetated soils. The plants tested represent a variety of root types-fibrous, tap. leguminous. and mycurrhizal Both of the legumes. $L$. cuneata and G. max, enhanced soil microbiai mineralization of ${ }^{14} \mathrm{C}$-TCE. athough oniy $L$. cuneata is indigenous to the contaminated site. In addition. the enhanced mineralization observed in soil containing loblolly pine seedlings. which iraditionally have abundant ectomycormizal associations (Curl and Truelove. 1986). rases the question of whether mycormizae contribute to the degradation of TCE or other hazardous organic compounds. Because elevated ${ }^{14} \mathrm{CO}_{2}$ production was observed in soils containing soybean germinated from commercially available seeds, prolonged TCE exposure to the plant does not appear to be a requirement for enhanced ${ }^{14} \mathrm{C}$-TCE mineralization. This may be a possible explanation for the lack of a statistically significant difference between ${ }^{14} \mathrm{CO}_{2}$ production in soil containing the indigenous composite, Solidago sp. compared with nonvegetated soil. Although prolonged exposure of the plant to TCE may not be essential for enhanced degradation in the mizosphere, prolonged exposure of the soil to TCE may be required for enhanced degradation of TCE. It is not clear whether the enhanced mineralization is most influenced by the structure or surface area of the root system (tap vs. fibrous), the selective influence of the root exudates, or the kind(s) of root associations present ( $\mathrm{N}_{2}$-fixing, mycorrhizal). Attempts to control the ${ }^{14} \mathrm{C}$-TCE degradation in the rhizosphere by influencing root exudation were successful but very preliminary. 
The results of degradation experiments described above were obtatined for soil samples and freshly added TCE. In these instances, the TCE is readily available to the microorganisms. In the latter stages of the degradation experiments, the TCE degradation rate decreases, probably because through sorption and volatilization, less of the TCE is available to the microorganisms. Thus, whether similar degradation rates could be obtained with soil contaminated with TCE for some time or at low TCE concentrations is a question that has yet to be answered and could possibly limit the application of vegetation to remediate contaminated surface soils. However, evidence from the literature on the phenomenon of secondary sutsstrate utilization (Schmint and Alexander, 1985; Schmidt et al., 1987) is encouraging. Schmict and coworkers found that dissolved organic substrates such as glucose could be used to enhance biodegradation of organic contaminants such as nitrophenol at low concentrations or after initial biodegradation of these compounds had stopped. Additionally, it may be possible to manipulate other environmental variables (Thorton-Manning et al., 1987) to positively influence TCE degradation in the field.

Root uptake of ${ }^{14} \mathrm{C}$ into plant tissues at the conclusion of the experiments (in most cases 18 days) was minimal for most of the plants tested. Uptake of organic compounds from soil solution is primarily affected by three factors; (1) physicochemical properties of the compounds, (2) environmental conditions, and (3) plant characteristics (Paterson et al., 1990). In these experiments where environmental conditions such as temperature, relative humidity, soil organic carbon content, and soil moisture content remained relatively constant, root 
uptake appeared to be dependent on plant characteristics and physicochemical properties of TCE and/or its metabolites. The plants used in this study represent a variety of root and leaf characteristics. Additionally, the metabolic products of TCE degradation are dependent on the existing environmental conditions in the system. Under aerobic conditions, TCE is oxidized by a variety of oxygenases to an epoxide which spontaneously breaks down to water soluble metabolites (formic acid, glyoxylic acid) (Little et al., 1988). These water-soluble metabolites could be readily taken up by plants or could be metabolized quite easily by a wide variety of microoganisms. Under arraerobic conditions, TCE is metabolized through reductive dechlorination (Vogel and McCarty, 1985) in which more lipophilic metabolites (dichloroethylene, vinyl chloride) are formed. These metabolites would have different fates in the soil-plant systems than the water soluble metabolites of aerobic TCE metabolism. Paterson and coworkers (1990), in a recent review on the uptake of organic compounds by plants, hypothesized that root uptake from soil solution was a function of the compound's octanol-water partition coefficient $\left(\mathrm{K}_{\mathrm{ow}}\right)$. Namely, that more lipophilic compounds readily partition into roots, but tend to remain there and are not translocated. However, compounds with high $\mathrm{K}_{\mathrm{ow}}$ would also be expected to partition from soil solution into soil organic matter, thus making them less available for uptake into the root. The $\log _{10} K_{\text {ow }}$ for TCE is 2.3-2.4 (Lyman et al., 1990). The increased ${ }^{14} \mathrm{C}$ observed in stems, leaves, and the charcoal trap during experiments when elevated water use was observed, is consistent with the concept of bulk water flow, induced by evapotranspiration, as being the driving force behind translocation (Mengel, 1974). 
Simulations using the Pesticide Root Zone Model (PRZM) (Carsel et al., 1984) and microbial degradation data from laboratory experiments were successful in illustrating the influence of vegetation on the biodegradation of TCE in soil at the MCB. However, the model lacked the ability to incorporate volatilization into the overall fate simulations. Thus the analyses for a highly volatile compound such as TCE using PRZM were somewhat compromised. Uptake into plant tissues was underestimated by PRZM compared with uptake experiments with ${ }^{14} \mathrm{C}$-TCE in the laboratory. Root uptake in the model is based on a root uptake concentration factor (Briggs et al., 1982) related to Kow, the evapotranspiration rate, and the amount of chemical in soil solution. Under conditions where the degradation rate was decreased, such as with $P$. notatum and Solidago sp., uptake was elevated. It appeared that degradation in the model was also based in part on the amount of chemical in the soil solution. This may account for the underestimation of uptake by the model. Surprisingly, the presence or absence of vegetation had little influence on the speed in which the front of TCE migrated through the soil profile. It was hypothesized that the presence of vegetation, because of its influence on the microorganisms and soil in the root zone, would significantly retard breakthrough of TCE. The simulations indicated that the front of TCE would reach $150 \mathrm{~cm}$ after 109 days under all conditions. However, there was at least one order of magnitude more breakthrough of TCE under nonvegetated conditions.

The data from the literature on microbial activity of the rhizosphere, the observation of enhanced pesticide degradation in the root zone, and the results of TCE degradation in the rinizosphere presented here provides a strong 
incentive for continued exploration of the soll-root-microbial interaction and the variables that may influence biodegradation of waste chemicals in surface and near-surface soils. 


\section{CHAPTER VI. \\ CONCLUSIONS}

The objective of this study was to collect data that would provide a foundation for the concept of using vegetation to enhance in situ bloremediation of contaminated surface soils. The Miscellaneous Chemicals Basin at the Savannah River Site provided an ideal area for testing this hypothesis because of its previous exposure history and its present condition (naturally revegetated). This dissertation represents a systematic approach to answering initial fundamental questions which were critical to meeting the overall objective and providing a foundation for further studies. The results presented provide strong evidence for the potential role of vegetation in remediation of surface soils contaminated with hazardous organic compounds. In addition, the reviewed literature on rhizosphere microbiology, accelerated microbial degradation of agricultural chemicals in the root zone, and recent research on similar observations with hazardous organic compounds provide additional impetus for further exploring bioremediation of contaminated soils using vegetation.

The microbial activity, biomass, and degradation of TCE in rhizosphere soils from the MCB was found to be significantly greater than corresponding nonvegetated soils. In addition, the presence of vegetation had a positive effect on microbial degradation of ${ }^{1.4} \mathrm{C}$-TCE providing additional evidence for the positive role of vegetation in remediation of the MCB. Furthermore, biodegradation of TCE may be much slower than biodegradation rates for less persistent waste chemicals such as nonhalogenated monoaromatics and 
diaromatics. Therefore, the data presented herein are likely to be a conservative estimate of the potential for enhanced degradation of waste chemicals in the plant mizosphere. Certainly, a critical part of using vegetation in remedlating contaminated surface soils is determining the magnitude of uptake of parent cornpound or hazardous metabolite into the plant tissue. In most of the whole plant experiments conducted, uptake was minimal and was related to water use and plant species.

Issues which must be addressed further include (1) the role of mycorrhizae in degradation in the root zone, (2) the influence of different root morphologies, (3) identifying the microbial communities associated with different plant species and the role of exudates in selection of those communities, (4) determining if different rhizosphere communities exist under different conditions (contaminated vs. uncontaminated) and (5) the influence of multiple contaminants, as would occur at waste sites, on microbial degradation in the rhizosphere.

Certainly, there may be limitations to using vegetation in site remediation, as there are limitations to bioremediation as a whole. However, continued exploration of critical environmental variables affecting the soil-plant-microbechemical relationship will help to identify situations in which bioremediation using vegetation may be inappropriate. 
LIST OF REFERENCES 


\section{CHAPTER VII.}

\section{LIST OF REFERENCES}

Abdel-Nasser, M., A. A. Makawl, and A. A. Abdel-Moneim. 1979. Occurrence of certain microorganisms in rhizosphere soils of common bean and cotton as affected by the application of Temik or orthocide pesticides. Egyptian Journal of Microbiology. 14:37-44.

Abueva, A. A. and V. B. Bagaev, 1975. Transformation of nitrogen fertilizer in soddy-podzolic soil under the effect of 2,4-D. Izvestiva Iimilinazevskol Selskokhozyaistvennol Akademill 2:127-130.

Alvarez-Cohen, L. and P. L. McCarty. 1991a. Effects of toxicity, aeration, and reductant supply on trichloroethylene transformation by a mixed methanotrophic culture. Applied and Environmental Microbiologx. $57: 228-235$.

Alvarez-Cohen, L. and P. L. McCarty. 1991b. Product toxicity and cometabolic competitive inhibition modeling of chloroform and trichloroethylene transformation by methanotrophic resting cells. Applied and Environmental Microbiologk 57:1031-1037

Alvarez-Cohen, L. and P. L. McCarty. 1991C. Two-stage dispersed-growth treatment of halogenated aliphatic compounds by cometabolism. Environmental Science and Technology. 25:1387-1393.

Alvarez-Cohen, L. and P. L. McCarty. 1991d. A cometabolic biotransformation model for halogenated aliphatic compounds exhibiting product toxicity. Enironmental Science and Technologk 25:1381-1387.

Ampova, G. 1971. Effect of MN-30 ( $30 \%$ maleic hydrazide) on the tobacco microflora and rhizosphere. Bulgarski Iyutyun, 16:39-4's.

Aprill W. and R. C. Sims. 1990. Evaluation of the use of prairie grasses for stimulating polycyclic aromatic hydrocarbon treatment in soil. Chemesphere, 20:253-265.

Atlas, R. M. and D. Pramer. 1990. Focus on bioremediation. ASM News. $56: 352-353$.

Atlas, R. M., and R. Bartha. 1987. Microbial Ecology: Fundamentals and Applications. Benjamin/Cummings. Menlo Park, CA. 
Baek, N. H., and P. R. Jaffe. 1989. The degradation of trichloroethylene in mixed methanogenic cultures. Jeurnal of Environmental Quality. 18:515-518.

Balkwill, D. L., F. R. Leach, J. T. Wilson, J. F. McNabb, and D. C. White. 1988. Equivalence of microbial biomass measures based on membrane lipid and cell wall components, adenosine triphosphate, and direct counts in subsurface aquifer sediments. Microbial Ecology 16:73-84.

Barber, D. A. and K. B. Gunn. 1974. The effect of mechanical forces on the exudation of organic substances by the roots of cereal plants grown under sterile conditions. New Phytelegist. 73:39-45.

Barnhart, C. L., and J. R. Vestal. 1983. Effects of environmental toxicants on metabolic activity of natural microbial communities. Applied and Environmental Microbiology 46:970-977.

Barrio-Lage, G. A., F. Z. Parsons, and R. S. Nassar. 1987a. Kinetics of the depletion of trichloroethene. Envirenmental Science and Iechnology. 21:366-370.

Barrio-Lage, G. A., F. Z. Parsons, R. S. Nassar, and P. A. Lorenzo. $1987 \mathrm{~b}$. Biotransformation of trichloroethylene in a variety of subsurface materials. Environmental Ioxicology and Chemistry, 6:571-578.

Barrio-Lage, G. A., F. Z. Parsons, and P.'A. Lorenzo. 1988. Inhibition and stimulation of trichloroethylene biodegradation in microaerophilic microcosms. Environmental Ioxicology and Chemistry, 7:889-895.

Bligh, E. G., and W. J. Dyer. 1959. A rapid method of total lipid extraction and purification. Canadian Joumal of Biochemical Physiology. 37:911-917.

Bobbie, R. J., and D. C. White. 1980. Characterization of benthic microbial community structure by high resolution gas chromatography of fatty acid methyl esters. Applied and Environmental Microbielegy. 39:1212-1222.

Boulter, D., J. J. Jeremy, and M. Wilding. 1966. Amino acids liberated into the culture medium by pea seedling roots. Plant and Soll 24:121-127.

Bouwer, E. J., B. E. Rittmann, and P. L. McCarty. 1981. Anaerobic degradation of halogenated 1- and 2-carbon organic compounds. Environmental Science and Technology, 15:596-599. 
Bouwer, E. J. and P. L. McCarty. 1983a. Transformation of 1- and 2-carbon halogenated aliphatic organic compounds under methanogenic conditions. Applled and Environmental Microbiology. 45:1286-1294.

Bouwer, E. J. and P. L. McCarty. 1983b. Transformation of halogenated organic compounds under denitrifying conditions Applled and Environmental Microblology 45:1295.

Bowen, G. D. 1969. Nutrient status effects on loss of amides and amino acids from pine roots. Plant and Soll. 30:139-142.

Briggs, G. G., R. H. Bromilow and A. A. Evans. 1982. Relationships between lipophilicity and root uptake of nonionised chemicals by barley. Pesticide Science, 13:495-504.

Brock, T. D. 1966. Principles of Microblal Ecology. Prentice-Hall. New Jersey. $306 \mathrm{pp}$.

Broholm, K., B. K. Jensen, T. H. Christensen, and L. Olsen. 1990. Toxicity of 1,1,1-trichloroethane and trichloroethylene on a mixed culture of methane-oxidizing bacteria. Applied and Environmental Microbiology. 56:2488-2493.

Campbell, R. 1985. Plant Microbiology. Edward Arnold. Baltimore. 191 pp.

Campbell, R. and A. D. Rovira. 1973. The study of the rhizosphere by scanning electron microscopy. Soil Biology and Biochemistry. 5:747-752.

Carsel, R. F., C. N. Smith, L. A. Mulkey, D. Dean and P. Jowsie. 1984. User's manual for the pesticide root zone model (PRZM): Release I. EPA/600/384/109. Athens, GA.

Curl, E. A. and B. Truelove. 1986. The Rhizosphere. Springer-Verlag. Berlin Heidelberg. $288 \mathrm{pp}$.

Daughton, G. G. and D. P. H. Hsieh. 1977. Parathion utilization by bacterial symbionts in a chemostat. Applied and Environmental Microbiology. 34:175-184.

Davis, W. M., and D. C. White. 1980. Fluorimetric determinations of adenosine nucleotide derivatives as measures of the microfouling, detrital and sedimentary microbial biomass and physiological status. Applied and Environmental Microbiology. 40:539-548. 
Edwards, N. T. 1982. A timesaving technique for measuring respiration rates In incubated soll samples. Soll iclence Soclety of Amerloa Journal. 46:1114-1116.

Federle, T. W. and B. S. Schwab. 1989. Minerallzation of surfactants by microbiota of aquatic plants. Applled and Environmental Microblology. 55:2092-2094.

Federle, T. W. and R. M. Ventullo. 1990. Minerallzation of surfactants by the microblota of submerged plant detritus. Applied and Environmental Microbiology. 56:333-339.

Findlay, R. H., and D. C. White. 1983. Polymeric beta-hydroxyalkanaoates from environmental samples and Bacillus megaterium. Applied and Environmental Microbiologk 45:71-78.

Findlay, R. H., and D. C. White. 1987. A simplifled method for bacterial nutritional status based on the simultaneous determination of phospholipld and endogenous storage lipid poly- $B$-hydroxyalkanoate. Journal of Microbiological Methods. 6:113-120.

Findlay, R. H., P. C. Pollard, D. J. W. Moriarity, and D. C. White. 1985. Quantitative determination of microbial activity and community nutritional status in estuarine sediments: evidence for a disturbance artifact. Canadian Journal of Microbiology 31:493-498.

Fliermanns, C. B., T. J. Phelps, D. Ringlelberg, A. T. Mikell, and D. C. White. 1988. Minerlaization of trichloroethylene by heterotrophic enrichment cultures. Applied and Environmental Microbiology. 54:1709-1714.

Fogel, M. M., A. R. Taddeo and S. Fogel. 1986. Blodegradation of chlorinated ethenes by a methane-utilizing mixed culture. Applied and Environmental Microbiologx 51:720-724.

Folsom, B. R., P. J. Chapman, and P. H. Pritchard. 1990. Phenol and trichloroethylene degradation by Pseudomonas cepacia G4: Kinetics and interactions between substrates. Applied and Envireninental Microbiology, 56:1279-1285.

Folsom, B. R. and P. J. Chapman. 1991. Performance characierization of a model bioreactor for the biodegradation of trichloroethylene by

Pseudomonas cepacia G4. Applied and Environmental Microbiology. 57:1602-1608.

Foster, R. C., A. D. Rovira, and T. W. Cook. 1983. Ultrastructure of the Root-Soil Interface. American Phytopathological Society. St. Paul, MN. 154 pp. 
Freedman, D. L., and J. M. Gossett. 1989. Blological reductive dechlorination of tetrachloroethylene and trichloroethylene to ethylene under methanogenic conditions. Applied and Environmental Microblology. $55: 2144-2151$.

Gavrilova, E. A., Y. V. Kruglov, and N. G. Garankina. 1983. Effects of plants and microflora of the rhizosphere on the degradation of Basudin in the soil. Irudy Vsesoyuznyi Nauchno-Issledovatelskill Institut Selskokhozyaistevennol Milkroblologil. 52:67-70.

Gray, T. R. G. and D. Parkinson. 1968. The Ecology of Soll Bacteria. University of Toronto Press. Toronto, Canada. pp.

Guckert, J. B., C. P. Antworth, P. D. Nichols, and D. C. White. 1985. Phospholipid, ester-linked fatty acid profiles as reproducible assays for changes in prokaryotic community structure structure of estuarine sediments. EEMS Microbial Ecologk, 31:147-158.

Guckert, J. B., M. A. Hood, and D. C. White. 1986. Phospholipid ester-linked fatty acid profile changes during nutrient deprivation of Vibrio cholerae: increase in the trans/cis ratio and proportions of cyclopropiyl fatty acids. Applied and Environmental Microbiology. 52:794-801.

Gunner, H. B., B. M. Zuckerman, R. W. Walker, C. W. Miller, K. H. Deubert, and R. E. Longley. 1966. The distribution and persistence of diazinon applied to plant and soll and its influence on rhizosphere and soil microflora. Plant and Soill 25:249-264.

Haber, C. L., L. N. Allen, S. Zhao, and R. S. Hanson. 1983. Methylotrophic bacteria: biochemical diversity and genetics. Science, 221:1147-1153.

Harker, A. R. and Y. Kim. 1990. Trichloroethylene degradation by two independent aromatic-degrading pathways in Alcaligenes eutrophus jmp134. Applied and Environmental Microbiology. 56:1179-1181.

Heath, C. W., C. R. Dumont, J. Gamble, and R. J. Waxweiler. 1977. Chromosomal damage in men occupationally exposed to vinyl chloride monomer and other chemicals. Environmental Research. 14:68-72.

Henry, S. M. and D. Grbic-Galic. 1991a. Influence of endogenous and exogenous electron donors and trichloroethylene oxidation toxicity on trichloroethylene oxidation by methanotrophic cultures from a groundwater aquifer. Applied and Environmental Microblology. 57:236-244. 
Henry, S. M. and D. Grbic-Galic. 1991b. Inhibition of trichloroethylene oxidation by the transformation intermediate carbon monoxide. Applied and Environmental Microbiology. 57:1770-1776.

Henson, J. M., M. V. Yates, J. W. Cochran, and D. L. Shackierord. 1988. Microbial removal of halogenated methanes, ethanes, and ethylenes in an aerobic soil exposed to methane. FEMS Microbial Ecology. 53:193-201.

Henschler, D., W. R. Hoos, H. Fetz, E. Dallmeier, and M. Metzler. 1979. Reactions of trichloroethylene epoxide in aqueous systems. Biochemical Pharmacology, 28:543-548.

Hiltner, L. 1904. Uber neuere Erfahrungen and Probleme auf dem Geibert der Bodenbakteriologie und unter besonderer Berucksichtigung der Grundungung und Brache. Arb Dtsch Landwirt. Ges 98:59-78. In Curl, E. A. and B. Truelove. 1986. The Rhizosphere. Springer-Verlag. Berlin Heidelberg. 288 pp.

Hou, C. T., R. Patel, A. L. Laskin. N. Barnabe, and I. Barist. 1983. Epoxidation of short-chain alkenes by resting-cell suspensions of propane-grown bacteria. Applied and Environmental Micrcioiology. 46:171-177.

Hsu, T. S. and R. Bartha. 1979. Accelerated mineralization of two organophosphate insecticides in the rhizosphere. Applied and Environmental Microbiology, 37:36-41.

Jenkinson, D. S., and J. M. Oades. 1979. A method for measuring adenosine triphosphate in soil. Soil Biology and Biochemistry. 11:193-199.

Kanazawa, S. and Z. Filip. 1986. Effects of trichloroethylene, tetrachloroethylene and dichloromethane on enzymatic activiies in soil. Applied Microbiology and Biotechnology. 25:76-81.

Kanazawa, S. and Z. Filip. 1987. Effects of trichloroethylene, tetrachloroethylene and dichloromethane on soil biomass and microbial counts. Zbl. Bakt. Hya. 184:24-33.

Kastner, M. 1991. Reductive dechlorination of tri- and tetrachloroethylene depends on transition from aerobic to anaerobic conditions. Applied and Environmental Microbiology. 57:2039-2046.

Katznelson, H. 1946. The rizosphere effect of mangels on certain groups of micro-organisms. Soil Science. 62:343-354. 
Katznelson, 1965. Na.ure and importance of the rhizosphere. In Baker, K. F. and W. C. Snyder, eds. Ecology of Soil-Borne Plant Pathogens. University of Califomia Press. Berkeley. pp. 187-207.

Katznelson, H., J. W. Rouatt, and T. M. B. Payne. 1955. The liberation of amino acids and reducing compounds by plant roots. Plant and Soil. 7:35-48.

Klaassen, C. D. and G. L. Plaa. 1967. Relative effects of various chlorinated hydrocarbons on liver and kidney function in dogs. Toxicology and Applied Pharmacology. 10:119-131.

Kleopfer, R. D., D. M. Easley, B. B. Haas, Jr., T. G. Deihl, D. E. Jackson, and C. J. Wurrey. 1985. Anaerobic degradation of trichloroethylene in soil. Environmental Science and Technology, 19:277-280.

Kloskowski, R., I. Scheunert, W. Klein, and F. Korte. 1981. Laboratory screening of distribution, conversion and mineralization of chemicals in the soil-plant-system and comparison to outdoor experimental data. Shemosphere, 10:1089-1100.

Lappin, H. M., M. P. Greaves, and J. H. Slater. 1985. Degradation of the herbicide mecoprop [2-(2-methyl-4chlorophenoxy) propionic acid] by a synergistic microbial community. Appolied and Environmental Microbiology. 49:429-433.

Large, P. J. 1983. Methylotrophy and Methanogenesis. American Society for Microbiology. Washington, D.C. 88 pp.

Lee, L. S., P. S. C. Rao, M. L. Brusseau, and R. A. Ogwada. 1988. Nonequilibrium sorption of organic contaminants during flow through columns of aquifer $\mathrm{m}$ : aterials. Environmental Toxicology and Chemistry, 7:779-793.

Leiser, A. T. 1968. A mucilaginous root sheath in Ericaceae. American Journal of Botany, 55:391-398.

Linford, M. B. 1942. Methods of observing soil flora and fauna associated with roots. Soil Science, 53:93-103.

Little, C. D., A. V. Palumbo, S. E. Herbes, M. E. Lindstrom, R. L. Tyndall, and P. J. Gilmer. 1988. Trichloroethylene biodegradation by a methaneoxidizing bacterium. Applied and Environmental Microbiology. 54:951-956. 
Lovelock, J. E. 1979. Gaia: A New Look at Life on Earth. Oxford University Press. New York.

Lyman, W. J., W. F. Reehl, and D. H. Rosenblatt. 1990. Handbook of Chemical Property Estimation Methods: Environmental Behavior of Organic Compounds. American Chemical Society, Washington, DC.

Lynch, J. M. 1982. The mizosphere. In Burns, R. G. and J. H. Slater, eds. Experimental Microbial Ecology. Blackwell Scientific Publishers. Oxford, England. pp. 395-411.

Mailhot, H. and R. H. Peters. 1988. Emperical relationships between the 1-octanol/water partition coefficient and nine physicochemical properties. Environmental Science and Technology. 22:1479-1488.

McClellen, K. L., N. Buras, and R. C. Bales. 1989. Biodegradation of trichloroethylene by bacteria indigenous to a contaminated site. Journal of Environmental Science and Health. 24:561-570.

McKinley, V. L., and J. R. Vestal. 1984. Biokinetic analysis of adaptation and succession: microbial activity in composting sewage sludge. Applied and Environmental Microbiology, 47:933-941.

McKinney, L. L., E. H. Uhing, J. L. White, and J. C. Picken. 1955. Autoxidation products of trichloroethylene. Journal of Agriculture and Food Chemistry. 3:413-419.

Mengel, K. 1974. Ion Uptake and Translocation. In E. W. Carson, Ed. The Plant Root and Its Environment. University Press of Virginia. Charlottesville, VA.

Merck Index. 1989. Windholz, M., S. Budavari, L. Y. Stroumtsos, and M. N. Fertig, eds. Merck and Co., Inc. Rahway, N.J. 1606 pp.

Microseeps Ltd. 1986. "Soil and Soil gas sampling in Old Ellenton, the SRL Oil Test Site, the Fire Training Area, and the Miscellaneous Chemicals Basin." Final Report RFP86-89. University of Pittsburgh Applied Research Center: Pittsburgh, PA 15238. pp. 107.

Millar, W. N., and L. E. Casida, Jr. 1970. Evidence for muramic acid in soil. Canadian Journal of Microbiology. 16:299-304.

Miller, R. E. and F. P. Guengerich. 1982. Oxidation of trichloroethylene by liver microsomal cytochrome P-450: Evidence for chlorine migration in a transition state not involving trichloroethylene oxide. Biochemistry. 21:1090-1097. 
Miller, R. E. and F. P. Guengerich. 1983. Metabolism of trichloroethylene in isolated hepatocytes, microsomes, and reconstituted enzyme systems containing cytrochrome P-450. Cancer Research. 43:1145-1152

Molla, M. A. Z., A. A. Chowdhury, A. Islam, S. Hoque. 1984. Microbial mineralization of organic phosphate in soil. Plant and Soil. 78:393-399.

Moriarty, D. J. W., and P. C. Pollard. 1981. DNA synthesis as a measure of bacterial growth rates in seagrass sediments. Marine Ecology Program Series. 5:151-156.

Moriarty, D. J. W., D. C. White, and T. J. Wassenberg. 1985. A convenient method for measuring rates of phospholipid synthesis in seawater and sediments: its relevance to the determination of bacterial productivity and the disturbance artifacts introduced by measurements. Journal of Microbiological Methods. 3:321-330.

Nakas, J. P. and D. A. Klein. 1980. Mineralization capacity of bacteria and fungi from the rhizosphere-rhizoplane of a semiarid grassland. Applied and Environmental Microbiology, 39:113-117.

Nelson, D. W. and L. E. Sommers. 1982. Total carbon, organic carbon, and organic matter. In A. L. Page, R. H. Miller and D. R. Keeney, Eds. Methods of Soil Analysis, Part 2. Chemical and Microbiological Properties. Agronomy Monograph no. 9 (2nd Edition). p. 539-579. American Society of Agronomy, Inc. and Soil Science Society of America, Inc. Madison, WI.

Nelson, M. J. K., S. O. Montgomery, E. J. O'Neill, and P. H. Pritchard. 1986. Aerobic metabolism of trichloroethylene by a bacterial isolate. Applied and Environmental Microbiology, 52:383-384.

Nelson, M. J. K., S. O. Montgomery, W. R. Mahaffey, and P. H. Pritchard. 1987. Biodegradation of trichloroethylene and involvement of an aromatic biodegradative pathway. Applied and Environmental Microbiology. 53:949-954.

Nelson, M. J. K., S. O. Montgomery, and P. H. Pritchard. 1988. Trichloroethylene metabolism by microorganisms that degrade aromatic compounds. Applied and Environmental Microbiology. 54:604-606.

Newman, L. M. and L. P. Wackett. 1991. Fate of 2,2,2-trichloroacetaldehyde (chloral hydrate) produced during trichloroethylene oxidation by methanotrophs. Applied and Environmental Microbiology. 
57:2399-2402.

Nichols, P. D., J. M. Henson, C. P. Antworth, J. Parsons, J. T. Wilson, and D. C. White. 1987. Detection of a microbial consortium, including type II methanotrophs, by use of phospholipid fatty acids in an aerobic halogenated hydrocarbon-degrading soil column enriched with natural gas. Environmental Toxicology and Chemistry, 6:89-97.

Norby, R. J., E. G. O'Neill, W. G. Hood, and R. J. Luxmoore. 1987. Carbon allocation, root exudation and mycorrhizal colonization of Pinus echinata seedlings grown under $\mathrm{CO}_{2}$ enrichment. Tree Physiology. 3:203-210.

Oldenhuis, R., R. L. J. M. Vink, D. B. Janssen, and B. Witholt. 1989. Degradation of chlorinated aliphatic hydrocarbons by Methylosinus trichosporium OB3b expressing soluble methane monooxygenase. Applied and Environmental Microbiology. 55:2819-2826.

Oldenhuis, R., J. Y. Oedzes, J. J. van der Waarde, and D. B. Janssen. 1991. Kinetics of chlorinated hydrocarbon degradation by Methylosinus trichosporium OB3b and toxicity of trichloroethylene. Applied and Environmental Microbiology, 57:7-14.

Ong, S. K. and L. W. Lion. 1991. Mechanisms for trichloroethylene vapor sorption onto soil minerals. Journal of Environmental Quality. 20:180-188.

Parkinson, D. and E. A. Paul. 1982. Microbial Biomass. In A. L. Page, R. H. Miller, and D. E. Keeney, Eds. Methods of Soil Analysis, Part 2. Chemical and Microbiological Properties. Agronomy Monograph no. 9 (2nd Edition). p. 821-830. American Society of Agronomy, Inc. and Soil Science Society of America, Inc., Madison, WI.

Parsons, F. and G. Barrio-Lage. 1985. Chlorinated organics in simulated groundwater environments. Journal of the American Water Works Association. 77:52-59.

Parsons, F., P. R. Wood, and J. DeMarco. 1984. Transformations of tetrachloroethene and trichloroethene in microcosms and groundwater. Journal of the American Water Works Association. 76:56-59.

Paterson, S., D. Mackay, D. Tam, and W. Y. Shiu. 1990. Uptake of organic chemicals by plants: a review of processes, correlations and models. Chemosphere, 21:297-331 
Peterson, M. S., L. W. Lion, and C. A. Shoemaker. 1988. Influence of vaporphase sorption and diffusion on the fate of trichloroethylene in an unsaturated aquifer system. Environmental Science and Technology. 22:571-579.

Phelps, T. J., J. J. Niedzielski, R. M. Schram, S. E. Herbes, and D. C. White. 1990. Biodegradation of trichloroethylene in continuous-recycle expanded-bed bioreactors. Applied and Environmental Microbiology. 56:1702-1709.

Phelps, T. J., J. J. Niedzielski, K. J. Malachowsky, R. M. Schram, S. E. Herbes, and D. C. White. 1991a. Biodegradation of mixed-organic wastes by microbial consortia in continuous-recycle expanded-bed bioreactors. Environmental Science and Technology, 25:1461-1465.

Phelps, T. J., K. Malachowsky, R. M. Schram, and D. C. White. 1991b. Aerijbic mineralization of vinyl chloride by a bacterium of the order Actinomycetales. Applied and Environmental Microbiology. 57:12521254.

Pickett, J. B., H. W. Bledsoe, C. F. Muska, and I. W. Marine. 1986. Environmental information document: metals burning pit, miscellaneous chemicals basin. Final draft DPST-85-691. E. I. Du Pont de Nemours and Co., Savannah River Plant, Aiken, SC.

Plaa, G. L. 1986. Toxic responses of the liver. In Claassen, C. D., M. O. Amdur, and J. Doull, eds. Casarett and Doull's Toxicology: The Basic Science of Poisons. Macmillan Publishing Company. New York. pp. 286-309.

Plaa, G. L., G. J. Traiger, G. K. Hanasono, and H. P. Witschi. 1975. Effect of alcohols on various forms of chemically induced liver injury. In Khanna, J. M., Y. Israel, and H. Kalant, eds. Alcoholic Liver Pathology. Addiction Research Foundation. Toronto. pp. 225-244.

Ramakrishna, C. and N. Sethunathan. 1982. Stimulation of autotrophic ammonium oxidation in rice rhizosphere by the insecticide carbofuran. Applied and Environmental Microbiology, 44:1-4.

Rasolomanana, J. L. and J. Balandreau. 1987. Role de la rhizosphere dans la biodegradation de composes recalcitrants: cas d'une riziere polluee par des residus petroliers. Revue d'Ecologie et de Biologie du Sol. 24:443-457.

Reddy, B. R. and N. Sethunathan. 1983. Mineralization of parathion in the rice rhizosphere. Applied and Environmental Microbiology. 45:826-829. 
Roberts, P. V., J. E. Schreiner, and G. D. Hopkins. 1980. Wastewater Reuse for Groundwater Recharge. Asano, T. and P. V. Roberts, eds. California State Water Resources Control Board. pp. 283-316.

Rovira, A. D. 1956. Plant root excretions in relation to the rhizosphere effect. I. The nature of root exudate from oats and peas. Plant and Soil. 7:178-194.

Rovira, A. D. 1959. Root excretions in relation to the rizosphere effect. IV. Influence of plant species, age of plants, light, temperature and calcium nutrition on exudation. Plant and Soil. 11:53-64.

Rovira, A. D. and C. B. Davey. 1974. Biology of the Rhizosphere. In Carson, E. W., ed. The Plant Root and Its Environment. University of Virginia Press. Charlottesville, VA. pp. 153-204.

Rovira, A. D., E. I. Newman, H. J. Bowen, and R. Campbell. 1974. Quantitative assessment of the rhizosphere microflora by direct microscopy. Soil Biology and Biochemistry, 6:211-216.

Rovira, A. D., R. C. Foster, and J. K. Martin. 1979. Note on terminology: Origin, nature, and nomenclature of the organic materials in the rhizosphere. In Harley, J. L. and R. S. Russell, eds. The Soil-Root Interface. Academic Press. New York. pp. 1-4.

Russell, R. S. 1977. Plant Root Systems: Their Function and Interaction with Soil. McGraw-Hill. London. pp.

Ryan, J. A., R. M. Bell, J. M. Davidson, and G. A. O'Connor. 1989. Plant uptake of non-ionic organic chemicals from soils. Chemosphere. 17:2299-2323.

Sandmann, E. and M. A. Loos. 1984. Enumeration of 2,4-D-degrading microorganisms in soils and crop plant rhizospheres using indicator media: High populations associated with sugarchane (Saccharum officinarum ). Chemosphere, 13:1073-1084.

Sato, K. 1989. Effect of the herbicide, benthiocarb (thiobencarb) on seasonal changes in microbial populations in paddy soil and yield of rice plants. In Vancura, V., and F. Kunc, eds. Interrelationships between Microorganisms and Plants in Soil. Elsevier. New York. pp. 335-342.

Scheunert, I., D. Vockel, J. Schmitzer, and F. Korte. 1987. Biomineralization rates of $14 \mathrm{C}$-labelled organic chemicals in aerobic and anaerobic soil. Chemosphere. 16:1031-1041. 
Schmidt, S. K., K. M. Scow, and M. Alexander. 1987. Kinetics of pnitrophenol mineralization by a pseudomonas sp.: Effects of second substrates. Applled and Environmental Microbiology, 53:2617-2623.

Schrnidt, S. K. and M. Alexander. 1985. Effects of dissolved organic carbon and second substrates on the biodegradation of organic compounds at low concentrations. Applied and Environmental Microbiology. 49:822-827.

Seibert, K., F. Fuehr, and H. H. Cheng. 1981. Experiments on the degradation of atrazine in the maize mizosphere. Theory and Practical Use of Soil Applied Herbicides Symposium. European Weed Resource Society. Paris, France. pp. 137-146.

Sipes, I. G. and A. J. Gandolfi. 1986. Biotransformation of Toxicants. In Claassen, C. D., M. O. Amdur, and J. Doull, eds. Casarett and Doull's Toxicology: The Basic Science of Poisons. Macmillan Publishing Company. New York. pp. 64-98.

Smith, G. A., J. D. Davis, A. M. Muscat, R. L. Moe, and D. C. White. 1989. Lipid composition and metabolic activities of benthic near-shore microbial communities of Arthur harbor, Antartic peninsula: comparisons with McMurdo sound. Polar Biology, 9:517-524.

Smith, G. S., J. S. Nickels, B. D. Kerger, J. D. Davis, S. P. Collins, J. T. Wilson, J.F. McNabb, and D. C. White. 1986. Quantitative characterization of microbial biomass and community structure in subsurface material: a prokaryotic consortiurn responsive to organic contamination. Canadian Journal of Microbiology. 32:104-111.

Stern, K. R. 1982. Introductory Plant Biology. Wm. C. Brown Company Publishers, Dubuque, IA. 493 pp.

Strandberg, G. W., T. L. Donaldson, and L. L. Farr. 1989. Degradation of trichloroethylene and trans-1,2-dichloroethylene by a methanotrophic consortiurn in a fixed-film, packed-bed bioreactor. Environmental Science and Technology, 23:1422-1425.

Stotzky, G., W. Culbreth, and L. B. Mish. 1961. A sealing compound for use in biological work. Nature. 191:410.

Thorton-Manning, J. R., D. D. Jones, and T. W. Federle. 1987. Effects of experimental manipulation of environmental factors on phenol mineralization in soil. Environmental Toxicology and Chemistry. 6:615-621. 
Topp, E., I. Scheunert, A. Attar, and F. Korte. 1986. Factors affecting the uptake of ${ }^{14} \mathrm{C}$-labelled organic chemicals by plants from soil. Ecotoxicology and Environmental Safety. 11:219-228.

Tsien, H., G. A. Brusseau, R. S. Hanson, and L. P. Wackett. 1989. Biodegradation of trichloroethylene by Methylosinus trichosporium OB3b. Applied and Environmental Microbiology. 55:3155-3161.

Tunlid, A., B. H. Baird, M. B. Trexler, S. Olsson, R. H. Findlay, G. Odham, and D. C. White. 1985. Determination of phospholipid ester-linked fatty acids and poly B-hydroxybutyrate for the estimation of bacterial biomass and activity in the rhizosphere of the rape plant Brassica napus (L.). Canadian Journal of Microbiology. 31:1113-1119.

Uchiyama, H., T. Nakajima, O. Yagi, and T. Tabuchi. 1989. Aerobic degradation of trichloroethylene at high concentration by a methaneutilizing mixed culture. Agricultural Biological Chemistry. 53:1019-1024.

U.S. Environmental Protection Agency. 1982. National revised primary drinking water regulations, volatile synthetic organic chemicals in drinking water: Advanced notice of proposed rulemaking. Federal Register. 47:9349-9358.

Vancura, V. 1964. Root exudates of plants. 1. Analysis of root exudates of barley and wheat in their initial phases of growth. Plant and Soil. 21:231-248.

Vandenbergh, P. A., and B. S. Kunka. 1988. Metabolism of volatile chlorinated aliphatic hydrocarbons by Pseudomonas fluorescens. Applied and Environmental Microbiology, 54:2578-2579.

Vannelli, T., M. Logan, D. M. Arciero, and A. B. Hooper. 1990. Degradation of halogenated aliphatic compounds by the ammonia-oxidizing bacterium Nitrosomonas europaea. Applied and Environmental Microbiology. 56:1169-1171.

Vestal, J. R. 1988. Carbon metabolism of the cryptoendolithic microbiota from the Antarctic desert. Applied and Environmental Microbiology. 54:960-965.

Vestal, J. R., and D. C. White. 1989. Lipid analysis in microbial ecology. BioScience. 39:535-541.

Vogel, T. M., and P. L. McCarty. 1985. Biotransformation of tetrachloroethylene to trichloroethylene, dichloroethylene, vinyl chloride, and carbon dioxide 
under methanogenic conditions. Applied and Environmental Microbiology. 49:1080-1083.

Vogel, T. M. and P. L. McCarty. 1987. Abiotic and biotic transformations of 1,1,1-trichloroethane under methanogenic conditions. Environmental Science and Technology. 21:1208-1213.

Wackett, L. P., and D. T. Gibson. 1988. Degradation of trichloroethylene by toluene dioxygenase in whole-cell studies with Pseudomonas putida F1. Applied and Environmental Microbiology. 54:1703-1708.

Wackett, L. P., G. A. Brusseau, S. R. Householder, and R. S. Hanson. 1989. Survey of microbial oxygenases: Trichloroethylene degradation by propane-oxidizing bacteria. Applied and Environmental Microbiology. 55:2960-2964.

Wackett, L. P., and S. R. Householder. 1989. Toxicity of trichloroethylene to Pseudomonas putida $\mathrm{F} 1$ is mediated by toluene dioxygenase. Applied and Environmental Microbiology. 55:2723-2725.

Walton, B. T. and T. A. Anderson. 1990. Microbial degradation of trichloroethylene in the rhizosphere: Potential application of biological remediation of waste sites. Applied and Environmental Microbiology. 56:1012-1016.

Walton, B. T., T. A. Anderson, M. S. Hendiricks, and S. S. Talmage. 1989. Physicochemical properties as predictors of organic chemical effects on soil microbial respiration. Environmental Toxicology and Chemistry. 8:53-63.

White, D. C., R. J. Bobbie, S. J. Morrison, D. K. Oosierhof, C. W. Taylor, and D. A. Meeter. 1977. Determination of microbial activity of estaurine detritus by relative rates of lipid biosynthesis. Limnology and Oceanography. 22:1089-1099.

White, D. C., W. M. Davis, J. S. Nickels, J. D. King, and R. J. Bobbie. 1979. Determination of the secimentary microbial biomass by extractable lipid phosphate. Oecologia. 40:51-62.

Wilson, J. T. and B. H. Wilson. 1985. Biotransformation of trichloroethylene in soil. Applied and Environmental Microbiology. 49:242-243.

Williams, G. M. and J. H. Weisburger. 1986. Chemical Carcinogens. In Claassen, C. D., M. O. Amdur, and J. Doull, eds. Casarett and Doull's Toxicology: The Basic Science of Poisons. Macmillan Publishing Company. New York. pp. 64-98. 
Winter, R. B., K. Yen, and B. D. Ensley. 1989. Efficlent degradation of trichloroethylene by a recombinant Escherichia coli. Bio/Technology. 7:282-285.

Zelles, L., I. Scheunert, and F. Korte. 1986. Comparison of methods to test chemicals for side effects on soil microorganisms. Ecotoxicology and Environmental Safety, 12:53-69.

Zylstra, G. J., L. P. Wackett, and D. T. Gibson. 1989. Trichloroethylene degradation by Escherichia coli containing the cloned Pseudomonas putida F1 toluene dioxygenase genes. Applied and Environmental Microbiology, 55:3162-3166. 


\title{
INTERNAL DISTRIBUTION
}

\author{
1-3. T. A. Anderson \\ 4. L. D. Bates \\ 5. J. H. Cushman \\ 6. N. T. Edwards \\ 7. M. P. Farrell \\ 8. D. E. Fowler \\ 9. C. W. Gehrs \\ 10. J. K. Greer, Jr. \\ 11. S. E. Herbes \\ 12. S. G. Hildebrand \\ 13. A. M. Hoylman \\ 14. P. M. Jardine \\ 15. A. P. Malinauskas \\ 16. D. E. Reichle \\ 17. D. S. Shriner \\ 18. S. H. Stow \\ 19. R. I. Van Hook \\ 20-24. B. T. Walton \\ 25. S. D. Wullschleger \\ 26. Central Research Library \\ 27-41. ESD Library \\ 42-43. Laboratory Records Dept. \\ 44. Laboratory Records, ORNL-RC \\ 45. ORNL Patent Section \\ 46. ORNL Y-12 Technical Library
}

\section{EXTERNAL DISTRIBUTION}

47. T. L. Bulman, Soil Scientist, Residue Management, Wastewater Technology Center, Environmental Protection Service, Canada Centre for Inland Waters, Environment Canada, Burlington, Ontario L7R $4 A 6$

48. J. R. Coats, Environmental Toxicologist, Department of Entomology, lowa State University, Insectary Building, Ames IA 50011-3140

49. R. A. Conway, Senior Research Fellow, Union Carbide Corporation, P. O. Box 8361 (770-341), South Charleston, WV 25303

50. J. F. Franklin, Bloedel Professor of Ecosystems Analysis, College of Forest Resources, University of Washington, Anderson Hall (AR-10), Seattle, WA 98195

51. J. Goodrich-Mahoney, Electric Power Research Institute, 1019 19th Street, N. W., Suite 1001, Washington, DC 20036 
52-53. T. C. Hazen, Research Microbiologist, Environmental Sciences Division, Building 773-442A, Savannah River Laboratory, Aiken, SC 29808

54. G. M. Hornberger, Professor, Department of Environmental Sciences, University of Virginia, Charlottesville, VA 22903

55. T. R. Johnson, Microbiologist, Department of Biology, St. Olaf College, Northfield, MN 55057

56. G. Y. Jordy, Director, Office of Program Analysis, Office of Energy Research, ER-30, G-226, U. S. Department of Energy, Washington, DC 20545

57. J. J. Krajicek, Environmental Specialist, Environmental Affairs Division, Nebraska Public Power District, 1414 5th Street, P. O. Box 499, Columbus, NE 68602-0499

58. J. E. Matthews, Robert S. Kerr Environmental Research Laboratory, U. S. Envirunmental Protection Agency, P. O. Box 1198, Ada, OK 74820

59. I. Murarka, Electric Power Research Institute, 3412 Hillview Avenue, P. O. Box 10412, Palo Alto, CA 94303

60. E. F. Neuhauser, Niagara Mohawk Power Corporation, 300 Erie Boulevard West, Syracuse, NY 13202

61. R. H. Olsen, Vice President for Research, University of Michigan, Medical Science Building II, \#5605, 1301 East Catherine Street, Ann Arbor, MI 48109-0620

62. A. Patrinos, Acting Director, Environmental Sciences Division, Office of Health and Environmental Research, ER-74, U. S. Department of Energy, Washington, DC 20585

63. F. J. Wobber, Environmental Sciences Division, Office of Health and Environmental Research, ER-74, U. S. Department of Energy, Washington, DC 20585

64. Office of Assistant Manager for Energy Research and Development, Oak Ridge Operations, P.O. Box 2001, U. S. Department of Energy, Oak Ridge, TN 37831-8600

65-74. Office of Scientific and Technical Information, P. O. Box 62, Oak Ridge, TN 37831 

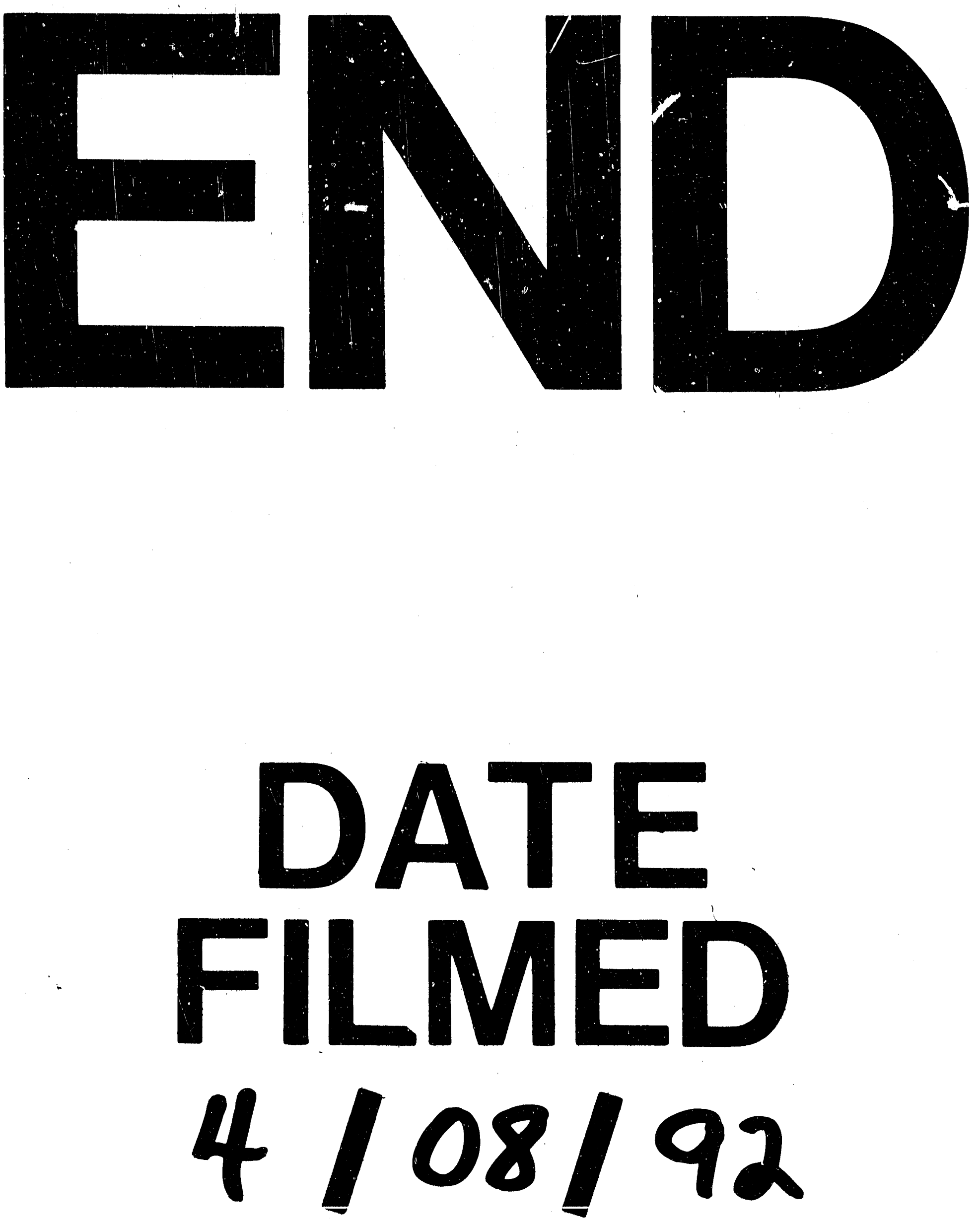
